\title{
Airframe Noise Component Interaction Studies
}

Martin R. Fink and Robert H. Schlinker

CONTRACT NAS1-15083

MARCH 1979 
NASA Contractor Report 3110

\section{Airframe Noise Component Interaction Studies}

Martin R. Fink and Robert H. Schlinker

United Technologies Research Center

East Hartford, Connecticut

Prepared for

Langley Research Center

under Contract NAS1-15083

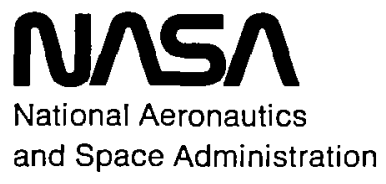

Scientific and Technical

Information Otfice 
SUMMARY . . . . . . . . . . . . . . . . . . . . • • • • • 1

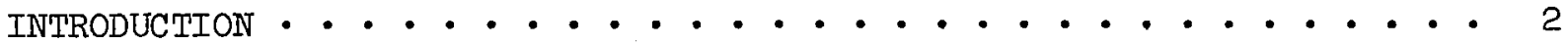

LIST OF SYMBOLS. . . . . . . . . . . . . . . . . . . . 3

DESCRIPTION OF EXPERTMENT

Acoustic Wind Tunnel. . . . . . . . . . . . . . . . 4 Instrumentation

Conventional Far-Field Microphones . . . . . . . . . . 5

Directional Microphone . . . . . . . . . . . . . . 5

Airframe Component Model

Clean wing . . . . . . . . . . . . . . . 7

Trailing Edge Flaps. . . . . . . . . . . . . . . 8

Leading Edge Slat and Flap . . . . . . . . . . . . . 9

Landing Gear . . . . . . . . . . . . . . . . . 9

Combined Configurations. . . . . . . . . . . . . . . 11

Test Conditions and Procedures. . . . . . . . . . . . . . . 11

Wind Tunnel Corrections

Shear Layer Refraction Effects . . . . . . . . . . . 14

Open Jet Effect on Angle of Attack . . . . . . . . . . . 17

COMPARISONS OF SINGLE-COMPONENTT DATA AND PREDICTIONS

Clean Wing. . . . . . . . . . . . . . . . . . . . 19

Leading Edge Flap . . . . . . . . . . . . . . . . . . . 21

Leading Edge Slat . . . . . . . . . . . . . . . . . . 22

Landing Gear. . . . . . . . . . . . . . . . . . . 25

Trailing Edge Flaps . . . . . . . . . . . . . . . . . 28

Far Field Acoustic Spectra . . . . . . . . . . . 28

Surface Pressure Spectra . . . . . . . . . . . . . 30

Distribution of Noise Source Strength. . . . . . . . . . 31

Directivity. . . . . . . . . . . . . . . . . . 35

EVALUATION OF NOISE PROCESS FOR TRAILING EDGE FLAP

Analytical Concepts . . . . . . . . . . . . . . 36

Turbulence Measurements . . . . . . . . . . . . . . . 37

Comparison of Calculated and Measured Spectra . . . . . . . . 40 
Page

AIRFRAME COMPONENT NOISE INTERACTIONS

Leading Edge Devices and Landing Gear. . . . . . . . . . 41

Leading Edge Flap and Trailing Edge Flaps. . . . . . . . . 43

Leading Edge Slat and Trailing Edge Flaps. . . . . . . . . 45

Landing Gear and Trailing Edge Flaps ........... . . 47

Approach Configurations With Leading Edge Flaps. . . . . . 48

Approach Configurations With Leading Edge Slats. . . . . . 50

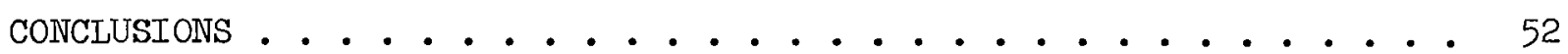

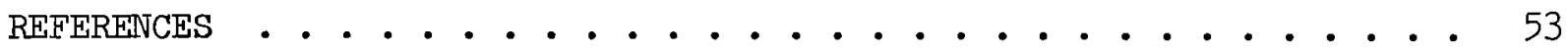




\section{SUMMARY}

Acoustic wind tunnel tests were conducted of a two-dimensional wing section with removable high-lift leading and trailing edge devices and a removable two-wheel landing gear with open or closed cavity. An array of far field conventional microphones and an acoustic mirror directional microphone were utilized to determine far field spectrum levels and noise source distributions. Data were obtained for the wing with components deployed separately and in various combinations.

The basic wing model had $0.305 \mathrm{~m}$ ( $1.00 \mathrm{ft}$ ) chord, which is roughly $1 / 10$ scale for a one-hundred passenger transport airplane. Data were obtained at $70.7,100$, and $141 \mathrm{~m} / \mathrm{sec}(232,328$, and $463 \mathrm{ft} / \mathrm{sec})$ airspeeds, which covers the range of practical approach speeds. Spectra were recorded at frequencies to $40 \mathrm{kHz}$ so that, when scaled to a typical full sized airframe, the frequency region which strongly influences perceived noise level would be included.

Noise radiated by the leading edge slat was about 5 dB larger in amplitude than was predicted by the noise component method. This noise was caused by convection past the slat trailing edge of locally separated flow from the slat lower surface. Noise radiation along the span of the trailing edge flaps was shown to be caused by convection of turbulent flow inducing fluctuations of incidence and loading, as with isolated airfoils in turbulent flow. Part-span trailing edge flaps were found also to generate significant noise from their side edges at large deflection angles.

Relatively few component interaction effects greater than 1 dB occurred at frequencies which scale to those of practical importance. The largest was a 3 to $4 \mathrm{~dB}$ reduction for a part-span leading edge flap in line with a partspan trailing edge flap. This occurred because noise radiation from the side edges of the trailing edge flap was reduced by the spanwise variation in aerodynamic flow field caused by the part-span leading edge flap. Combining a landing gear and trailing edge flap caused about $2 \mathrm{~dB}$ noise reduction because of the decreased local velocity at the landing gear. The above two noise reduction effects were not additive; the combination of a part-span leading edge flap, landing gear, and part-span trailing edge flap produced only 2 to $3 \mathrm{~dB}$ noise reduction. At lower frequencies, landing gear cavity noise was 
reduced markedly by leading edge flaps located upstream of the cavity and leading edge slat noise was increased by a downstream trailing edge flap.

Deflected trailing edge flaps can cause redistribution of noise radiation, reducing the local velocity and therefore the noise from landing gear at the expense of increased flow turbulence and increased noise from the flaps. Use of trailing edge flaps having variations of acoustic impedance along their surfaces to reduce pressure fluctuations induced by inflow turbulence might provide a significant reduction of airframe noise.

\section{INTRODUCTION}

Airframe noise, generated by motion of aircraft external surfaces through the atmosphere, imposes a limit on aircraft minimum noise levels. As propulsion-system noise is reduced by changes to the engines and more extensive use of inlet and exhaust duct acoustic suppression, airframe noise becomes relatively more important. This is most apparent during approach, when engines are operated at relatively low power settings and airframe noise-generating components such as landing gear and wing flaps are deployed.

Several methods are available for predicting airframe noise for approach configurations. Early methods such as the drag element method (reference 1) were summarized by Hardin, et al. in reference 2. The noise component method, developed and evaluated in reference 3, has been adopted (reference 4) for use in the NASA Aircraft Noise Prediction Program. These methods assume that noise radiated by each individual component of the airframe can be calculated independent of the presence of other components. Only the data analysis method (references 5 and 6) implicitly includes component interactions by using analytical methods with constants matched to measured flyover data for one specific aircraft in different configurations. However, acoustic wind tunnel tests (reference 7) showed that noise radiation from an airframe model with several deployed components differed, over some portions of the frequency range, from the sum of spectra measured by deploying each component separately. These differences were shown therein to be statistically significant and were about 1 to $3 \mathrm{~dB}$ in magnitude. The tests were conducted at relatively low Reynolds numbers (less than 106), so these component interaction effects might have been caused by flow process not typical of full scale airframes.

If noise-reducing interactions can be produced by flow processes which occur at full scale, use of such processes would provide a technique for aircraft noise reduction. If certain geometries have an adverse interaction on noise, they should be identified so that they can be avoided. The objectives of the investigation reported herein were to (1) measure the noise radiation 
from individual deployed airframe components, (2) compare those data with predictions by available methods in order to assess the adequacy of those available methods, (3) measure the noise radiation from airframe components deployed together and compare with the acoustic sum of data from individual components, and (4) identify aerodynamic changes which produce the measured component interaction noise effects to indicate how noise could be reduced.

\section{IIST OF SYMBOLS}

c Wing chord, $m$

$c_{f}$ Total trailing edge flap. chord, $m$

D Landing gear wheel diameter, m

f $1 / 3$ octave band center frequency, $\mathrm{Hz}$

h Height of open jet test section, $m$

L Ianding gear cavity streamwise length, $m$

M Free stream Mach number

$\mathrm{p}$ Root mean square static pressure fluctuation on flap surface, $\mathrm{N} / \mathrm{m}^{2}$

q Free stream dynamic pressure, $\mathrm{N} / \mathrm{m}^{2}$

$\mathrm{R}$ Distance from airframe quarter-chord to field point, $m$

$\mathrm{S}_{\mathrm{F}} \quad$ Planform area of trailing edge flap, $\mathrm{m}^{2}$

$\mathrm{S}_{\mathrm{S}} \quad$ Planform area of leading edge slat, $\mathrm{m}^{2}$

$\mathrm{S}_{\mathrm{W}}$ Planform area of wing, $\mathrm{m}^{2}$

$t \quad$ Wing maximum thickness, $m$

U Free stream velocity, $\mathrm{m} / \mathrm{sec}$

$\checkmark \quad$ Root mean square turbulence velocity normal to local mean velocity in centerline plane, $\mathrm{m} / \mathrm{sec}$

$\mathrm{X} \quad$ Streamwise distance, $\mathrm{m}$

$\Lambda$ Turbulence integral length scale for normal velocity, m

$\theta_{c} \quad$ Corrected acoustic radiation ray path angle, equal to radiation angle within airflow, deg

$\theta_{\mathrm{m}}$ Angle between tunnel centerline and line connecting noise source with far field measurement position, deg

$\theta_{\mathrm{t}}$ Angle at which refracted ray path is transmitted after passing through shear layer, deg 


\section{DESCRIPTION OF EXPERIMENT}

\section{Acoustic Wind Tunnel}

The acoustic wind tunnel, designed specifically for aerodynamic noise research and described in reference 8 , is of the open-circuit, open-jet type (Eiffel configuration). Use of an open circuit and a muffling section upstream of the tunnel fan reduces fan-generated noise to low levels for frequencies above which the chamber surrounding the test section is anechoic. The open jet is contained within a $5.5 \mathrm{~m}$ (18 ft) long, $6.7 \mathrm{~m}$ (22 ft) wide, and $4.9 \mathrm{~m}$ (I6 ft) high sealed anechoic chamber. The test section area and shape can be varied by use of interchangeable tunnel nozzles. The maximum tunnel speed is in excess of $200 \mathrm{~m} / \mathrm{sec}(660 \mathrm{ft} / \mathrm{sec}$ ) for the $53 \mathrm{x} 79 \mathrm{~cm}$ (2l x 31 in.) cross section used in this test program and in excess of $90 \mathrm{~m} / \mathrm{sec}(300 \mathrm{ft} / \mathrm{sec}$ ) for a $1.07 \mathrm{~m}$ (42 in.) dia cross section. The rectangular test section was installed with its larger dimension (test section height) horizontal. Reflection-free conditions for broadband noise have been experimentally verified at frequencies above $200 \mathrm{~Hz}$. Data are corrected for refraction at the shear layer by the method of references 9 and 10. The anechoic chamber and test section are shown in figures 1 and 2 .

The inlet section has a contraction ratio of 16.5 for the test section used for this program. It is equipped with five turbulence suppression screens and a fine cell honeycomb section. The net effect of the contraction and turbulence suppression devices is to provide a spatially uniform, temporally steady, jet flow with a turbulence level on the order of $0.2 \%$. The test section airflow is brought into the tunnel diffuser by a collector with anechoic treatment on its flow-impingement lip. The tunnel is driven by a $1500 \mathrm{hp}$ variable speed motor coupled to a centrifugal fan.

Tunnel speed control and model jet pressure and temperature control have been demonstrated to be steady. This provides a statistically stationary test signal permitting sequential acquisition of data. Microphone data were amplified and then recorded on a fourteen channel FM tape recorder which at $76 \mathrm{~cm} /$ sec (30 ips) is capable of flat response operation to about $100,000 \mathrm{~Hz}$. A real time spectrum analyzer and ensemble averager provided time-averaged narrow-band spectrum analyses, and real time third-octave bandwidth analyses, of direct and tape-recorded signals over a frequency range that exceeds the 200 to $40,000 \mathrm{~Hz}$ range. A correlation and probability analyzer is used to obtain real time computation of acoustical signal auto and cross-correlation functions. 
Instrumentation

Conventional Far-Field Microphones. - A top view of the acoustic wind tunnel test configuration and microphone installation is shown in figure 1 . The directional microphone, with its sphere-segment reflector surface and focal point microphone on a forward support arm, was traversed along a track parallel to the nozzle centerline. Fixed conventional far-field omidirectional microphones were mounted behind or to the side of this track at positions that did not interfere with motion of the directional microphone. Also, the fixed microphones were placed sufficiently far from the chamber acoustic wedges to be in the acoustic free field. Recent calibrations indicated that diffraction of sound waves near the wedge tips caluse irregularities in noise measured within $1 \frac{1}{2}$ to 2 acoustic wavelengths from those tips. A $0.76 \mathrm{~m}$ (2.5 ft) distance was selected as the closest allowable distance from any microphones to the wedges. At this distance, measurements should be correct within $0.5 \mathrm{~dB}$ down to $630 \mathrm{~Hz}$ center frequency. Location of the wing pitching axis at an existing circular cutout in the horizontal sideplates (figure 1) placed a constraint on the omnidirectional microphone locations. Three fixed microphone positions were chosen as $75^{\circ}, 90^{\circ}$, and $105^{\circ}$ angular position at $3.25 \mathrm{~m}$ (10.66 ft) sideline distance. Two other fixed microphones were placed at $60^{\circ}$ and $120^{\circ}$ angular positions at $3.05 \mathrm{~m}$ ( $10.0 \mathrm{ft}$ ) radius. All microphones were at least 10 wing chords and 5.7 wing spans away from the model. For frequencies down to $1 \mathrm{kHz}$ they were at least 10 acoustic wavelengths away. Thus the microphones were in the geometric and acoustic far field.

Commercially available $0.635 \mathrm{~cm}$ ( $1 / 4 \mathrm{in.)}$ condenser microphones were used at these five locations. These microphones were mounted at grazing incidence and were installed with protective grids. Several of these omnidirectional microphones are shown in figures 2 and 3(a) mounted on support posts in the anechoic chamber. Frequency response of the microphone and grid combination for this noise source direction is flat to $8 \mathrm{kHz} 1 / 3$ octave center frequency, increases to about $3 \mathrm{~dB}$ too high at $31.5 \mathrm{kHz}$, and decreases at higher frequencies. This installation was chosen because the increased response nearly compensates for atmospheric absorption along the acoustic path as calculated from Table C.3 of reference 11. Since the sum of the se two frequency-dependent corrections was less than $0.2 \mathrm{~dB}$ through $25 \mathrm{kHz}$ center frequency, it was not necessary to apply an amplitude correction to those data. Combined corrections of $-0.3 \mathrm{~dB}$ at $31.5 \mathrm{kHz}$ and $+1.9 \mathrm{~dB}$ at $40 \mathrm{kHz}$ were applied.

Directional Microphone. - The directional microphone used in this test program, and the manner in which its focal point acoustic pressures are used in calculating noise radiation spectra, are described in reference 12 . The reflecting surface, shown from the rear in figure 2 and the front in figure 3(a), is a $1.067 \mathrm{~m}$ (42.0 in.) aperture spherical reflector with $1.346 \mathrm{~m}$ ( $53.0 \mathrm{in.})$ 
radius of curvature. A low-power laser mounted at the back of the reflector permits aiming the system and aligning the focal point microphone. The polished reflecting surface is used to align the laser with the reflector axis by optical autocollimation techniques. A spherical reflector was used instead of a parabolic reflector in order to attain reasonable depth of field with reduced focal point aberration. Spatial discrimination (response of the directional microphone to off-axis noise sources) is controlled by diffraction. As shown in reference 12, measured response to very small off-axis noise sources at frequencies from 1 to $50 \mathrm{kHz}$ closely matched the prediction by Fraunhofer diffraction theory for a circular aperture. This spectral resolution is shown in figure $3(\mathrm{~b})$ for the frequencies used herein. Measured gain of the directional microphone system (ratio of mean square acoustic pressure at the focal point microphone to that of an omnidirectional microphone having the same acoustic path length) was shown to nearly follow the behavior calculated from diffraction theory. This gain measured in the absence of tunnel airspeed is reduced by scattering of sound by the open jet shear layer. Scattering of sound increases at high frequencies and high velocities, and has been calibrated for the open jet test section used in the present study. The data were corrected for this effect.

This procedure gives a direct relationship between sound pressure level (SPL) measured at the focal point microphone and absolute SPL at the same acoustic path length for a point noise source. Based on the data correlation of airframe noise developed in reference 3, the noise source distribution on a wing or flap was more likely to resemble a line source with constant strength per unit span, spanwise extent larger than the diffraction pattern half-power width, and chordwise extent smaller than that width. An equation which relates focal point SPL to absolute SPL of such a line source was derived in reference 12 and used in the data analysis herein. If the noise source is distributed over a larger chordwise extent or is nonuniform along the span, a far more complicated method is needed to obtain absolute levels of noise radiation. In this report, noise radiation from the full span wing and full span trailing edge flaps was taken as that from a constant-intensity line source. Noise from part-span high lift devices was assumed to be the sum of a constant-intensity line source plus a point source located at each lateral edge.

The directional microphone system with its focal point microphone was mounted on a track parallel to the tunnel centerline with the reflector axis perpendicular to the test section centerline. Vertical position of the reflector centerline was at midspan of the test section. The directional microphone could be aimed at midspan or $8.9 \mathrm{~cm}(3.5 \mathrm{in.})$ above or below the 
tunnel centerline by tilting the reflector about a horizontal axis. These latter positions corresponded to the side edges of the part-span high lift devices. Output of the focal point microphone and the axial position sensor were recorded on magnetic tape as the directional microphone system traversed along the track at $0.85 \mathrm{~m} / \mathrm{min}(2.8 \mathrm{ft} / \mathrm{min})$. For frequencies down to $1 \mathrm{kHz}$, below which spatial resolution would be relatively poor, amplitudes obtained at this low traverse velocity are identical to those measured with the reflector stationary.

\section{Airframe Component Model}

Clean Wing. - An important consideration for this test program was that the test Reynolds numbers be large enough to achieve aerodynamic flow processes typical of those at full scale. This requirement dictated using the largest practical wing chord. However, chord was limited by flow distortion produced by the lifting wing in the open jet. As discussed in the following section entitled "Wind Tunnel Corrections", this consideration limited the airfoil chord with extended flaps to slightly less than half the open jet height. The resulting basic wing model was chosen to have $0.305 \mathrm{~m}$ ( $1.00 \mathrm{ft}$ ) wing chord with all high-lift devices retracted. It was built as an unswept constant-chord. airfoil model of $53.3 \mathrm{~cm}$ (2l.0 in.) span to fit within the existing solid sidewalls of the UTRC Acoustic Wind Tunnel. Tabs were machined integral with the model to permit bolting it firmly to an existing support structure, shown in figure 2, which permits varying the angle of attack. Tests at a typical full scale approach velocity of $100 \mathrm{~m} / \mathrm{sec}$ (328 ft/sec) correspond to a Reynolds number of about $2 \times 10^{6}$ based on wing chord. Therefore it was necessary to choose an airfoil section known to have good aerodynamic performance when tested with high-lift devices at this Reynolds number.

Supercritical airfoil sections were initially considered for this wing model. However, only limited aerodynamic data were available for performance of such airfoils with leading edge and trailing edge high-lift devices. Most of those tests had been peformed at larger Reynolds numbers. It was not clear that representative local flow conditions could be achieved at airspeeds attainable in the acoustic wind tunnel. The NACA 6A series of airfoils, utilized on the first generation of business jets, was also evaluated. Extensive tests with high-lift devices have indicated that aerodynamic performance of these airfoils deteriorates as Reynolds number is decreased from $6 \times 10^{6}$ to $3 \times 10^{6}$. Acoustic wind tunnel tests would thus have local flow separation that was not representative of full scale operation.

The NACA 4-digit and 5-digit series of airfoils, developed in the 1930's, still are used on propeller-driven general aviation airplanes. Of these, the NACA 23012 airfoil has been used extensively because of its high maximum lift coefficient, low drag coefficient at high lift coefficients below stall, and 
relatively high maximum lift-drag ratio at cruise. These favorable aerodynamic features are retained at the low Reynolds numbers typical of small lightplanes at approach flight speeds and of these acoustic tunnel tests. Aerodynamic performance of the NACA 23012 airfoil at Reynolds numbers near $2 \times 10^{6}$ with various high-lift devices is known (references 13 and 14) to be only slightly below the documented performance at nominal full scale Reynolds numbers of $12 \times 10^{6}$ for larger aircraft. This airfoil shape was therefore chosen for the clean wing model.

Trailing Edge Flaps. - The single slotted trailing edge flap was one of the contours developed in reference 13 for use with an NACA 23012 airfoil section. This shape, designated therein as slotted flap 2-i, had a chord length 0.2566 times that of the basic airfoil. As shown in figure 4(a), the retracted position of the flap produced a closed slot except for the portion of the

lower surface close to the slot entry. Data had been presented in reference 13 for this flap shape at a test Reynolds number of $2.19 \times 10^{6}$ based on airfoil chord with the flap retracted. This Reynolds number is close to that for the present acoustic wind tunnel tests. From figure 37 of reference 13, maximum lift coefficient was found to vary smoothly with Reynolds number for this airfoil alone and with a generally similar flap. Contours of maximum lift coefficient as a function of flap leading edge position had been shown in figure 19 of reference 13 for this t'lap geometry at various deflections. The resulting trajectory of optimum flap leading edge position as a function of flap angle was utilized to choose the flap positions sketched in figure $4(\mathrm{~b})$ for $15^{\circ}$, $24^{\circ}$, and $40^{\circ}$ flap deflection. Maximum lift coefficient was known to occur approximately at $40^{\circ}$ deflection angle. The two smaller deflection angles were chosen because, according to the noise prediction method of reference 3 , approximately $4 \mathrm{~dB}$ increase of noise amplitude could be expected for each successive increase of angle. This flap could be deployed over the entire $53.3 \mathrm{~cm}$ (21.0 in.) span or only the central $1 / 3$ span of $17.8 \mathrm{~cm}(7.0 \mathrm{in}$.$) .$

Numerous tests of double slotted trailing edge flaps are summarized in reference 13. However, the configurations tested with NACA 23012 airfoils emphasized fore flaps with large leading edge radius and large camber. In contrast, double slotted flaps typical of aircraft with high subsonic cruise Mach numbers tend to have thinner fore flaps with smaller leading edge radius. It has been shown in test of under-the-wing externally blown flaps, reported in reference 15, that use of thick, large leading edge radius flaps reduces noise radiation at moderate and high frequencies. Airframe noise from deflected flaps had been assumed in reference 3 to be caused by lift force fluctuations induced on the flaps by the wing turbulent wake. From reference 16, such noise radiation is reduced at high frequencies if the leading edge radius is large compared with the turbulence length scale associated with those frequencies. That is, noise is reduced if the leading edge is not sharp relative to the turbulence. Noise radiation spectra from a realistic double slotted flap would therefore be simulated only if the fore flap had a smaller leading edge radius than that of the main flap. 
Design of the double slotted flap was based primarily on configurations described in reference 17 for a Reynolds number of $2.4 \times 10^{6}$. It was shown therein that maximum lift coefficient of a wing with a $25 \%$ chord main flap increased as fore flap size was increased to $10 \%$ chord. However, that $10 \%$ chord fore flap had a relatively large leading edge radius. Therefore the design was arbitrarily chosen to have the upper surface of that fore flap, taken from Table 17 of reference 17, and the forward lower surface of a thinner profile taken from Table 4 of reference 18. The aft lower surface was faired to provide a representative shape. As shown by data from references 14, 17, and 18, maximum lift generally occurs at a fore flap deflection of half the main flap deflection. The test double slotted trailing edge flap was chosen to have $20^{\circ}$ fore flap and $40^{\circ}$ main flap deflection. The $25 \%$ chord single slotted flap model was used as the main flap of this double slotted flap. Position of the fore flap relative to the main wing, and of the main flap relative to the fore flap, was taken from the optimum positions reported in reference 17 . The resulting configuration is shown in figure $4(\mathrm{c})$. This double slotted trailing edge flap extended only over the central $1 / 3$ span.

Leading Edge Slat and Flap. - Leading edge slat shapes tested with an NACA 23012 airfoil section were reported in reference 19. These shapes are representative of aircraft designed for low subsonic flight speeds. A more practical shape for high-speed cruise was obtained by using the forward upper $15 \%$ chord of an NACA 23012 airfoil and the forward lower chord of the leading edge slat given in Table 3 of reference 18. The slat lower surface contour was empirically faired downstream of the $1 / 3$ slat chord ( $5 \%$ airfoil chord) station. Maximum lift coefficient was shown in figure 9 of reference 18 to occur between $22^{\circ}$ and $28^{\circ}$ slat deflection. (At zero deflection, the slat upper surface would have the same slopes as the wing upper surface.) An arbitrary $25^{\circ}$ slat deflection, and optimum slat position for maximum lift coefficient, was chosen from those data. This leading edge slat was tested at constant deflection with both the optimum gap and rero gap. At zero gap j.t represented a leading edge Kreugex flap as used on the Boeing 747 . The se two positions of the leading edge slat are shown in figure $4(d)$. This leading edge high-lift device extended only over the central $1 / 3$ span.

Landing Gear. - Design of the landing gear was based on relative proportions of the nose and main landing gear for the Boeing 727 and Douglas DC-9, scaled from drawings in reference 20. Ratios of wheel width to wheel (tire) diameter and lateral spacing to wheel diameter generally matched those in Table 1 of reference 21 for the Douglas DC-10 and Lockheed 1011 landing gear. However, the ratio of exposed landing gear height to wheel diameter was about half as large for the two smaller narrow-body jet transports of reference 20 as for the two wide-body aircraft of reference 21. The wide-body aircraft need landing gear struts long enough to provide ground clearance for high bypass 
ratio turbofan engines mounted beneath the wings. The smaller aircraft have their engines mounted on the aft fuselage so they need relatively less ground clearance. Turbulent wakes shed by main landing gear of the smaller aircraft are a relatively smaller distance below the wing trailing edge flaps. Aerodynamic and acoustic interaction between the landing gear and trailing edge flaps is more likely for these configurations. Exposed strut length therefore was selected to match these short to medium range narrow-body aircraft.

Main landing gear of these aircraft are mounted in the wings and retract toward the fuselage. Tach landing gear strut fits into a cavity that extends from the wing mount to the fuselage. These cavities are open when the landing gear is extended; the cavity door actuator is linked to the strut. The wheels fit into cavities within the fuselage. These fuselage cavities connect to the wing cavities but are closed to external airflow except during gear retraction and extension. As with the test reported in reference 22 but unlike that of reference 2l, the landing gear configuration built for these tests included a strut cavity but not the enclosed wheel cavity.

Wheel tire diameter was chosen to maintain a large enough Reynolds number to ensure that the measured spectra would be representative of full scale spectra. It was shown in reference 21 that spectra mecsured with model twowheel landing gear at a Reynolds number of $1.6 \times 10^{5}$ disagreed somewhat with those for Reynolds numbers of $2.4 \times 10^{5}$ and $3.4 \times 10^{5}$ based on wheel diameter. An average of spectra measured for the two higher Reynolds numbers and scaled for dipole noise agreed with flyover data of full scale aircraft with landing gear extended. At the lowest planned test airspeed for the program reported here, a Reynolds number of $2.4 \times 10^{5}$ corresponds approximately to $5 \mathrm{~cm}$ (2 in.) wheel diameter.

The resulting landing gear configuration is shown in figure 5. The model comprised two wheels, an axle, a vertical strut, a diagonal brace between the strut and cavity, a door, a door brace, and a rectangular cavity. Ratios of various length dimensions to the $5.0 \mathrm{~cm}(2.0 \mathrm{in}$.) wheel diameter, given in this figure, were obtained as averages of these ratios for the Boeing 727 and Douglas DC-9 main gear. Spanwise extent of the cavity was large enough to permit mounting the strut at either midspan or $I / 3$ span. Consequently, the cavity was somewhat longer than a typical strut cavity.

Although the wing chord and wheel diameter sizes were each determined by separate criteria, their ratio (6) is typical of that for narrow-body commercial jets and for business jets. However, a full scale cavity extends from the wing lower surface to the under side of the upper-surface wing skin. It would have been impractical to reproduce this cavity depth at the correct chordwise location. Therefore the vertical wheel strut was mounted at $30 \%$ wing chord rather than a more typical aft location. A two-piece cover plate, 
contoured to the airfoil lower surface shape, could be installed in the cavity. Use of this cover plate allowed the wing to be tested with the landing gear extended but without a cavity, or without either the landing gear or cavity.

Combined Configurations. - The basic wing model with retracted full-span single slotted trailing edge flap (figure $6(a)$ ) comprised the clean-wing configuration. The wing with full-span (figure $6(b)$ ) and $1 / 3$ span (figure $6(c)$ ) single slotted trailing edge flap is shown at one of the three deflection angles tested. Figure $6(d)$ represents the wing with $1 / 3$ span double slotted trailing edge flap at its one test deflection. The third row from the top shows the wing with each of its two leading edge high-lift devices, a slat (figure 6(e)) and a flap (figure 6(f)). Finally, the midspan and $1 / 3$ span positions of the landing gear extending from its cavity are shown in figures $6(g)$ and $6(h)$.

The leading edge, landing gear, and single slotted trailing edge flap configurations were installed in various combinations to investigate firstorder and second-order interactions. Each leading edge device was combined with both spanwise positions of the landing gear. Each leading edge and/or landing gear configuration was combined with both the part-span and the fullspan single slotted trailing edge flap. The approach configuration which consists of the leading edge flap, landing gear at midspan with open landing gear cavity, and part-span trailing edge flap is shown in figure 7 installed in the acoustic wind tunnel. This same configuration also can be seen in figures 2 and 3. A total of thirty-one model configurations (including the clean wing at two different lift coefficients as two configurations) were tested during this investigation. These configurations and their geometric angles of attack are listed in TABLE I. Corrections to angle of attack due to open jet deflection, and the resulting corrected lift coeficicnts, are discussed in the section entitled "Wind Tunnel Corrections".

Test Conditions and Procedures

Airframe noise generally is important only on approach to landing, when all high-lift airframe components are deployed and engine thrust levels are reduced. Tests of airframe noise therefore were conducted to obtain aerodynamic flows representative of those past the airframe components during approach. This was done by matching the expected lift coefficient of each test configuration to that which would be flown on approach by an airframe operating with the same geometry. As described in reference 23, an approach flight path at low altitude is generally flown at 1.3 times stalling speed to provide a safety margin for gusts and control motion. For a given altitude and wing loading, flight speed in steady level flight varies inversely with 
the square root of lift coefficient. Stalling speed is reached when lift coefficient has been increased to its maximum value. Thus, lift coefficient during approach is $(1 / 1.3)^{2}$ or about 0.6 times maximum lift coefficient. Lift coefficient in these tests therefore was increased as trailing edge flaps were deployed to larger angles and leading edge high-lift devices were added. Maximum lift coefficient, and therefore approach lift coefficient, varied by a factor of about 2 for the full range of configurations. The clean wing also was tested at its design lift coefficient of 0.3 which provides minimum aerodynamic drag of the basic airfoil section. Maximum lift coefficients, and approach lift coefficients corrected for the expected open-jet induced reduction to effective angle of attack, are listed for each configuration in the following section entitled "Wind Tunnel Corrections".

Tests were conducted at $70.7,100$, and $141.4 \mathrm{~m} / \mathrm{sec}(232,328$, and $463 \mathrm{ft} /$ sec) wind tunnel velocities for all configurations except those with the leading edge slat. Those configurations were not tested at the highest velocity because estimates indicated that airloads might overstress the slat supports. These velocities differing by a factor of $\sqrt{2}$ were chosen to facilitate checking the manner in which normalized spectra varied with velocity. These test velocities also bracket the flyover velocities of nearly all flight test measurements of airframe noise from turbojet and turbofan aircraft (references 6, 23, 24, 25, and 26). Any effects of flight Mach number on noise amplitude and spectrum shape should then be reproduced. The three airspeeds provided Reynolds numbers of about $1.47 \times 10^{6}, 2.08 \times 10^{6}$, and $2.94 \times 10^{6}$ based on wing chord, and Mach numbers of about $0.209,0.296$, and 0.422 .

When the directional microphone was at either end of its track, the reflector dish shielded noise from one fixed microphone and reflected noise toward the adjacent microphone. Thus it was necessary to take the reflector position into account when examining data from the far field microphones. At each velocity, output of the five conventional far-field microphones was recorded on magnetic tape while the directional microphone was at one end of its track. The directional microphone was then traversed to the other end, and its output signal was passed through a $1 / 3$ octave filter having $10 \mathrm{kIlz}$ center frequency and plotted on-line as a function of axial position. For $100 \mathrm{~m} / \mathrm{sec}$ tunncl velocity, the unfiltered signal also was recorded on magnetic tape. When the directional microphone traverse was completed, the farfield microphone data were again recorded on magnetic tape. On-line $1 / 3$ octave spectra for center frequencies from 50 to $50,000 \mathrm{~Hz}$ were recorded for the $90^{\circ}$ microphone at all velocities. At first these spectra were taken for both the upstream and downstream positions of the directional microphone. Both spectra proved to be the same except for small reductions of high-frequency noise when the reflector was downstream and therefore partially shielding the background noise from the open jet flow collector. On-line 
far-field spectra then were taken only with the directional microphone upstream.

Directional microphone traverses were taken along streamwise lines at midspan for all configurations, along the side edges of part-span high-lift devices, and along streamwise lines through the landing gear strut and the opposite side edge of the landing gear cavity. It was necessary to shut down the tunnel airspeed in order to change manually the spanwise position of the directional microphone aiming point.

All microphones were calibrated daily with a pistonphone. Air temperature and relative humidity in the anechoic chamber were recorded manually during each run, for use in calculating attenuation of acoustic signals. Air temperature in the atmospheric-inlet wind tunnel settling chamber was measured for use in determining the difference between settling-chamber stagnation pressure and tunnel inlet nozzle static pressure at the test velocities. This pressure difference was measured by a pressure gage having a dial marked linearly in inches of water, to an estimated error less than $0.3 \mathrm{~cm}\left(\mathrm{O} . \mathrm{I}\right.$ in.) $\mathrm{H}_{2} \mathrm{O}$.

Tape-recorded data were played back during and after the test program, through a 1/3 octave band analyzer, to obtain 1/3 octave band spectra for the conventional microphones. Data showing distinct peaks were rerun with constant-bandwidth narrowband filters. Directional microphone output was passed through $1 / 3$ octave band filters having $2.5,5$, and $20 \mathrm{kHz}$ center frequencies. The riltered signals were connected to an $x-y$ plotter, along with the traverse position signal, to obtain plots of signal amplitude versus axial distance. All acoustic pressures were normalized relative to $2 \times 10^{-5} \mathrm{n} / \mathrm{m}^{2}\left(2 \times 10^{-4}\right.$ microbar) reference pressure.

Far-field spectra were found to contain a hump at high frequencies (above $8 \mathrm{kHz}$ at $100 \mathrm{~m} / \mathrm{sec}$ ) which increased in amplitude as the configuration was changed to increase the lift coefficient. This noise was found to be radiated from the portion of the open-jet collector closest to the microphones, where the deflected jet impinged against the collector lip. Such noise had been observed in the past with smaller models operated at smaller lift coefficients in the low-turbulence airstream. It was unimportant relative to noise radiated by those models in airstreams containing grid-generated incident turbulence. In contrast, these tests used a larger model at larger lift coefficients and without upstream turbulence. The additional noise was somewhat larger than airframe noise at frequencies which scale to those which are highly weighted in calculation of perceived noise level. Therefore an acoustic shield consisting of $0.3 \mathrm{~m}$ ( $1 \mathrm{ft}$ ) depth anechoic wedges attached to a $1.2 \times 2.4 \mathrm{~m}$ ( $4 \times 8$ ft) plywood panel was installed midway between the collector Iip and the $90^{\circ}$ microphone. This shield was placed at an arbitrary position to intercept 
noise radiated from the collector without obstructing sound waves leaving the trailing edge flap and refracted through the shear layer to that microphone. Most configurations were rerun at 70.7 and $100 \mathrm{~m} / \mathrm{sec}$ velocities with that shield in place, and $1 / 3$ octave spectra were recorded on-line for only the $90^{\circ}$ microphone. Tests were not conducted with the acoustic shield at 141.4 $\mathrm{m} / \mathrm{sec}$ velocity because the shield anechoic wedge tips closest to the shear layer were visibly buffeted by induced airflow at that velocity. Spectra measured at the $90^{\circ}$ microphone with and without the anechoic shield generally agreed within $1 \mathrm{~dB}$ for frequencies below the hump of collector noise.

\section{Wind Tunnel Corrections}

Shear Layer Refraction Effects. - Sound waves generated at the model are convected downstream within the acoustic wind tunnel airstream and refracted at the shear layer before reaching the far-field microphones within the anechoic chamber. Resulting effects on measured directivity can be significant at the test Mach numbers of about $0.21,0.30$, and 0.42 . The associated changes in acoustic path length of the convected and transmitted sound waves, and divergence of acoustic ray tubes, produce corrections to measured SPL amplitude.

An exaggerated ray path geometry associated with these corrections is sketched in figure 8 . For an observer measurement location at position $O_{1}$ along sideline 1 , the geometric measurement angle $\theta_{\mathrm{m}}$ is the angle of a ray path from the source to the observer in the absence of tunnel flow, measured from the upstream tunnel direction. For a subsonic flow Mach number $M$, sound waves which travel from the source to the observer move within the flow at a larger angle $\theta_{c}$ from the upstream direction. This ray path reaches the shear layer at point $A$, and nearly all the incident acoustic pressure I'luctuation is transmitted across the shear layer. The ray path is refracted to a transmitted angle $\theta_{t}$ smaller than the radiation angle within the flow. This same ray path would cross sideline 2 at the observer location $\mathrm{D}_{2}$. Measurements at locations $O_{1}$ and $O_{2}$ therefore must be corrected to the radiation angle $\theta_{c}$ of the ray path within the flow. This extended ray path crosses the two lines of constant sideline distance at positions $B_{1}$ and $B_{2}$. As is shown in references 9 and 10, negligible error is introduced by approximating the finitethickness shear layer with a discontinuity and by neglecting multiple reflections of sound within the jet. If the noise source directivity were known, correclions could then be derived as corrections to amplitude at the measurement position. However, directivities of the several types of airframe noise sources are not known. Each measurement must therefore be shifted to a point along the ray path which existed within the flow (corrected angle $\theta_{c}$ ) at a specified sideline distance or far-field radius. The ratio of far field 
distance at that point to the sum of in-flow and refracted ray path length is then utilized to calculate the inverse-distance-squared amplitude correction.

Effects of this refraction on amplitude and direction of the transmitted sound waves were calculated by the method of reference 9. Resulting ray path direction angles are plotted in. figure 9. The upper portion of this picture shows ray paths extending from the model within the moving airstream to the shear layer and then within the quiescent air to the microphones, for $100 \mathrm{~m} /$ sec airspeed. Sound waves that move through the test section at $79^{\circ}$ from upstream would be refracted to the sideline measurement position $60^{\circ}$ from upstream. Because the ray tube divergence along this refracted ray is greater than that on a straight line from the model to the sideline at $79^{\circ}$, the measured sound pressure levels must also be increased. The resulting corrected amplitude then corresponds to that which would be measured by a microphone moving with the airframe at constant sideline distance and at $79^{\circ}$ from the airframe. The corresponding ray paths are shown in the lower half of figure 2 for the highest airspeed, and at the extreme angles for the lowest airspeed.

Corrections to measurement direction and measured amplitude, as calculated by this analysis, are tabulated below for the three microphones at $3.25 \mathrm{~m}$ (128.0 in.) sideline distance. Corrections are listed for both constant-sideline and constant $3.25 \mathrm{~m}$ radius positions. The correction to SPL is added to the measured levels.

$\begin{array}{crrrr}\begin{array}{c}\text { Velocity } \\ \text { m/sec }\end{array} & \begin{array}{c}\text { Measurement } \\ \text { Angle, } \theta_{\mathrm{m}}, \text { deg }\end{array} & \begin{array}{c}\text { Corrected } \\ \text { Angle, } \theta_{\mathrm{c}}, \text { deg }\end{array} & \begin{array}{c}\text { Correction to } \\ \text { Sideline }\end{array} & \begin{array}{r}\text { SPL, dB } \\ \text { Radius }\end{array} \\ 70.6 & 75.0 & 86.5 & 0.9 & 0.9 \\ & 90.0 & 100.5 & 0.1 & 0.2 \\ 100.0 & 105.0 & 115.2 & -1.3 & -0.9 \\ & 75.0 & 91.8 & 1.5 & 1.5 \\ 141.4 & 90.0 & 104.9 & 0.2 & 0.4 \\ & 105.0 & 119.0 & -1.7 & -1.1 \\ & 75.0 & 99.8 & 2.3 & 2.4 \\ & 90.0 & 110.5 & 0.4 & 0.7 \\ & 105.0 & 123.8 & -2.1 & -1.3\end{array}$

The other two microphones were at $2.64 \mathrm{~m}$ (102.0 in.) sideline distance, corresponding to $3.05 \mathrm{~m}$ (120.0 in.) radius. The following calculated corrections include the correction to SPL incurred by shifting to either $3.25 \mathrm{~m}$ sideline distance or $3.25 \mathrm{~m}$ radius as for the above three microphones. 


$\begin{array}{crrrr}\begin{array}{c}\text { Velocity } \\ \text { m/sec }\end{array} & \begin{array}{c}\text { Measurement } \\ \text { Angle, } \theta_{m}, \text { deg }\end{array} & \begin{array}{c}\text { Corrected } \\ \text { Angle, } \theta_{c}, \text { deg }\end{array} & \begin{array}{c}\text { Correction to SPL, dB } \\ \text { Sideline }\end{array} & \begin{array}{r}\text { Radius } \\ 70.7\end{array} \\ & 60.0 & 73.0 & -0.6 & -0.4 \\ 100.0 & 120.0 & 130.5 & -5.3 & -4.1 \\ & 60.0 & 79.4 & 0.5 & 0.6 \\ 141.4 & 120.0 & 134.0 & -6.2 & -4.8 \\ & 60.0 & 88.2 & 1.9 & 1.9 \\ & 120.0 & 138.4 & -7.3 & -5.6\end{array}$

Thus the absolute correction to measurement angle was largest for the microphone position furthest upstream but the amplitude correction was largest at the most downstream position. Knowing the corrected angle, one can then compute amplitude corrections for other geometric arrangements such as a comparison at any other sideline or radius.

These corrections convert the measurements in the wind tunnel coordinate system to a measurement system in which the microphones are fixed relative to the noise source. Thus it corresponds to an airframe flyover measurement in which the microphones are moving at the flight speed in a direction parallel to the flight velocity. For ease in comparison with theoretical predictions, it is convenient to use a retarded-time coordinate system. This coordinate transformation effectively moves the noise source downstream relative to its physical location, decreasing the corrected angles to values not very different from the original measurement angles. The ray path direction in retarded time, $\theta_{r}$, is given by

$$
\cos \theta_{r}=\cos \theta_{c} \sqrt{1-M^{2} \sin ^{2} \theta_{c}}+M \sin ^{2} \theta_{c}
$$

and the associated change in SPL caused by shifting to a constant radius relative to the retarded source position is

$$
\Delta \mathrm{SPL}=20 \log \left(\sin \theta_{\mathrm{c}} / \sin \theta_{\mathrm{r}}\right)
$$

Resulting total corrections from measured quantities to those in a constantradius retarded-time frame of reference that is fixed relative to the airframe are tabulated on the following page. 
Measurement Retarded-Time Corrected Angle, deg and Correction to SPL, dB

$\begin{array}{rrrr}\text { Angle, deg } & 70.7 \mathrm{~m} / \mathrm{sec} & 100.0 \mathrm{~m} / \mathrm{sec} & 141.14 \mathrm{~m} / \mathrm{sec} \\ 60.0 & 61.4,0.3 & 62.5,1.5 & 63.3,2.9 \\ 75.0 & 74.5,1.2 & 74.6,1.8 & 75.2,2.6 \\ 90.0 & 88.6,0.1 & 88.3,0.1 & 87.2,0.1 \\ 105.0 & 104.3,-1.5 & 104.0,-2.0 & 103.3,-2.7 \\ 120.0 & 121.4,-5.1 & 121.7,-6.3 & 122.1,-7.7\end{array}$

Thus the direction angles evaluated at the retarded time were within 3.3 deg of the measurement angles. Amplitude changes were large for the downstream measurement angle. For the $90^{\circ}$ measurement position, data were shifted less than $2^{\circ}$ in angle and $0.1 \mathrm{~dB}$ in amplitude between measured quantities and those for a retarded-time frame of reference.

Airframe flyover data have been presented (e.g., references 5 and 6 ) in a retarded-time frame of reference which is fixed relative to the ambient air. If spectra measured in those tests are corrected for the Doppler shift of frequency, they should agree with those measured in an acoustic wind tunnel and corrected by the above procedure to a retarded-time frame of reference that is fixed relative to the airframe.

Open Jet Effect on Angle of Attack. - Lifting airfoils within an open jet induce curvature of the shear layer and deflection of the jet. If the wind tunnel has no downstream physical constraint on position of the deflected jet, the lifting airfoil rotates the jet until its downward momentum is equal to the lift force per unit time. Relative angle of attack is reduced by the jet deflection, and curvature of the jet centerline produces an effective negative camber that can be regarded as an additional decrease in angle of attack. The first of these reductions in angle of attack (radians) is given by equation $(6: 23 \mathrm{~b})$ of reference 27 as $(1 / 4) \mathrm{c} / \mathrm{h}$ per unit lift coefficient. Here, c is the wing chord and $h$ is the height of the open jet. The second term, due to open-jet curvature imposed by the condition of constant static pressure along the jet boundary, is $(\pi / 24)(\mathrm{c} / \mathrm{h})^{2}$ per unit lift coefficient. Suppose that the correction to lift coefficient is arbitrarily limited to $20 \%$ so that flow field distortion should not be excessive. Then approximating the lift coefficient by $2 \pi$ times the angle from zero lift in radians, the ratio of airfoil chord to test section height is limited to $0.4 / \pi$. For the $79 \mathrm{~cm}$ height of this acoustic tunnel, this would limit the wing chord to only $10 \mathrm{~cm}(4 \mathrm{in.})$ which is impractically small for airframe component tests. 
If the open jet collector imposes a constraint on vertical position of the jet, the jet is deflected upward ahead of the lifting airfoil and downward behind it. Then only the second correction, proportional to chord to height ratio squared rather than the first power, is applicable. This correction is of opposite sign and four times the magnitude of the corresponding correction for a solid-wall test section, given by equation $(6: 23 a)$ of reference 27 . The same constraint of a $20 \%$ correction then limits the chord to height ratio to $(2.4)^{\frac{1}{2}} / \pi$, or a $39 \mathrm{~cm}$ ( $\left.15.3 \mathrm{in.}\right)$ chord for this test section.

An airfoil model with $22.9 \mathrm{~cm}$ (9.00 in.) chord and NACA 0012 airfoil section had previously been tested in this acoustic wind tunnel. This airfoil section would be expected to have a maximum lift coefficient near 1.5, at an angle of attack of about $15^{\circ}$, in free air at the test Reynolds numbers and Mach numbers. Assuming that the change in airfoil pressure distribution due to flow distortion would not significantly change the maximum lift coefficient, the increases of angle of attack at stall were calculated for the above two possible flows. If the collector imposed a constraint on vertical position of the test section airflow, only about $1^{\circ}$ increase of angle of attack for stall onset would be expected. More than $7^{\circ}$ increase was calculated for a flow without downstream constraint. Measured stall onset, determined by the onset of loud broadband noise, was found to occur when uncorrected angle of attack was increased beyond $16^{\circ}$. This measurement confirmed the assumption that the open jet flow collector imposes sufficient constraint on deflected jet position so that the smaller of the two open-jet corrections is needed. This correction, while small compared with that for a simple open jet, is four times the magnitude of the correction for a closed-wall wind tunnel of the same dimensions.

Corrections were applied as an increase of geometric angle of attack such as to achieve the approach lift coefficient of 0.6 times maximum lift coefficient. Part-span and full-span variants of the same configuration were assumed to have the same maximum lift coefficient, and were tested at the same corrected angle of attack. Because the variation of lift coefficient with angle of attack was nonlinear for the high-lift configurations, the correction to angle of attack was applied by calculating the required lift coefficient prior to correction. The data of references 12, 16, and 18 were utilized to determine the geometric angle of attack which would yield that uncorrected lift coefficient. Expected maximum lift coefficients, approach lift coefficients, intended (corrected) approach angles of attack, and geometric (uncorrected) angles of attack are tabulated in the next page for each configuration. 
Angle of Attack, deg

Configuration Maximum $C_{I}$ Approach $C_{I}$ Corrected Geometric

$\begin{array}{lccrr}\text { Clean wing, cruise } & - & 0.30 & 2.0 & 2.5 \\ \text { Clean wing } & 1.52 & 0.91 & 7.5 & 9.6 \\ \text { Single flap, 15 } & 2.25 & 1.35 & 5.0 & 7.7 \\ \text { Single flap, 240 } & 2.52 & 1.51 & 4.0 & 6.0 \\ \text { Single flap, 40 } & 2.67 & 1.60 & 2.0 & 5.0 \\ \text { Double flap, 40 } & 2.95 & 1.77 & -8.0 & -3.5 \\ \text { LE slat or flap } & 2.10 & 1.26 & 11.5 & 15.2 \\ \text { IE+TE devices } & 3.02 & 1.81 & 1.5 & 6.5\end{array}$

Application of the open-jet wall curvature correction at large lift coefficients, where the variation of lift coefficient with angle of attack is nonlinear, has not been thoroughly established in aerodynamic testing. It is possible that the true lift coefficients were somewhat larger than the nominal approach lift coefficients. Flow visualization data confirmed that the test conditions did not have extensive flow separation and therefore were well below stall.

\section{COMPARISON OF SINGIE-COMPONENT DATA WITH PREDICTIONS}

\section{Clean Wing}

The clean wing with retracted flap was tested at two angles of attack. These corresponded to the airfoil design lift coefficient of 0.30 and the nominal approach lift coefficient of 0.90 for this airfoil without high-lift devices. At the lower lift coefficient, far field spectra measured with omnidirectional microphones were essentially identical to the background noise of the empty test section. Increased lift coefficient caused an increase of measured SPLs, particularly at high frequencies. However, this additional noise is believed to be increased background noise of the wind tunnel caused by curvature and deflection of the open jet due to wing lift.

Directional microphone measurements for the clean wing at a lift coefficient of 0.90 and for the wing with a part-span leading edge flap are plotted in figure 10. Traces are shown for $1 / 3$ octave band center frequencies of 5,10 , and $20 \mathrm{kHz}$ at $100 \mathrm{~m} / \mathrm{sec}$ velocity. They are plotted against streamwise distance, adjusted for the predicted distance that a sound wave moving perpendicular to the flow would be convected downstream before it reached the shear layer. Denoting the test section height by $h$ and the free stream Mach 
number by $M$, this distance is $M h / 2$. A convection-adjusted distance of zero corresponds to the position at which a sound wave leaving the clean wing leading edge at $90^{\circ}$ to the tunnel centerline would be observed by the directional microphone. For 5 and $10 \mathrm{kHz}$ center frequencies the traces for the clean wing had peaks centered at the convection-adjusted trailing edge location. This result is consistent with the noise mechanism assumed for clean wings in reference 3: trailing edge noise caused by flow of the wing boundary layer over the wing trailing edge. Directional microphone, data previousIy given in reference 12 for NACA 0012 and 0018 airfoils had demonstrated the same result. The peak noise radiation at $20 \mathrm{kHz}$ center frequency was located at $75 \%$ chord and was only about $1 \frac{1}{2} \mathrm{~dB}$ above tunnel background noise. This very low amplitude noise came from locally separated flow in the indentation to the wing lower surface (figure 4) at the forward position of the retracted trailing edge flap.

Tape-recorded signals from the directional microphone traverses were played back through $1 / 3$ octave band filters for all center frequencies for which the measured peak amplitude was more than $3 \mathrm{~dB}$ above background noise. Resulting peaks, corrected for background noise, were used for calculation of absolute SPL by the method of reference 12. In this calculation the wing trailing edge is assumed to be a line source. Spectra obtained in this manner for the clean wing at both lift coefficients and $100 \mathrm{~m} / \mathrm{sec}$ velocity are compared in figure 11 with the spectrum predicted by the method of reference 3 . Measured levels were approximately independent of lift coefficient. They were about $5 \mathrm{~dB}$ below the predicted curve except for a measured local peak centered at $8 \mathrm{kHz}$ frequency that matched the prediction. Overprediction had been found in the study reported in reference 12 for tests at comparable Reynolds numbers. It had been attributed to the differences in boundary layer turbulence spectrum shape and level which occur at different Reynolds numbers. (Absolute level of the predicted spectrum is based on a correlation of aircraft flyover data for Reynolds numbers an order of magnitude larger than those of the wind tunnel tests.) Peak frequency of the clean-wing measured spectrum was at or below $2 \mathrm{kHz}$, in general agreement with the prediction. In contrast, the total aircraft method of reference 2 would have predicted a peak frequency given by $1.3 \mathrm{U} / \mathrm{t}$ which would be in the $3.15 \mathrm{kHz}$ frequency band for this model and velocity, well above the peak frequency.

In addition to broadband noise, clean wings can radiate discrete tones or very sharp narrowband-random peaks if the Reynolds number is too low. The laminar boundary layer on one or both surfaces of the airfoil then extends to the trailing edge. Instabilities convected within the laminar boundary layer can become coupled with trailing edge noise in a feedback process. Such behavior is affected by the airfoil static pressure distribution. It tends to occur on the lower surface of uncambered airfoils at high lift 
coefficients and the upper surface of cambered airfoils at low lift coefficients. The three velocities of this test program provided Reynolds numbers of about 1.5, 2.1, and 2.9 million based on airfoil chord. The boundary layer had been expected to become turbulent ahead of the trailing edge for all test conditions. However, a hump occurred in the $1 / 3$ octave band centered at $3.15 \mathrm{kHz}$ for the clean wing at the lower lift coefficient and $70.7 \mathrm{~m} / \mathrm{sec}$ airspeed. Narrowband analysis resolved this disturbance as two narrowband-random peaks centered at 3.23 and $3.34 \mathrm{kHz}$ frequencies. The tone frequency for laminar instability noise from a flat-plate airfoil was calculated by the method of reference 28 as $2.64 \mathrm{kHz}$ for this test condition. Thus the tone frequency was predicted within about $1 / 3$ octave, which is acceptable for showing that this was the noise-generating process.

\section{Leading Edge Flap}

Spectra measured at the $90^{\circ}$ microphone at 70.7 and $100 \mathrm{~m} / \mathrm{sec}$ velocities, with the acoustic shield placed between the collector and microphone, are presented in figure 12. Amplitudes are normalized to $100 \mathrm{~m} / \mathrm{sec}$ velocity assuming a dependence on velocity to the sixth power (a 9 dB difference between the two sets of data at constant strouhal number). This assumed velocity dependence produces close agreement between the two spectra (open circles and triangle symbols). However, these measured levels at a nominal lift coefficient of 1.26 are only about $2.5 \mathrm{~dB}$ above those for the wing alone at 0.90 lift coefficient. Thus they probably include background noise resulting from wing lift. The clean wing without an acoustically shielded collector had a hump in its spectrum above a Strouhal number of 20 (frequency of $6.3 \mathrm{kHz}$ at $100 \mathrm{~m} / \mathrm{sec}$ ). This collector-radiated noise at high lift coefficients was blocked from this microphone by the shield.

Output traces from directional microphone traverses at midspan and the side edge of the leading edge flap at $100 \mathrm{~m} / \mathrm{sec}$ velocity are plotted in figure 10. Also shown are traverse data for the wing alone. If the leading edge flap had produced constant noise per unit span, amplitudes measured at the side edge would have been $3 \mathrm{~dB}$ below those at midspan. Instead, peak amplitudes at the edge were about $4 \mathrm{~dB}$ above those at midspan. These peaks occurred at a convection-adjusted position approximately 10\% wing chord downstream of the wing leading edge for both spanwise positions. Oil flow patterns on the forward lower surface showed a region of separated flow on the flap lower surface and forward lower portion of the wing. This region was approximately centered at the wing leading edge, where the surface slope changes discontinuously. Presumably the stagnation point for the wing and flap combination was near the flap leading edge, and the separated flow was imbedded between the surface discontinuity and an otherwise smooth flow which attached to the wing lower 
surface. Within the separated flow region, turbulent eddies caused by unsteady flow attachment moved upstream and then moved spanwise to the regions of lower static pressure at the side edges. Turbulence generated elsewhere along the flap span was convected toward the side edges, so it is reasonable that those edges should be strong noise sources. A much smaller noise peak was centered at the adjusted trailing edge position and had the same strength at both spanwise positions. This peak has approximately the amplitude that would be expected if the peak of leading edge flap noise had been faired smoothly into the background noise and added to the wing-alone trailing edge noise. That is, the noise caused by the presence of a leading edge flap seems to be associated with unsteady separated flow on the lower surface of the flap and wing, and is radiated from the forward lower portion of the wing.

Directional microphone data for $100 \mathrm{~m} / \mathrm{sec}$ velocity were utilized to calculate $1 / 3$ octave spectra by the method of reference 12. Resulting data are shown as solid symbols in figure 12. The solid circles are SPLs calculated for a line source with length equal to the leading edge flap span and peak amplitude determined from the measurement at midspan. For 2.5 and $5 \mathrm{kHz}$ center frequencies these results were 1 to $2 \mathrm{~dB}$ below those measured with the conventional far field microphone. For higher frequencies, the directional microphone half-power width is less than the distance from midspan to the flap side edges. Noise from those edges then has only a small contribution to the measurement taken at midspan. For 10 and $20 \mathrm{kHz}$ frequencies, the data trace at the side edge was assumed to be the sum of a line source equal to the midspan level for half the field of view and a point source located at the edge. Noise radiation from two point sources (both spanwise edges) determined in this manner are plotted as diamond symbols, and sums of the line and point sources are shown by $X$ symbols. These sums are 2 and $3 \mathrm{~dB}$ below the spectrum measured with the conventional microphone, which therefore was sensing a combination of leading edge flap noise and wind tunnel background noise. For this reason, directivity measurements with the conventional microphones showed only a near-constant amplitude dependent of direction angle. Future measurements of noise radiation directivity from leading edge flaps will require use of a directional microphone with its resolving axis rotated through a range of angles from the tunnel centerline.

\section{Leading Edge slat}

The leading edge slat was first tested with $0.64 \mathrm{~cm}$ (1/4 in.) diameter circular support struts located at $1 / 4$ the slat span from each edge. With these supports, the measured far-field spectrum contained peaks in the $1 / 3$ octave bands which corresponded to a strouhal number of 0.2 based on strut 
diameter and free stream velocity. To reduce this noise, modeling clay was added to the downstream ends of the struts to produce an arbitrary streamlined shape. The peaks were eliminated and SPLs were decreased about $4 \mathrm{~dB}$ at higher frequencies. All configurations which included the leading edge slat were re-run with the faired support struts. Tests with the slat were conducted only at 70.7 and $100 \mathrm{~m} / \mathrm{sec}$ velocity because the estimated maximum airloads on the slat at $14 \mathrm{Im} / \mathrm{sec}$ might have overstressed the support struts.

Normalized $1 / 3$ octave spectra measured at the $90^{\circ}$ microphone position for both test velocities are plotted in figure 13 for two possible velocity dependences. Frequencies are normalized as Strouhal number based on wing chord, and amplitude is normalized relative to slat area and far-field distance. Amplitude is normalized to $100 \mathrm{~m} / \mathrm{sec}$ by use of two assumed velocity scaling laws: a fifth-power dependence appropriate for trailing edge noise and assumed in reference 3 and the sixth-power dependence generally assumed (e.g., reference 2) for surface-radiated noise. Both scaling laws produce agreement between data for these two velocities. However, flyover tests with the DC-9 aircraft (reference 6) over a larger range of aixspeeds closely matched the fifth-power variation, so that velocity exponent should be used.

The normalized spectrum predicted by the method of reference 3 is compared with data in the upper part of figure 13. This curve, based on flyover data for the Vickers VC 10 aircraft with and without its slat extended, is 4 to $5 \mathrm{~dB}$ below the data for these wind tunnel tests for all but the lowest frequencies. Noise radiation from this model slat probably is unrealistically high compared with that of a real slat, possible due to additional noise from the support struts. Thus the prediction of reference 3 should be retained.

Noise source strength distributions at midspan and at the side edge of the leading edge slat are compared in figure 14 with those for the leading edge flap. Data are shown for $2.5,5,10$, and $20 \mathrm{kHz}$ center frequencies and $100 \mathrm{~m} / \mathrm{sec}$ velocity. The slat noise radiation generally was about $15 \mathrm{~dB}$ stronger than that from the leading edge flap. This is much larger than 6 dB increment predicted by the method of reference 3. Slat noise radiation as measured by the directional microphone at the three higher frequencies was 3 $\mathrm{dB}$ lower when the reflector was aimed at the slat side edge rather than at midspan. At the edge position, the slat occupied only half of the spanwise extent of the region viewed by the reflector. At midspan the slat extended across the entire region. Therefore the $3 \mathrm{~dB}$ difference shows that the slat radiated only as a line source without an additional point source located at the edges as for the leading edge flap. Spectrum levels calculated from these data agreed within $I \mathrm{~dB}$ with those measured with the conventional microphone and are not shown. 
The observed noise source distributions for the leading edge slat were maximum at the slat trailing edge, which was located approximately at the wing leading edge. Trailing edge noise of the wing was increased, but that noise was 10 to $15 \mathrm{~dB}$ below noise from the slat. Contrary to the noise generation process assumed in reference 3, the dominant noise increase caused by the presence of the slat was radiated entirely from the slat. Oil flow visualization showed that the airflow was attached to all surfaces except the slat lower surface. The measured slat noise apparently was generated by convection of the slat lower surface separated turbulent flow past the slat trailing edge. Additional noise may be generated by motion of this turbulence past the wing leading edge. The observed noise radiation was strong over an order of magnitude range of strouhal number, as shown in figure 13. This is a wide range, compared with the relatively sharp peak usually radiated by trailing edge noise. It can be explained only if the spectrum of turbulence intensity for this separated turbulent flow also is very broad.

Directivity of the leading edge slat and of other airframe components was evaluated at the highest frequencies that were felt to be unaffected by noise from the tunnel collector. These $1 / 3$ octave center frequencies were taken as 5 and $6.3 \mathrm{kHz}$ for 70.7 and $100 \mathrm{~m} / \mathrm{sec}$ velocities, respectively (and $10 \mathrm{kHz}$ at $141 \mathrm{~m} / \mathrm{sec}$ for other configurations). They correspond to strouhal numbers near 20 based on wing chord and near 3 based on slat chord. The resulting measured directivity for the leading edge slat at 70.7 and $100 \mathrm{~m} / \mathrm{sec}$ velocities is shown in figure 15 as variations of $1 / 3$ octave band SPL with retarded-time directivity angle. Also shown are the directivity shapes calculated for two posible noise gencration processes. Slat noisc seemed to be caused by convection of turbulence past the slat trailing edge. Directivity of trailing edgc noise was shown in reference 29 to vary with Mach number in a manner which depends on the assumed trailing edge boundary condition. If the Kutta condition is not imposed at the trailing edge, and if the turbulence convection velocity is close to free stream velocity, equation (5.36) of reference 29 stales that mean square acoustic pressure in the flyover plane is proportional to $\left(1-M \cos \theta_{r}\right)^{-3} \sin ^{2}\left(\theta_{x} / 2\right)$. This predicted trailing edge noise directivity with convective amplification is plotted as dashed lines in figure 15. If the Kutta condition is imposed at the trailing edge, and if the velocity of shed vorticity in the near wake is close to free stream velocity, equation (5.37) of reference 29 gives the directivity function as $\left(1-M \cos \theta_{r}\right)^{-1} \sin ^{2}$ $\left(\theta_{r} / 2\right)$. That is, if the Kutta condition is assumed to be satisfied at the trailing edge, the variation of predicted trailing edge noise directivity shape with Mach number is greatly reduced.

The above analysis applies to trailing edge noise from a very long flat plate relative to the wavelength. For acoustic wavelengths of the order of or greater than chord, acoustic waves would be refracted around the leading 
edge. The directivity shape would change toward that of a lift dipole, with mean square acoustic pressure proportional to $\left(1-\mathrm{M} \cos \theta_{r}\right)^{-4} \sin ^{2} \theta_{r}$. This shape is plotted in figure 15 as solid lines. Absolute levels for the two sets of predicted curves were matched to data at $90^{\circ}$ retarded angle. The two predicted curves differ by less than $2 \mathrm{~dB}$ over most of the measurement range. Data taken at the most forward microphone cause the measured directivity to be best matched by the shape predicted for a lift dipole with convective amplification. However, predicted directivity of trailing edge noise for a flow field that satisfies the Kutta condition (not shown) also would give a close match to the data. That result would also be consistent with the fifth-power velocity dependence found in these data (figure 13) and in the flight test program reported in reference 6 . This velocity variation is predicted for trailing edge noise with both boundary conditions but not for dipole noise.

\section{Landing Gear}

The $1 / 3$ octave band SPLs measured at $90^{\circ}$ for the wing and landing gear, with the landing gear cavity both open and closed, are compared in figure 16 for $100 \mathrm{~m} / \mathrm{sec}$ airspeed. Spectrum levels measured with the directional microphone for $2.5,5,10$, and $20 \mathrm{kHz}$ center frequencies are plotted as solid symbols. These levels were calculated by assuming that the landing gear assembly was a point scurce. Good agreement is obtained except for the highest frequency, where the directional microphone half-power width is less than the total width of the two wheels so the landing gear assembly is seen as a distributed source. Note that noise radiation from the clean wing, as measured with the directional microphone, was of the order of $10 \mathrm{~dB}$ below tunnel background noise. Also shown is the spectrum for the wing alone at the same angle of attack, corresponding to a nominal 0.90 lift coefficient. Note that the spectrum for the wing and landing gear at frequencies below $800 \mathrm{~Hz}$ is dominated by that of the lifting wing alone. As shown in the previous discussion of noise radiated by the wing alone, this spectrum actually is background noise of the acoustic wind tunnel calused by the wing lift force. The highfrequency noise peak which occurred above $6.3 \mathrm{kHz}$ for the wing alone was shown to be wind tunnel background noise originating at the collector. The open cavity added 5 to $10 \mathrm{~dB}$ over a frequency range from about 1.6 to $6.3 \mathrm{kHz}$ at this model scale. It added about $1 \mathrm{~dB}$ at higher frequencies corresponding to the range in which large contributions to annoyance-weighted noise at full scale would occur. This result that the presence of an open landing gear cavity has little effect on landing gear noise radiation above the cavity noise frequency region was first shown by Heller and Dobrzynsky (reference 21). Amplitudes of the two cavity tones shown in figure 16 were less than 85 $\mathrm{dB}$, which is smaller than the values of 92 and $96 \mathrm{~dB}$ calculated from equation (21) of reference 20 for the isolated cavity. As was also shown in reference 
21, the presence of the landing gear strut and brace protruding through the cavity shear layer weakens the feedback process.

Narrowband spectra for the landing gear and cavity were measured at 70.7 , 100 , and $141 \mathrm{~m} / \mathrm{sec}$ velocities. These spectra all contained three distinct peaks, all of which were broader than a pure tone signal at the same bandwidth. Measured frequencies at peak amplitude were converted into strouhal number based on cavity length and free stream velocity. The variation of these Strouhal numbers with free stream Mach number is compared in figure 17 with that predicted by the method of reference 22. Two types of oscillation were predicted by that method. Strouhal numbers for streamwise modes, calculated from equation (1) of reference 22 for mode numbers from 1 to 4 , are plotted as solid lines. They decrease slowly with increasing Mach number. Strouhal numbers for a depthwise standing wave, calculated from equation (?) of reference 22, are plotted as a dash line. Comparisons with data for cavities without landing gear, given in reference 22, had shown that streamwise modes for which the Strouhal number was far below that of the depthwise mode would rot be excited. This prediction was validated for the landing gear cavity configuration in that noise peaks did not occur near the fundamental $(n=1)$ strouhal number. Measured Strouhal numbers were 5\% to 10\% higher than those predicted, and followed the predicted trend. This good agreement is within the range of scatter for two sets of data at nearly this same cavity length to depth ratio but different sizes, given in figure 4 of reference 22 . From those data, cavity noise radiation had occurred for clean cavities at streamwise mode numbers of only 2, 3, and 4 at approximately the two higher velocities of these tests. Thus the disturbance to the shear layer by the landing gear did not affect the number of modes excited at 100 and $141 \mathrm{~m} / \mathrm{sec}$ velocities. However, mode numbers from 2 to 6 had been reported in reference 22 for the clean cavity at approximately $70.7 \mathrm{~m} / \mathrm{sec}$ velocity, while only mode numbers from 2 to 4 were found for the cavity with landing gear. Thus the method of reference 22 for isolated clean cavities predicted the tone frequencics of a landing gcar and cavity within 10\%, but the presence of the landing gear decreased somewhat the number of modes excited.

The $1 / 3$ octave spectra measured at the $90^{\circ}$ microphone, with the cavity open, were corrected for background noise caused by the lifting wing. They were then normalized in amplitude by adding $20 \log (\mathrm{R} / \mathrm{D})+60 \log (\mathrm{V} / 100 \mathrm{~m} / \mathrm{sec})$ where $D$ is the wheel diameter. Frequency was normalized as strouhal number based on wheel diameter and free stream velocity. Results for the three test velocities are compared in figure 18 with the prediction taken from equation (11) of reference 3 adjusted to free field conditions. This prediction consisted of an empirically picked analytical expression fitted to the data correlation in reference 21. It can be seen from figure 18 that the data of this test program are coalesced except for cavity noise and are about 2 or 3 $\mathrm{dB}$ below that predicted by the method of reference 3 . 
The effect of velocity on landing gear noise directivity is shown in figure 19. Data points are corrected $1 / 3$ octave SPLs for $5,6.3$, and $10 \mathrm{kHz}$ center frequencies at $70.7,100$, and $141 \mathrm{~m} / \mathrm{sec}$ velocities, corresponding to Strouhal numbers near 3.4 based on wheel diameter. Flagged and unflagged symbols represent data for the wing and landing gear without and with the open cavity. At the two lower velocities, noise radiation was increased by the presence of the open cavity, causing different SPLs for the two configurations. Also shown are directivity curves calculated for a lift dipole with convective amplification and matched to the data at $90^{\circ}$ retarded-time angle. These calculated shapes closely match the data. They predict the large measured change in directivity shape as Mach number was varied from 0.2 to 0.4 . The result that landing gear noise has the directivity pattern of a lift dipole with convective amplification agrees with the landing gear noise mechanism assumed in reference 30. That study had attributed the noise radiation to unsteady pressure fluctuations on the wheel lower surface, fully correlated along the wheel width. The measured directivity differs from constant amplitude at all direction angles in the flyover measurement plane as assumed in reference 3 .

Landing gear directivity data in the aft quadrant were reported in figure 9 of reference 22 for a model with the same wheel diameter as this model, tested at nearly the same Mach numbers ( 0.18 and 0.40 ). Those data, uncorrected for refraction at the shear layer or for retarded-time position, were shown therein to be closely matched by the predicted directivity of a lift dipole without convective amplification. The effects of the two corrections on direction angle are small, but both corrections reduce the measured SPLs in the aft quadrant. If those two corrections had been applied, measured directivities would have been closer to the shapes reported herein.

Streamwise variations of directional microphone signal strength at 2.5, 5 , 10 , and $20 \mathrm{kHz}$ center frequencies and $100 \mathrm{~m} / \mathrm{sec}$ velocity are compared in figure $20(a)$. Because the noise radiation and system gain have different strengths at all these frequencies, the data are plotted normalized to peak measured amplitude. Traces are shown for three spanwise positions: the landing gear strut, the far edge of the open cavity $8.9 \mathrm{~cm}(3.5 \mathrm{in.})$ away, and the same distance to the other side of the strut. Noise radiation at the two lower frequencies is primarily from the cavity, while at the two higher frequencies it is from the landing gear assembly. All four curves had their maxima on the aft portion of the wheels and cavity. It is known (reference 20) that cavity noise originates from the downstream edge. Apparently, as shown in reference 21 by crosscorrelation experiments, landing gear noise is radiated from the lower aft quadrant of the wheels. 
Streamwise plots of relative signal strength at 5 and $20 \mathrm{kHz}$ and $100 \mathrm{~m} /$ sec velocity are shown in figure 20(b) for the three spanwise positions. These frequencies correspond to Strouhal numbers of 2.5 and 10 referenced to wheel diameter. At the spanwise position of the wheel strut, the landing gear plus cavity was about 1 to $2 \mathrm{~dB}$ louder than the landing gear alone at $20 \mathrm{kHz}$ frequency. The cavity side edge opposite from the landing gear assembly (denoted as far edge of cavity) radiated a signal roughly $5 \mathrm{~dB}$ smaller at $5 \mathrm{kHz}$ and $10 \mathrm{~dB}$ smaller at $20 \mathrm{kHz}$ frequency. The signal measured at an equal spanwise distance in the other direction includes some noise from the strut door but is primarily noise originating at the landing gear, off-center from the directional microphone image point and was therefore $10 \mathrm{~dB}$ weaker than that for the midspan traverse.

Trajling Edge Flaps

Far-Field Acoustic Spectra. - Spectra measured at the $90^{\circ}$ microphone position for 70.7 and $100 \mathrm{~m} / \mathrm{sec}$ velocities are plotted in figure 21 for four test configurations. Two of these are the wing alone at a nominal lift coefficient of 0.9 and the $15^{\circ}$ deflection full span single slotted trailing edge flap. Both were tested without the acoustic shield. At the lower velocity, the presence of the trailing edge flap added several dB up to $0.8 \mathrm{kHz}$ center frequency. This portion of the measured spectrum is believed to be tunnel background noise caused by the curved deflected shear layer produced by the lifting wing and flap. Near $2 \mathrm{kHz}$ the wing with trailing edge flap was about $10 \mathrm{~dB}$ Iouder than the wing alone, due to noise radiated by the deflected flap.

Both of these spectra had local peaks at 10 to $16 \mathrm{kHz}$ center frequency. This high-frequency noise was found to come from impingement of the deflected tunnel airstream against the tunnel collector. Two additional spectra are shown for the $15^{\circ}$ deflection full-span and part-span single slotted trailing edge flaps, with an acoustic shield placed between the collector and the $90^{\circ}$ microphone. Below about $8 \mathrm{kHz}$ frequency this shield had essentially no effect on spectra measured with the full-span flap. At higher frequencies, shielding the collector noise radiation caused about $6 \mathrm{~dB}$ noise reduction. The resulting irregularly shaped spectrum qualitatively agrees with the prediction by the method of reference 3 , given in this figure by three straight-line segments .

The part-span trailing edge flap had the same chord as the full-span flap but $1 / 3$ the span. It would be predicted by the method of reference 3 to have the same spectrum shape but $4.7 \mathrm{~dB}$ lower amplitude. Measured spectrum shape generally was the same for these full-span and part-span flaps, but the 
smaller flap was 4 to $5 \mathrm{~dB}$ quieter only above $8 \mathrm{kHz}$ frequency. The difference was only 2 to $3 \mathrm{~dB}$ at lower frequencies.

Normalized spectra for the part-span and full-span flaps at this deflection and measurement position are compared in figure 22. Amplitudes are normalized for flap area and tunnel velocity, and depend only on flep deflection angle. Therefore the same normalized spectrum is predicted for both part and full span flaps. Frequency is normalized as Strouhal number based on flap chord. Data for the part-span flap with the acoustic shield at 70.7 and 100 $\mathrm{m} / \mathrm{sec}$, and without the acoustic shield at $141 \mathrm{~m} / \mathrm{sec}$ excluding the highest frequencies, are coalesced by the assumed sixth power velocity variation. Measured levels are underpredicted about $4 \mathrm{~dB}$ below a strouhal number of 4 but predicted within about $2 \mathrm{~dB}$ for strouhal numbers larger than 6.3. The spectrum measured with the full span flap at $70.7 \mathrm{~m} / \mathrm{sec}$ was closely predicted, but spectra for the two higher velocities were about 4 dB lower between strouhal numbers of 2.5 and 8 . From these measured spectra one might assume that noise is radiated by trailing edge flaps by two processes, having peak amplitudes at strouhal numbers near 2 and 16 .

Spectra measured at larger flap deflection angles are plotted in normalized form in figure 23. Normalized spectra for the $24^{\circ}$ deflection partspan trailing edge flap, plotted in the upper part of this figure, were only about $2 \mathrm{~dB}$ higher than the average of the data band for $15^{\circ}$ deflection. The method of reference 3 had predicted a $4 \mathrm{~dB}$ difference between SPLs at those two angles. The predicted normalized spectrum generally is 2 to $3 \mathrm{~dB}$ above these data.

Normalized spectra measured with the $40^{\circ}$ deflection part-span and fullspan trailing edge flaps are compared in the lower part of figure 23 . These levels are normalized for flap area, so the same curve is predicted for both part and full span. However, the normalized data for the full span flap are 4 to $5 \mathrm{~dB}$ below those for the part span flap. Both configurations radiated about the same amount of noise, even though one had 3 times the span of the other. The prediction matched the data for the part-span flap for Strouhal numbers less than 1 and more than 25 but was about $4 \mathrm{~dB}$ above data within that range. Again, the effect of a factor of 2 change in velocity was predicted by use of Strouhal number and a sixth power velocity dependence.

Measured $1 / 3$ octave band SPLs radiated by the $40^{\circ}$ deflection part-span double slotted trailing edge flap were about 2 dB larger than those from the same-deflection same-span single slotted flap. However, use of a Strouhal number based on total flap chord causes these data points to be shifted half an octave higher in Strouhal number, where predicted noise amplitude is smaller. The resulting comparison of measured and predicted normalized spectra for the double slotted flap is shown in figure 24. Measured levels were 
overestimated by about $2 \mathrm{~dB}$ for strouhal numbers from 5 to 31.5 and closely predicted at larger strouhal numbers. Although the method of reference 3 overpredicted noise radiation from the $40^{\circ}$ deflection single slotted flap (figure 23), it generally was within $3 \mathrm{~dB}$ for the same deflection double slotted flap.

Surface Pressure Spectra. - Additional diagnostic information was obtained for selected configurations, including the part-span and full-span $40^{\circ}$ deflection single slotted flap. Commercially available thin-film static pressure transducers were attached to the central flap panel upper surface at four positions. These positions were at $25 \%$ and $75 \%$ of the flap chord, at both midspan and 25\% chord from the side edge. The 25\% flap chord position was $1.9 \mathrm{~cm}$ ( $0.75 \mathrm{in.}$ ) downstream of the flap leading edge and was just barely far enough behind the wing slot to permit calibration of the transducexs with a pistonphone. Data were taken at both 70.7 and $100 \mathrm{~m} / \mathrm{sec}$ tunnel velocities. Amplitudes of surface pressure fluctuation were normalized as 10 times the logarithm of the ratio of $1 / 3$ octave band mean square pressure fluctuation to tunnel dynamic pressure squared. Center frequencies were normalized as Strouhal number referenced to wing chord and tunnel velocity.

These normalized $1 / 3$ octave surface pressure spectra are shown in figures 25 and 26 for the full-span and part-span flaps, respectively. Data for the two velocities were brought into general agreement by this normalization. Typical. maximum amplitudes are about $-40 \mathrm{~dB}$ corresponding to $1 / 3$ octave rms fluctuations which are $1 \%$ of free stream dynamic pressure. Spectra generally contain a broad peak at strouhal numbers of order one and, for the forward transducer positions, a sharper peak at Strouhal numbers of 20 to 50 . Moving from midspan toward the edge decreased the peak strouhal number. It is likely that this higher-frequency peak at $25 \%$ chord represents turbulence generated in the flap slot region and convected above the airfoils. This high-frequency turbulence probably is dissipated in the flap upper surface boundary layer by $75 \%$ chord. The one condition at which this turbulence persisted to the aft position was for the full span flap at midspan and 100 $\mathrm{m} / \mathrm{sec}$ velocity, possibly due to locally separated flow. The difference in peak strouhal number between the two spanwise measurement positions on the full-span flap may have resulted from the nominal edge position being closer to a flap support bracket.

Pressure fluctuations at midspan of the full-span and part-span flaps had about the same amplitudes at $25 \%$ chord but were about $5 \mathrm{~dB}$ stronger for the full-span flap at $75 \%$ chord. In contrast, pressure fluctuations near the edge were about $5 \mathrm{~dB}$ stronger for the part-span flap at both chordwise positions. Note that for a full scale aircraft with $3 \mathrm{~m}$ (10 ft) wing chord and $100 \mathrm{~m} / \mathrm{sec}(328 \mathrm{ft} / \mathrm{sec}$ ) flight speed, Strouhal numbers larger than 15 
correspond to greater than $500 \mathrm{~Hz}$ center frequency. In this region which is important for predicting annoyance-weighted noise, both the midspan and edge spanwise positions on the part-span flap at the forward chordwise position had large fluctuating surface pressures. Pressure fluctuations at the forward position on the full-span flap were of comparable size near mid-span but were up to $10 \mathrm{~dB}$ weaker near the edge. For both flap configurations, surface pressure fluctuations at these strouhal numbers of practical importance were of the order of $10 \mathrm{~dB}$ smaller at the aft than the forward position. Thus it is likely that noise associated with inflow turbulence in the flap slot would be more important than flap trailing edge noise.

Surface pressure fluctuations on the upper surface of the trailing edge flap were crosscorrelated with each other and with the far field acoustic pressure in an attempt to obtain further understanding of the noise process. These tests were conducted at both 70.7 and $100 \mathrm{~m} / \mathrm{sec}$ velocities for the $40^{\circ}$ deflection single slotted part-span flap. Signals were filtered to pass the portion of the signal between 0.5 and $50 \mathrm{kHz}$ frequency. For both velocities and both spanwise locations, the crosscorrelations between upstream and downstream positions showed a clearly discernible peak. The delay times corresponded to a pressure disturbance convected downstream at about $84 \%$ of free stream velocity. Normalized correlation coefficient for these signals was about 0.20 for the edge location at the lower velocity and 0.13 for the other three cases. Crosscorrelations also were tried between the surface pressures at the same chordwise location but different spanwise positions, and of surface pressures and far-field acoustic pressure measured at the $90^{\circ}$ microphone. None of these combinations gave a noticeable signal, within an accuracy of about 0.01 in normalized correlation coefficient. This absence of a measurable correlation between surface pressure and acoustic pressure can be understood by use of the hot wire data discussed in a later section. Transverse integral scale lengths of the turbulence in the flap slot and near the flap trailing edge were two orders of magnitude smaller than the flap span. At any instant of time, noise was being radiated from a very large number of statistically independent source regions. No one surface region would have had a large enough contribution to produce a significant correlation with farfield acoustic pressure.

Distribution of Noise Source Strength. - Streamwise variations of noise source strength, as measured during traverses of the directional microphone at midspan, are compared in figure 27 for the full-span single slotted trailing edge flap at three deflection angles. These data were obtained at $100 \mathrm{~m} /$ sec tunnel speed and are presented for the 1/3 octave bands having 2.5, 5, 10, and $20 \mathrm{kHz}$ center frequencies. The traces for each frequency are plotted at their correct relative amplitudes. Streamwise distances are shown relative to 
the position at which an acoustic wavefront leaving the wing leading edge in the direction normal to the tunnel centerline, but convected downstream within the test section airflow, would be predicted to leave the test section shear layer.

The streamwise distribution of noise source strength at each frequency can be determined from the normalized width of these curves. At $2.5 \mathrm{kHz}$ the resolution is so broad that all three flap angles radiate if they were line sources. The distributions measured for the two smaller angles were approximately centered at the flap leading edge. That for $40^{\circ}$ deflection was centered about $1 / 4$ wing chord further downstream, near the flap trailing edge. At this center frequency, increased flap angle decreased the noise radiation. For 5 and $10 \mathrm{kHz}$ center frequencies, widths of the traces were halved by each frequency doubling. Their noise radiation continued to resemble that of a line source at the flap leading edge, within the instrument resolution. However, the traces for $40^{\circ}$ deflection were wider and were centered further downstream along the flap. This increase of center frequency reversed the effect of flap angle on amplitude of noise radiation, with increased angle causing increased noise at $10 \mathrm{kHz}$ center frequency. For $20 \mathrm{kHz}$ center frequency the data traces for the two smaller flap angles are not noticeably narrower than the $10 \mathrm{kHz}$ case. Therefore the noise source is distributed along roughly the forward quarter-chord of the trailing edge flap. The data trace for $40^{\circ}$ flap angle increased rapidly as the reflector moved downstream toward the convection-adjusted flap leading edge position. However, it decayed more gradually after passing the peak in the source distribution. This less rapid decrease was attributed to quadrupole noise generated by the turbulent wake downstream of the flap.

Flow visualization pictures of surface oil-flow patterns showed that the local flow was attached to the wing and flap upper and lower surfaces at the two smaller deflections. At $40^{\circ}$ deflection, airflow on the flap upper surface was separated along roughly the rear half of the flap chord. The chordwise distribution of noise source strength along the trailing edge flap at small angles is consistent with what would be expected for noise radiation from an isolated airfoil in turbulent flow. Judged from the source strength distribution shape and the flow visualization results, noise radiation from a highly deflected trailing edge flap is a combination of two processes. These are the noise caused by turbulent inflow and trailing edge noise caused by motion of upper-surface separated flow past the flap trailing edge.

Streamwise variations of noise source strength at midspan and along a side edge of a part-span single slotted trailing edge flap are compared in figure 28 with those for a full-span flap at the same deflection. Data are shown for all three flap deflection angles at 5 and $20 \mathrm{kHz} 1 / 3$ octave band 
center frequencies. For $15^{\circ}$ deflection the data traces all were centered near the flap leading edge. The full-span flap had the largest source strength at $20 \mathrm{kHz}$, with midspan location of the part-span flap about I dB quieter. The side edge of the part-span flap was a weaker noise source. If the source strength per unit span was constant along the part-span flap, the signal at a side edge would be half of that at midspan and should be $3 \mathrm{~dB}$ lower. This size difference occurred at $20 \mathrm{kHz}$ (and, not shown, at $10 \mathrm{kHz}$ ) center frequency. At this flap deflection and these frequencies, noise radiation from the part-span and full-span flaps had an amplitude directly proportional to flap span.

Results for $24^{\circ}$ flap angle resembled those for $15^{\circ}$ except that source strengths at midspan approximately matched those for the full-span flap, and the curves for the side edge were centered further aft along the flap chord. Flow visualization showed separation on the flap upper surface along the rearward half of the flap chord, with flow toward the side edges. At $40^{\circ}$ deflection the full-span flap had the weakest of the three traces. The $40^{\circ}$ deflection full-span flap had no more noise radiation than the $15^{\circ}$ deflection flap, despite its drag coefficient being more than twice as large (reference 13 ). This result disproves the fundamental assumption of the drag element method (reference 1) that airframe component sound power is directly proportional to drag coefficient. Midspan of the part-span flap was strongest at $5 \mathrm{kHz}$, but the side edge was $3 \mathrm{~dB}$ above midspan and $5 \mathrm{~dB}$ above the full-span flap at 20 $\mathrm{kHz}$ center frequency. The traces for both spanwise positions along the partspan flap were centered near midchord of the flap. Flow visualization showed the upper surfaces of both the full-span and part-span flap to be fully separated aft of the flap slot. The upper surface of the part-span flap had a strong flow toward the edges, starting just past the slot. In contrast, the lower surfaces of all trailing edge flaps had attached flow that was nearly streamwise except very near the side edges of the part-span flap.

The 1/3 octave spectra determined from directional microphone traces for the part-span and full span single slotted trailing edge flaps are compared in figure 29 with spectra measured by the acoustically shielded conventional microphone at the $90^{\circ}$ position. Amplitudes of the directional microphone measurements were corrected to the $3.25 \mathrm{~m}$ far-field distance of the conventional microphone. This comparison is shown for $100 \mathrm{~m} / \mathrm{sec}$ velocity. Noise radiation for the full span trailing edge flaps (circle symbnls) was calculated as that for a line source. That for the part-span flaps was calculated as a line source based on the level measured at midspan (square symbols). For 10 and $20 \mathrm{kHz}$ frequencies, the edge signal was assumed to be the sum of the midspan line source over half the viewed area and an edge-located point source. Noise radiation from the inferred point sources is plotted as diamond symbols, and the acoustic sum of the line and point sources is plotted as $X$ symbols. 
Spectrum levels determined by the two methods generally agreed within $1 \mathrm{~dB}$. The largest differences occurred at $20 \mathrm{kHz}$ frequency, where levels measured with the directional microphone for $15^{\circ}$ and $40^{\circ}$ flap deflection were $2 \mathrm{~dB}$ above those for the conventional microphone. These directional microphone data confirm the approximate variation of trailing edge flap noise with flap area to the first power ( $4.7 \mathrm{~dB}$ difference between data for full-span and part-span flaps) at $15^{\circ}$ and $24^{\circ}$ deflection but not at $40^{\circ}$ deflection.

Noise source strength distributions at midspan and the side edge of the $40^{\circ}$ deflection part-span double slotted flap are compared in figure 30 with those for the single slotted flap. Data traces for the double slotted flap are displaced rearward by approximately the length of the flap vane. That is, peak noise radiation from the double slotted flap at most frequencies came from the leading edge region of the large-chord flap panel. At 5 and $20 \mathrm{kHz}$ it was roughly equal to what was measured when that panel was tested as a single slotted flap. At $2.5 \mathrm{kHz}$ the double slotted flap was 2 aB louder at both the edge and midspan, and at $10 \mathrm{kHz}$ it was $2 \mathrm{~dB}$ louder at midspan and $1 \mathrm{~dB}$ louder at the edge. For the double slotted flap at $10 \mathrm{kHz}$, noise at midspan apparently came from the small-chord vane while that measured at the edge came from near the main flap trailing edge. 'l'his was the only example of significant noise radiation from the flap vane. Most of the noise radiated by this double slotted trailing edge flap was radiated by the large-chord main flap. The edges were the strongest noise source locations at the higher model frequencies of $10 \mathrm{kHz}$ and higher, which would scale to high-annoyance frequencies on full scale airframes.

Flow visualization patterns showed that the airflow was attached on the wing, vane, and main flap lower surface and wing upper surface. The vane upper surface flow was separated ahead of the trailing edge. The flap upper surface had some separated flow on its upper surface followed by reattachment, with strong spanwise flow toward the edges. Turbulence generated by the flow separation could have been convected to the edges, causing the stronger edge noise radiation at some frequencies.

The $1 / 3$ octave band spectrum levels determined from directional microphone measurements for the double slotted trailing edge flap are compared in figure 31 with those measured with the conventional microphone at $90^{\circ}$ direction. Levels obtained by regarding the midspan trace as that from a line source were 2 to $4 \mathrm{~dB}$ below those measured by the conventional microphone. The point source determined by regarding the edge measurement as a sum of a line and point source was stronger than the line source. From figure 30, this concentrated noise radiation was coming from the rearward corners of the flap (junction of the main flap side edge and trailing edge). The sum of the two kinds of noise radiation was about $I \mathrm{~dB}$ above that measured with the conventional microphone and within $2 \mathrm{~dB}$ of levels predicted by the method of Ref. 3 . 
Directivity. - The effect of velocity on noise directivity for the full span single slotted flap is shown in figure 32. Symbols with no, one, or two flags denote data for $15^{\circ}, 24^{\circ}$, and $40^{\circ}$ deflection angle. Data are compared for $5,6.3$, and $10 \mathrm{kHz}$ center frequencies at $70.7,100$, and $14 \mathrm{~m} / \mathrm{sec}$ velocities, respectively, giving a strouhal number of about 5 based on flap chord and 20 based on wing chord. Increased velocity caused the directivity shape to change, with relative increases in the forward and decreases in the aft quadrant. These measured shapes and their variation with velocity were generally matched by the directivity predicted for a lift diple normal to the free stream, with convective amplification. Data for $15^{\circ}$ deflection at all three velocities, and $24^{\circ}$ deflection at the highest and lowest velocity, decrease somewhat more rapidly with increasing retarded-time angle than is predicted for this orientation of a lift dipole. They would be more closely matched (not shown) by the predicted directivity of a lift dipole rotated through about half the flap deflection angle, with convective amplification. However, data for the largest flap deflection were closely matched by the curve predicted for a lift dipole normal to the flow. Perhaps this difference occurred because the airstream was attached to the flap upper surface at the two smaller deflection angles but was separated at the largest angle.

The same type of directivity comparison for the part-span single slotted flap is shown in figure 33. Data points at the $120^{\circ}$ measurement angle are not shown for $15^{\circ}$ flap deflection and are questionable for the other two deflections because of instrumentation problems with that microphone and preamplifier. Excluding those data points, the measured directivities are matched by the predicted shape for a lift dipole normal to the flow, with convective amplification.

Directivity data for the part-span double slotted trailing edge flap are shown in figure 34. They also have questionable levels at the most rearward angle and are matched by an unrotated lift dipole with convective amplification. Directivity data for a simplified $40^{\circ}$ deflection trailing edge flap, not corrected for shear-layer refraction or retarded-time effects (reference 22), also do not seem to be rotated through the flap deflection angle. There is no obvious reason why the noise directivity pattern for the three $40^{\circ}$ deflection trailing edge flap configurations of this test program, and for the configuration of reference 22, should be that of an undeflected lift dipole. The assumption in reference 3 that this directivity pattern is rotated through the flap deflection angle apparently is wrong and should be corrected. 


\section{Analytical Concept}

Noise radiation from deflected trailing edge flaps is a major contributor to annoyance-weighted airframe noise (references 2, 3, 25, and 26). The data correlation developed in reference 3 showed relatively flat $1 / 3$ octave band spectra over a factor of 10 in frequency for single and double slotted flaps and a larger factor for triple slotted flaps. Because of this large amplitude over a range of frequency, flap noise reduction will require altering the initial noise radiation source rather than shape and size changes which redistribute acoustic energy to Low-annoyance frequencies. Reduction of noise source strength can best be achieved if the noise-generating mechanism is understood. The apparent variation of trailing edge flap noise radiation with flap area to the first power and flyover velocity to the sixth power, and the general spectrum shape, are what would be expected for noise radiation from airfoils immersed in a turbulent flow. If fluctuations of loading on the flap due to convected turbulence are the cause of this noise, then methods for reducing such noise radiation from isolated airfoils could be applied directly.

Another possible noise generation mechanism for trailing edge flaps is trailing edge noise (reference 32). If the flow over the flap aft upper surface is separated, then turbulent eddies within this flow would be convected downstream causing large fluctuations of loading very near the trailing edge. Noise generated by this process for an attached turbulent boundary layer normally is relatively low in amplitude. However, the high turbulence levels and large eddy sizes in the high-shear region of a separated flow can generate much stronger noise. Trailing edge noise generally has a much more sharply peaked spectrum than that observed during flyover measurements of aircraft with deflected trailing edge flaps.

An exact analytical method for predicting noise radiation from thin isolated airfoils in uniform isotropic turbulent flow was developed in reference 31. This method includes acoustic noncompactness. Noise radiation spectrum in a given direction is predicted as a function of airfoil chord and span, far-field distance, flow velocity, flow Mach number, turbulence rms velocity, and turbulence integral scale length. The digital computer program developed in the study reported in reference 31 was readily available. Derivation of the computer program includes some assumptions that are not necessarily valid for deflected trailing edge flaps: isotropic turbulence which is homogeneous in both the chordwise and spanwise directions, small leading edge radius relative to the turbulence scale length, and no other 
solid surfaces nearby which might reflect or refract sound waves. Also, the data correlation of reference 32 was available for predicting spectrum shape and amplitude of trailing edge noise for a given direction, velocity, farfield distance, and turbulence intensity and scale length. Spectrum levels produced by both of these noise generating processes therefore could be calculated from the measured turbulence properties.

The objective of this portion of the investigation was to determine whether the measured turbulence properties near both the leading and trailing edges of a deflected trailing edge flap, utilized in available methods for predicting noise radiation from an isolated airfoil in turbulent flow, gave reasonable predictions of measured noise spectra from trailing edge flaps.

\section{Turbulence Measurements}

Spatial variations in the mean and turbulence velocity fields were examined by traversing the regions of the flap slot and flap trailing edge with a single hot wire. This wire was parallel to the spanwise direction so it measured the resultant of the mean and turbulence velocities in the other two orthogonal directions. Data were taken at midspan of the $40^{\circ}$ deflection part-span single and double slotted flaps. As sketched in figure 35, traverses were taken normal to the airfoil chord line within the slot of the single slotted flap and within the two slots of the double slotted flap. Traverses also were taken normal to the $40^{\circ}$ deflection chord line just downstream of the main flap trailing edge. A remotely controlled traverse mechanism was installed outside the. free shear layer for these tests, and the probe support rod extended across a considerable length of flow. These tests were utilized to locate the position of maximum rms turbulence velocity within each traverse line.

At each of these five positions, a crossed-wire probe was used to measure flow direction, mean velocity, turbulent intensity, and length scale of the velocity component parallel and perpendicular to the mean velocity in the mean flow direction, within the midspan plane. The crossed-wire probe consisted of two $0.0005 \mathrm{~cm}$ ( $0.002 \mathrm{in.}$ ) diameter tungsten hot wires perpendicular to each other and located in the midspan plane. The probe support extended spanwise through holes drilled in the tunnel sidewall. Hot-wire anemometer linearizing circuits were used to produce the same linear relationship between mean velocity and anemometer dc output voltage for both channels. The two sets of signals were input to a sum and difference network. With this arrangement, the difference between the two dc signals was zero when the probe was rotated to a position at which the mean velocity vector bisected the angle between the two wires. The sum of the two dc signals was 
proportional to mean velocity. The rms sum and difference of the two ac signals was proportional to the turbulence components parallel and perpendicular to the mean velocity, respectively. These turbulence signals were input to a real-time correlator to obtain autocorrelations and therefore Eulerian time scales. From Taylor's hypothesis, the local streamwise and transverse turbulence integral scale lengths are the product of Eulerian time scale and local streamwise mean velocity.

All turbulence data were taken at $76.2 \mathrm{~m} / \mathrm{sec}$ (250 ft/sec) free stream velocity. To facilitate their use at other speeds, data are presented as ratios of local velocity to free stream velocity.

Results of the single-wire traverses within the slot and above the trailing edge of the single slotted flap are presented in figure 36 . Maximum mean velocity in the slot, at the edge of the wing lower surface boundary layer, was about $90 \%$ of free stream velocity. It decreased as the probe entered the region of flow which was approaching the flap stagnation point and then increased toward free stream velocity. The maximum rms turbulence level (6.6\% of free stream velocity) occurred roughly half way between the slot upper surface and the flap stagnation streamline, in the velocity gradient produced by the flow deceleration imposed by the flap leading edge region. This turbulence level is typical of a jet free shear layer. The high mean velocities near the slot lower surface show that airflow was attached to the slot surface. In contrast, measurements above the trailing edge showed mean velocities less than $37 \%$ of free stream velocity for more than $2 \mathrm{~cm}(0.8$ in.) above the flap upper surface. Two free shear regions occurred, one betwen the flow which had passed through the flap slot and the flow which originated in the wing upper surface boundary layer, and the other between that second viscous region and the free stream. The inner shear region, which presumably was the only one close enough to the surface to influence noise radiation, had more than $13 \%$ rms turbulence level.

Corresponding results for the double slotted flap are plotted in figure 37. Data are shown only for the slot between the airfoil and the fore flap, and above the main flap trailing edge. The traverse in the slot between the fore flap and main flap gave maximum mean velocities of about half the free stream velocity and maximum turbulence intensity of $0.6 \%$ for streamlines that passed within the slot. The low value for mean velocity is caused by the very high lift coefficient for the fore flap of a double slotted flap, which greatly reduced the local velocity near that flap's lower surface. The low turbulence level is reasonable if all of the wing lower surface turbulent boundary layer had passed through the first slot and only an inviscid low turbulence flow approached this second slot. Noise spectra calculated for flow of this low-amplitude turbulence at the measured low velocity ratio were 
about $30 \mathrm{~dB}$ below data. Thus the turbulence entering the second slot is not associated with noise radiation from this double slotted flap. Because the directional microphone measurements had shown that noise was produced by the main flap panel at midspan, this noise may have been produced by turbulence from the first slot that was convected past the vane upper surface.

Maximum mean velocity ratio of 1.1 , and $6.7 \%$ turbulence level, in the forward slot were reasonably close to those measured with the single slotted flap. In contrast, mean velocities above the trailing edge of the double slotted flap were about twice, and peak turbulence levels about half, those for the single slotted flap. The profile of mean velocity for the double slotted flap shows a region of high velocity at about $0.75 \mathrm{~cm}(0.3 \mathrm{in}$.) above the surface, probably coming from the second slot. This region is bracketed by local maximum of about 5\% turbulence level. The combined wakes of the fore flap and the wing upper surface cause a local minimum in mean velocity at about $1.5 \mathrm{~cm}$ ( $0.6 \mathrm{in.}$ ) above the trailing edge. Flow over the upper aft face of the double slotted flap clearly is well-attached compared with that for the single slotted flap (figure 36). This improved flow attachment is the reason for using multiple slotted flaps.

As shown in figure 35, positions of the crossed-wire probes generally were slightly ahead of the traverse probe lines. Actual positions may differ from those indicated by as much as $0.08 \mathrm{~cm}(0.03 \mathrm{in}$.$) . Results of the$ crossed-wire measurements are tabulated below. Mean velocity direction is measured as the upward angle relative to airfoil chord line, which was at $5^{\circ}$ angle of attack. Turbulence levels are the ratio of streamwise and transverse rms velocity to the free stream velocity. Here, streamwise is parallel to the local mean velocity and transverse is perpendicular to that direction within the midspan plane.

\begin{tabular}{|c|c|c|c|c|c|c|}
\hline & $\begin{array}{c}\text { Mean } \\
\text { Velocity }\end{array}$ & \multicolumn{5}{|c|}{ Turbulence } \\
\hline Probe Position & Ratio & Direction & Stream & Trans & Stream & Trans \\
\hline $\begin{array}{l}\text { Single slotted, slot } \\
\text { trailing edge }\end{array}$ & $\begin{array}{l}0.72 \\
0.29\end{array}$ & $\begin{array}{r}69^{\circ} \\
-36^{\circ}\end{array}$ & $\begin{array}{l}0.053 \\
0.110\end{array}$ & $\begin{array}{l}0.040 \\
0.076\end{array}$ & $\begin{array}{l}0.38 \\
0.66\end{array}$ & $\begin{array}{l}0.22 \\
0.33\end{array}$ \\
\hline $\begin{array}{l}\text { Double slotted, } \\
\text { forward slot } \\
\text { aft slot } \\
\text { trailing edge }\end{array}$ & $\begin{array}{l}0.99 \\
0.43 \\
0.78\end{array}$ & $\begin{array}{r}53^{\circ} \\
30^{\circ} \\
-30^{\circ}\end{array}$ & $\begin{array}{l}0.052 \\
0.0045 \\
0.047\end{array}$ & $\begin{array}{l}0.039 \\
0.0037 \\
0.025\end{array}$ & $\begin{array}{l}0.58 \\
2.70 \\
0.58\end{array}$ & $\begin{array}{l}0.28 \\
1.04 \\
0.23\end{array}$ \\
\hline
\end{tabular}

Turbulence within the flap slots was not very far from isotropic, with transverse turbulence levels $75 \%$ to $80 \%$ of the streamise values rather than being equal and transverse scale lengths 0.4 to 0.6 rather than half the streamwise 
length. Transverse turbulence levels near the flap trailing edge were markedly smaller ( $53 \%$ and $69 \%$ ) than the streamwise levels but the ratio of scale lengths remained close to one-half. Mean velocity ratios and resultant turbulence levels obtained with the crossed-wire probe generally agreed with those measured with the single-wire probe.

\section{Comparison of Measured and Calculated Spectra}

Noise radiation was calculated by the method of reference 31 for a farfield position beneath an isolated airfoil the size of the part-span single slotted flap, immersed in uniform turbulent flow. These calculations used an rms fluctuating velocity normal to the flow, and transverse integral scale length, equal to those measured at midspan in the slot of that flap. Calculations were made for two different convection velocities, the $70.7 \mathrm{~m} / \mathrm{sec}$ free stream velocity and the corresponding velocity within the flap slot at the position of maximum measured turbulence. The increased velocity in going from the slot to free stream reduced the percentage turbulence level, increased the expected peak frequency, and increased the expected SPLs. A comparison of these two calculated spectra with that measured at the $90^{\circ}$ microphone for the $40^{\circ}$ deflection part-span single slotted flap is given in figure 38 . Oscillations in the calculated spectra are caused by acoustic noncompactness, which causes phase cancellation and reinforcement of sound waves arriving at the same far-field point from different chordwise and spanwise positions. The measured spectrum also was oscillatory. Its amplitude and general shape were matched by the calculation which used the free stream velocity. However, noise radiated near the flap edge at high frequencies was about 5 dB larger than that from midspan. Therefore the spectrum calculated using the turbulence velocity measured within the flap slot might give closer agreement with noise radiated at midspan. The spectrum measured at $100 \mathrm{~m} / \mathrm{sec}$ by the directional microphone at midspan, and adjusted to $70.7 \mathrm{~m} / \mathrm{sec}$, does not clearly prove either viewpoint.

Trailing edge noise radiated by this single slotted flap was also calculated. Primarily because of the small convective velocity ratio measured near the trailing edge, the calculated peak value of this noise was about 20 $\mathrm{d} B$ below the data. Therefore the noise radiated by a single slotted trailing edge flap at midspan is incidence fluctuation noise resulting from inflow of slot turbulence.

The comparison for the double slotted flap, shown in figure 39, is less satisfactory. The noise spectrum calculated for the 10\% chord fore flap had a peak value of $5 \mathrm{~dB}$ above the far-field data. Turbulence levels measured in the aft slot were so low that the associated noise radiation was negligible. 
If it is assumed that the transverse turbulence velocity and integral scale length measured in the forward slot somehow were also convected past the main flap at the mean velocity within the aft slot, the bottom curve of this figure is obtained. This calculated spectrum is of the order of $3 \mathrm{~dB}$ below the data obtained with the conventional microphones and close to that from the directional microphone at midspan. Trailing edge noise calculated with the turbulence properties measured at the main flap trailing edge was maximum near 1 $\mathrm{kHz}$ and had a peak level nearly as large as the data. However, amplitude of noise generated by this process decays rapidly as frequency is increased beyond the peak. Trailing edge noise therefore may add a low-frequency peak or irregularity to the spectrum but is predicted to be unimportant at higher model frequencies which scale to the high-annoyance range.

The general shape and level of the measured spectrum would be matched if the turbulence properties measured in the forward slot were arbitrarily assumed to be convected past the main flap at the free stream velocity. There is no justification for this approximation; the wing and fore flap upper surface boundary layers would be expected to alter the turbulence of the airflow injected between these two layers. However, the directional microphone data of figure 30 indicate that the main flap rather than the fore flap is the primary noise source location for that portion of the spectrum between 5 and $20 \mathrm{kHz}$ center frequencies. This was the only manner in which the measured noise radiation levels could be generated by turbulence incident on the main flap.

In summary, the amplitude and spectrum shape of measured noise radiation from a single slotied trailing edge flap was matched by the noise calculated for an isolated airfoil within the turbulent flow measured in the flap slot. The observed increase of airframe rlyover noise radiation with increasing flap deflection probably is caused by increased slot turbulence level as the airflow is deflected through larger angles. The comparison was less satisfactory for a double slotted flap.

\section{AIRFRAME COMPONENT NOISE INTERACTIONS}

\section{Leading Edge Devices and Landing Gear}

Spectra measured at the $90^{\circ}$ microphone with the wing equipped with the leading edge flap, landing gear cavity, and landing gear at the midspan and the part-span locations are plotted as symbols in figure 40 for 70.7 , 100, and $14 \mathrm{~m} / \mathrm{sec}$ velocities. This figure also contains the measured spectra for the wing with leading edge flap and for the wing with landing gear and its open cavity, plotted as dash and dot-dash lines. Also shown as a solid line is the 
acoustic sum of the latter individual-component spectra, regarding them as statistically independent noise sources. Measured spectra for the leading edge flap and for both landing gear positions of the flap, landing gear combinations at the two lower velocities were obtained with the acoustic shield between the $90^{\circ}$ microphone and the wind tunnel collector. All other data in this figure were obtained without this shield.

The acoustic sum of the component spectra is dominated by landing gear cavity noise at low frequencies, landing gear noise at somewhat higher frequencies, and leading edge flap noise at the highest frequencies. The leading edge flap, landing gear combinations had much weaker landing gear cavity noise than the landing gear alone. From 5 to $8 \mathrm{~dB}$ reduction of the lowest-order tone was achieved. This reduction was 1 to $2 \mathrm{~dB}$ larger when the landing gear was at the part-span position, in line with the edge of the leading edge flap. However, the midspan gear position was about the same increment quieter than the edge position for cavity higher harmonics. At higher frequencies, corresponding to full-scale high-annoyance frequencies, SPLs for the two landing gear positions were approximately equal. They were about 1 dB below the acoustic sum of the two individual components. Because the spectrum measured with the landing gear included some noise radiated from the tunnel collector, this may not represent a real component interaction.

Noise source strength distributions at three spanwise positions are plotted in figures 41 and 42 for the two leading edge flap, landing gear combinations. These data were taken at $100 \mathrm{~m} / \mathrm{sec}$ velocity and are shown for 5 and $20 \mathrm{kHz}$ center frequencies. These traces represent the noise source strength seen locally; the leading edge flap extends over a larger spanwise distance so its arsolute level of noise radiation is not as small relative to the gear noise as this comparison seems to show. Note that source strength measured on a traverse through the landing gear assembly (midspan on figure 41 and at the lower edge denoted "gear" in figure 42) was reduced about $1 \mathrm{~dB}$ at both frequencies. The reduction of cavity noise by the presence of the leading edge flap can be seen in the traverse at the cavity edge in figure 41.

To understand the reason for the interaction effect on cavity tones, recall that the leading edge flap produced a region of separated flow on its lower surface. Chordwise extent of the separation region decreased as the edge was approached. The boundary layer on the wing lower surface, and therefore the flow entering the landing gear cavity shear layer, therefore was made less steady by a spanwise varying amount. The resulting shear layer would be less able to sustain an aerodynamic feedback process. This feedback would be most strongly disrupted when the landing gear strut protruded through one spanwise portion and the approaching boundary layer was most nonuniform at the other spanwise portion (gear midspan). 
Spectra for the leading edge slat, landing gear cavity, and landing gear at the midspan and part-span locations are plotted in figure 43 . Also shown are measured spectra for the wing with leading edge slat and for the wing with extended landing gear and open cavity, and the acoustic sum of those two spectra. All but the landing gear configurations were measured with the collector shielded. Unlike the situation for the landing gear and leading edge flap, this sum was dominated by noise radiated by the slat for all but the cavity tone frequencies. The slat seems to have suppressed the lowest-order cavity tone for the midspan gear position. However, this lowest-order tone was strengthened and shifted to the next lower $1 / 3$ octave band for the part-span landing gear position. The next-order tone apparently was not affected by the slat. Higher-frequency noise was unaffected by landing gear spanwise position and was essentially the same as that for the wing with only the slat. Directional microphone traverses for these two leading edge slat, landing gear combinations are shown in figures 44 and 45 . They also show essentially no interaction effects on noise radiation for 5 and $20 \mathrm{kHz}$ center frequencies.

Other than some changes in landing gear cavity noise, there were no component interaction noise effects for leading edge high-lift devices tested with landing gear at two spanwise positions.

\section{Leading Edge Flap and Trailing Edge Flaps}

Spectra measured at the $90^{\circ}$ microphone for the leading edge flap, $40^{\circ}$ deflection single slotted full span trailing edge flap configuration are plotted in figure 46. Also shown are the spectra measured for the wing with only the leading edge flap and for the wing with only the trailing edge flap, and their acoustic sum. All of these data are for configurations tested with the acoustic shield. The acoustic sum is dominated by noise radiation from the trailing edge flap, and spectra for the combination closely match the acoustic sum. Directional microphone traverses, shown in figure 47, generally validate the lack of interaction effects on trailing edge flap noise radiation. Noise from the leading edge flap at $5 \mathrm{kHz}$ center frequency apparently was reduced. Deflecting the trailing edge flap would be expected to shift the leading edge stagnation point further aft along the leading edge flap's lower surface. Resulting streamlines would more closely conform to the highly deflected shape of the leading edge flap, reducing the noise-producing flow separation on that flap's lower surface.

Normalized surface pressure spectra on the trailing edge flap upper surface for this configuration are plotted in figure 48 . As compared with those for the full span trailing edge flap alone (figure 25), pressure fluctuations at midspan were unchanged forward and decreased aft. Near the 
side edge, they were strengthened forward and unchanged aft. Apparently this combination of no change and opposite changes produced no effect on total noise radiation.

Spectra measured at the $90^{\circ}$ microphone with the leading edge flap, $40^{\circ}$ deflection single slotted part-span trailing edge flap are plotted in figure 49. Also shown are spectra measured for the wing with each of the two components, and the acoustic sum of these two spectra. As with the leading edge flap, full span trailing edge flap combination, the acoustic sum was dominated by the noise spectrum of the trailing edge flap. However, unlike that configuration, the measured spectra for greater than about $6.3 \mathrm{kHz}$ model frequency were about 3 to $4 \mathrm{~dB}$ below the acoustic sum of SPLs from the two components. They were 2 to $3 \mathrm{~dB}$ below levels measured with the wing and part-span trailing edge flap alone.

Directional microphone traverses at midspan and along the side edge of the part-span high-lift devices are shown in figure 50. These data are for 5 and $20 \mathrm{kHz}$ center frequencies at $100 \mathrm{~m} / \mathrm{sec}$ velocity. The traverses at midspan show no interaction at $5 \mathrm{kHz}$ and increased leading edge flap noise but slightly decreased trailing edge noise at $20 \mathrm{kHz}$ frequency. Thus the noise-reducjng interaction did not take place near midspan. The traverse along the edge for $5 \mathrm{kHz}$ frequency showed that noise from the leading edge flap region was reduced about $6 \mathrm{~dB}$ and noise from the trailing edge flap was essentially unchanged. There was almost no reduction of far-field SPL at this frequency (figure 49). However, noise radiation from the side edge of the part-span trailing edge flap was reduced by about $4 \mathrm{~dB}$ at $20 \mathrm{kHz}$ frequency. Peak amplitude of this noise radiation from the flap edge was reduced to about the level which had been measured at midspan with or without the leading edge flap. This was about I dB larger than peak amplitude measured on the full-span trailing edge flap. To further check this result, source strength distributions measured for this configuration at $10 \mathrm{kHz}$ center frequency and 70.7 , 100 , and $141 \mathrm{~m} / \mathrm{sec}$ velocity are compared in figure 51 with those of the components alone. Peak values at the trailing edge flap were reduced $I$ to $2 d B$ at midspan but were 4 to $6 \mathrm{~dB}$ quieter at the edge, for the two lower velocities. Thus the favorable component noise interaction shown in the far-field spectra (figure 49) was caused by a decrease of the very strong: noise radiation from the part-span trailing edge flap's side edge, at sufficiently large Strouhal numbers.

Surface pressure spectra on the upper surface of the part-span trailing edge flap are plotted in figure 52 for this configuration. Spectrum levels at midspan essentially matched those of figure 26 for midspan of the part-span trailing edge flap alone. Those at the forward transducer near the flap edge were up to $6 \mathrm{~dB}$ lower than those for the part-span trailing edge flap alone, at frequencies where the difference in far-field SPL occurred. There was 
essentially no change at the aft edge position. Flow visualization pictures were of little help in understanding the change in. flow pattern. However, the presence of a part-span leading edge flap clearly reduced the surface pressure fluctuations and local noise source strength near the side edge of the part-span trailing edge flap, causing significant ( 3 to $4 \mathrm{~dB}$ ) noise reduction.

\section{Leading Edge Slat and Trailing Edge Flaps}

Far-field spectra at the $90^{\circ}$ microphone for the leading edge slat, full span trailing edge flap combination are plotted in figure 53. These data and those for the two individual components were obtained with the acoustic shield between the collector and microphone. SPLs for the combination at frequencies up to about $10 \mathrm{kHz}$ were 1 to $2 \mathrm{~dB}$ above the acoustic sum of spectra measured with the slat and flap deflected separately. This sum is dominated by noise radiation from the leading edge slat. At higher frequencies corresponding to the full scale frequencies which have largest contributions to annoyance, the measured spectra agreed with the acoustic sum of component spectra.

Noise source strength distributions obtained with the directional microphone are plotted in figure 54. At midspan the noise contribution from the slat was not greatly changed, but that from the trailing edge flap was increased and was shifted downstream from the flap leading edge to its trailing edge. This change corresponds to the development of strong trailing edge noise caused by flow separation on the flap upper surface. Evidently the confluent boundary layer caused by merging of the slat wake and airfoil upper surface boundary layer could not withstand the additional adverse pressure gradient imposed by the deflected trailing edge flap. Noise radiation from the slat side edge was decreased about $5 \mathrm{~dB}$ at both 5 and $20 \mathrm{kHz}$ frequency, and that from the trailing edge flap downstream of that edge was decreased slightly. Surface pressure spectra on the trailing edge flap upper surface are plotted in figure 55. Data measured forward at midspan approximately match those for the full span trailing edge flap without other components. Those for the aft midspan position at $100 \mathrm{~m} / \mathrm{sec}$ velocity were up to $10 \mathrm{~dB}$ smaller for the trailing edge flap with the leading edge slat. These reduced levels at $75 \%$ chord probably represent a highly separated flow. Near the side edge, pressure at the forward position was about $5 \mathrm{~dB}$ higher for the combination but there was no difference further aft.

The part-span leading edge slat, full span trailing edge flap combination achieved a noise-increasing component interaction effect on far-field spectra at low frequencies (figure 53). Directional microphone data show this to be caused by increased noise from the aft portion of the trailing edge flap, but 
also show a reduction of slat noise that should have compensated for this increase. Far-field data show essentially no component interaction effect at high model frequencies, which scale to those of greatest importance fullscale. Directional microphone traces show a redistribution of noise source strength, with reduced noise radiation from the slat side edges but increased noise from the flap trailing.edge. This result is of practical importance because it may be difficult to apply noise-reduction concepts to a leading edge slat which is subjected to large aerodynamic loading and must fit flush with the wing during cruise. Porous (reference 33) or serrated (reference 34) trailing edges may be more readily applied to large-chord trailing edge flaps for noise reduction.

Far-field spectra measured at the $90^{\circ}$ microphone for the leading edge siat, part-span trailing edge flap combination are plotted in figure 56. These data, and those for the individual components, were taken with the acoustic shield between the microphone and the tunnel collector. As with the leading edge slat and full-span trailing edge slat, the acoustic sum of the component spectra was dominated by noise from the slat for all but the highest frequencies. The comparison between measured spectra for the combination and the acoustic sum of spectra for independent components is inconsistent below $10 \mathrm{kHz}$ frequency; the interaction apparently was about $2 \mathrm{~dB}$ favorable at 70.7 $\mathrm{m} / \mathrm{sec}$ and $2 \mathrm{~dB}$ unfavorable at $100 \mathrm{~m} / \mathrm{sec}$ velocities. For higher frequencies the data were about $I \mathrm{~dB}$ below the acoustic sum. Directional microphone data, shown in figure 57, indicate reduced slat noise and increased flap noise at midspan and relatively little change at the side edges. Surface static pressure spectra, plotted in figure 58, generally agreed with those on the flap upper surface of the leading edge slat, full span trailing edge flap combination (figure 55) at midspan and at the forward edge position. They were about $10 \mathrm{~dB}$ higher at the aft edge position, corresponding to the same high levels measured at this location for the part-span trailing edge flap without other components.

Noise from the slat edge therefore was markedly decreased by the presence of the full-span trailing edge flap but was only slightly affected by the part-span trailing edge flap. Noise radiation from the midspan region of both part-span and full-span trailing edge flaps was increased by the presence of a leading edge slat. The strong noise radiation from the side edge of a partspan trailing edge flap was unaffected by the upstream presence of a leading edge slat's spanwise edge. 
Spectra measured at the $90^{\circ}$ microphone for the part-span trailing edge flap, open landing gear cavity, landing gear at midspan and part-span configurations are plotted in figure 59. Also shown are measured spectra for the wing with only the part-span trailing edge flap and the wing with only the landing gear and open cavity, and the acoustic sum of those two spectra. The landing gear spectra were obtained without the acoustic shield between the microphone and far-field microphone; spectra for the other two configurations were measured with that shield. Landing gear cavity noise dominated the acoustic sum at the lower frequencies, and both components were important at high frequencies. Below about $12.5 \mathrm{kHz}$ model frequency, SPLs measured for the combination were approximately equal to the sum of the two individual spectra. Above that frequency the noise radiation for both landing gear positions was about $2 \mathrm{~dB}$ less than the acoustic sum.

Noise source distributions measured with the directional microphone are plotted in figures 60 and 61 for the two landing gear positions. The traces for $5 \mathrm{kHz}$ frequency show a 1 to $2 \mathrm{~dB}$ reduction of landing gear noise. Trailing edge flap noise downstream of the landing gear was increased several dB but noise from the flap side edge was reduced by about the same amount. Surface pressure spectra on the upper surface of the part span trailing edge flap for the flap and landing gear combination are plotted in figure 62. They show increased levels at low Strouhal numbers relative to those of the flap without the landing gear, corresponding to flow disturbances produced in the landing gear cavity. They were somewhat higher at the aft transducer for both spanwise locations.

The directional microphone traces do not clearly show the cause of the indicated $2 \mathrm{~dB}$ noise reduction at frequencies of practical importance. However, they do show a redistribution of noise source strength caused by aerodynamic interaction between the landing gear and trailing edge flaps. The deflected flap and increased lift coefficient would be expected to reduce the local velocity near the landing gear, thereby reducing its noise radiation. The landing gear, in turn, would be expected to shed a turbulent wake that impinges upon the trailing edge flap and increases its surface pressure fluctuations and noise radiation. Note that as had been mentioned in the discussion of the airframe component test model, the ratio of landing gear strut length to wheel diameter was relatively short as is typical of airframes with aft fuselage-mounted engines. Other airframe designs with high bypass ratio turbofan engines mounted under the wings might have longer landing gear struts and smaller relative interaction effects. The existence of this component effect is important because aircraft landing gears cannot be easily modified for noise reduction. However, the component interaction found in this 
study provides reduction of landing gear noise by the trailing edge flap aerodynamic flow field. Increased trailing edge flap noise caused by the landing gear turbulent wake could then be reduced by use of perforated or porous forward surfaces backed with a bulk acoustic absorber (reference 15), mounted on an impervious inner structure to sustain the steady aerodynamic loading.

To further examine this interaction, far-field acoustic data also were obtained for the wing with landing gear at midspan and the full-span trailing edge flap. Tests with this configuration would eliminate the problem of interaction effects on noise from the flap side edges. These data were taken with the acoustic shield and are presented in figure 63. SPLs measured with the combination generally matched the acoustic sum of spectra from the individual components. However, between approximately 10 and $16 \mathrm{kHz}$ model frequencies where the acoustic sum was dominated by noise radiation from the landing gear assembly, data for the combination were 1 to $2 \mathrm{~dB}$ below that sum. Normalized surface pressure spectra on the flap upper surface for this configuration are shown in figure 64. Pressure fluctuations at the forward edge position were about $6 \mathrm{~dB}$ higher than those for the flap alone but those at the other three positions were essentially unchanged. These data do not clearly validate the expected increase of surface pressure fluctuation and noise radiation from the trailing edge flap downstream of the landing gear. Unfortunately, directional microphone noise source distribution measurements were not taken with this configuration.

\section{Approach Configurations With Leading Edge Flaps}

In this report the phrase "approach configuration" denotes a wing with a deflected leading edge part-span high-lift device, part-span or full-span $40^{\circ}$ deflection single slotted flap, and extended landing gear with open cavity. The configurations having a leading edge flap were fundamentally different from those with a leading edge slat in that the flap was the quietest and the slat the noisiest component tested. Far field $1 / 3$ octave spectra for approach configurations with the leading edge flap were obtained with the acoustic shield between the $90^{\circ}$ microphone and the wind tunnel flow collector. This shield was developed near the end of the test program and was not used in tests of approach configurations having a leading edge slat.

Spectra measured at the $90^{\circ}$ microphone for approach configurations with the leading edge flap, full span trailing edge flap, and the midspan and part-span landing gear positions are plotted as symbols in figure 65. Also shown are spectra measured with each of the three individual components, and their acoustic sum as noninteracting components. At frequencies that would scale to those which are heavily weighted in calculating annoyance at fulI 
scale, there was essentially no effect of landing gear position. Measured SPLs at these model frequencies above $5 \mathrm{kHz}$ were about $1 \mathrm{~dB}$ below the acoustic sum of the three components regarded as acoustically independent. A similar result was described earlier for the leading edge flap with the two landing gear positions and for the full span trailing edge flap and midspan landing gear. These approach configurations eliminated the lowest-order cavity tone, and the next-order tone was eliminated for the midspan but not the part-span landing gear position. These results also were obtained for the two-component combinations of landing gear and leading edge flap. As with those cases, elimination of cavity tones can be explained by recalling that the leading edge flap produced a spanwise varying flow separation on its lower surface. The wing lower surface boundary layer therefore would be less likely to form a cavity shear layer that sustains an aeroacoustic feedback process. Reduction of landing gear noise due to the locally reduced flow velocity ahead of a deflected trailing edge flap would also be expected.

Directional microphone measurements of noise source strength distributions for these two approach configurations are plotted in figures 66 and 67 . They clearly show the reduction of landing gear and cavity noise, including considerable reduction of noise radiated by the landing gear and small increases of noise from the trailing edge flap immediately downstream of the landing gear. In general, noise from the full span trailing edge flap was not significantly changed.

Spectra measured at the $90^{\circ}$ microphone for combinations having a leading edge flap and part-span trailing edge flap, with either midspan or part-span landing gear positions, are plotted in figure 68. Spectra measured for the individual components, and their acoustic sum as noninteracting noise sources, also are shown. Both combinations had about the same SPLs at the highest frequencies but the midspan landing gear position was about 2 dB quieter for most of the frequency range. For frequencies of practical importance in predicting full scale annoyance-weighted noise levels, measured SPLs were 2 to $3 \mathrm{~dB}$ below the acoustic sum. In much of this region they were no noisier than the trailing edge flap alone. These reductions are less than the 3 to $4 \mathrm{~dB}$ decrease obtained for the part-span leading edge flap combined only with the part-span trailing edge flap. Also, $2 \mathrm{~dB}$ noise reductions had been obtained for the landing gear and part-span trailing edge flap, and the leading edge flap and landing gear combination had achieved about 1 dB decrease. Thus the favorable component noise interactions between any two components are not additive when three components are tested together. The amount of noise reduction measured for this three-component approach configuration was about half the sum of the reduction achieved with the three two-component combinations. 
Noise source distribution measurements obtained with the directional microphone for these leading edge flap, landing gear, part span trailing edge flap combinations are shown in figures 69 and 70 . Traces for the combination with landing gear midspan (figure 69) show that high-frequency noise from the trailing edge flap side edges was reduced to the levels expected at midspan. This favorable effect on trailing edge flap noise had also been achieved by the leading edge flap in a two-component combination (figure 50). Noise radiation from the midspan landing gear was reduced by more than had been indicated for two-component interactions between either the landing gear and leading edge flap (figures 41 and 42 ) or the landing gear and trailing edge flap (figures 60 and $6 \mathrm{l}$ ). These directional microphone results for $20 \mathrm{kHz}$ center frequency would indicate at least $4 \mathrm{~dB}$ noise reduction relative to the acoustic sum of individual spectra, rather than the 2 dB reduction measured with the omnidirectional microphone. In contrast, noise source traces for the approach configuration with landing gear at the part-span position (figure 70) had less noise reduction from the side edge of the trailing edge flap downstream of the landing gear. It also had little or no indicated reduction of landing gear noise. For this configuration, the smaller amount of noise reduction with the three-component combination relative to the sum of reductions from the three two-component cases can be understood as an absence of noise-reducing effects on landing gear noise radiation.

\section{Approach Configurations With Leading Edge Slats}

The approach configurations which consisted of the part-span leading edge slat, landing gear at either of two spanwise positions, and full span or part-span $40^{\circ}$ deflection single slotted trailing edge flaps were not tested with the acoustic shield. Spectra measured at the $90^{\circ}$ microphone for these combinations having the full span trailing edge flap are plotted in figure 71 . Thcy contain high-frequency bulges above $10 \mathrm{kHz}$ frequency for $70.7 \mathrm{~m} / \mathrm{sec}$ and above $12.5 \mathrm{kHz}$ for $100 \mathrm{~m} / \mathrm{sec}$ tunnel velocity, which protrude above the acoustic sum of the component spectra. This high-frequency noise was radiated from the open-jet collector because of the large flow deflection induced by the wing at large lift coefficients. Spectra measured for the leading edge slat and trailing edge flap without the landing gear, taken without the collector shield (not shown), closely matched that high-frequency portion of the spectra. Adding the landing gear would be expected to increase the noise radiation at constant lift and therefore constant collector noise. There were no component interaction effects for the frequency range below this bulge but above the landing gear cavity tones for these two approach configurations. Also, there were no component interaction effects at high frequencies for the leading edge slat and full span trailing edge flap without a landing gear (figure 53). Therefore it does not seem likely that component interactions on 
airframe noise radiation occurred for these approach configurations. There was no effect of landing gear spanwise position on measured spectrum.

Noise source strength distributions for these two configurations at 5 and $20 \mathrm{kHz}$ center frequencies for $100 \mathrm{~m} / \mathrm{sec}$ velocity are plotted in figures 72 and 73. Compared with distributions for each of the three deflected components, they show 1 to $2 \mathrm{~dB}$ reduction of slat and landing gear noise and 2 to $3 \mathrm{~dB}$ increase of trailing edge flap noise. As had been previously mentioned, use of tailored-impedance surfaces on the trailing edge flap to reduce its turbulence-induced noise radiation would be the only way to take advantage of the reduced slat and landing gear noise.

Spectra measured at the $90^{\circ}$ microphone for the approach configurations having a leading edge slat, landing gear, and part-span trailing edge flap are plotted in figure 74 . As with the other approach configurations having a leading edge slat, these data were obtained without an acoustic shield between the far field microphone and the collcctor. Aerodynamic loading for thcse two configurations was concentrated in the central third of the test section width and apparently the collector noise was not large relative to airframe noise. Again, there was no significant effect of landing gear spanwise position. At $70.7 \mathrm{~m} / \mathrm{sec}$ velocity, measured SPLs at frequencies above the landing gear cavity tone frequency were 1 to $2 \mathrm{~dB}$ below the acoustic sum of component spectra. This favorable interaction had decreased to about $1 \mathrm{~dB}$ at $100 \mathrm{~m} / \mathrm{sec}$ velocity. Measured noise source strength distributions, plotted in figures 75 and 76 , generally show several $d B$ reduction of noise radiation from the slat and also from the flap edges. The actual amount of far-field noise reduction is uncertain because of the contribution of collector noise to the far-field $1 / 3$ octave spectra. As with data for the slat and landing gear plus full span trailing edge flap, the interactions included decreased slat noise and increased noise from midspan of the trailing edge flap. However, the noise source at the side edges of the part-span trailing edge flap was reduced, leading to a decrease of total noise. As shown in figure 57, this small noise reduction also occurred for the leading edge slat and part-span trailing edge flap without landing gear.

Nondimensional surface pressure spectra on the upper surface of the trailing edge flap for this approach configuration are plotted in figure 77 . Surface pressure levels at the forward and aft midspan positions were increased up to $10 \mathrm{~dB}$ at low strouhal numbers, with little chahge above a Strouhal number of 50 (model frequency $16 \mathrm{kHz}$ at $100 \mathrm{~m} / \mathrm{sec}$ velocity). However, fluctuations were reduced about $4 \mathrm{~dB}$ at the forward edge position for strouhal numbers larger than 10. These surface pressure fluctuation data confirm the measured increased noise radiation at midspan on the trailing edge flap but reduced noise from the side edges. 


\section{CONCLUSIONS}

1. Airframe noise component interaction effects for hard-wall airframe components are small, and generally are within the accuracy of noise prediction for isolated components. However, if acoustic impedance of trailing edge flap surfaces and edges could be tailored to reduce their acoustic response to convected turbulence, larger favorable interactions could be achieved because of redistributions of local noise source strength.

2. Noise radiation from the side edges of deflected trailing edge flaps contributes significantly to total noise at large deflection angles. Noise radiation near midspan of such flaps approximately corresponds to that from an isolated airfoil in a turbulent airstream having inflow turbulence equal to the highest levels in the flap slot.

3. A leading edge slat having separated flow on its lower surface, convected past the trailing edge, can generate strong broadband airframe noise.

4. Landing gear cavity tones are greatly reduced in amplitude by the presence of a landing gear strut and side brace protruding through the cavity shear layer. They can be further reduced by the presence of a leading edge flap upstream of the cavity. The region of locally separated flow on the flap lower surface introduces turbulence which probably suppresses feedback in the cavity shear layer.

5. A part-span leading edge flap in line with a highly deflected part-span trailing edge flap can reduce noise radiation from the trailing edge flap's side edges. This component interaction produced noise levels 3 to 4 dB below the acoustic sum of spectra for the two components deflected individually at high frequencies, which scale to frequencies having high annoyance. Adding a landing gear and open cavity to this spanwise region produced noise levels 2 to $3 \mathrm{~dB}$ below the acoustic sum.

6. Combinations of a part-span leading edge slat and trailing edge flap produced several $\mathrm{dB}$ noise increase at low frequencies and little change at high frequencies relative to the acoustic sum of component spectra. Larger changes occurred in noise source distribution, with up to $5 \mathrm{~dB}$ local noise reduction from the slat and up to $4 \mathrm{~dB}$ local noise increase from the flap at high frequencies.

7. Combinations of a landing gear and a downstream trailing edge flap produced up to $2 \mathrm{~dB}$ noise reduction relative to the acoustic sum of component spectra at high frequencies. This small effect generally occurred as a 
combination of decreased landing gear noise and a smaller increase of trailing edge flap noise. The tested configuration had a relatively short landing gear strut typical of jet aircraft with all engines mounted on the aft fuselage. Use of relatively longer landing gear struts, as with aircraft having high bypass ratio turbofan engines mounted under the wings, might eliminate this small favorable interaction.

\section{REFERENCES}

1. Revell, J. D., Healy, G. J., and Gibson, J. S.: Methods for the Prediction of Airframe Aerodynamic Noise. Aeroacoustics: Acoustic Wave Propagation: Aircraft Noise Prediction: Aeroacoustics Instrumentation, Vol. 46, Progress in Aeronautics and Astronautics, M.I.T. Press, Cambridge, MA., 1976, pp 139-154. Also, AIAA Paper 75-539, March 1975.

2. Hardin, J. C., Fratello, D. J., Hayden, R. E., Kadman, Y., and Africk, S.: Prediction of Airframe Noise. NASA TN D-7821, February 1975.

3. Fink, M. R.: Airframe Noise Prediction Method. FAA-RD-77-29, March 1977. Also, AIAA Paper 77-1271, October 1977.

4. Raney, J. P.: Noise Prediction Technology for CTOL Aircraft. NASA TM 78700 , May 1978.

5. Munson, A. G.: A Modeling Approach to Non-Propulsive Noise. AIAA Paper 76-525, July 1976.

6. Bauer, A. B. and Munson, A. G.: Airframe Noise of the DC-9-3I. NASA CR-3027, 1978.

7. Shearin, J.G. and Fratello, D. J.: Airframe Noise of Component Interactions on a Large Transport Model. AIAA Paper 77-57, January 1977.

8. Paterson, R. G., Vogt, P. G., and Foley, W. M.: Design and Development of the United Aircraft Research Laboratories Acoustic Research Tunnel. Journal of Aircraft, Vol. 10, No. 7, July 1973, pp 427-433.

9. Amiet, R. K.: Correction of Open-Jet Wind-Tunnel Measurements for Shear Layer Refraction. Aeroacoustics: Acoustic Wave Propagation, Aircraft Noise Prediction: Aeroacoustic Instrumentation, Vol. 46, Progress in Aeronautics and Astronautics, M.I.T. Press, Cambridge, MA., 1976, pp 259- 
280. Also, AIAA Paper 75-532, March 1975.

10. Amiet, R. K.: Refraction of Sound by a Shear Layer. Journal of Sound and Vibration, Vol. 58, No. 4, June 1978, pp 467-482.

11. Shields, F. D. and Bass, H. E.: Atmospheric Absorption of High Frequency Noise and Application to Fractional-Octave Bands. NASA CR-2760, June 1977 .

12. Schlinker, R. H.: Airfoil Trailing Edge Measurements with a Directional Microphone Systems. AIAA Paper 77-1269, October 1977.

13. Wenzinger, C. J. and Harris, T. A.: Wind-Tunnel Investigation of an NACA 23012 Airfoil With Various Arrungements of Slotted Flaps. NACA Report No. 664, 1939.

14. Cahill, J. F.: Summary of Section Data on Trailing-Edge High-Lift Devices. NACA Report No. 938, 1949.

15. Pennock, A.P., Swift, G., and Marbert, J. A.: Static and Wind Tunnel Tests for the Development of Externally Blown Flap Noise Reduction Techniques. NASA CR-134675, Feb. 1975.

16. Fink, M. R.: A Method for Calculating Strut and Splitter Plate Noise in Exit Ducts - Theory and Verification. NASA CR-2955, March 1978.

17. Cahill, J. F. and Racisz, S. F.: Wind-Tunnel Investigation of Seven Thin NACA Airfoil Sections to Determine Optimum Double-Slotted-Flap Configurations. NNACA TN 1545, Apr. 1948.

18. Quinn, J.H., Jr.: Tests of the NACA 64, A212 Airfoil Section With a Slat, a Double Slotted Flap, and Boundary Layer Control by Suction. NACA TN 1293, May 1947.

19. Bamber, M. J.: Wind-Tunnel Tests of Several Forms of Fixed Wing Slot in Combination With a Slotted F'lap on a NACA 23012 Airfoil. INACA I'N 702, Apr. 1939.

20. Bliss, D. B. and Hayden, R. E.: Landing Gear and Cavity Noise Fredictions. NASA CR-2714, July 1976.

21. Heller, H. H. and Dobrzynski, W. M.: Sound Radiation From Aircraft Wheel-Well/Landing Gear Configurations. J. Aircraft, Vol. 4, No. 8, Aug. 1977, pp 768-774. 
22. Block, P. J.W.: An Experimental Investigation of Airframe Component Interference Noise. AIAA Paper 77-56, Jan. 1977.

23. Perkins, C. D. and Hage, R. E.: Airplane Performance; Stability and Control. John Wiley \& Sons, Inc., New York, 1949, p 199.

24. Lasagna, P. L. and Putnam, T. W.: Preliminary Measurements of Aircraft Aerodynamic Noise. AIAA Paper 74-572, June 1974.

25. Putnam, T.W., Lasagna, P. I., and White, K. C.: Meas urements and Analyses of Aircraft Airframe Noise. Aeroacoustics: STOL Noise: Airframe and Airfoil Noise, Vol. 45, Progress in Aeronautics and Astronautics, M.I.T. Press, Cambridge, MA., 1976, pp 363-378. Also AInA Paper 75-510, Mar. 1975.

26. Fethney, P.: An Experimental Study of Airframe Self-Noise. Aeroacoustics: STOL Noise: Airframe and Airfoil Noise, Vol. 45, Progress in Aeronautics and Astronautics, M.I.T. Press, Cambridge, MA., 1976, pp 379-403. Also AIAA Paper 75-5II, Mar. 1975.

27. Pope, A.: Wind Tunnel Testing. John Wiley \& Sons, Inc., New York, 1954, pp 250-252.

28. Fink, M. R.: Prediction of Airfoil Tone Frequencies. Journal of Aircraft, Vol. 12, No. 2, Feb. 1975, pp 118-120.

29. Howe, M. S.: A Review of the Theory of Trailing Edge Noise. NASA CR-3021, June 1978.

30. Heller, H. H. and Dobrzynski, W. M.: Unsteady Surface Pressure Characteristics on Aircraft Components and Farfield Radiated Airframe Noise. AIAA Paper 77-1295, Oct. 1977.

31. Paterson, R.W. and Amiet, R. K.: Acoustic Radiation and Surface Pressure Characteristics of an Airfoil Due to Incident Turbulence. NASA CR-2733, Sept. 1976. Also, Journal of Aircraft, Vol. 14, No. 8, July 1977, pp 729-736.

32. Fink, M. R.: Experimental Evaluation of Theories for Trailing Edge and Incidence Fluctuation Noise. AIAA Journal, Vol. 13, No. 11, Nov. 1975, pp $1472-1477$.

33. Bohn, A. J.: Edge Noise Attenuation by Porous-Edge Extensions. AIAA Paper 76-80, Jan. 1976. 
34. Filler, I.: Swept Edge to Reduce the Noise Generated by Turbulent Flow Over the Edge. Journal Acoust. Soc. Am., Vol. 59, No. 3, Mar. 1976, pp 697-699.

TABLE I - WING MODEL CONFIGURATIONS

Symbol

DT

GC

GO

G-

LF

LS

SF (angle)

ST(angle)

W
Airframe Component

Double-slotted trailing edge flap on central 1/3 span, zero deflection single-slotted trailing edge flap near sidewalls Landing gear at midspan position, cavity closed

Landing gear at midspan position, cavity open Landing gear at lower position, cavity open Leading edge (LE) flap pulled against wing, gap sealed Leading edge slat in forward position, gap open Single-slotted trailing edge (TE) flap, full span, at deflection angle Single-slotted trailing edge flap on central $1 / 3$ span, zero deflection single-slotted trailing edge flap near sidewalls Basic wing

\begin{tabular}{|c|c|c|c|}
\hline Components & $\begin{array}{c}\text { Model } \\
\text { Configuration }\end{array}$ & $\begin{array}{c}\text { Configuration } \\
\text { Number }\end{array}$ & $\begin{array}{c}\text { Angle of } \\
\text { Attack, deg }\end{array}$ \\
\hline Clean & $W, S F(0)$ & 1 & 2.5 \\
\hline Wing & $\mathrm{W}, \operatorname{SF}(0)$ & 2 & 9.6 \\
\hline Landing & $W, G C, \operatorname{SF}(0)$ & 3 & 9.6 \\
\hline Gear & $W, G O, \operatorname{SF}(0)$ & 4 & 9.6 \\
\hline \multirow[t]{2}{*}{ LE Devices } & LS,W,SF(O) & 5 & 15.2 \\
\hline & $L F, W, S F(O)$ & 6 & 15.2 \\
\hline Full Span & $W, S F(15)$ & 7 & 7.7 \\
\hline \multirow[t]{2}{*}{ TE Flaps } & $w, S F(24)$ & 8 & 6.0 \\
\hline & $\mathrm{W}, \mathrm{SF}(40)$ & 9 & 5.0 \\
\hline Part-Span & $\mathrm{W}, \operatorname{ST}(15)$ & 10 & 7.7 \\
\hline \multirow[t]{3}{*}{ TE Flaps } & W,ST( 24) & 11 & 6.0 \\
\hline & $\mathrm{W}, \mathrm{ST}(40)$ & 12 & 5.0 \\
\hline & H,DT & 13 & -3.5 \\
\hline Gear and TE Flap & $W, G-, \operatorname{ST}(40)$ & 14 & 5.0 \\
\hline Interaction & $W, G 0, \operatorname{ST}(40)$ & 15 & 5.0 \\
\hline LE Device and & $L S, H, \operatorname{ST}(40)$ & 16 & 6.5 \\
\hline TE Flap & $L S, W, S F(40)$ & 23 & 6.5 \\
\hline \multirow[t]{2}{*}{ Interaction } & $L F, W, \operatorname{ST}(40)$ & 17 & 6.5 \\
\hline & $L F, W, \operatorname{SF}(40)$ & 18 & 6.5 \\
\hline LE Device and & $L F, W, G O, S F(O)$ & 19 & 15.2 \\
\hline \multirow[t]{3}{*}{ Gear Interaction } & $L F, W, G-, S F(0)$ & 20 & 15.2 \\
\hline & LS,W,G-,SF(0) & 21 & 15.2 \\
\hline & $L S, W, G O, S F(O)$ & 22 & 15.2 \\
\hline Multi-component & LS ,W, GO, SF (40) & 24 & 6.5 \\
\hline Interaction & $L S, W, G-, S F(40)$ & 25 & 6.5 \\
\hline (Approach & LS , W, G-, ST(40) & 26 & 6.5 \\
\hline \multirow[t]{5}{*}{ Configurations) } & $L S, W, G O, \operatorname{ST}(40)$ & 27 & 6.5 \\
\hline & $L F, W, G O, \operatorname{ST}(40)$ & 28 & 6.5 \\
\hline & $L F, W, G-, \operatorname{ST}(40)$ & 29 & 6.5 \\
\hline & $L F, W, G-, S F(40)$ & 30 & 6.5 \\
\hline & $L F, W, G O, S B(40)$ & 31 & 6.5 \\
\hline
\end{tabular}




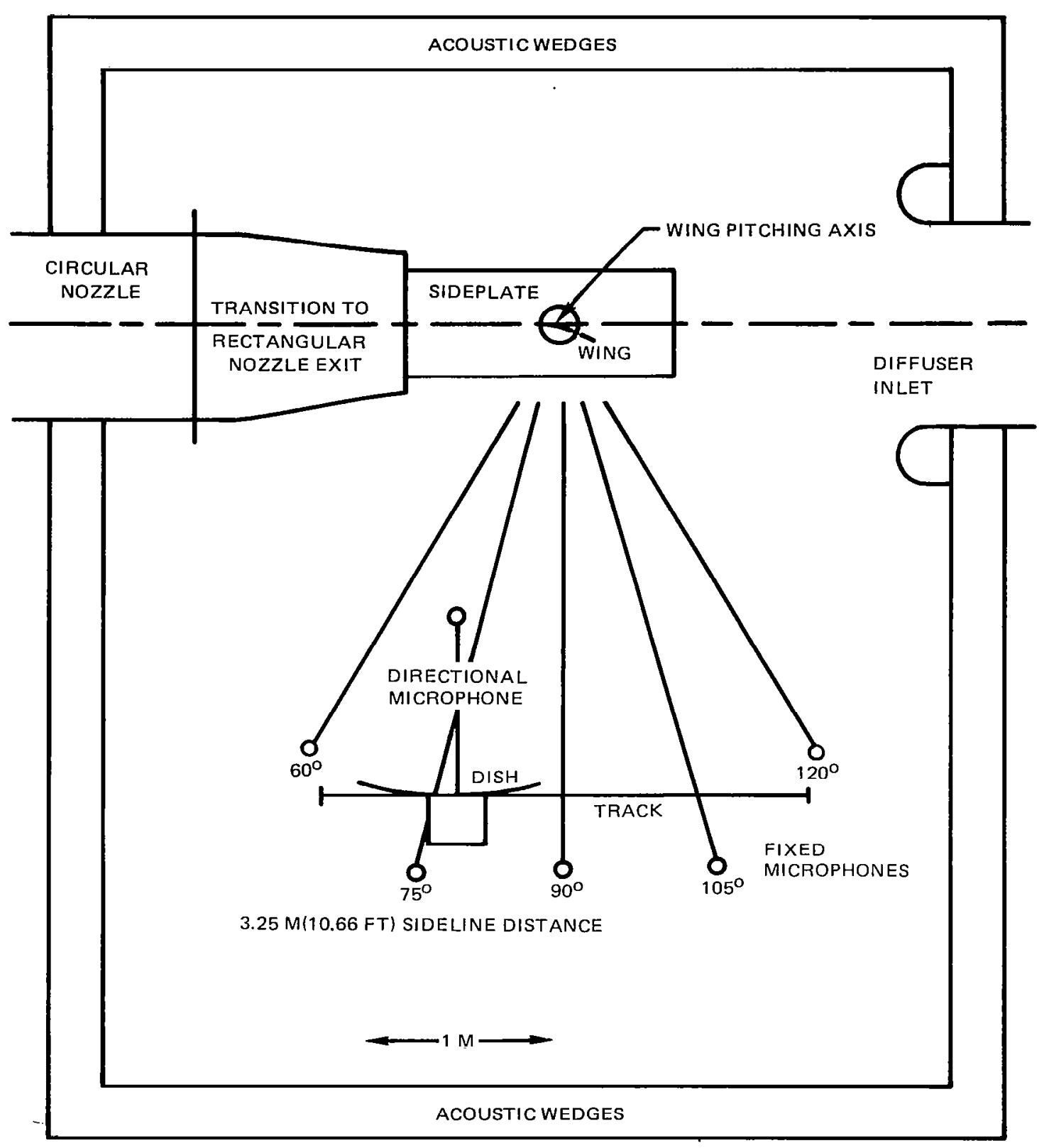

Figure 1 -Sketch of Acoustic Wind Tunnel Configuration and Microphone Installation 


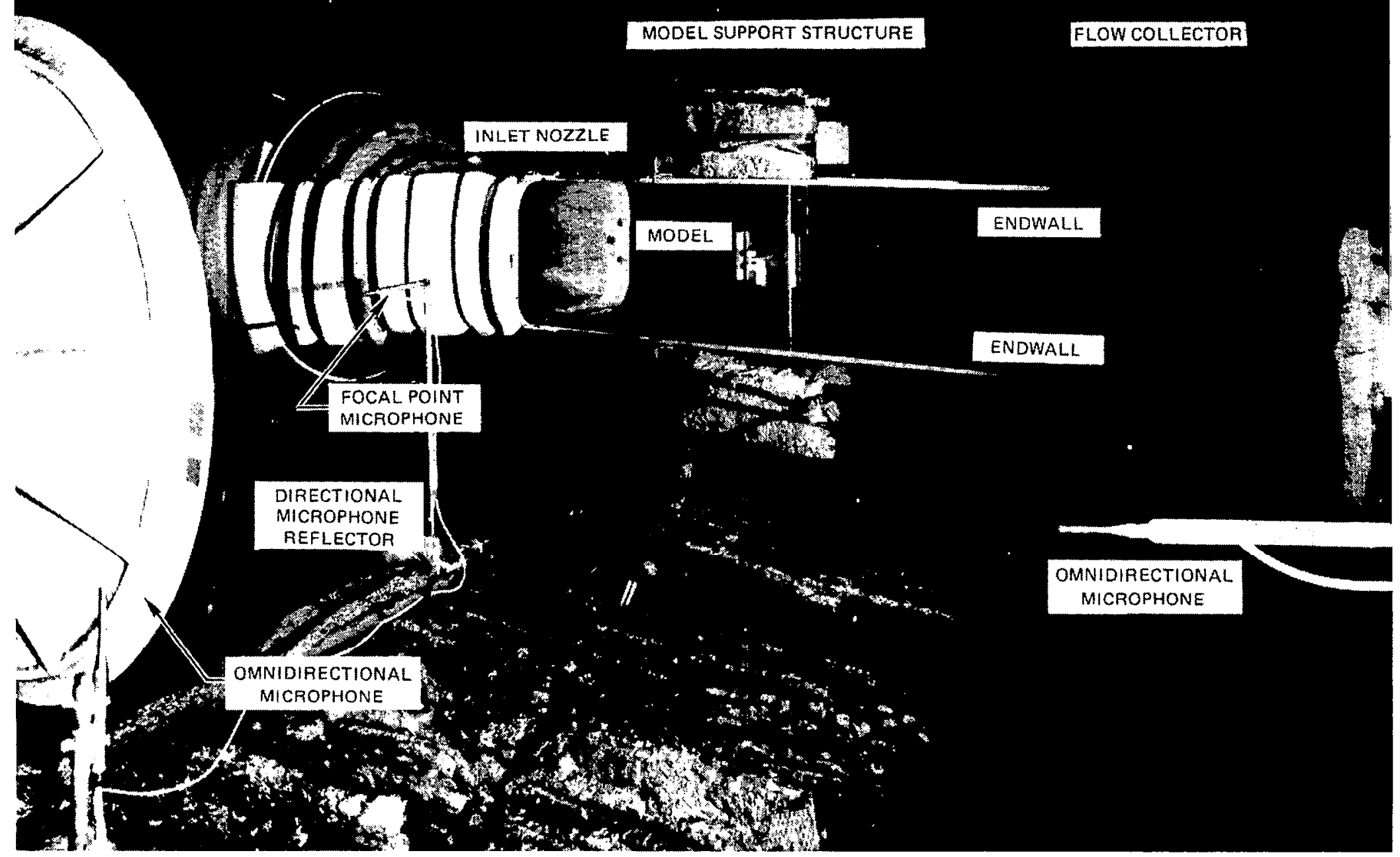

Figure 2 - Location of Airframe Noise Model and Far Field Microphones 


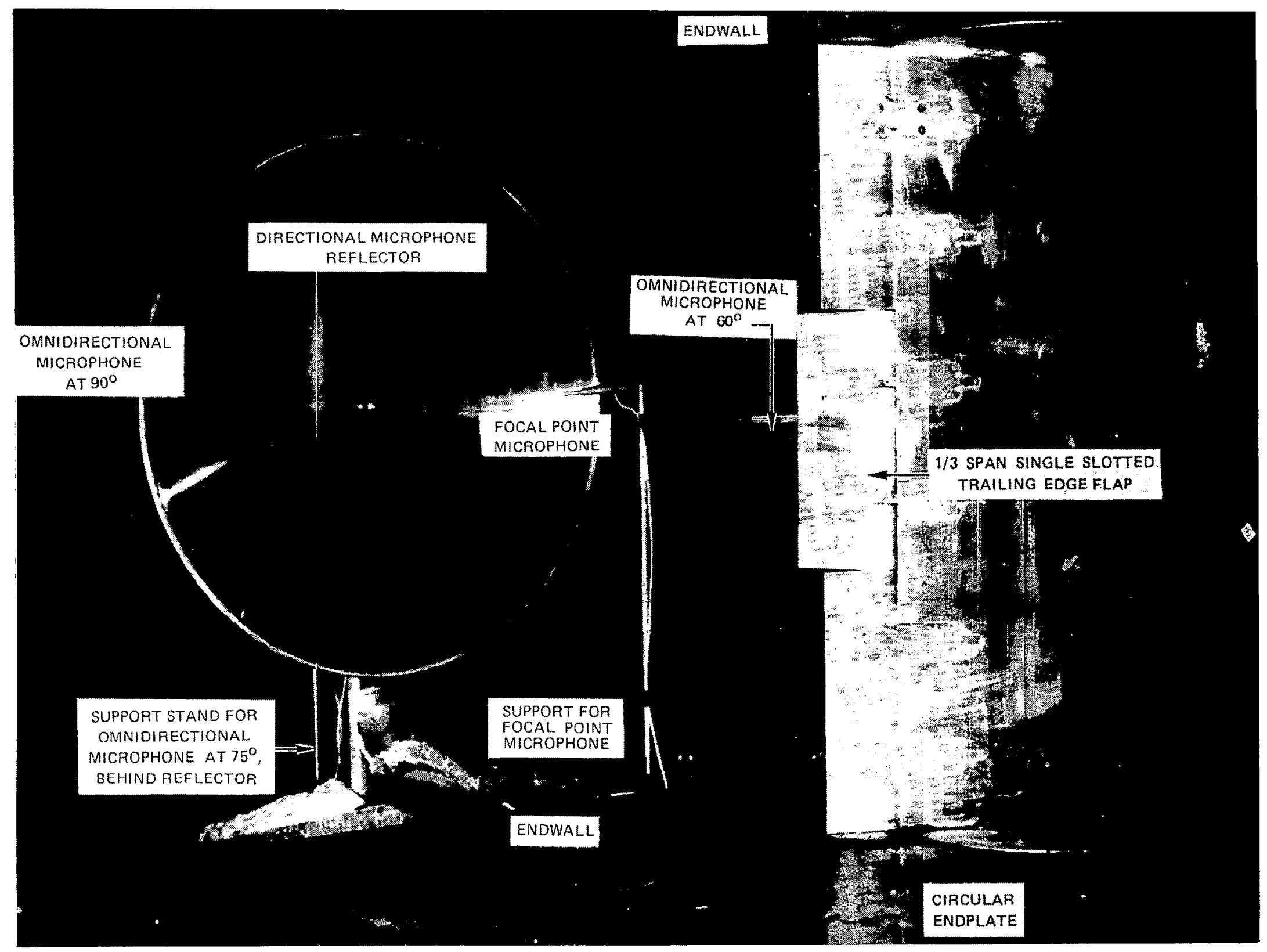




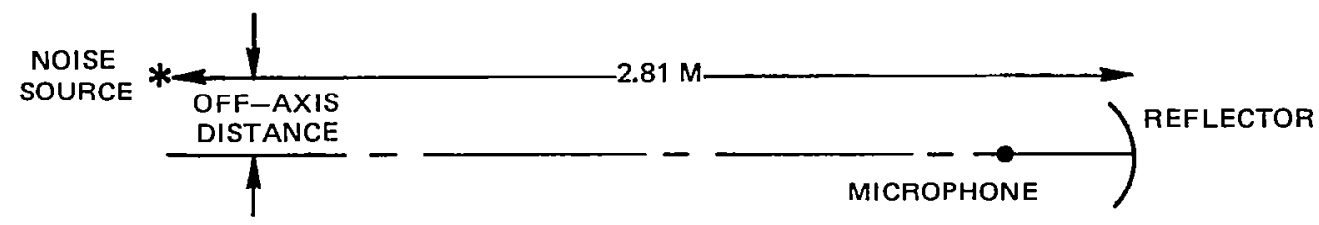

1/3 OCTAVE BAND CENTER FREQUENCY

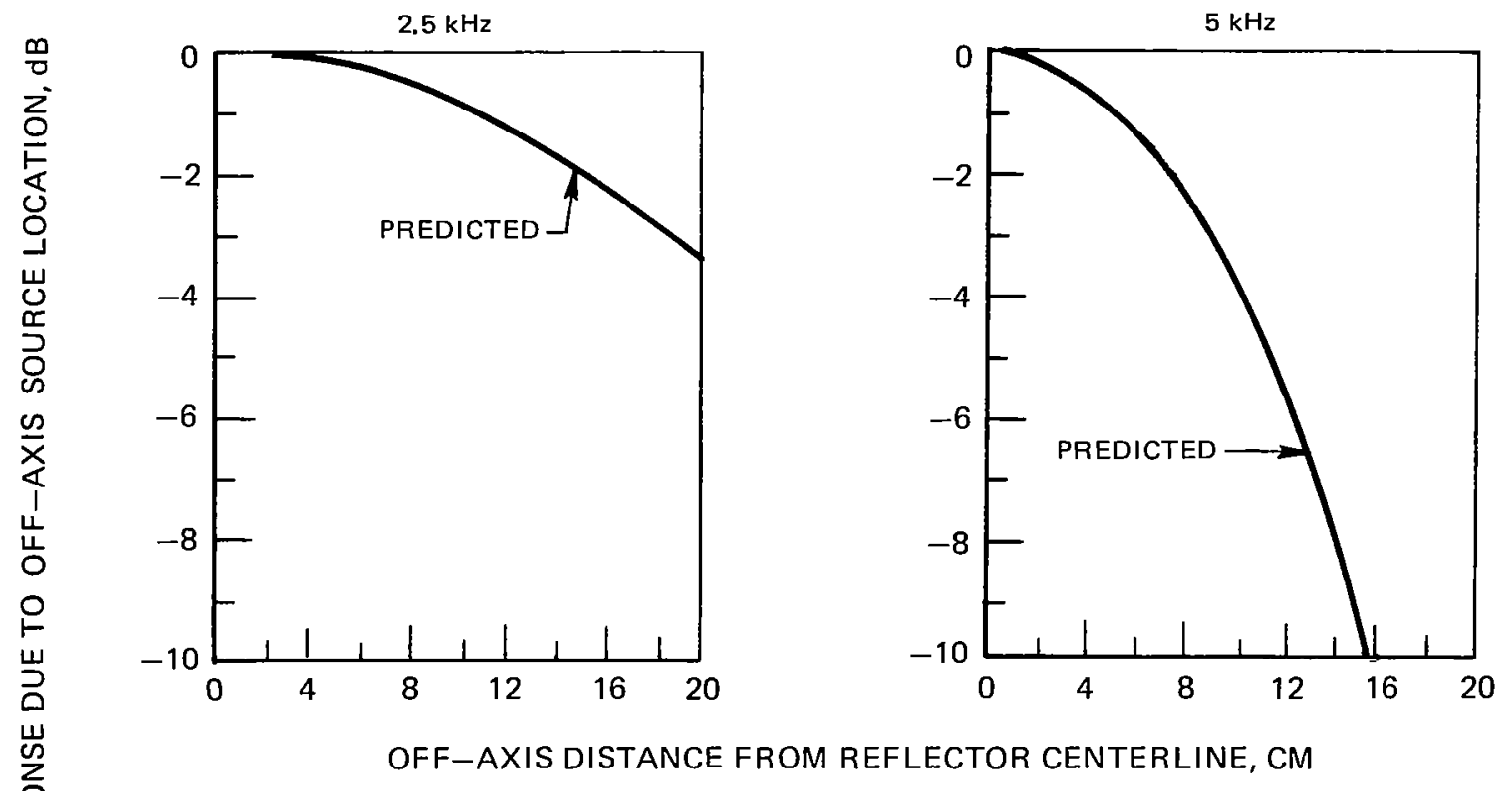

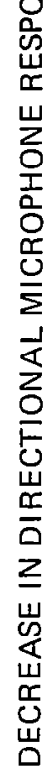

$10 \mathrm{kHz}$
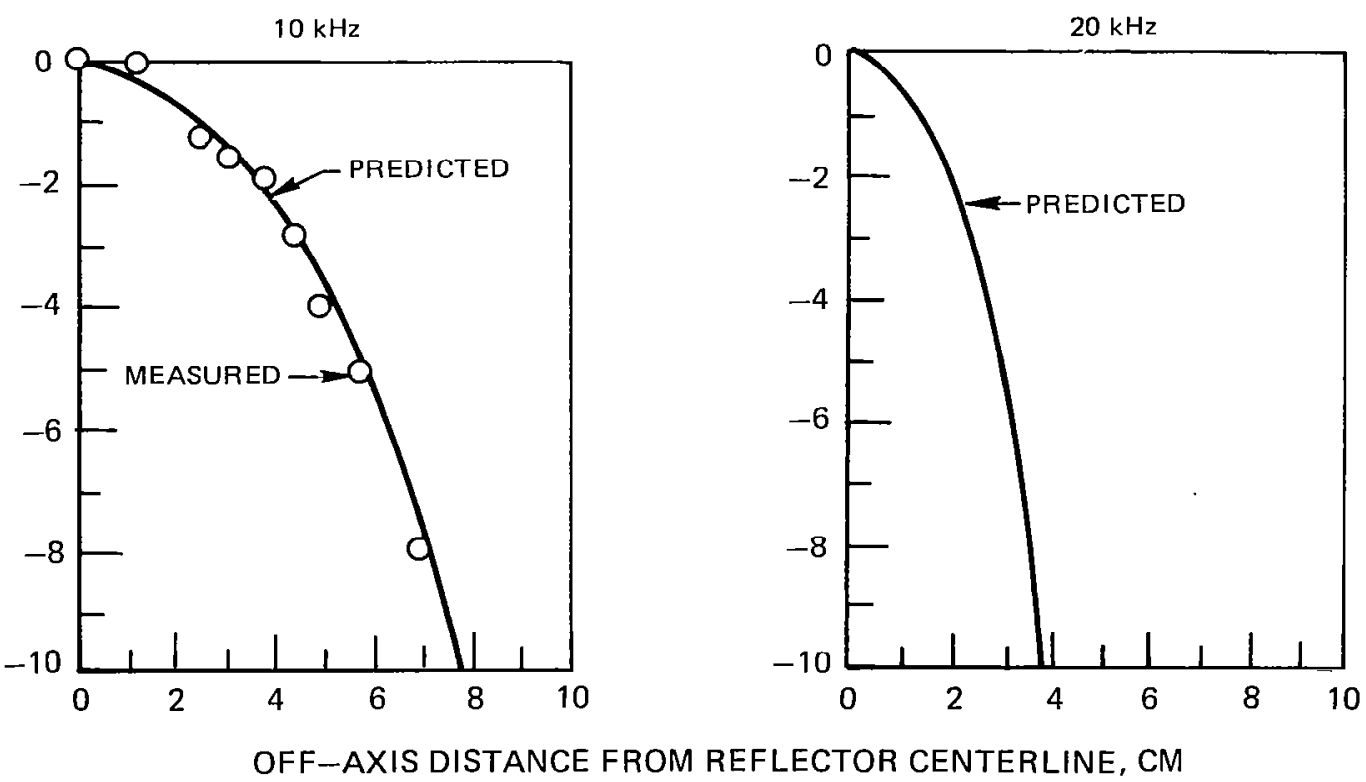

Figure 3 (b)-Spatial Discrimination of UTRC Directional Microphone 60 Calibration Measured for 1, 10, and $50 \mathrm{kHz}$ Center Frequencies. 


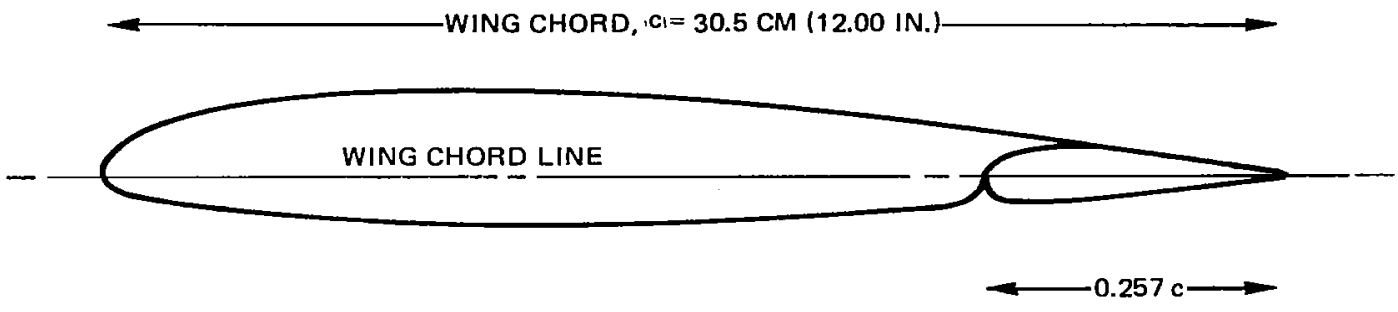

(a) WING AND 25\% CHORD SINGLE SLOTTED TRAILING EDGE FLAP IN RETRACTED POSITION

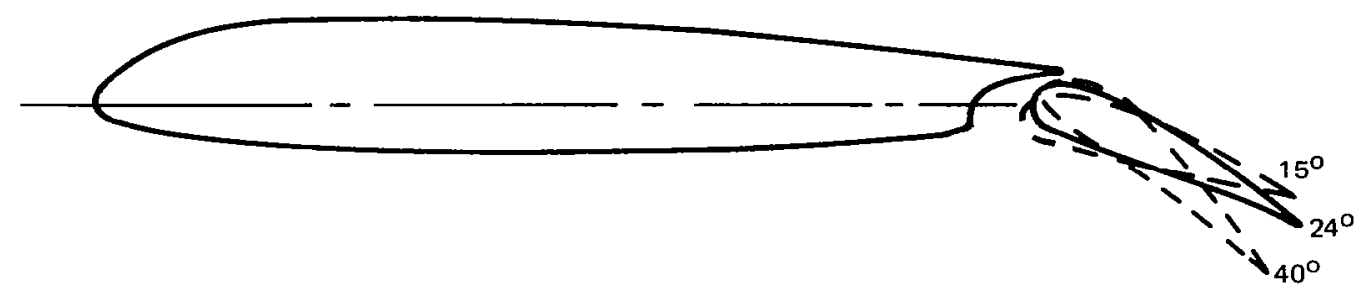

(b) WING AND 25\% CHORD SINGLE SLOTTED TRAILING EDGE FLAP AT $15^{\circ}, 24^{\circ}$, AND $40^{\circ}$ DEFLECTIONS
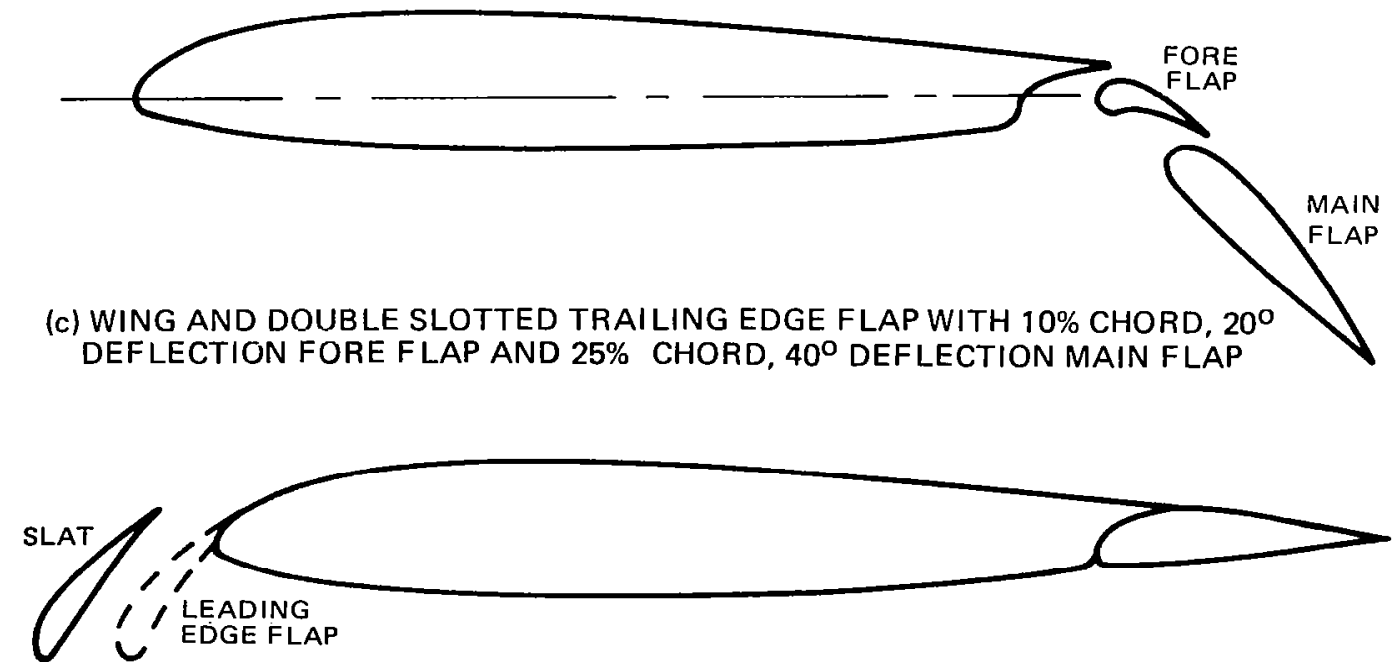

(d) WING AND 15\% CHORD, 25\% DEFLECTION SLAT INSTALLED AS EITHER A LEADING EDGE FLAP OR LEADING EDGE SLAT

Figure 4-Airfoil Sections of Wing Model and High-Lift Devices 


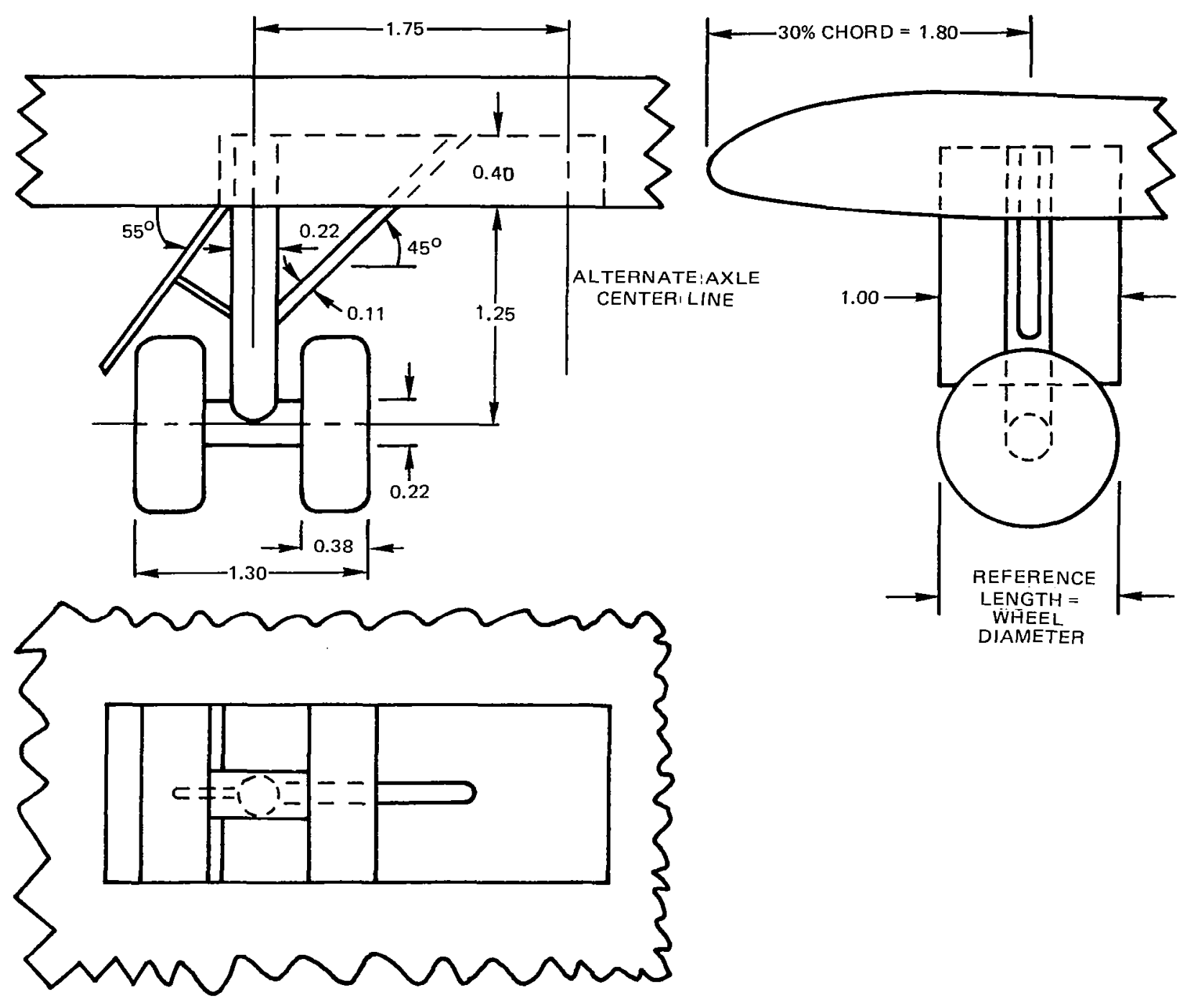

Figure 5-Landing Gear Assembly, Half Scale, Wheel Diameter $=5.08 \mathrm{~cm}(2.00 \mathrm{in}$. ),all Dimensions Referenced to Wheel Diameter 


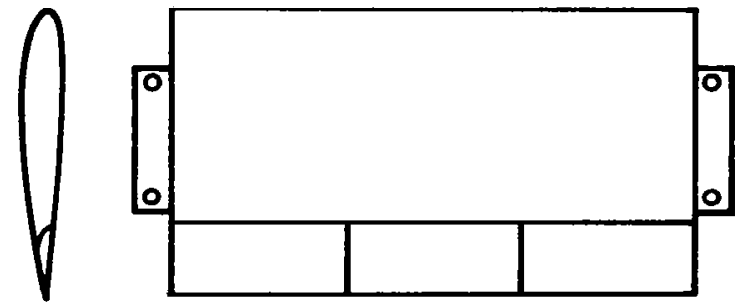

(a) WING WITH RETRACTED FULL SPAN SINGLE SLOTTED TRAILING EDGE FLAP
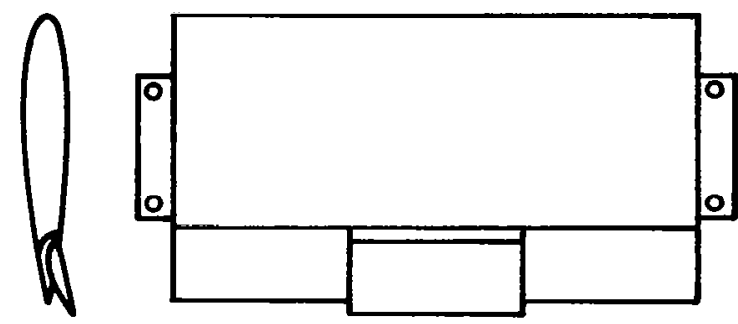

(c) WING WITH DEFLECTED 1/3 SPAN SINGLE SLOTTED TRAILING EDGE FLAP

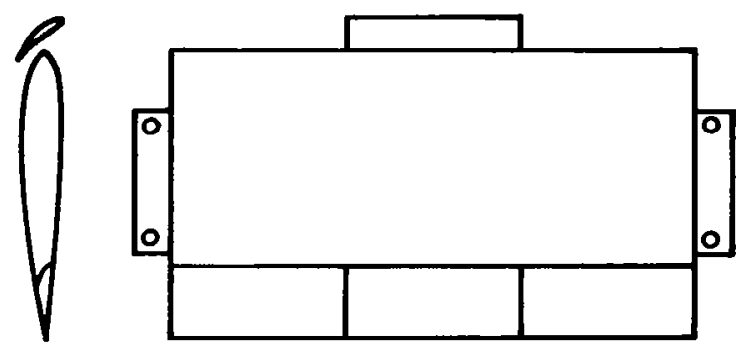

(e) WING WITH DEFLECTED $1 / 3$ SPAN LEADING EDGE SI.AT

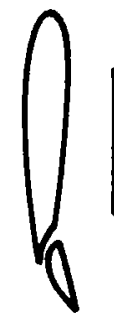

(b) WING WITH DEFLECTED FULL SPAN SINGLE SLOTTEID TRAILING EDGE FLAP

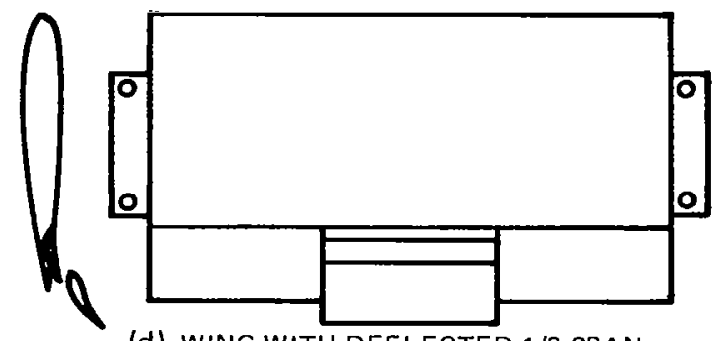

(d) WING WITH DEFLECTED 1/3 SPAN DOUBLE SLOTTED TRAILING EDGE FLAP

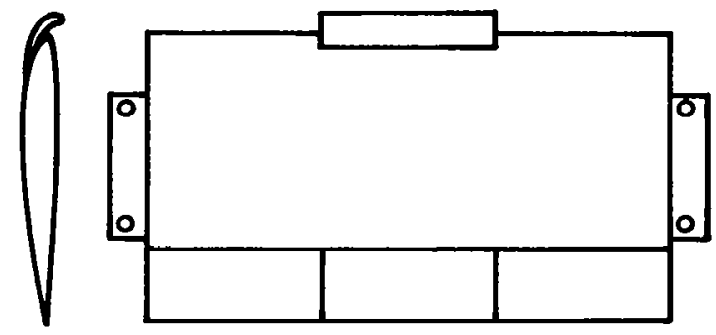

(f) WING WITH DEFLECTED 1/3 SPAN LEADING EDGE FLAP

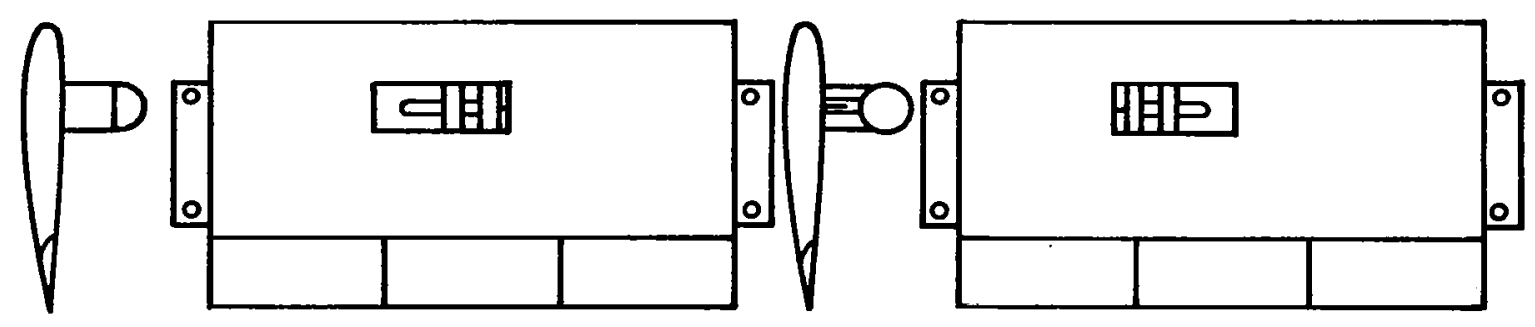

(g) WING WITH LANDING GEAR AT MIDSPAN

(h) WING WITH LANDING GEAR AT 1/3 SPAN

Figure 6-Wing Model with Single Noise-Radiating Components 1/10 Scale 


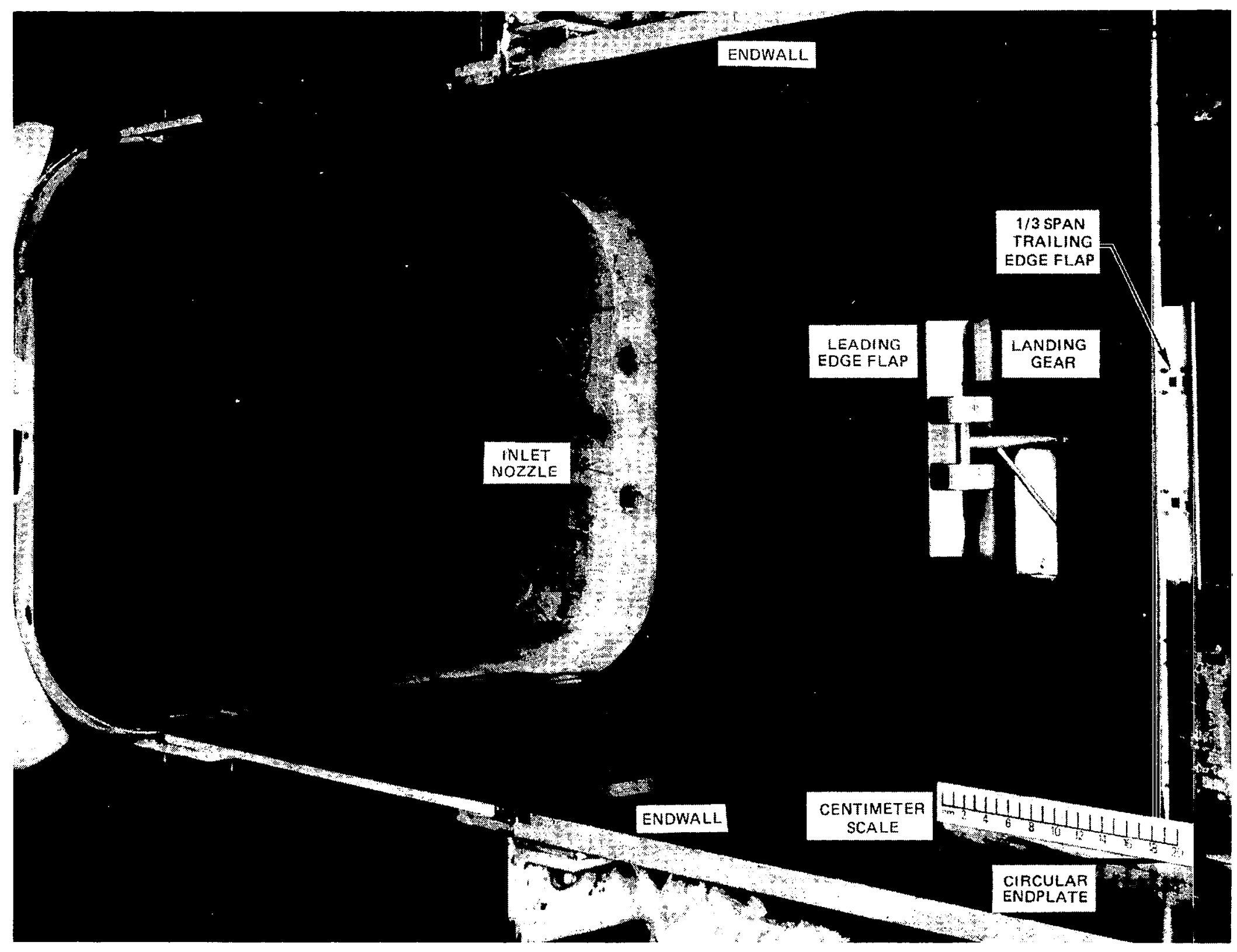

Figure 7 -Closeup of Airframe Noise Model Installation Looking Upstream 


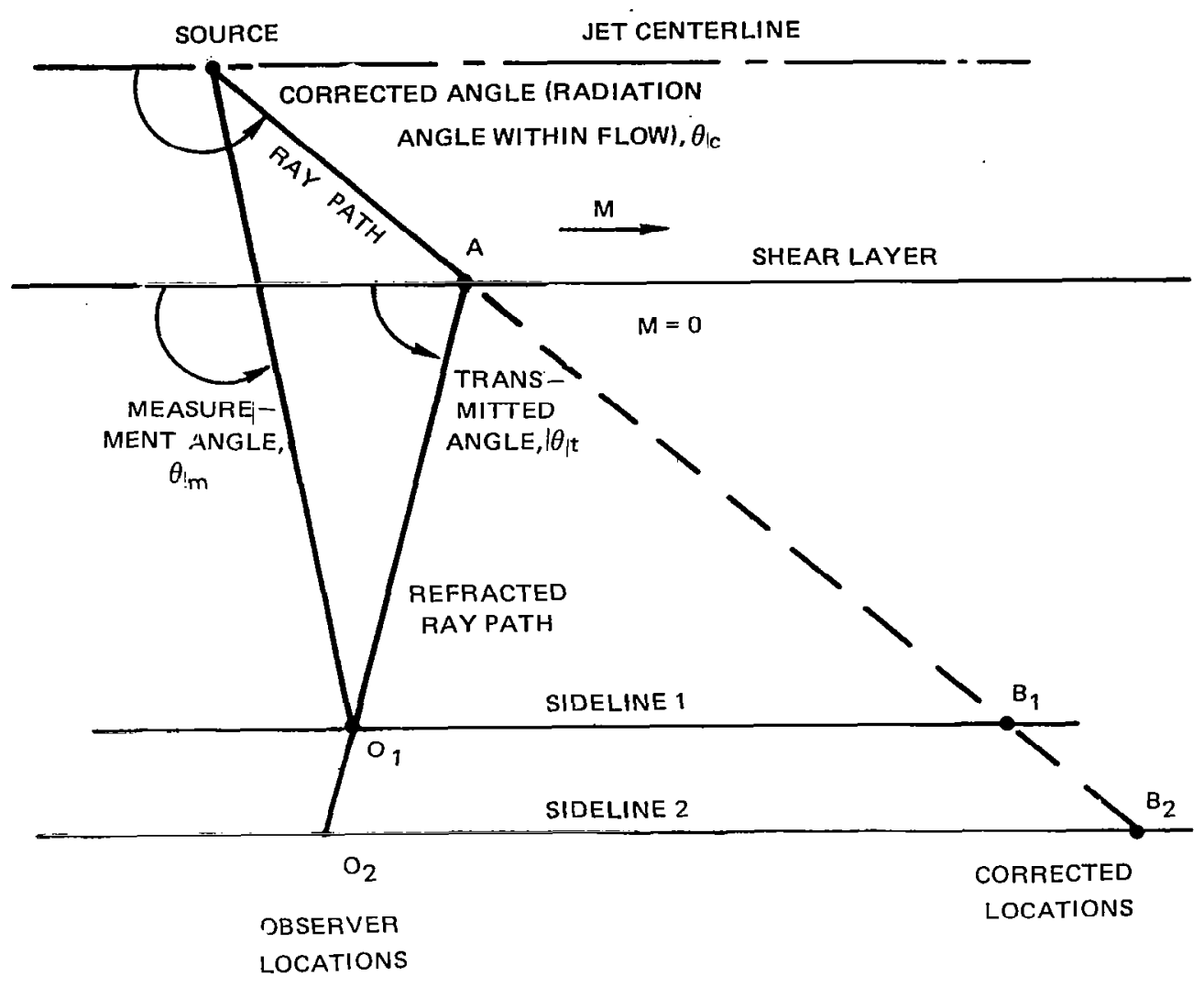

Figure 8-Geometry for Transmission of Sound Through a Shear Layer 

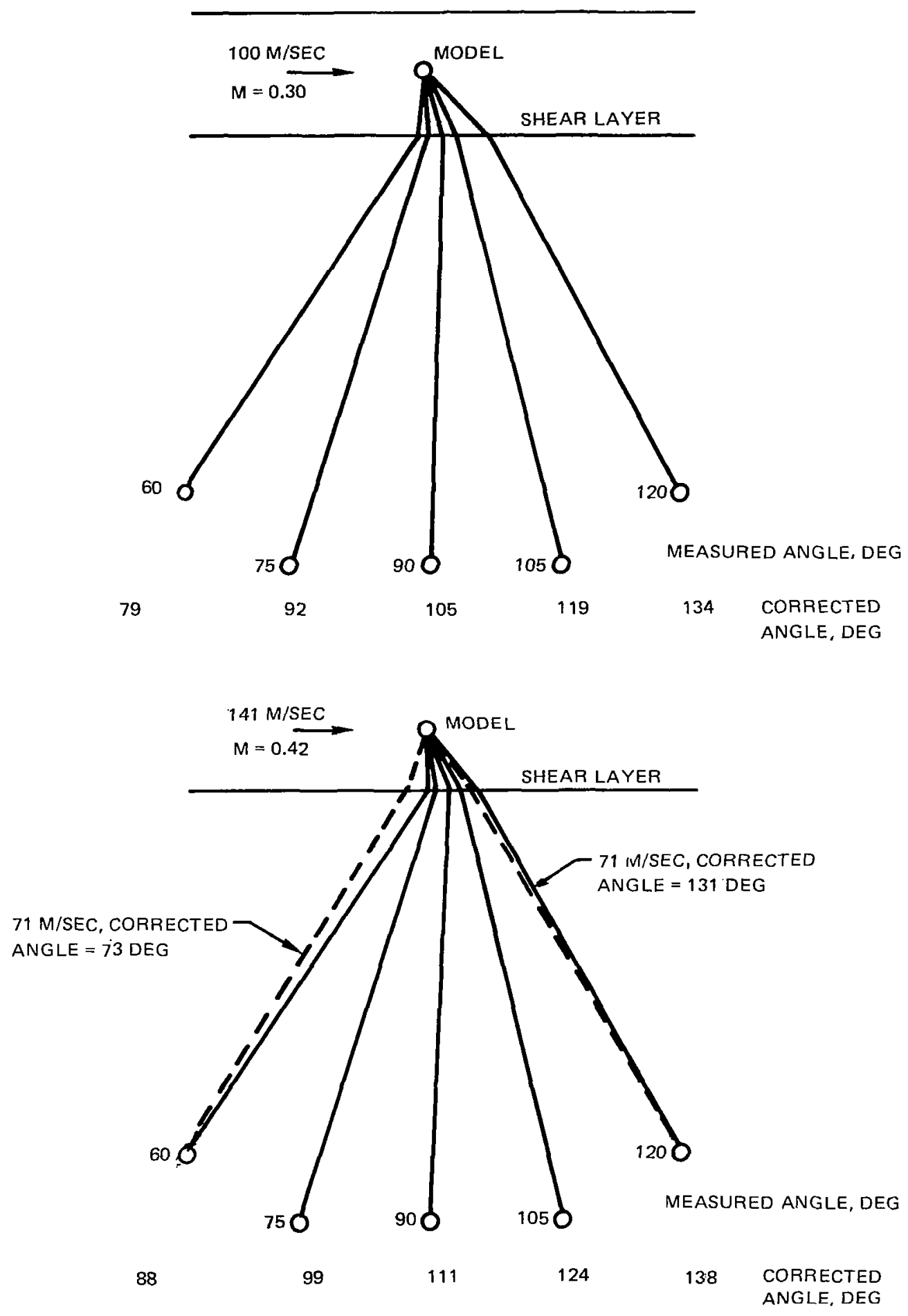

Figure 9,-Predicted Corrections to Far Field Direction Angle Due to Shear Layer Refraction 


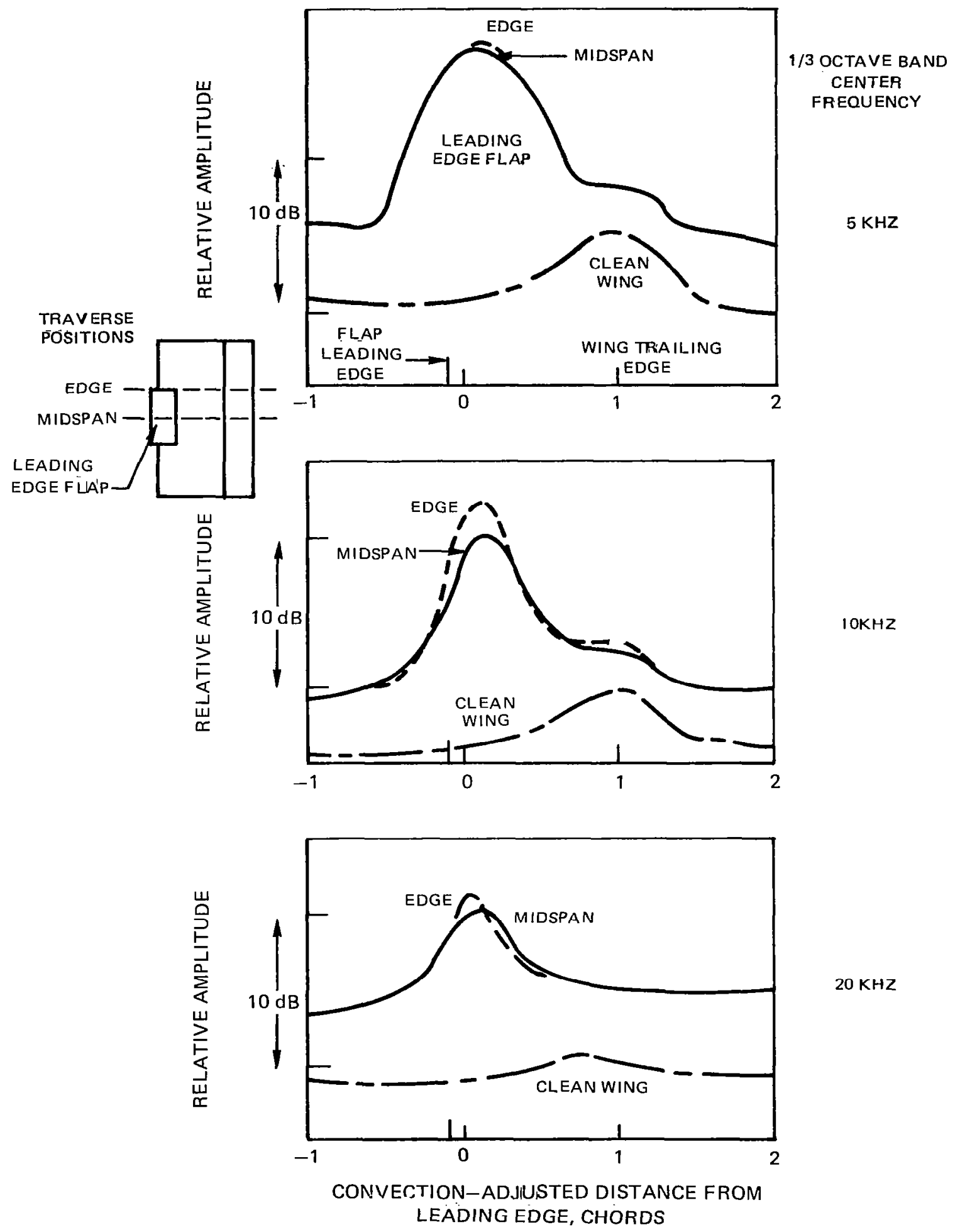

Figure 10-- Variation of Noise Source Strength Distribution with Spanwise Position on a Part-Span Leading Edge Flap at $100 \mathrm{M} / \mathrm{Sec}$ Velocity 


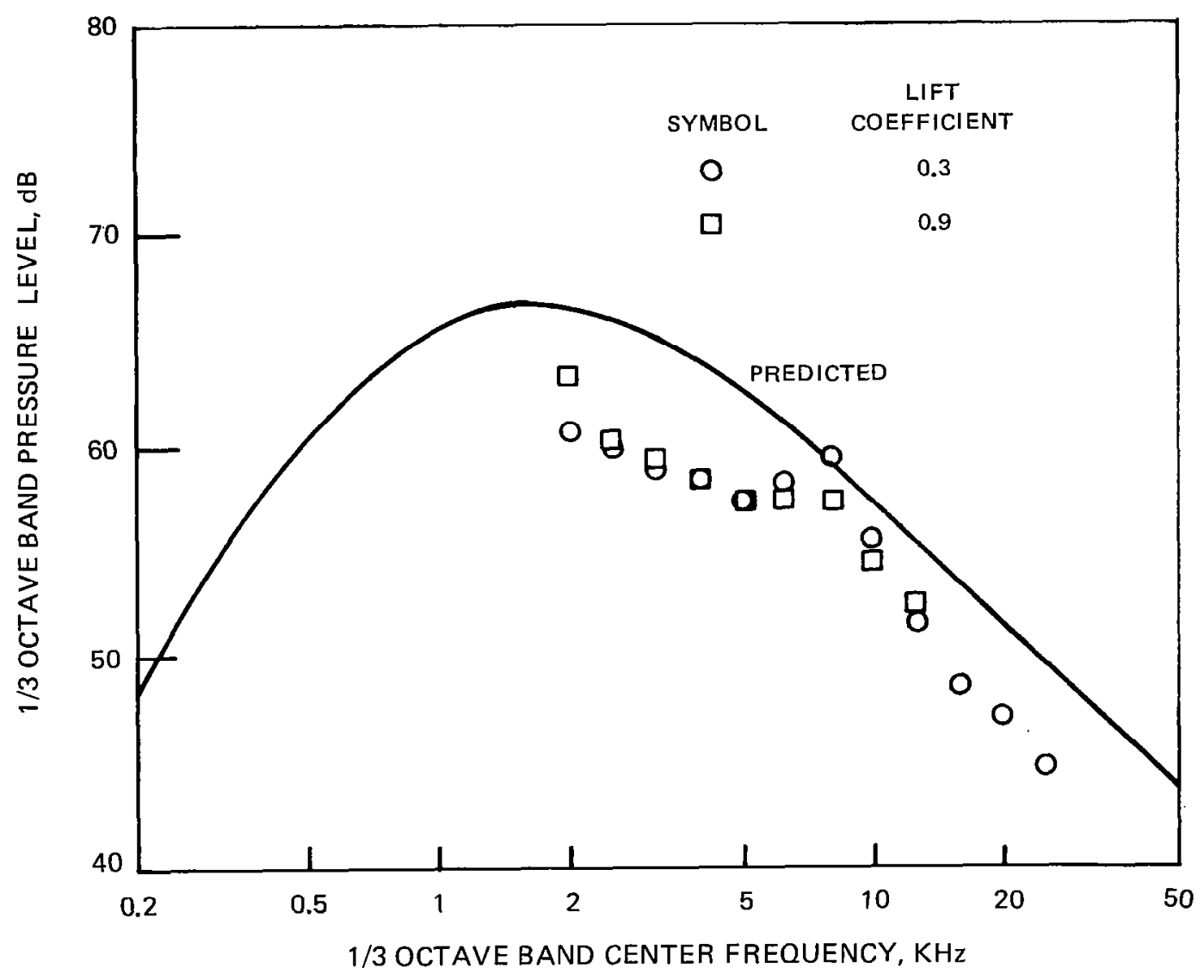

Figure 11-Clean Wing Trailing Edge Noise Spectra for Two Lift Coefficients at $90^{\circ}$ Direction and $100 \mathrm{~m} / \mathrm{sec}$ Velocity 


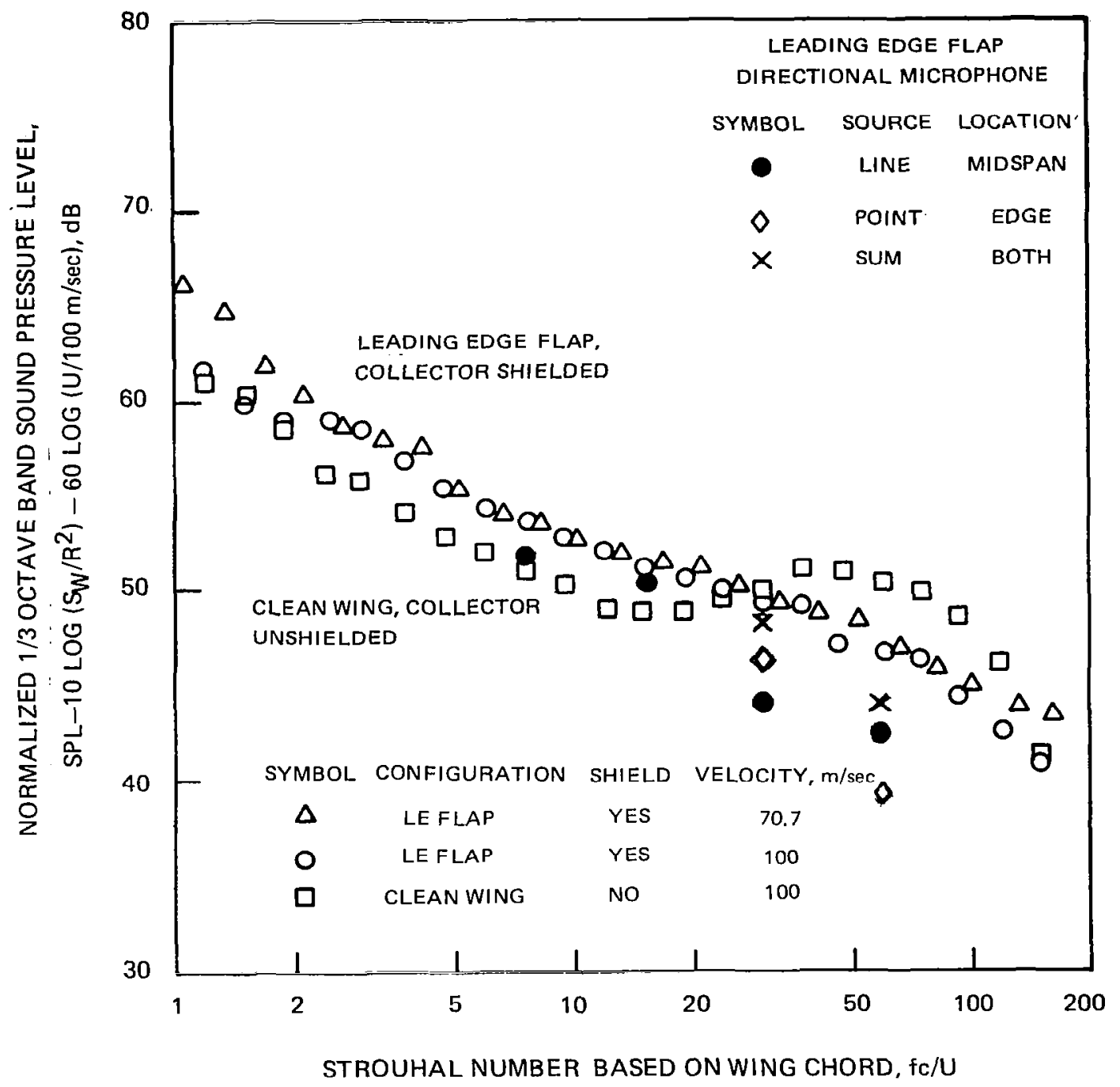

Figure 12-Normalized Spectra at $90^{\circ}$ Microphone for Leading Edge Flap, with Wind Tunnel Collector Shielded from Far Field Microphone 

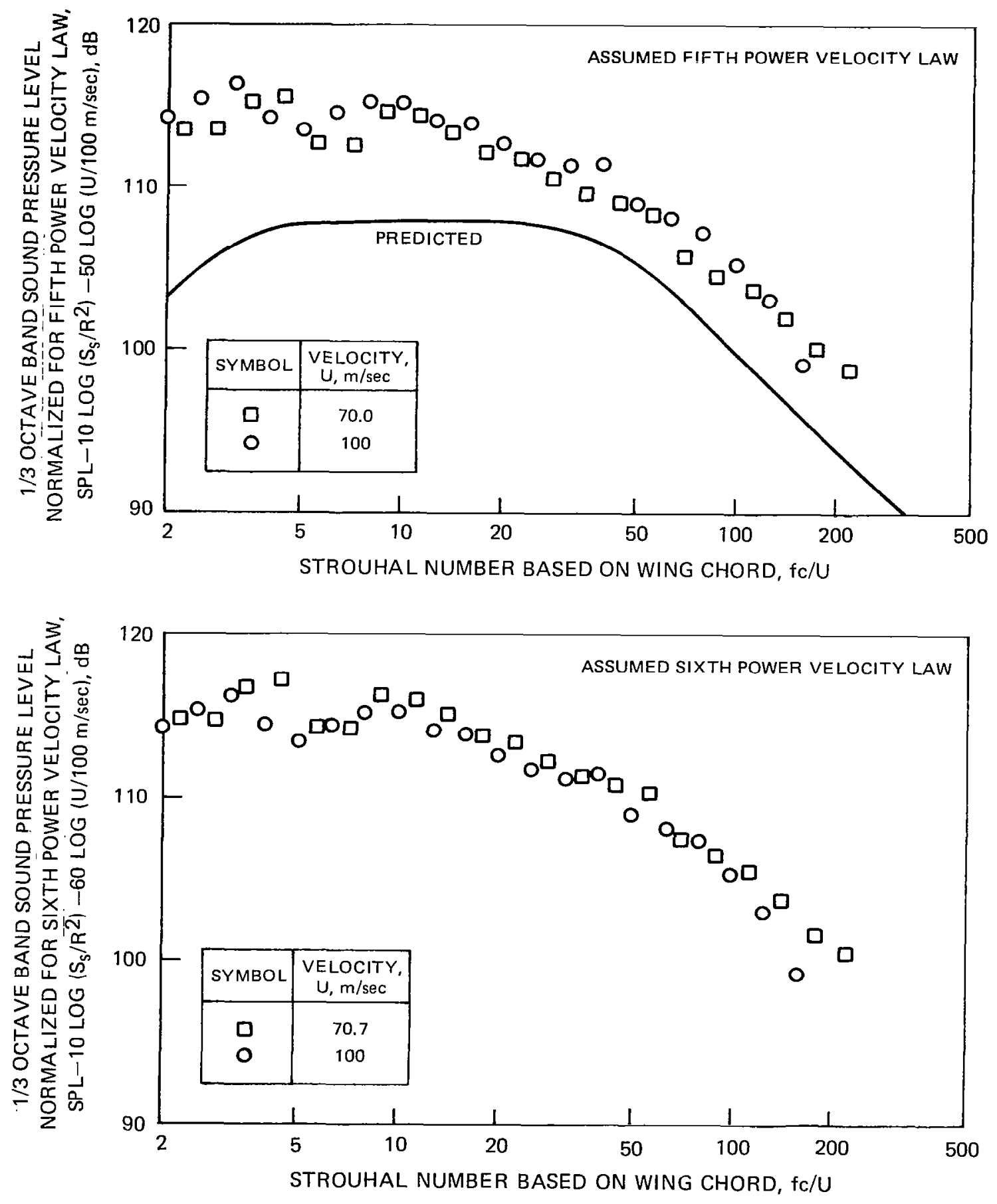

Figure 13-Comparison of Measured Spectra at $90^{\circ}$ Microphone, Normalized Assuming Either Fifth or Sixth Power Velocity Dependence, for Leading Edge Slat 


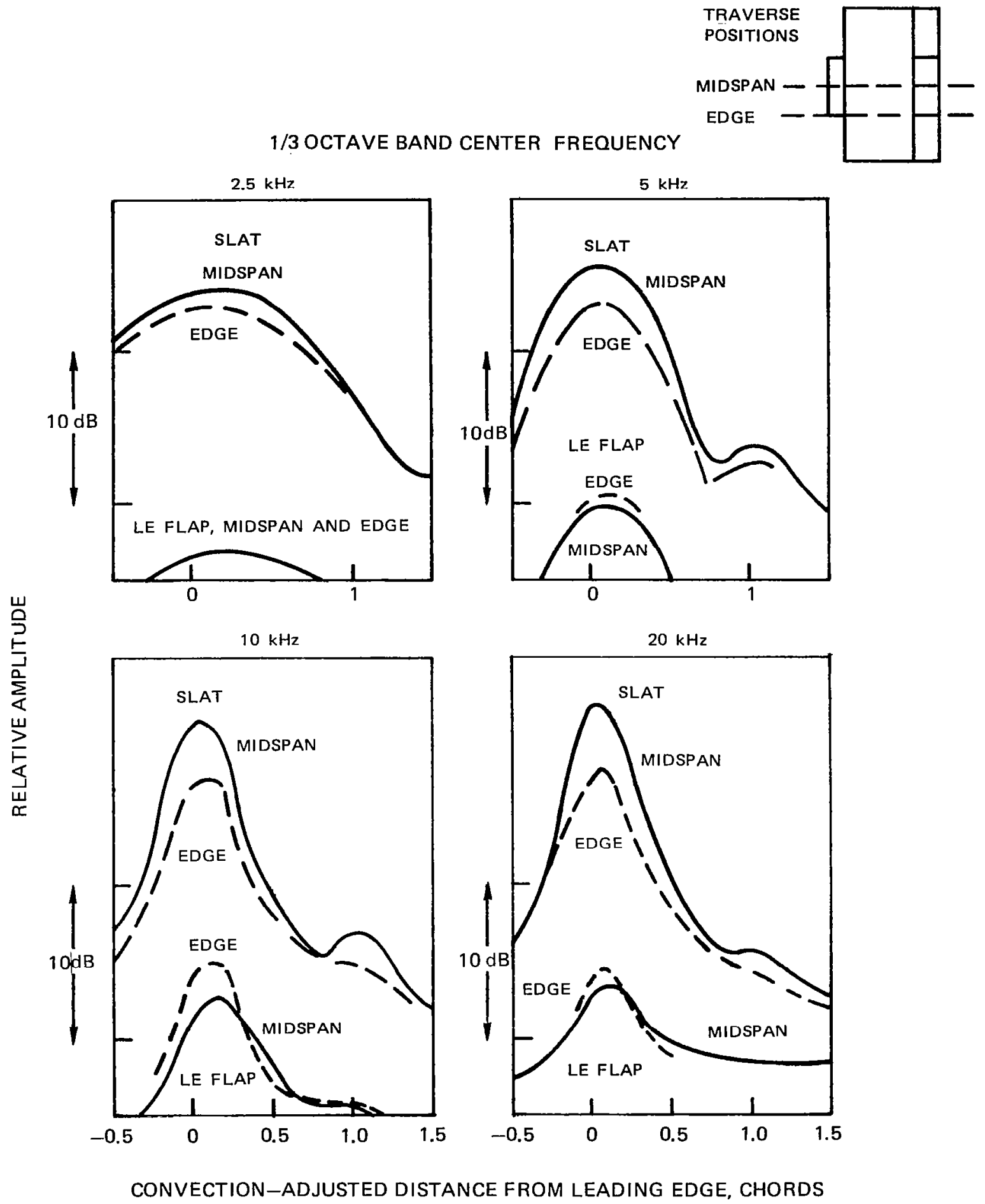

Figure 14-Comparison of Noise Source Strength Distributions at Edge and Midspan of Part Span Leading Edge Slat and Flap at $100 \mathrm{~m} / \mathrm{sec}$ Velocity 

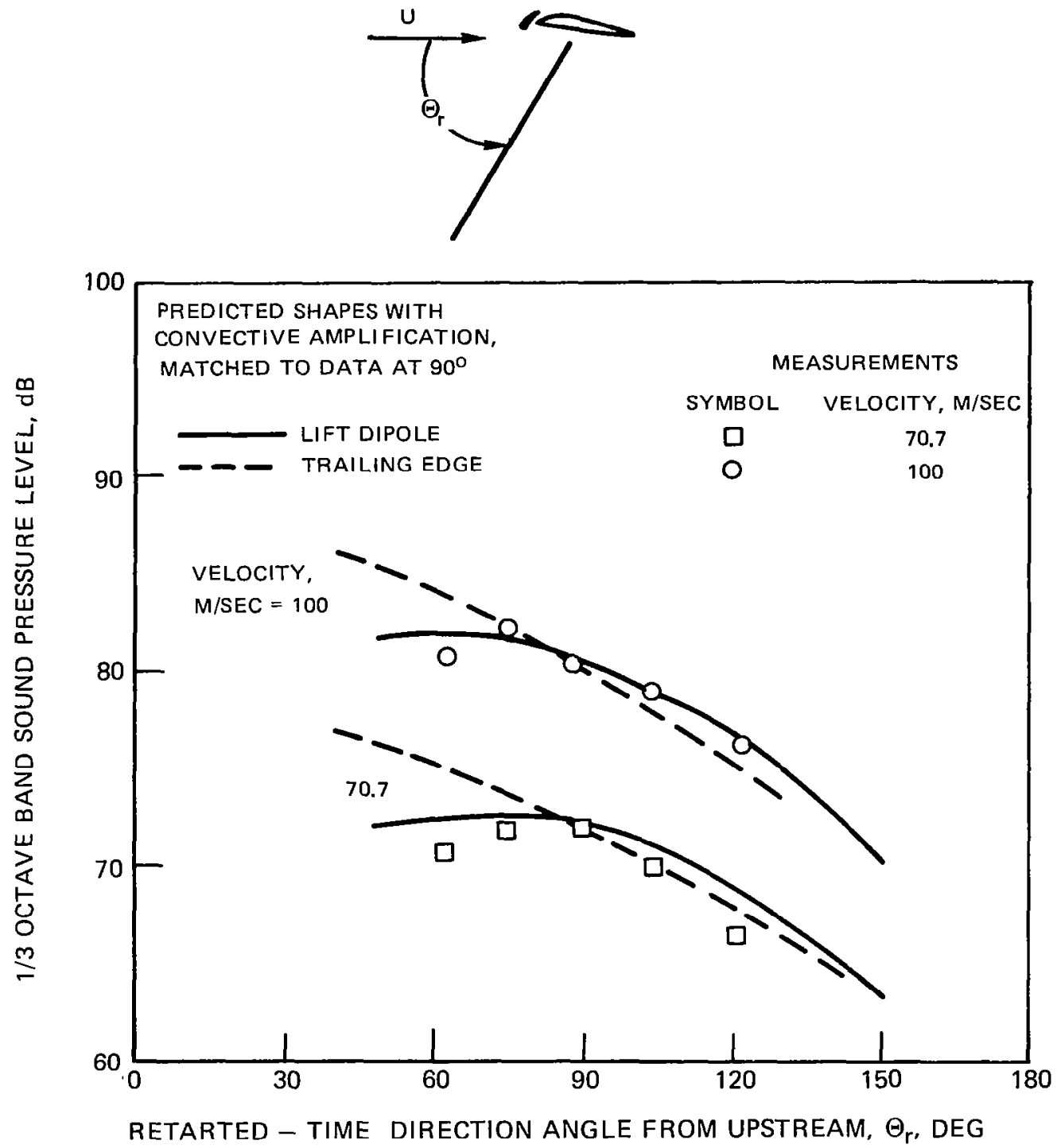

Figure 15 - Effect of Velocity on Leading Edge Slat Noise Directivity. Strouhal Number $=20$ Referenced to Wing Chord. 
DATA SYMBOL FOF. CONVENTIONAL MIC DIRECTIONAL MIC CONFIGURATION
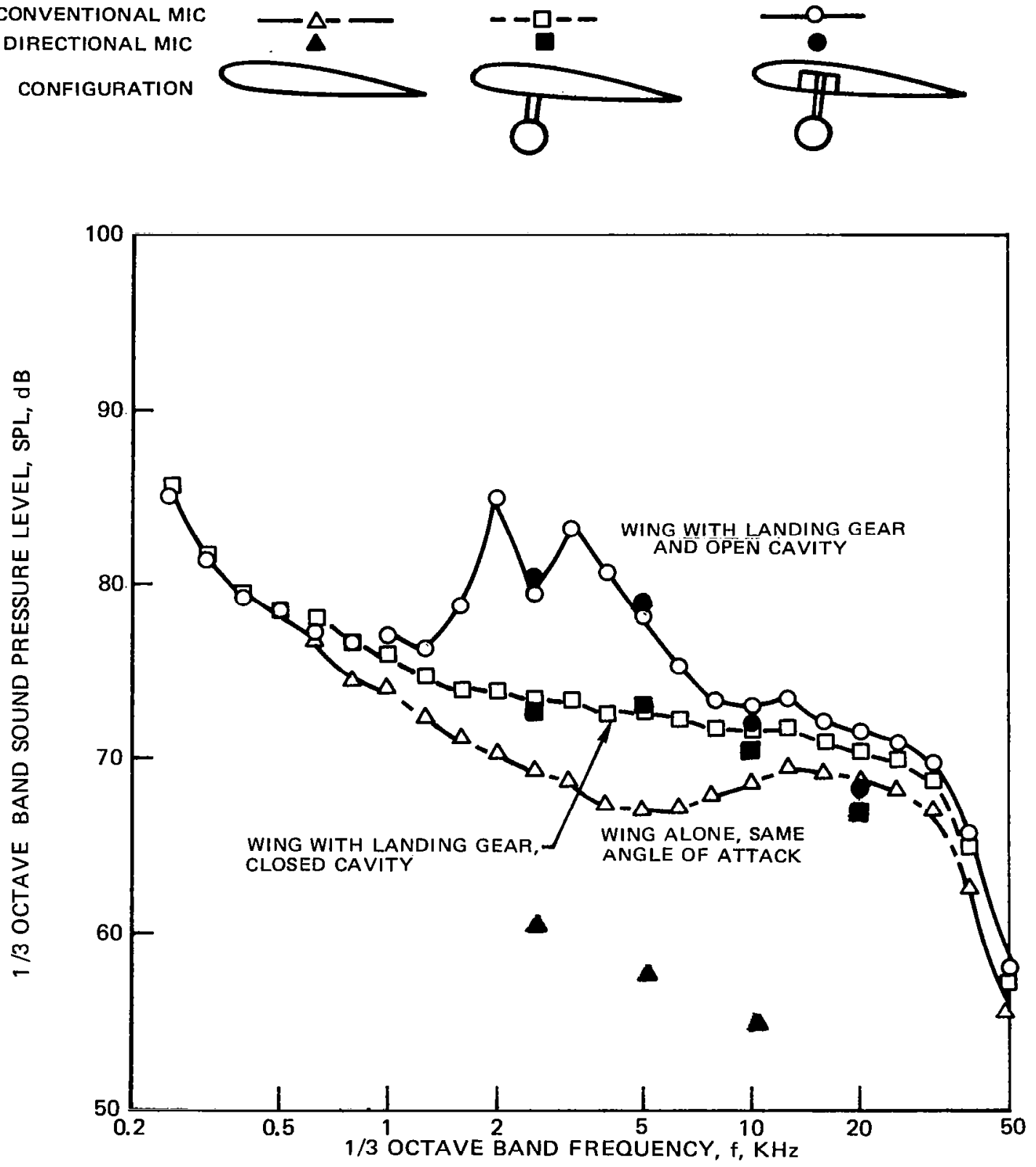

Figure 16 -Measured Spectra at $90^{\circ}$ Microphone for Landing Gear Configuration at $100 \mathrm{M} / \mathrm{Sec}$ Velocity 

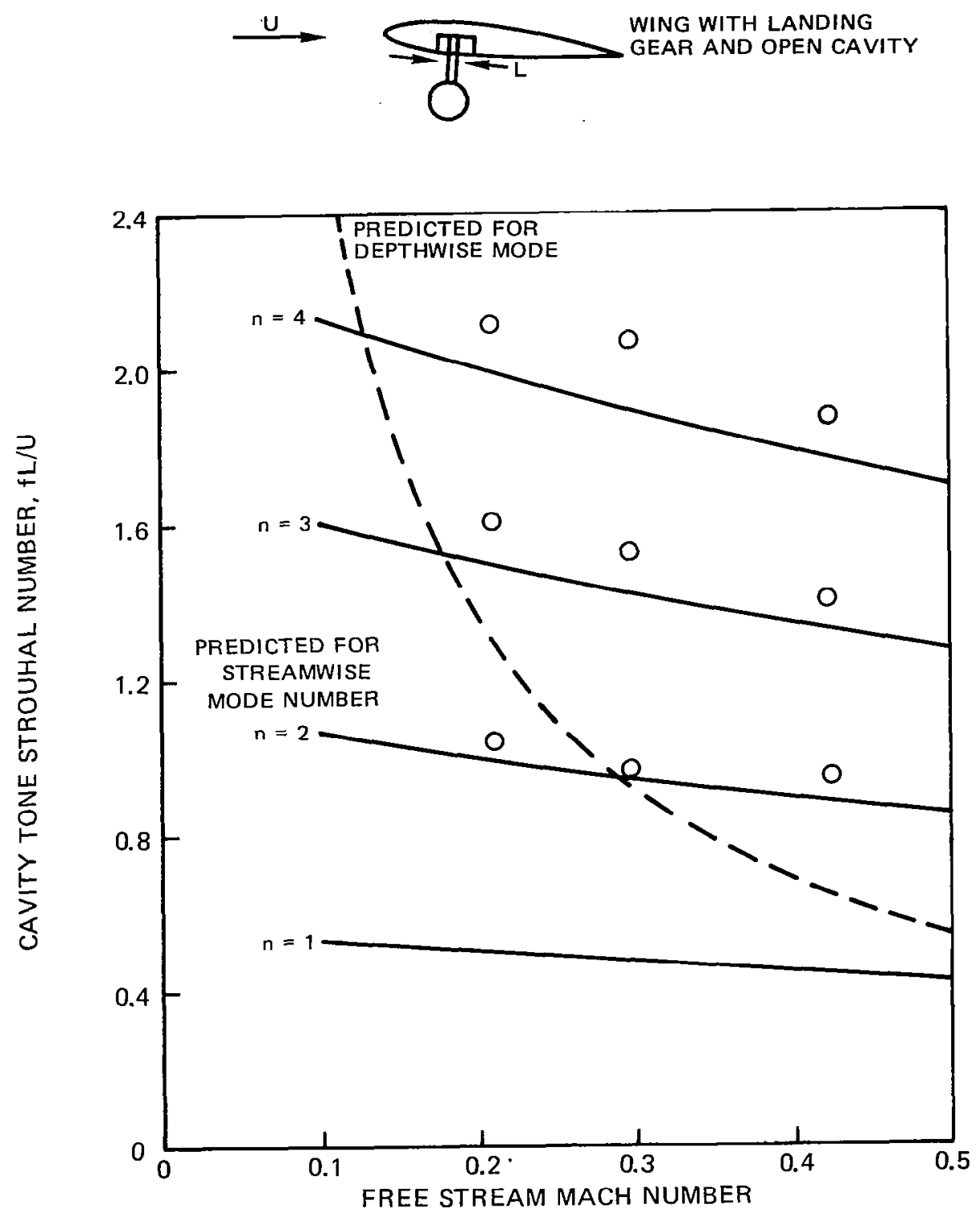

Figure 17-Comparison of Measured and Predicted Landing Gear Cavity Tone Strouhal Numbers. Data are for Wing with Open Cavity and Extended Landing Gear 

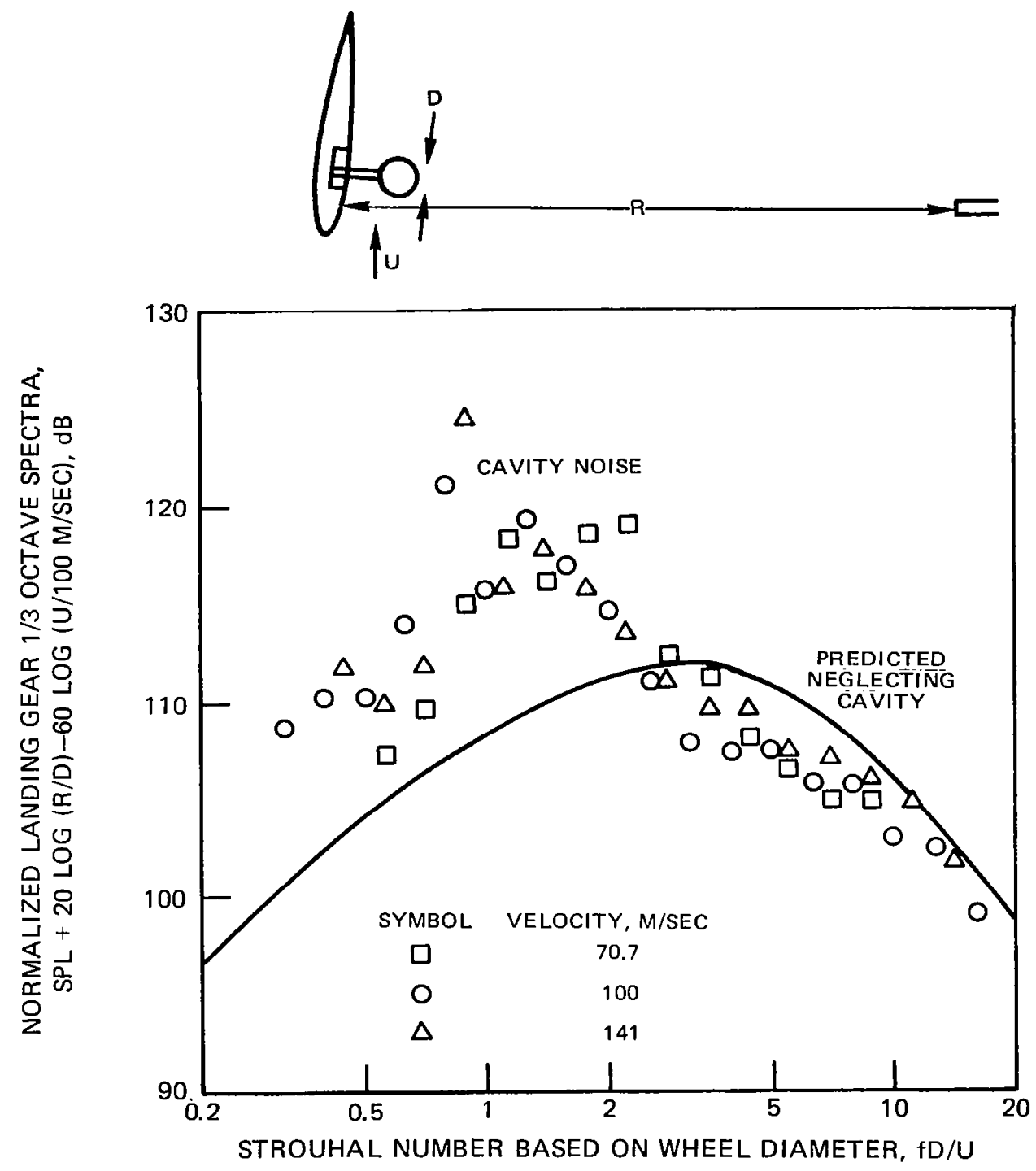

Figure 18-Comparison of Measured and Predicted Normalized Spectra for Two-Wheel Landing Gear at Flyover Position 

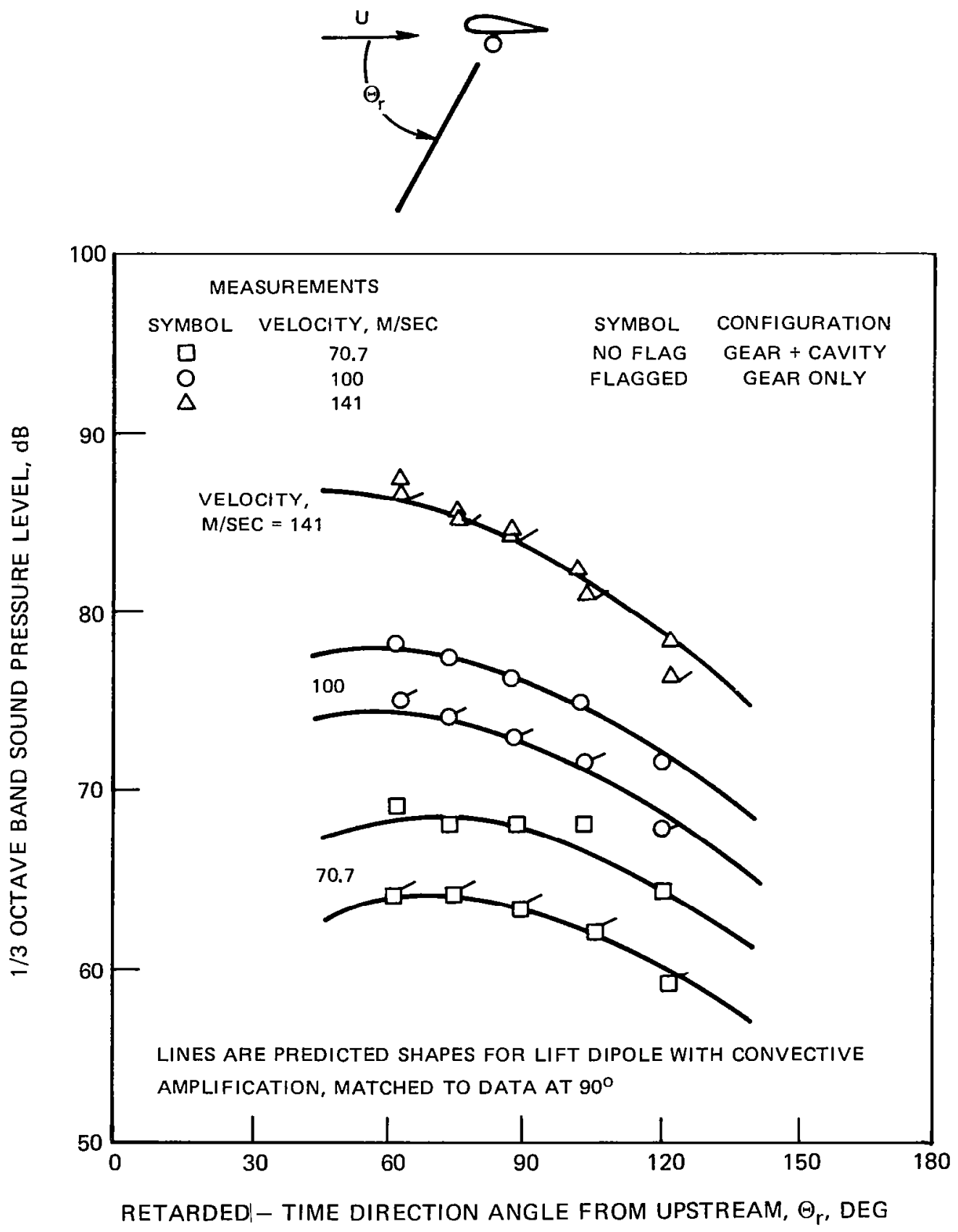

Figure 19 - Effect of Velocity on Landing Gear Noise Directivity. Strouhal Number $=3.4$ Referenced to Wheel Diameter. 

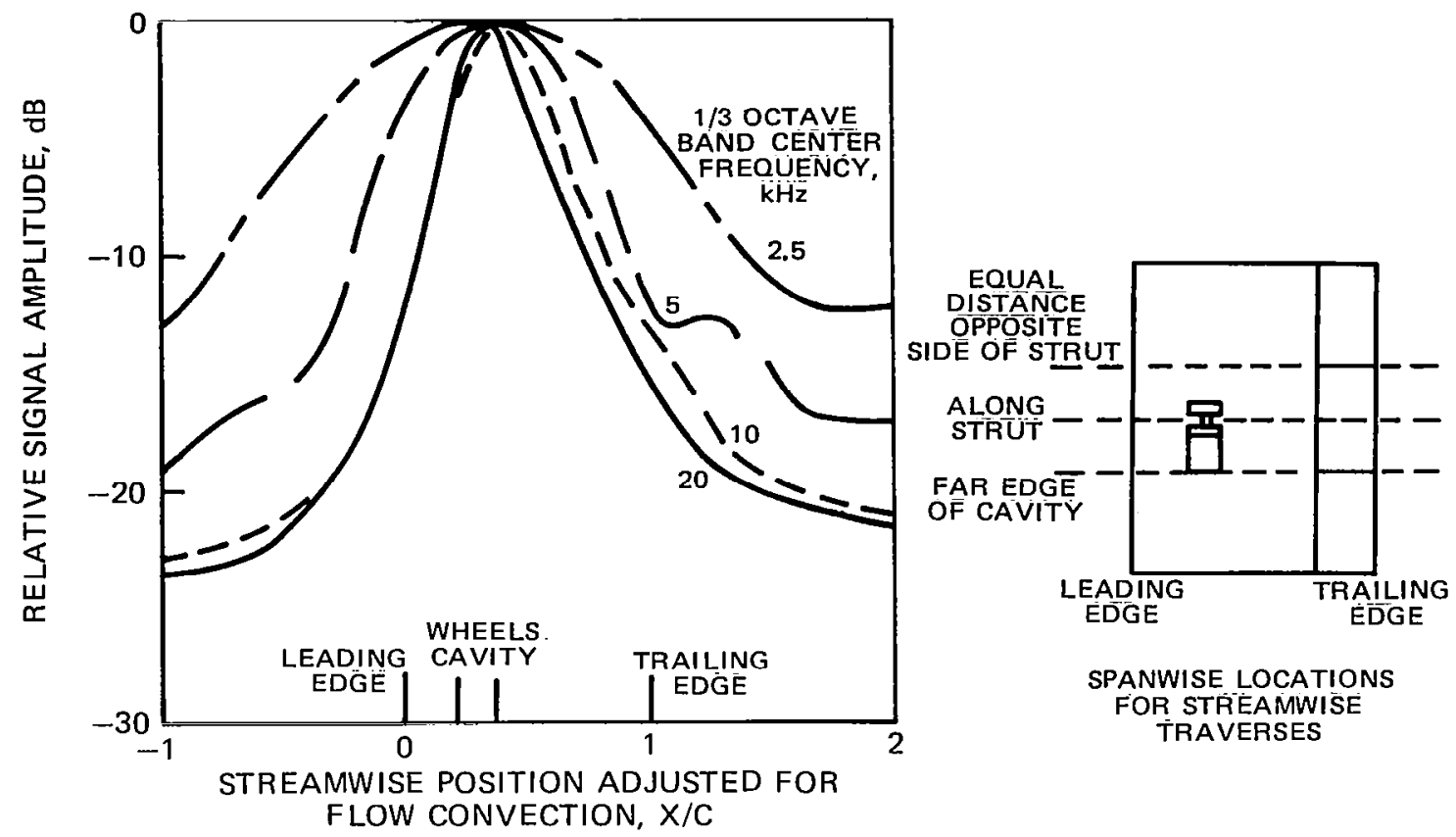

(a) EFFECT OF CENTER FREQUENCY ON RELATIVE AMPLITUDE FOR TRAVERSE ALONG STRUT, WITH OPEN CAVITY

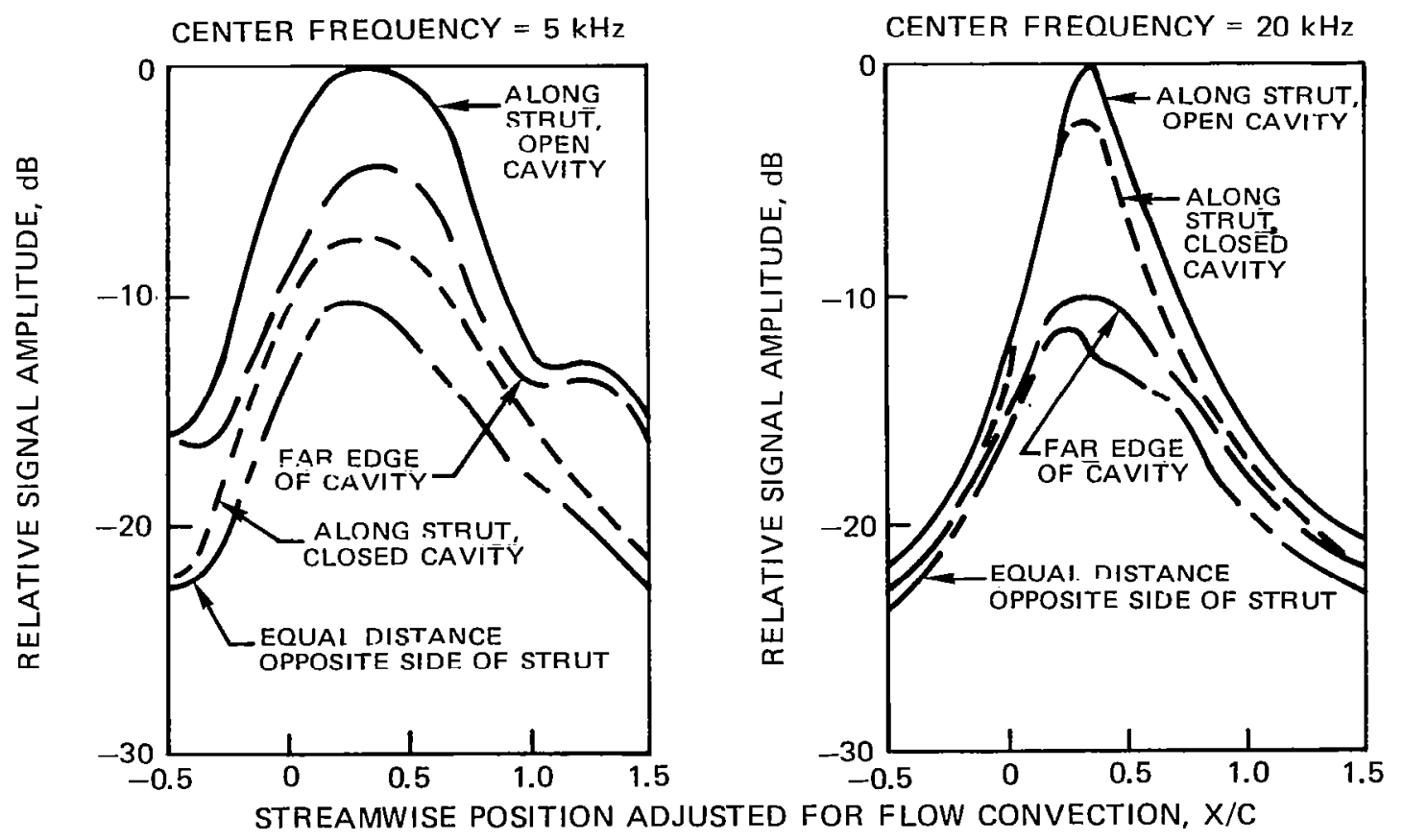

(b) EFFECT OF SPANWISE POSITION ON RELATIVE AMPLITUDE AT TWO FREOUENCIES

Figure 20-Directional Microphone Relative Signal Strengths for Landing Gear Configurations at $100 \mathrm{M} / \mathrm{Sec}$ Velocity 

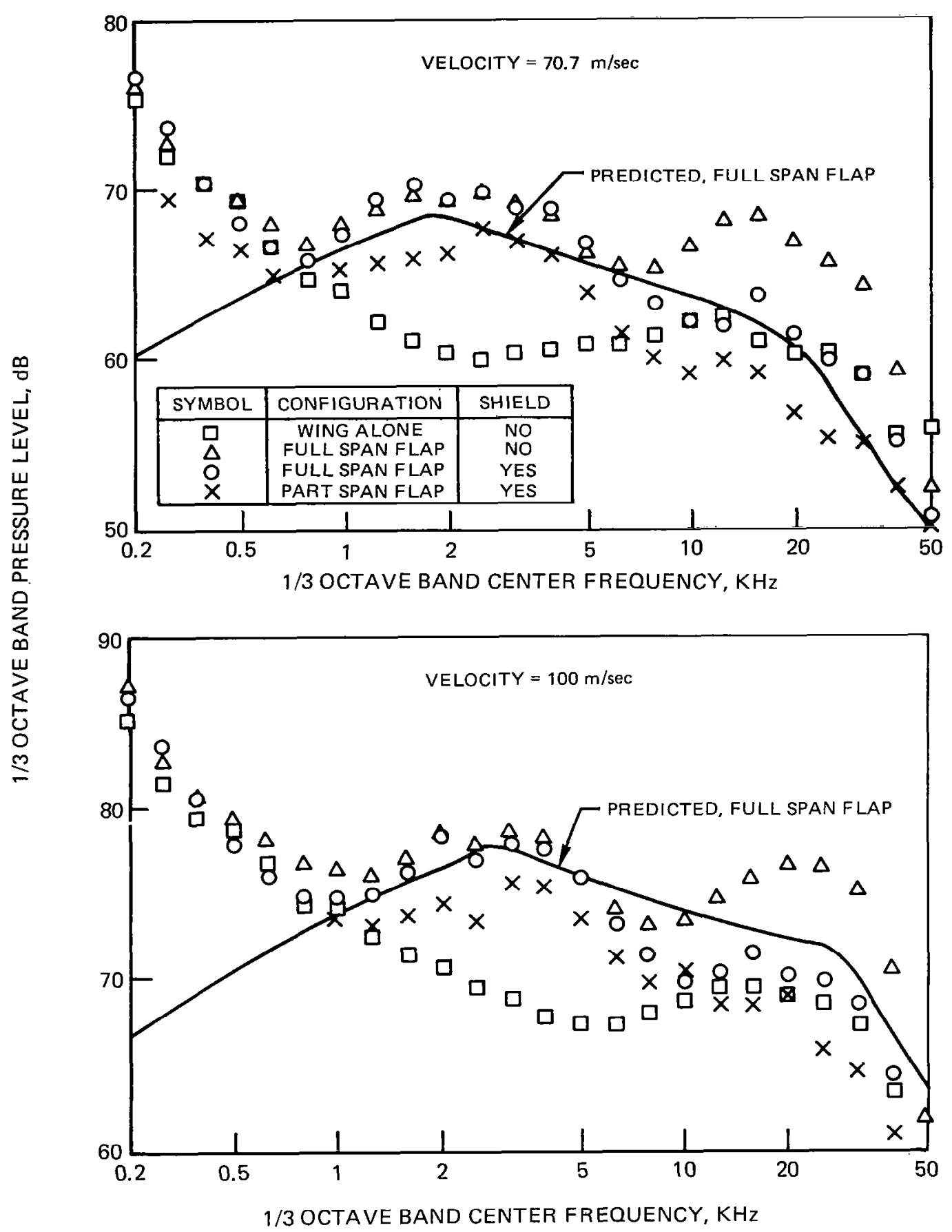

Figure 21 - Comparison of Spectra at $90^{\circ}$ Microphone for $15^{\circ}$ Deflection Full and Part Span Single Slotted Trailing Edge Flap 


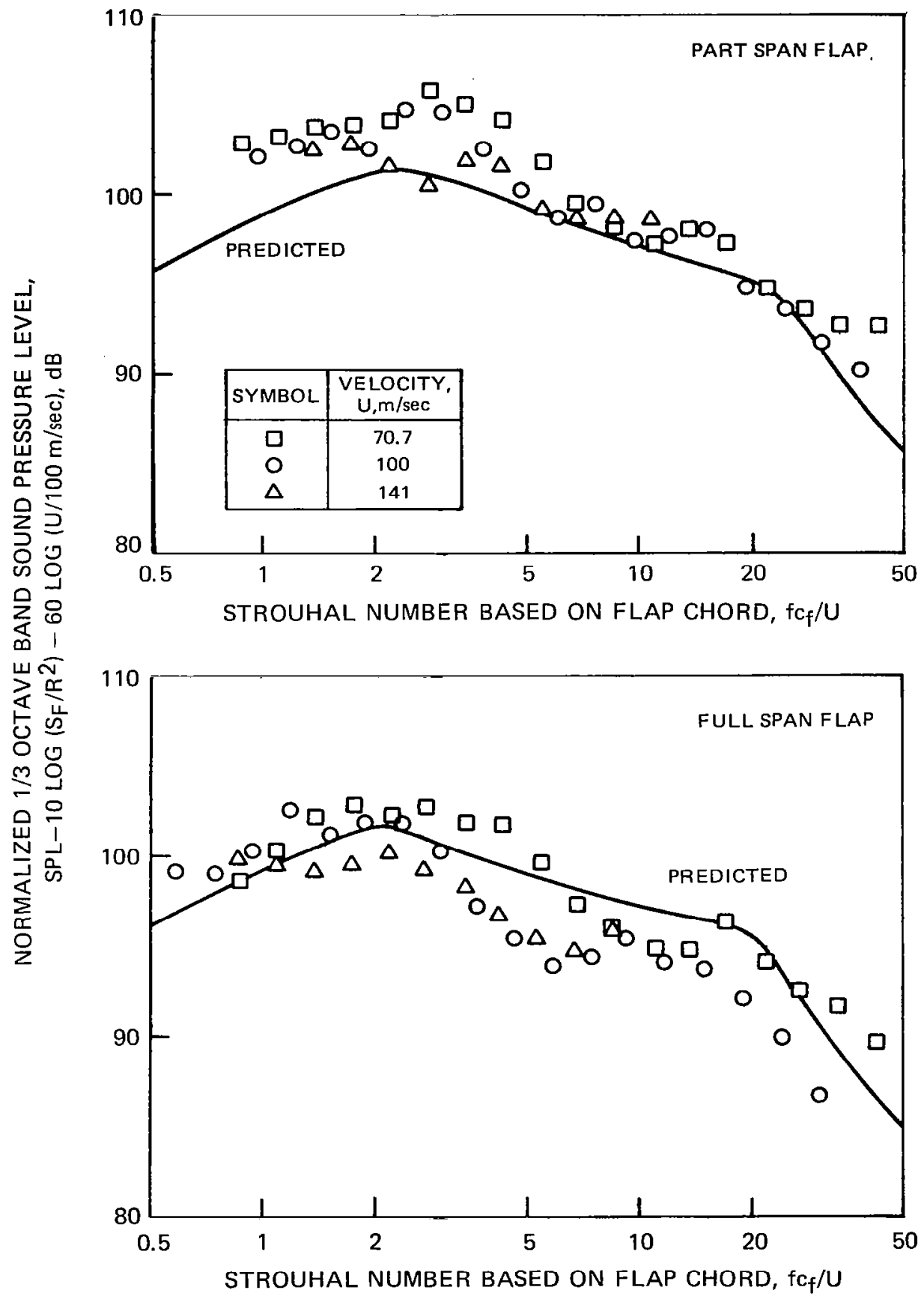

Figure 22- Measured and Predicted Normalized Spectra at $90^{\circ}$ Microphone for $15^{\circ}$ Deflection Full and Part Span Single Slotted Trailing Edge Flap 


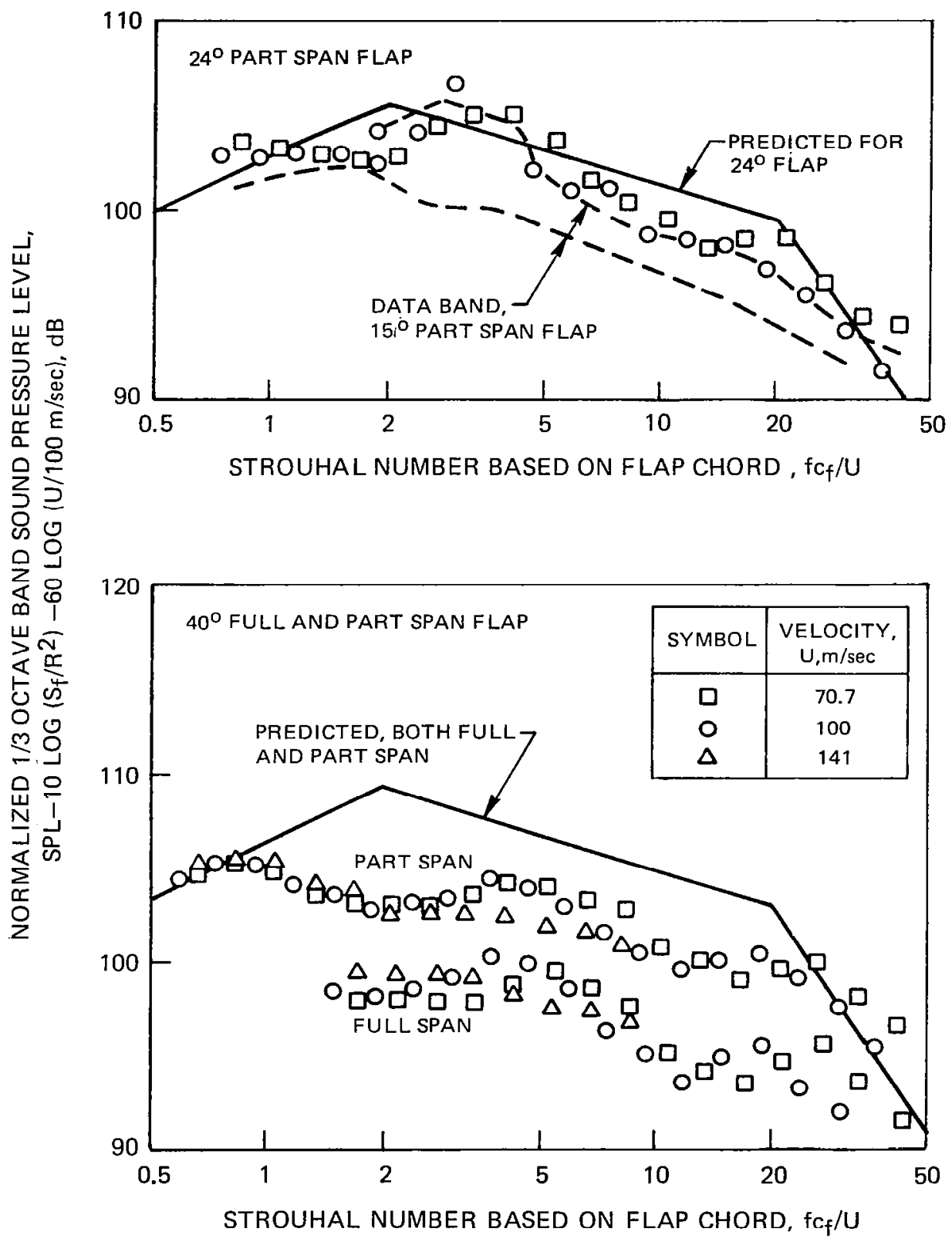

Figure 23- Measured and Predicted Normalized Spectra at $90^{\circ}$ Microphone for $24^{\circ}$ Deflection Part Span and $40^{\circ}$ Deflection Full and Part Span Single Slotted Flap 


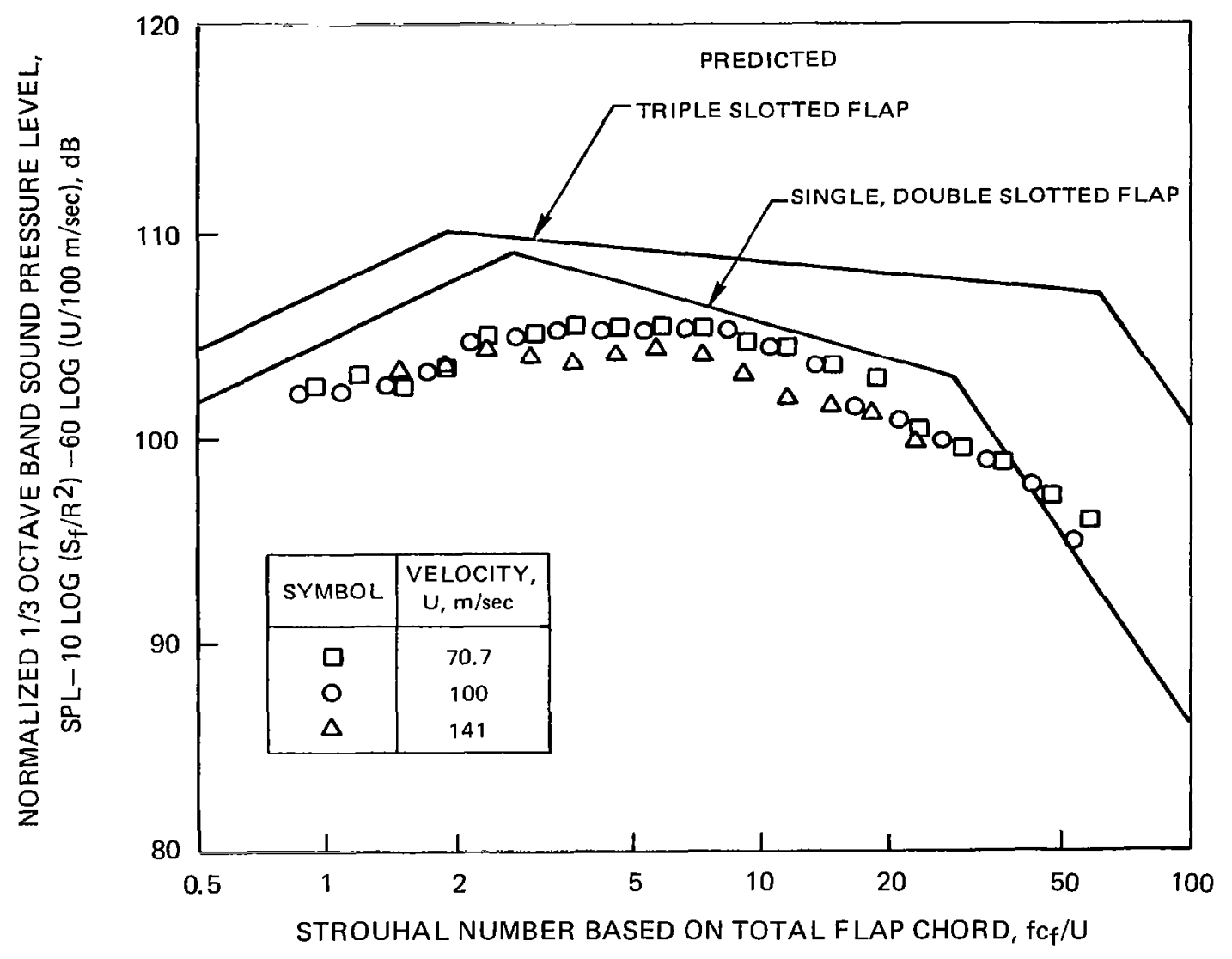

Figure 24- Measured and Predicted Normalized Spectra at $90^{\circ}$ Microphone for $40^{\circ}$ Deflection Part Span Double Slotted Trailing Edge Flap 


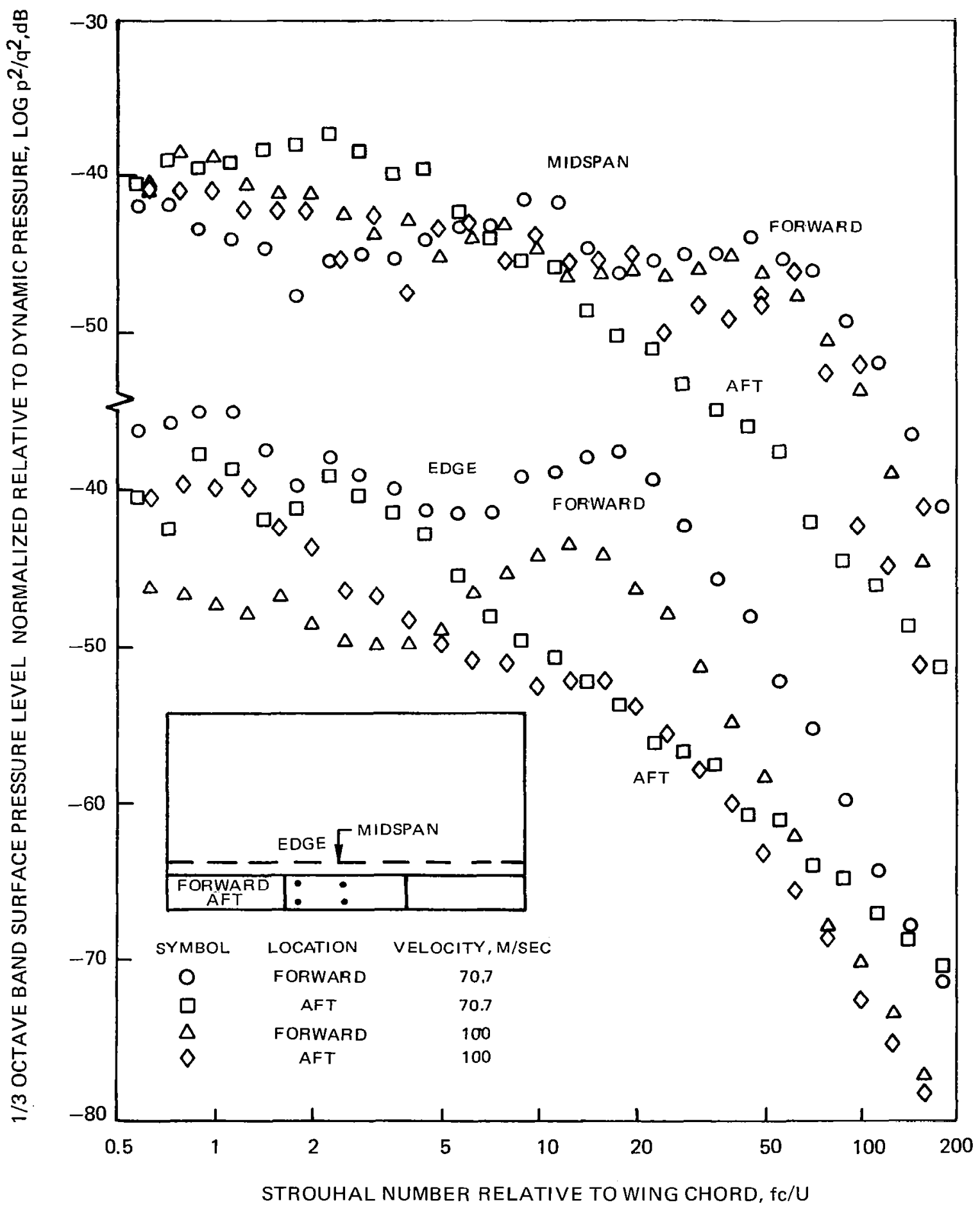

Figure 25-Normalized Surface Pressure Spectra on Upper Surface of Full Span $40^{\circ}$ Deflection Single Slotted Flap. Edge Position is Near Edge of Central Flap Panel. 


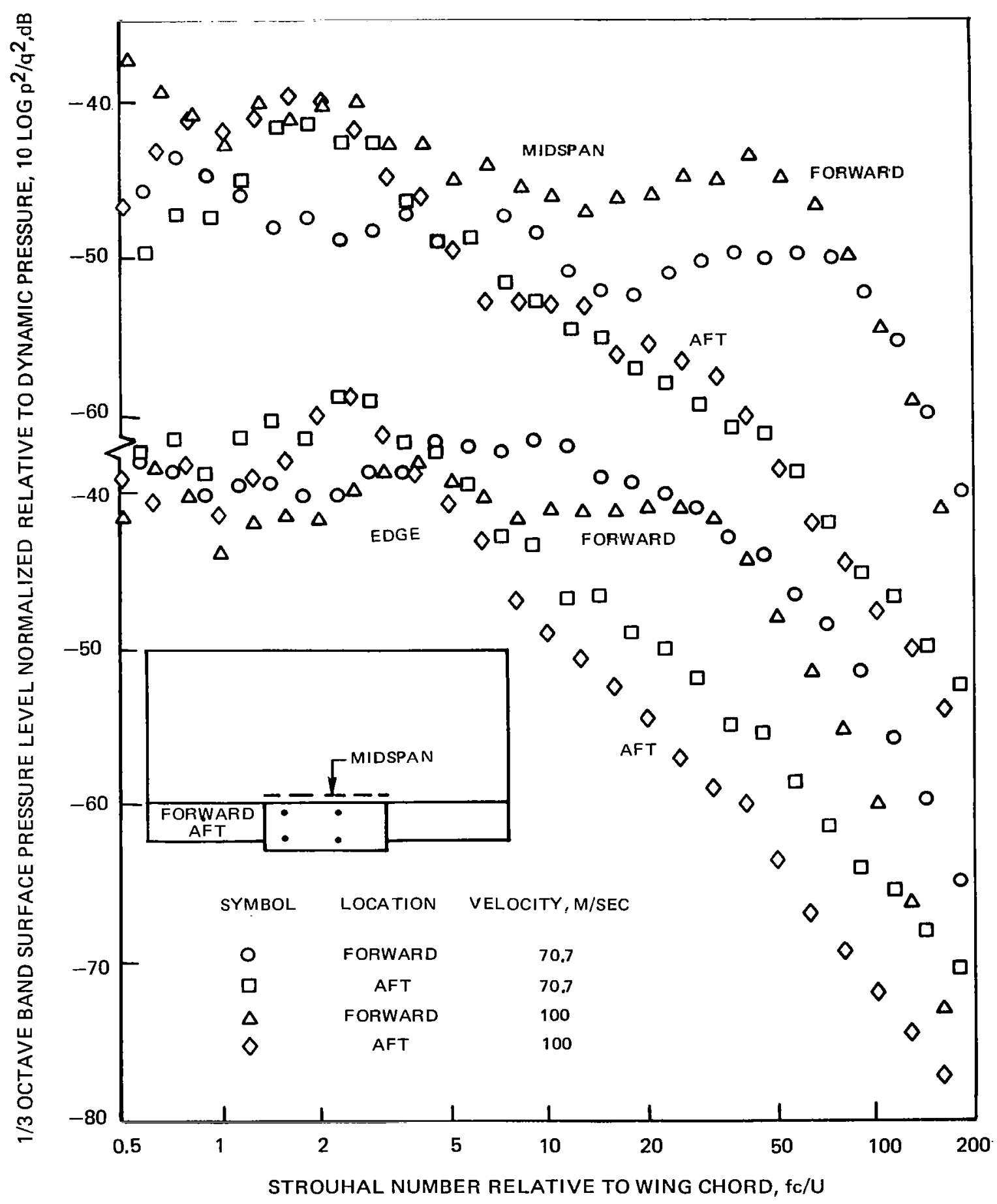

Figure 26 - Normalized Surface Pressure Spectra on Upper

Surface of Part Span $40^{\circ}$ Deflection Single Slotted Flap 


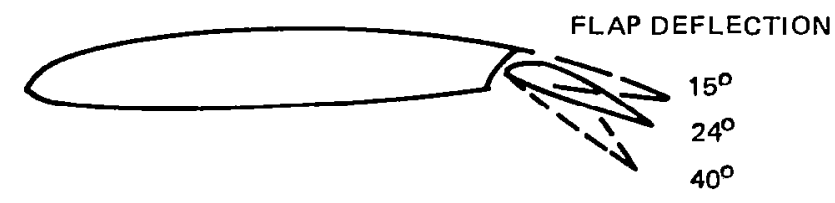

$1 / 3$ OCTAVE BAND CENTER FREQUENCY
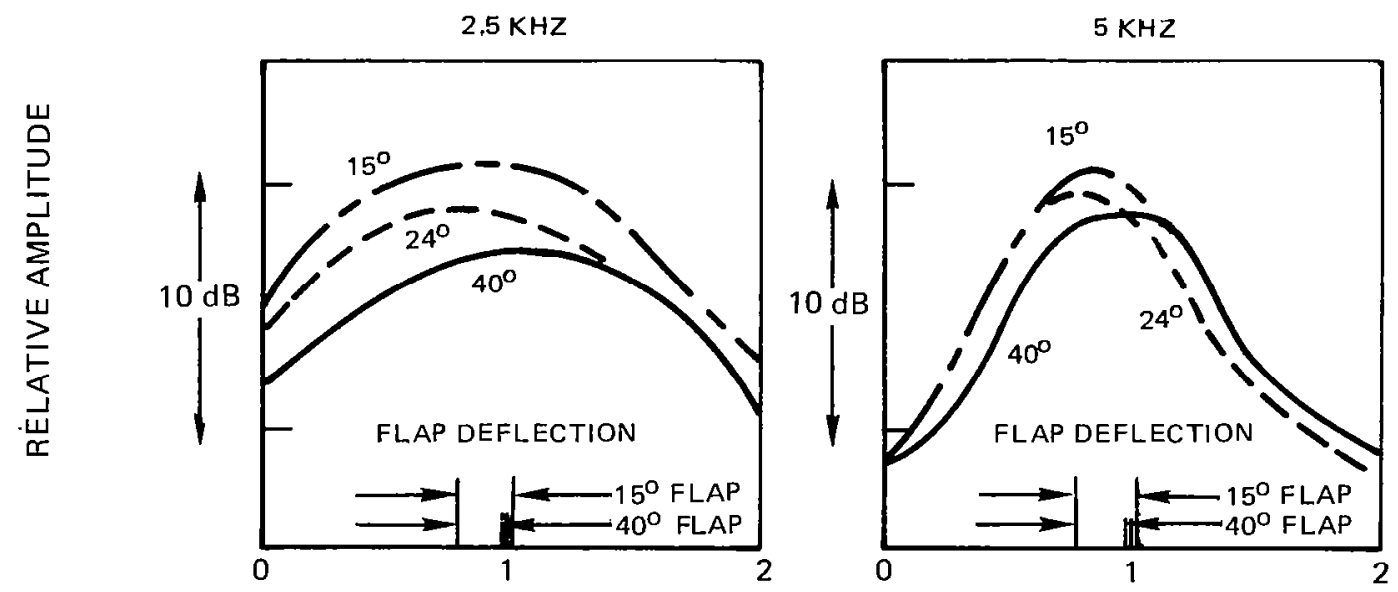

1/3 OCTAVE BAND CENTER FREQUENCY
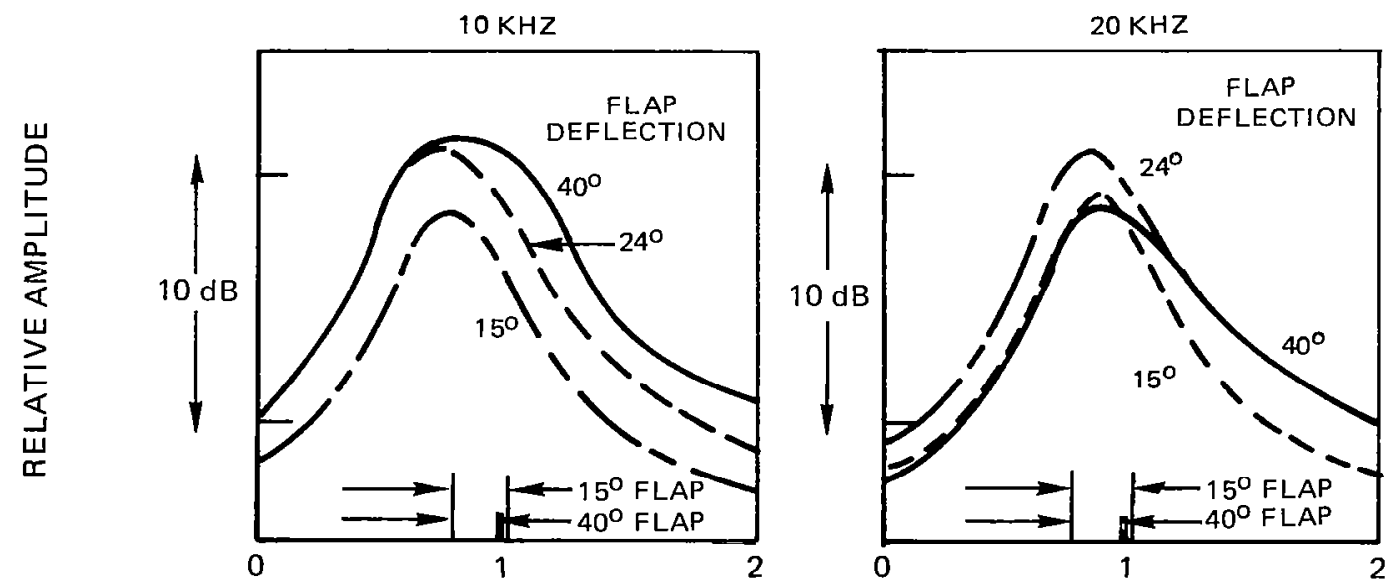

CONVECTION-ADJUSTED DISTANCE FROM LEADING EDGE, CHORDS

Figure 27 Effect of Flap Deflection Angle on Noise Source Strength Distribution for Full-Span Single Slotted Trailing Edge Flap at $100 \mathrm{M} / \mathrm{Sec}$ Velocity 
$1 / 3$ OCTAVE BAND CENTER FR EQUENCY
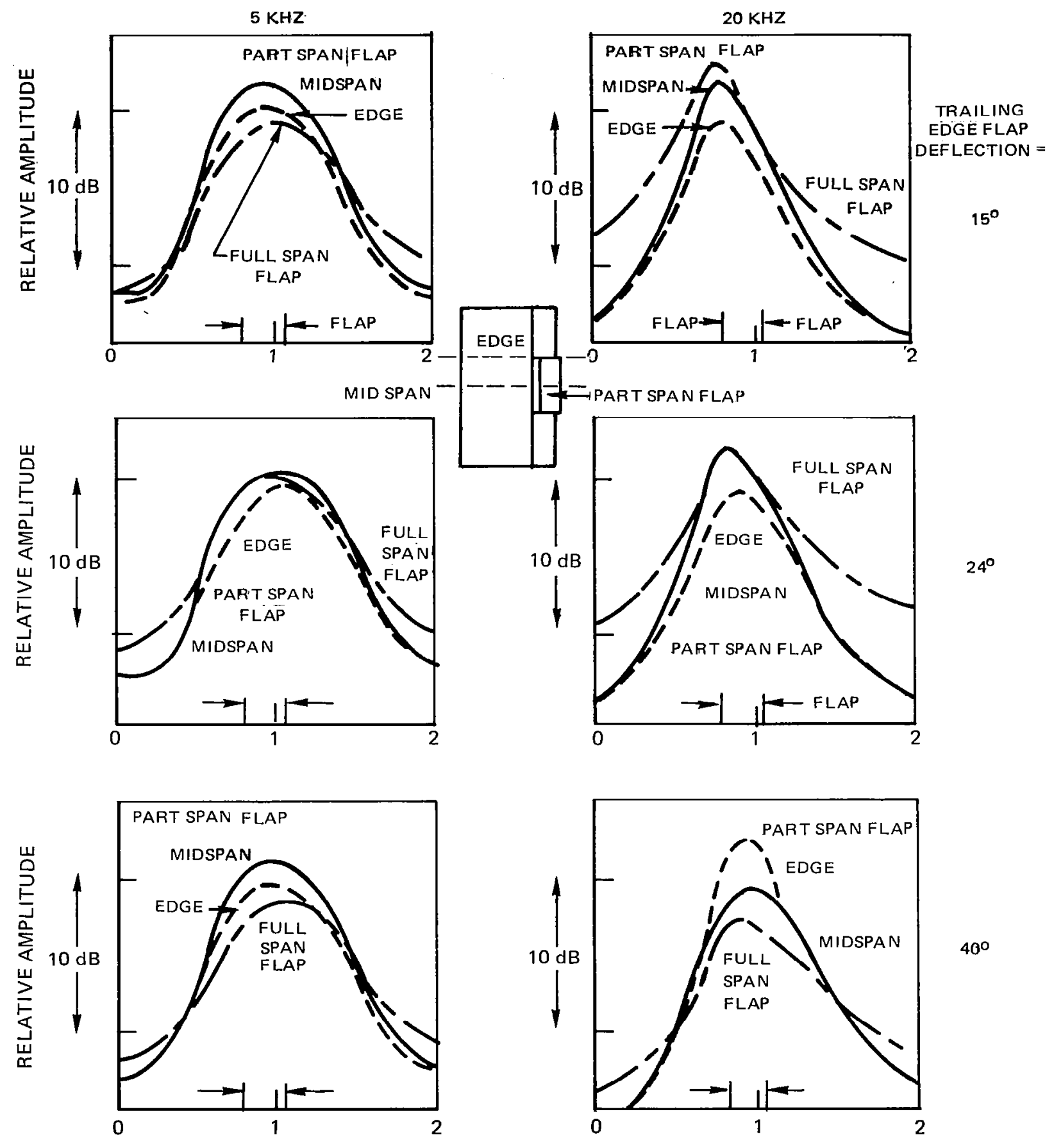

$40^{\circ}$

CONVECTION-ADJUSTED DISTANCE FROM LEADING EDGE, CHORDS

Figure 28 - Variation of Noise Source Strength Distribution with Spanwise Position on a Part-Span Single Slotted Trailing Edge Flap at $100 \mathrm{M} / \mathrm{Sec}$ Velocity 

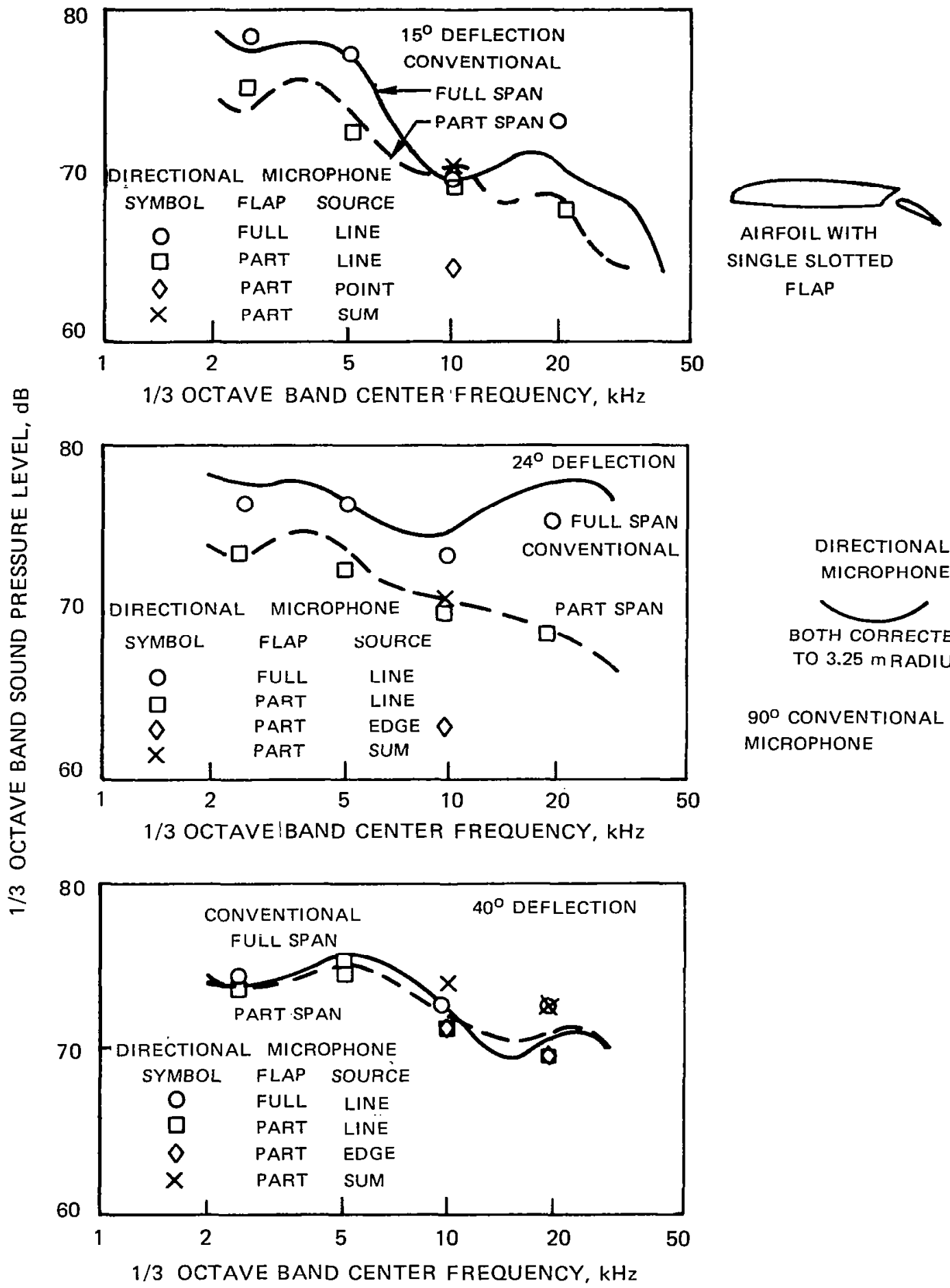

DIRECTIONAL MICROPHONE

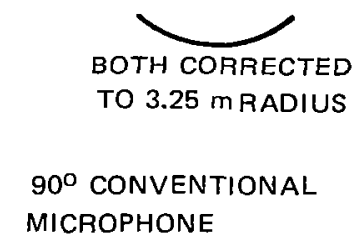

$90^{\circ}$ CONVENTIONAL MICROPHONE 

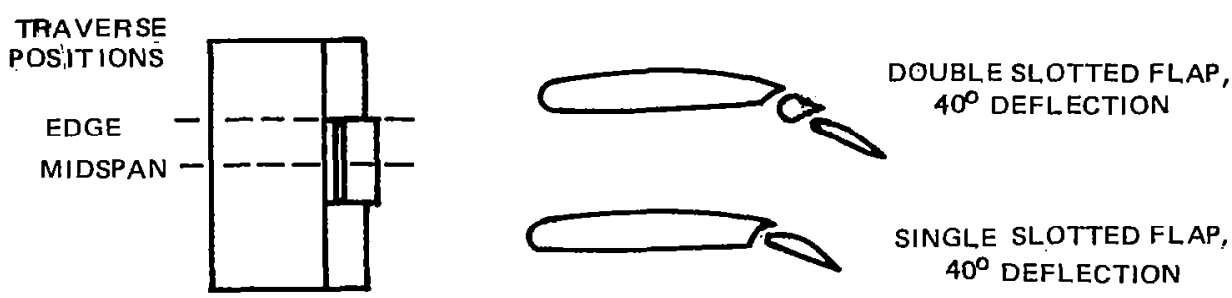

$1 / 3$ OCTAVE BAND CENTER FREQUENCY
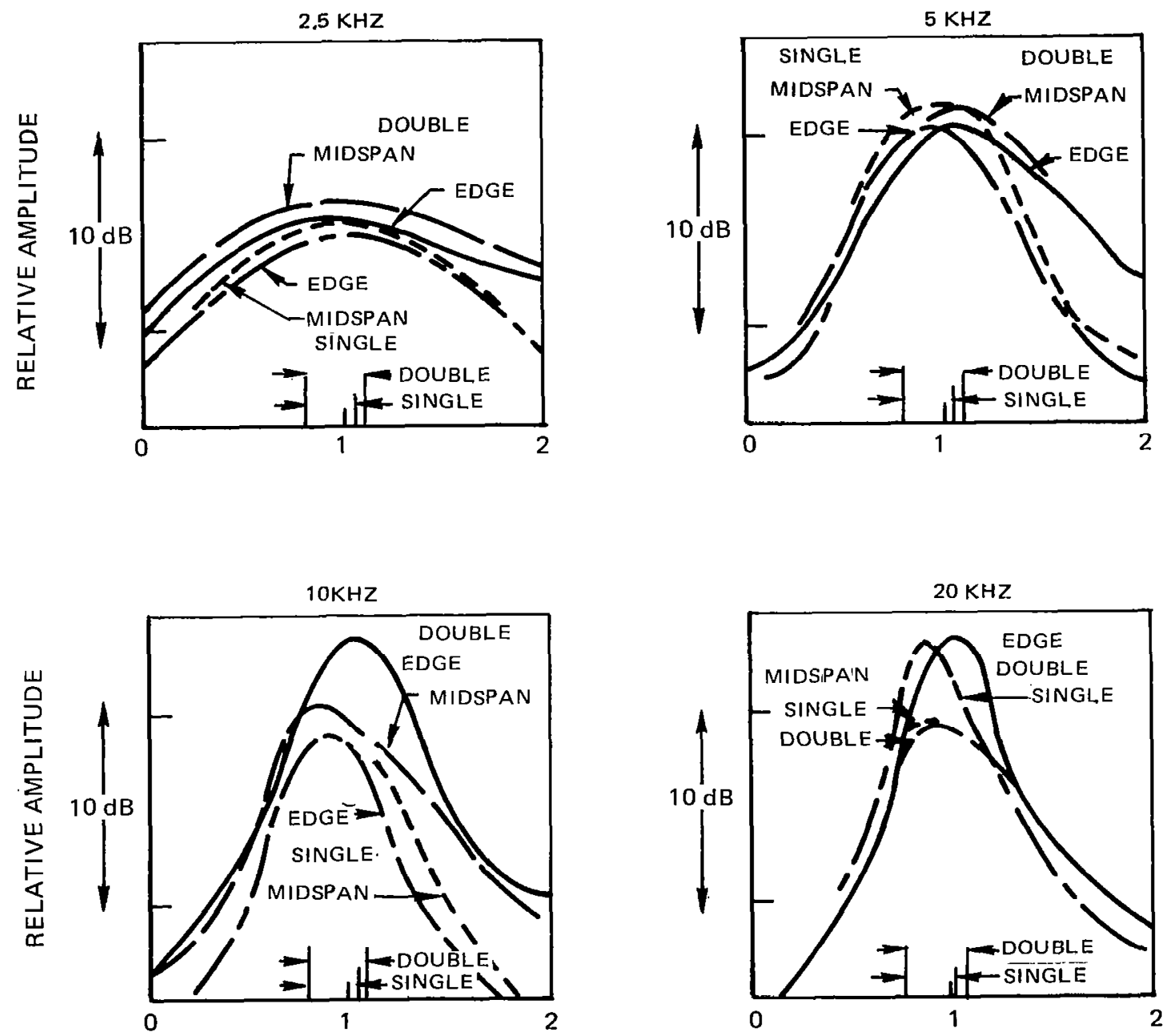

CONVECTION-ADJUSTED DISTANCE FROM LEADING EDGE, CHORDS

Figure 30-Comparison of Noise Source Strength Distributions at Midspan and Side Edge of $40^{\circ}$ Deflection Part-Span Single and Double Slotted Trailing Edge Flaps at $100 \mathrm{M} / \mathrm{Sec}$ Velocity 

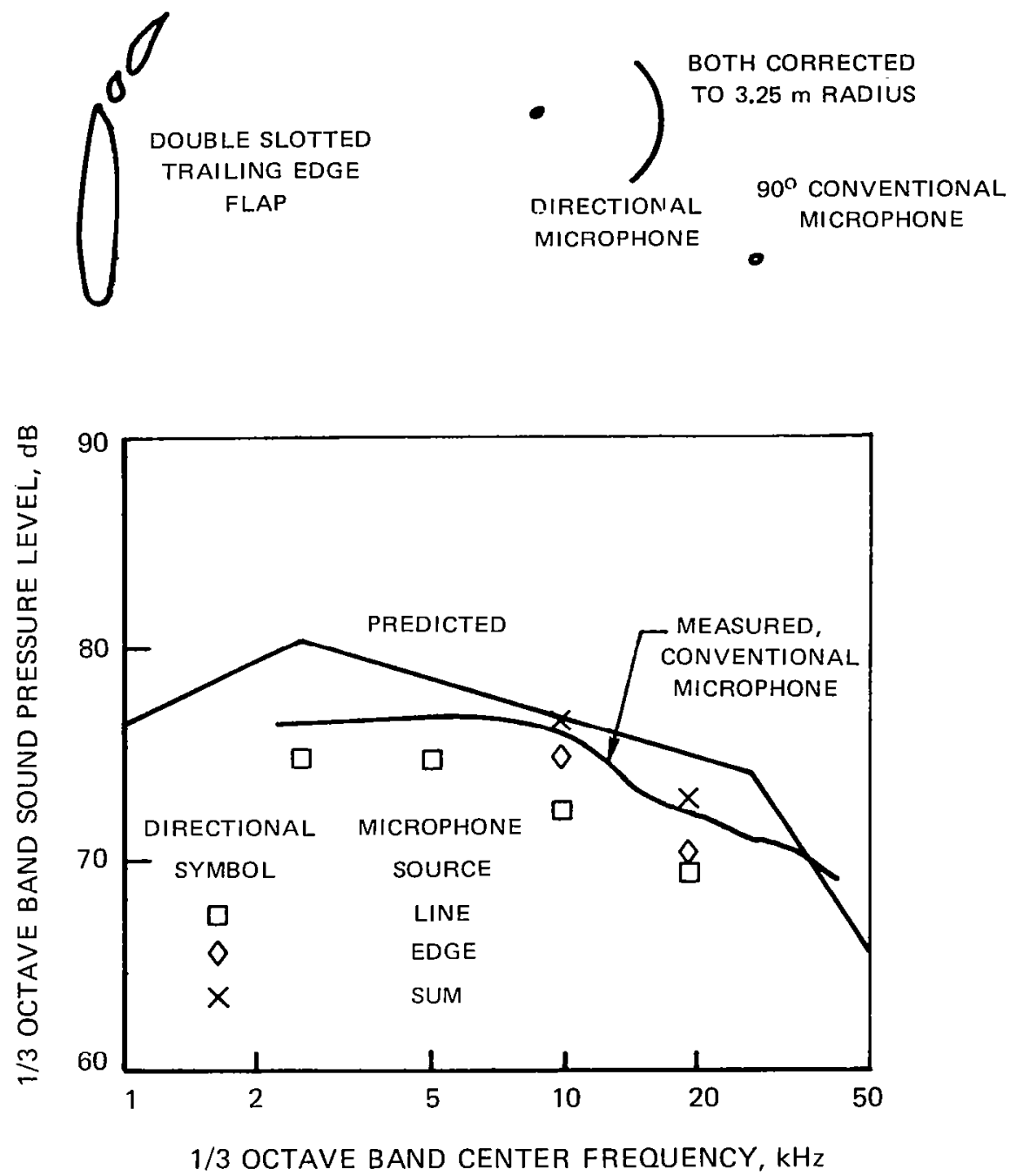

Figure 31-Comparison of 1/3 Octave Band Spectra for Double Slotted Trailing Edge Flap at $90^{\circ}$ Direction and $100 \mathrm{~m} / \mathrm{sec}$ Velocity as Measured with Directional and Conventional Microphones 

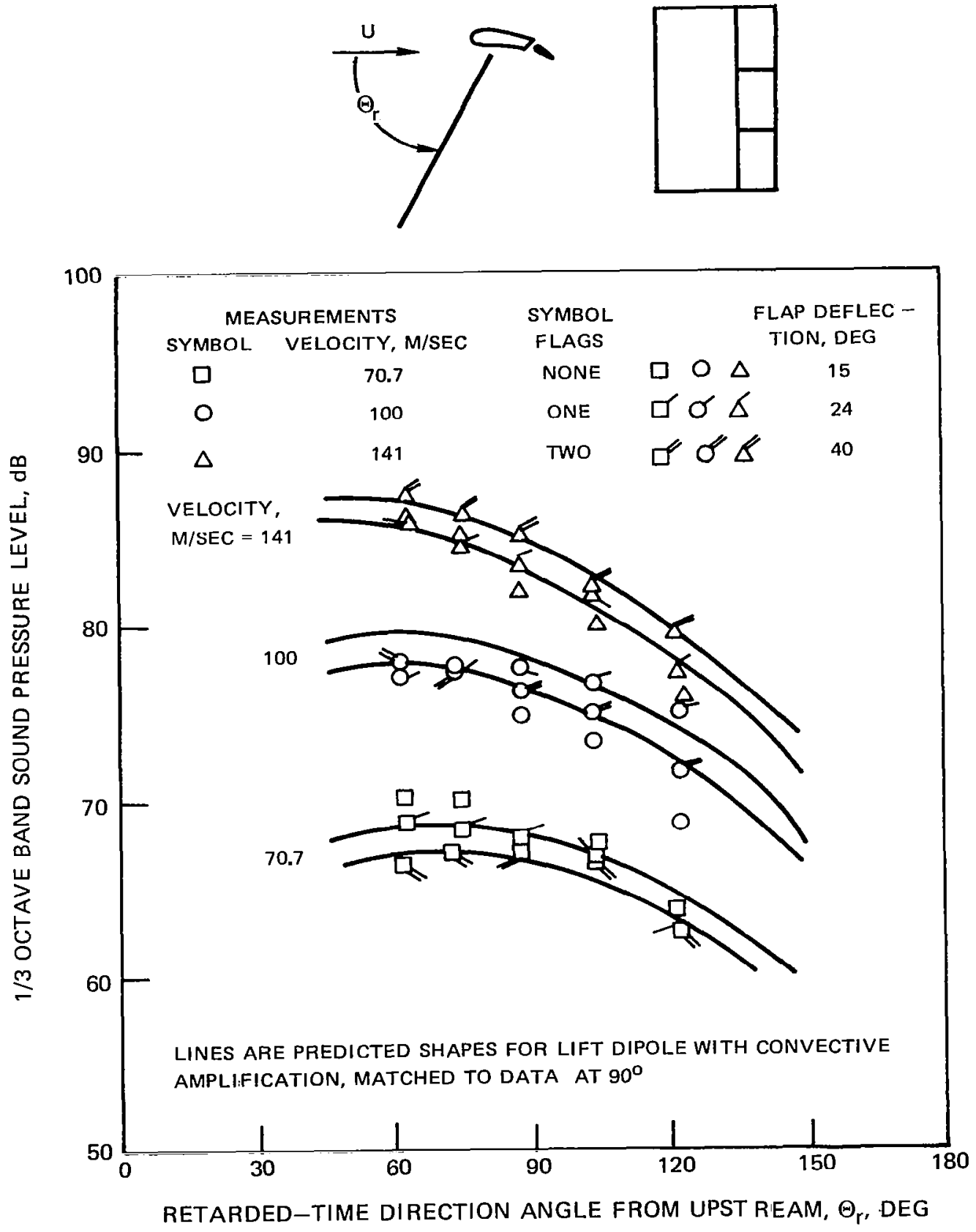

Figure 32 - Effect of Velocity on Full Span Single Slotted Trailing Edge Flap Noise Directivity. Strouhal Number $=5$ Referenced to Flap Chord. 

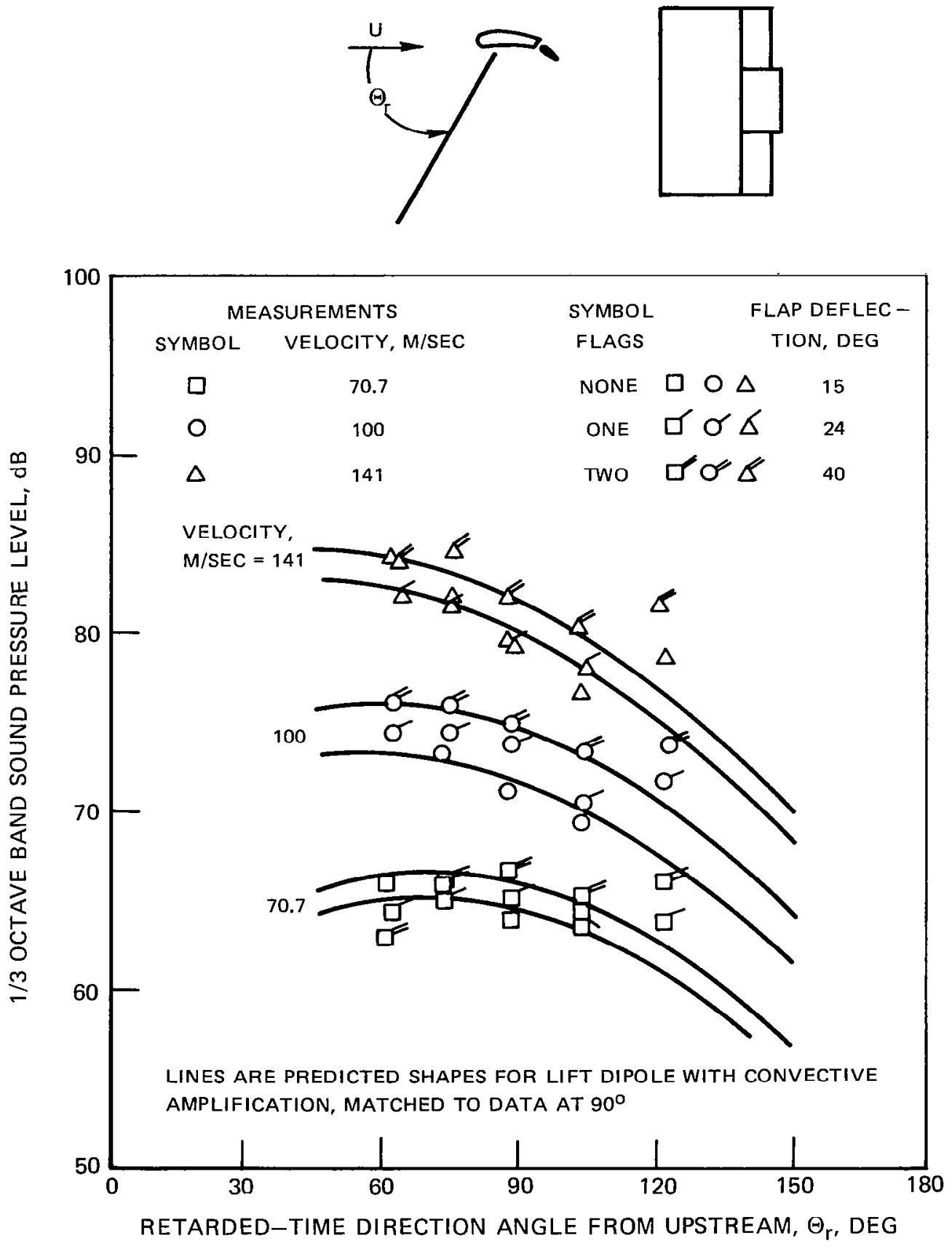

Figure 33 - Effect of Velocity on Part-Span Single Slotted Trailing Edge Flap Noise Directivity. Strouhal Number $=5$ Referenced to Flap Chord. 

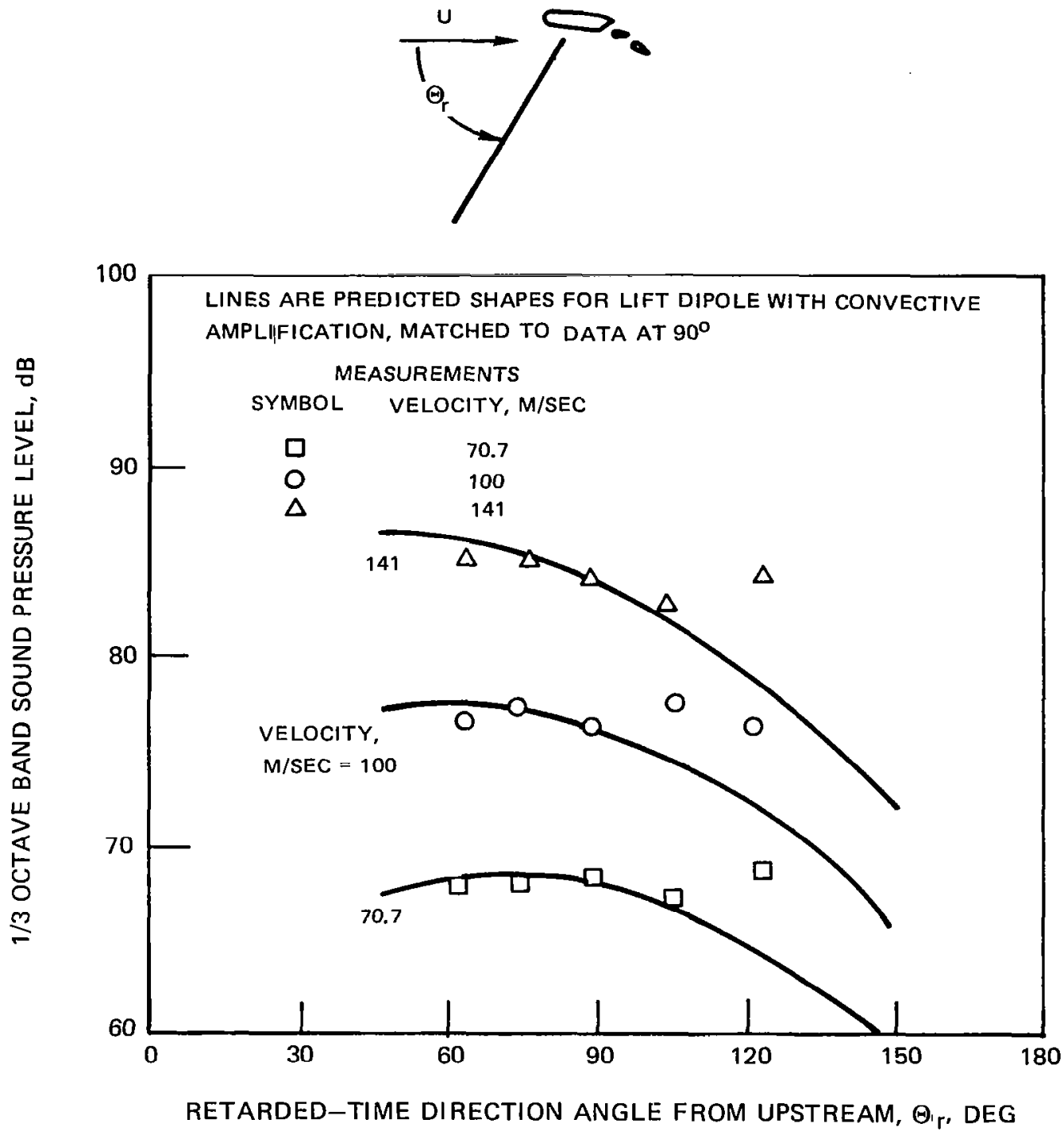

Figure 34 - Effect of Velocity on Part Span Double Slotted Trailing Edge Flap Noise Directivity. Strouhal Number $=8$ Referenced to Total Flap Chord. 


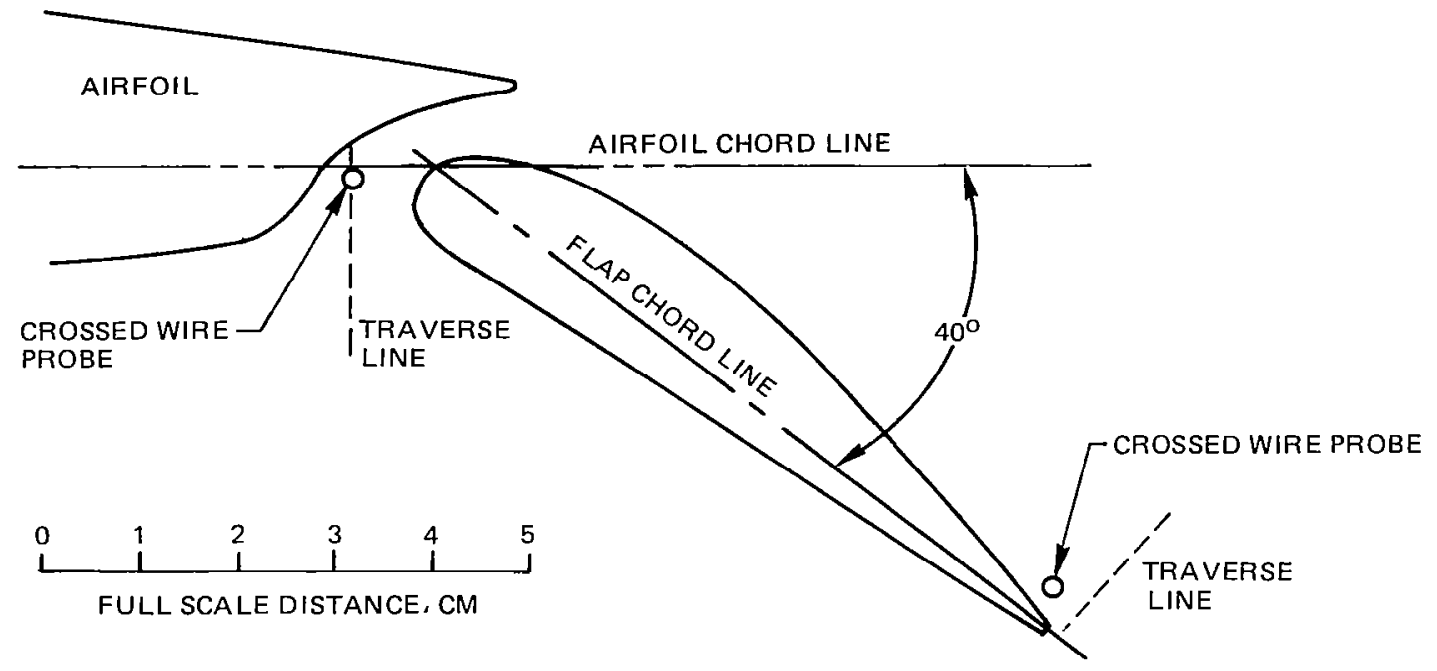

SINGLE SLOTTED TRAILING EDGE FLAP

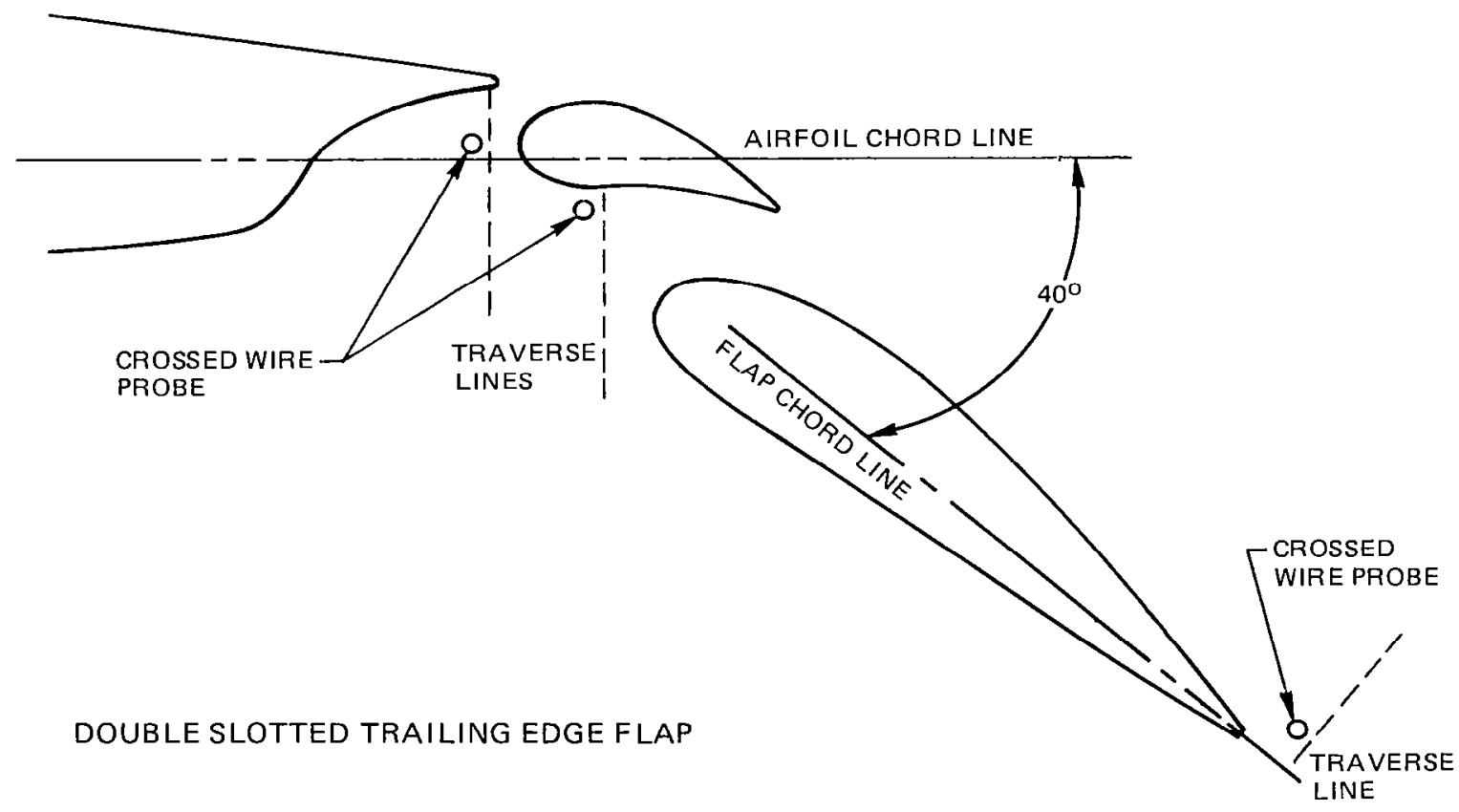

Figure 35- Locations of Single-Wire Hot Wire Traverses and Crossed-Wire Hot Wire Measurements for $40^{\circ}$ Deflection Single and Double Slotted Trailing Edge Flaps 

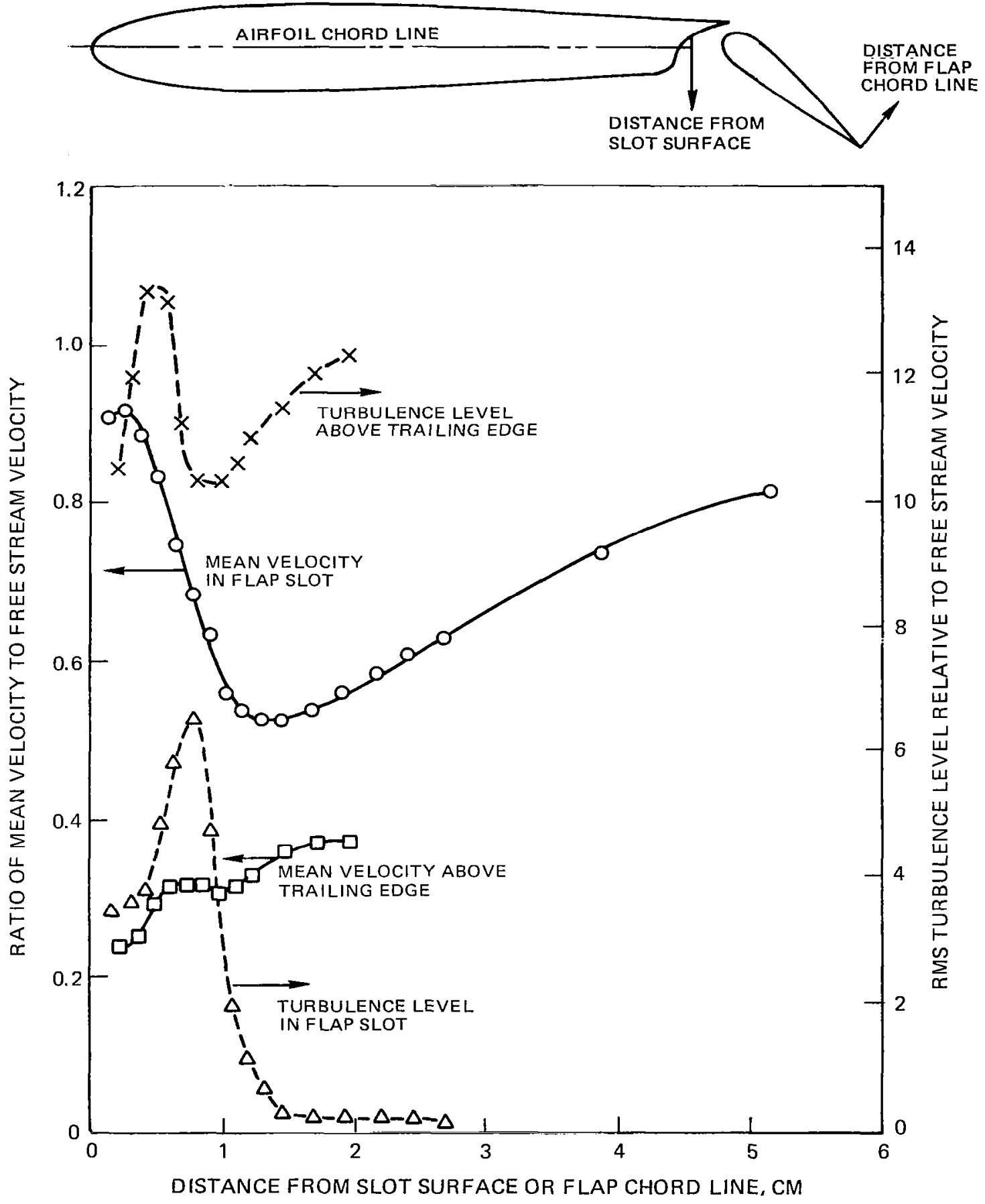

Figure 36 - Results of Single-Wire Hot Wire Traverses Near 400 Deflection Single Slotted Trailing Edge 

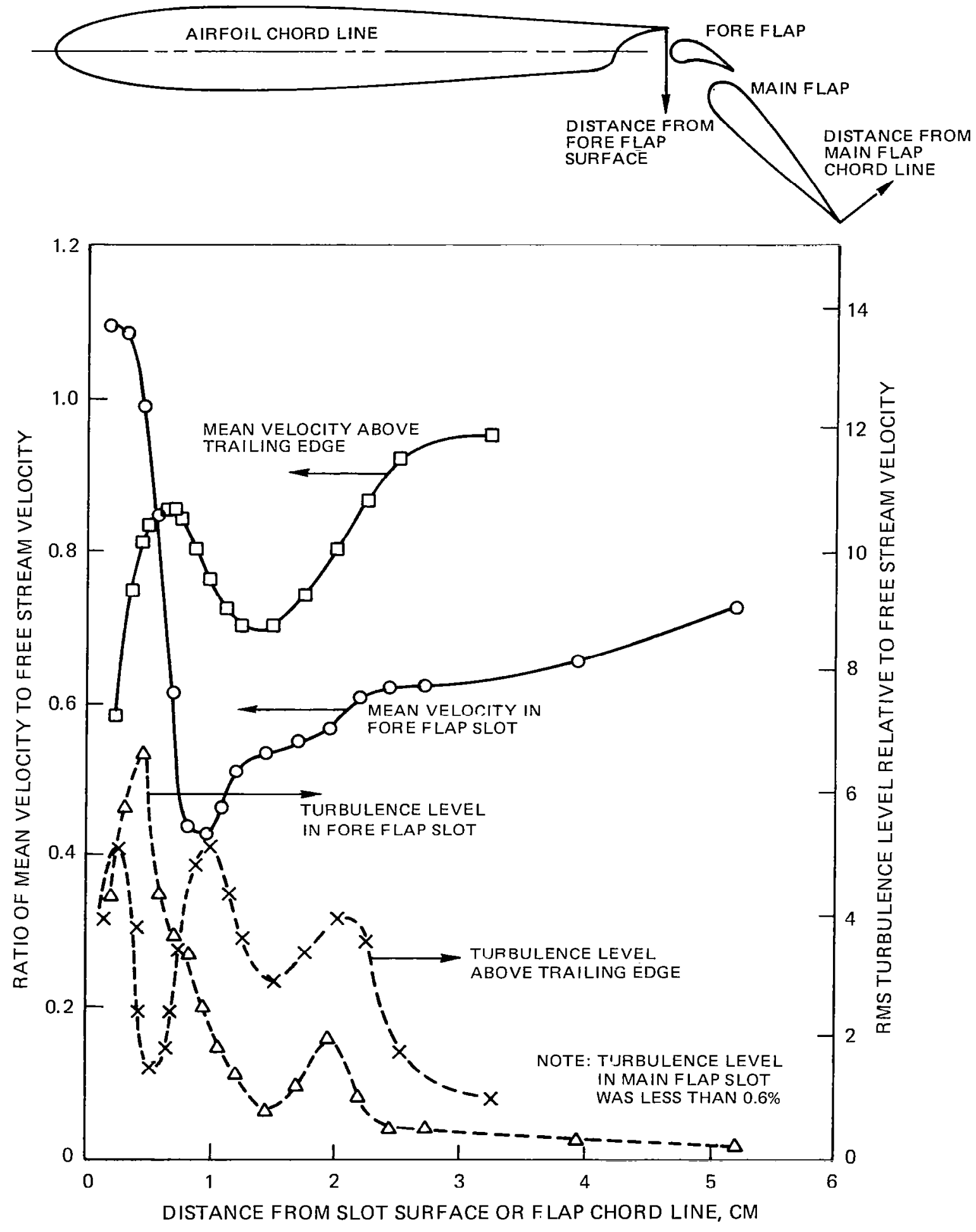

Figure 37 - Results of Single-Wire Hot Wire Traverses Near 400 Deflection Double Slotted Trailing Edge Flap 


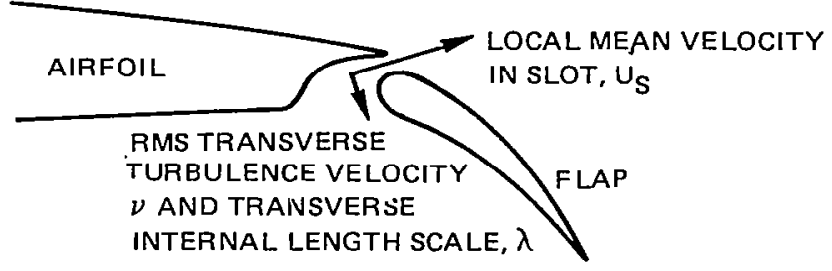

FREE STREAM

VELOCITY, $U=70.7 \mathrm{~m} / \mathrm{sec}$

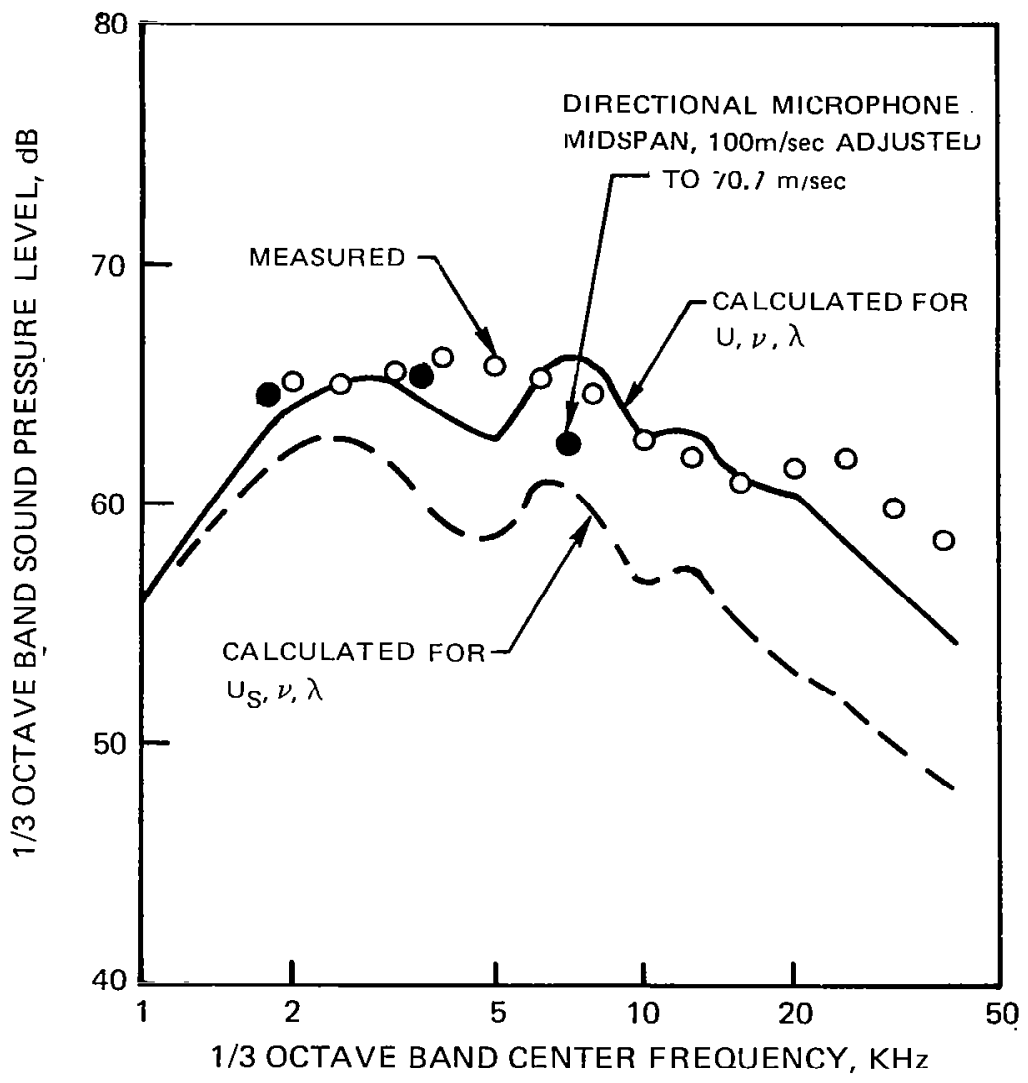

Figure 38-Comparison of Measured Trailing Edge Flap Noise Spectrum with Spectra Calculated for an Isolated Airfoil in Uniform Turbulent Flow. $40^{\circ}$ Detlection Part-Span Single Slotted Flap, $90^{\circ}$ Microphone Position, Transverse Velocity Fluctuations and Integral Scale Length Taken Equal to Values Measured in Flap Slot 

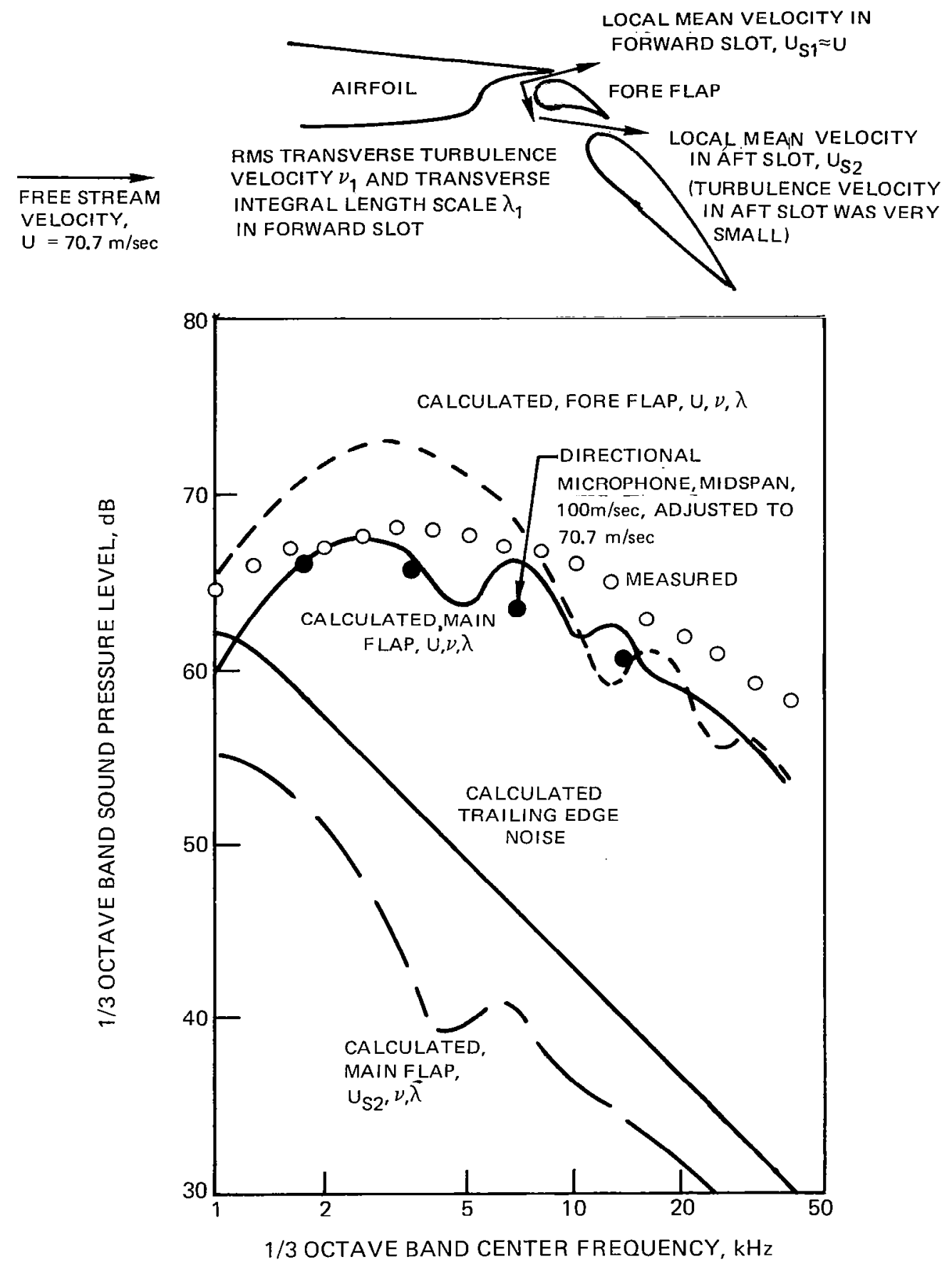

Figure 39 -Comparison of Measured Double Slotted Trailing Edge Flap Noise Spectrum at $90^{\circ}$ Microphone with Those Calculated by Regarding the Fore Flap and Main Flap as Isolated Airfoils in Uniform Turbulent Flow 

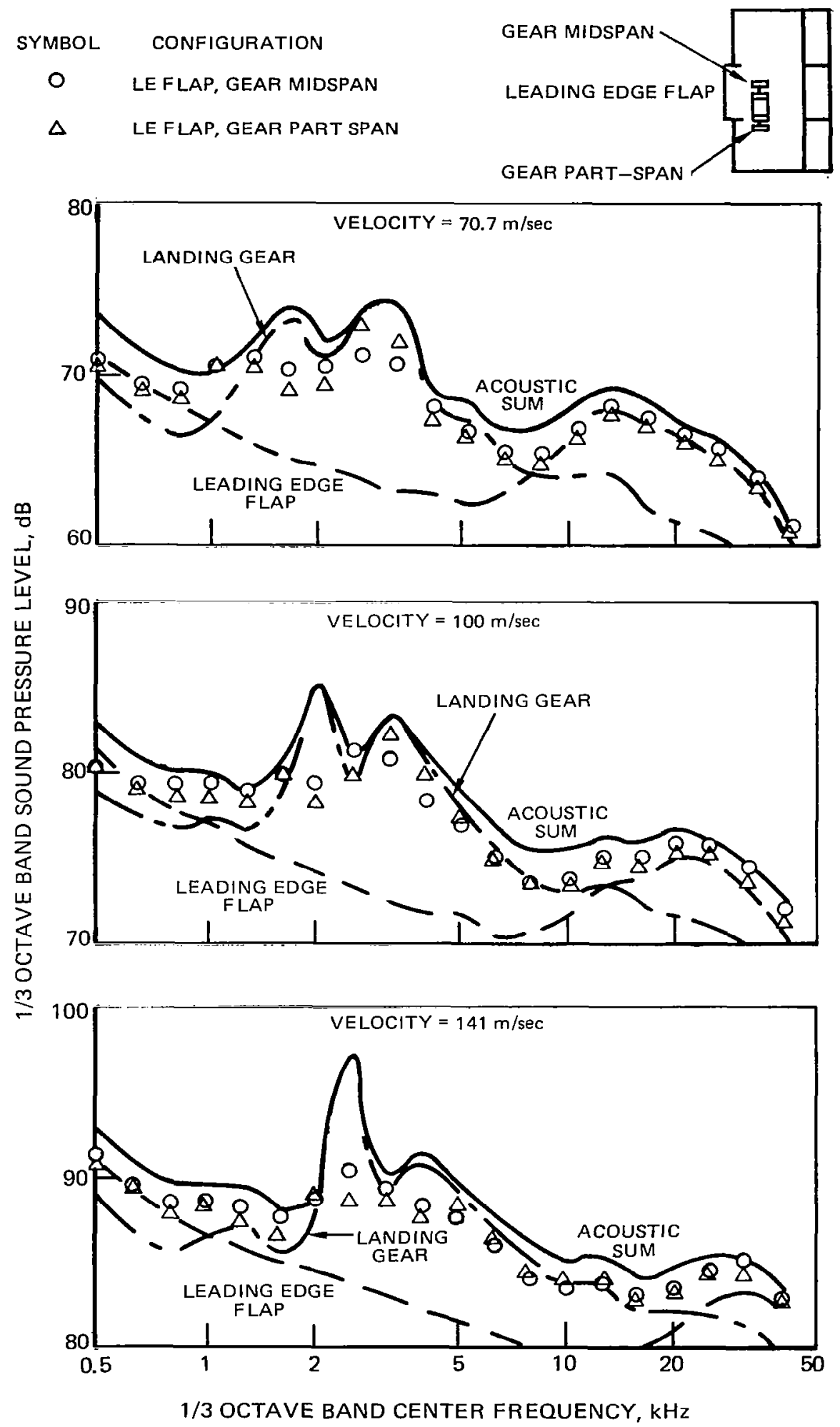

Figure 40 - Comparison of Spectra Measured with Leading Edge Flap, Landing Gear Combinations and Sum of Spectra Measured with Individual Components. $90^{\circ}$ Microphone Position, Unshielded from Collector 


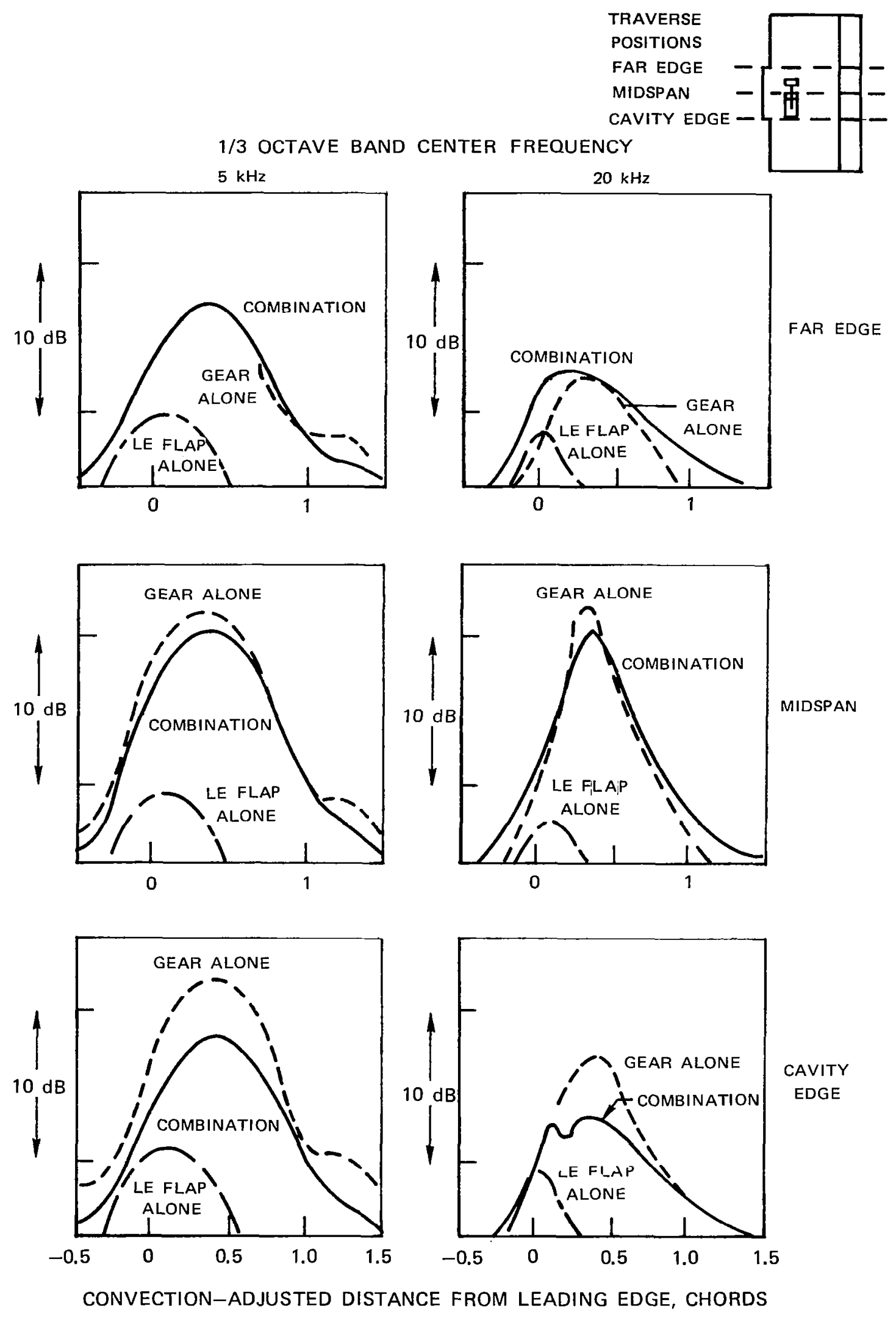

98 Figure 41-Comparison of Noise Source Strength Distributions for Leading Edge Flap, Landing Gear Midspan Combination with those of Components Alone 


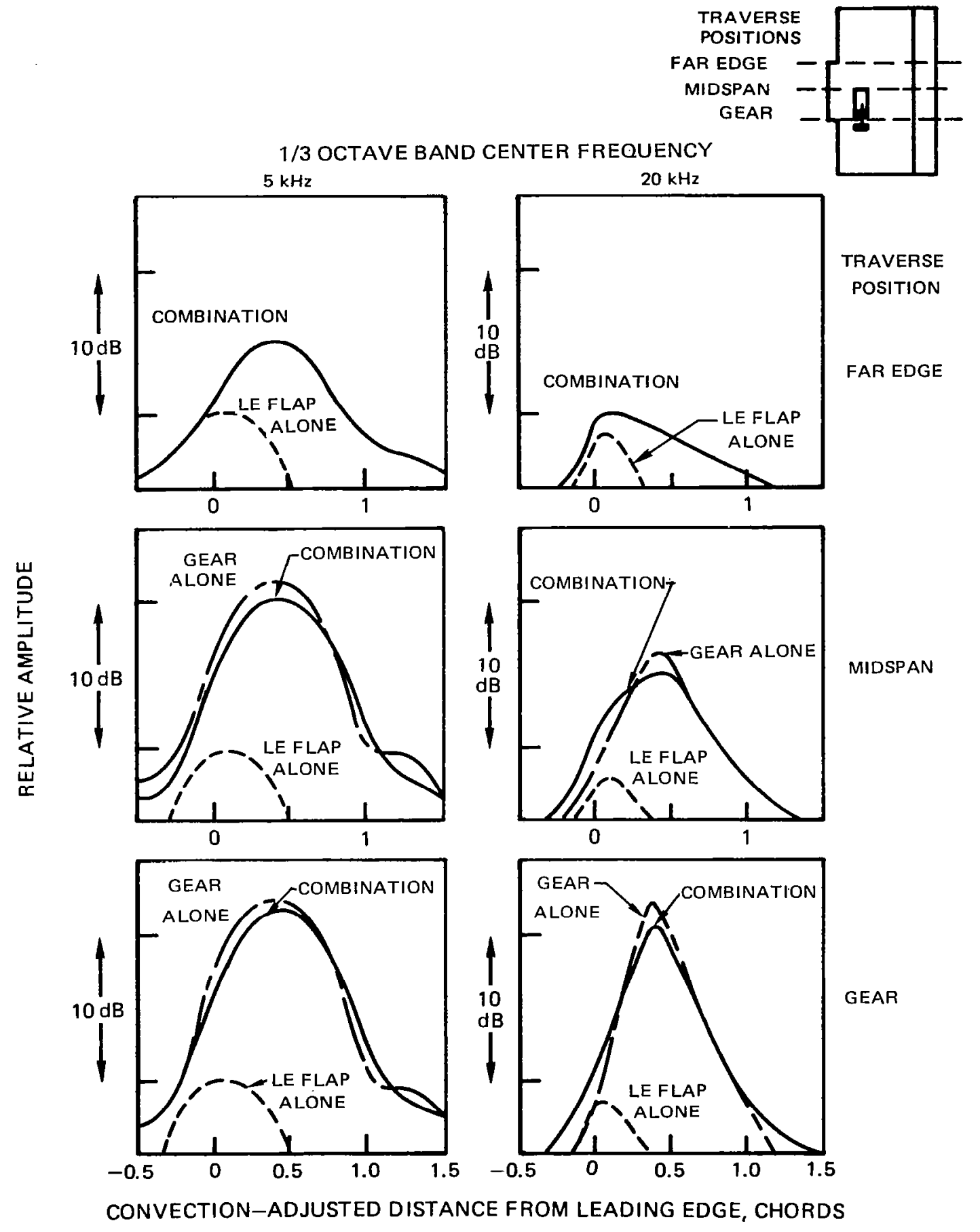

Figure 42 -Comparison of Noise Source Strength Distributions for Leading Edge Flap, Landing Gear Part-Span Combination with those of Components Alone 
SYMBOL CONFIGURATION

O LE SLAT, GEAR MIDSPAN

$\triangle$ LE SLAT, GEAR PART-SPAN
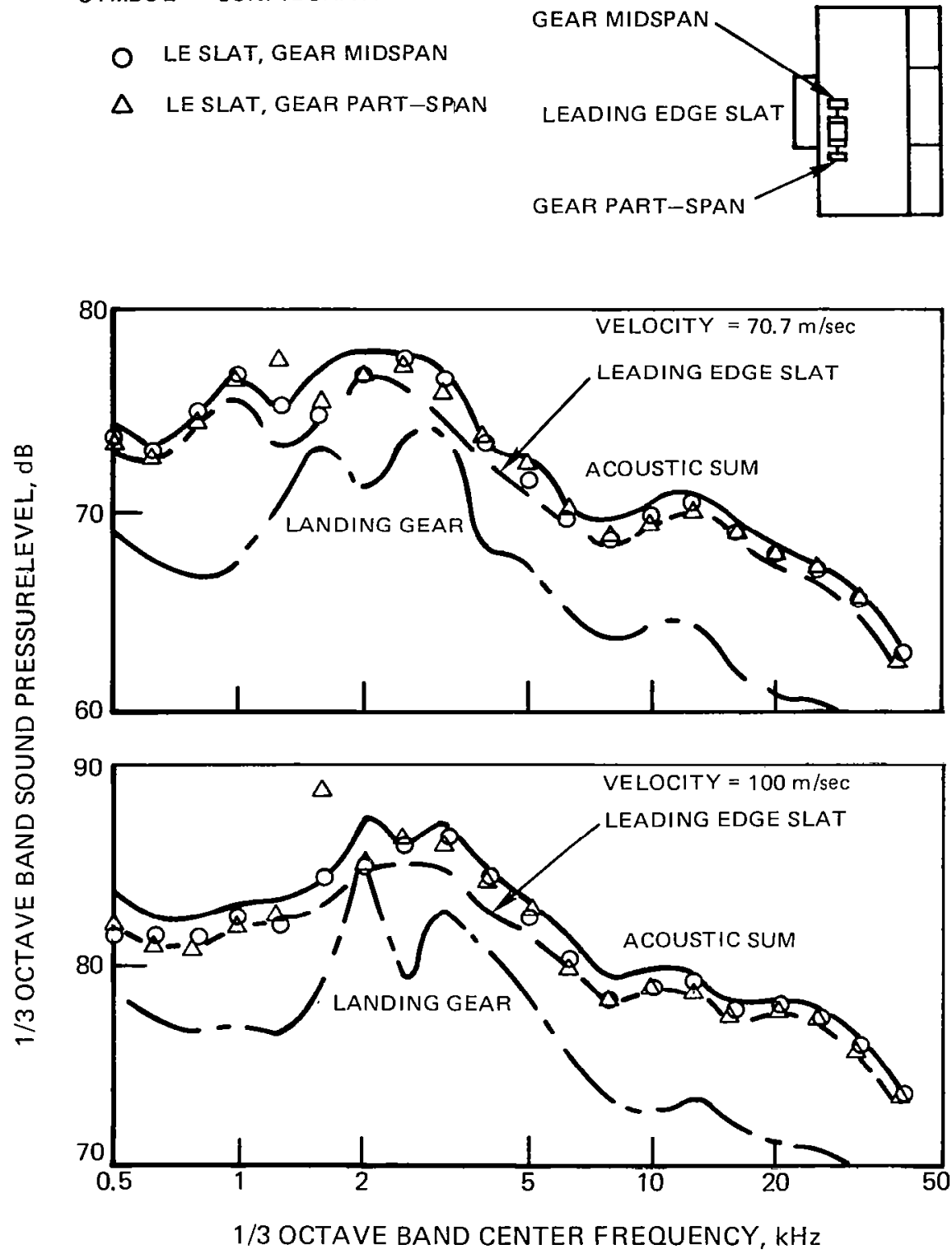

Figure 43 -Comparison of Spectra Measured with Leading Edge Slat, Landing Gear Combinations and Sum of Spectra Measured with Individual Components. $90^{\circ}$ Microphone, Collector Shielded for Combination and for Slat Alone but Unshielded for Landing Gear 


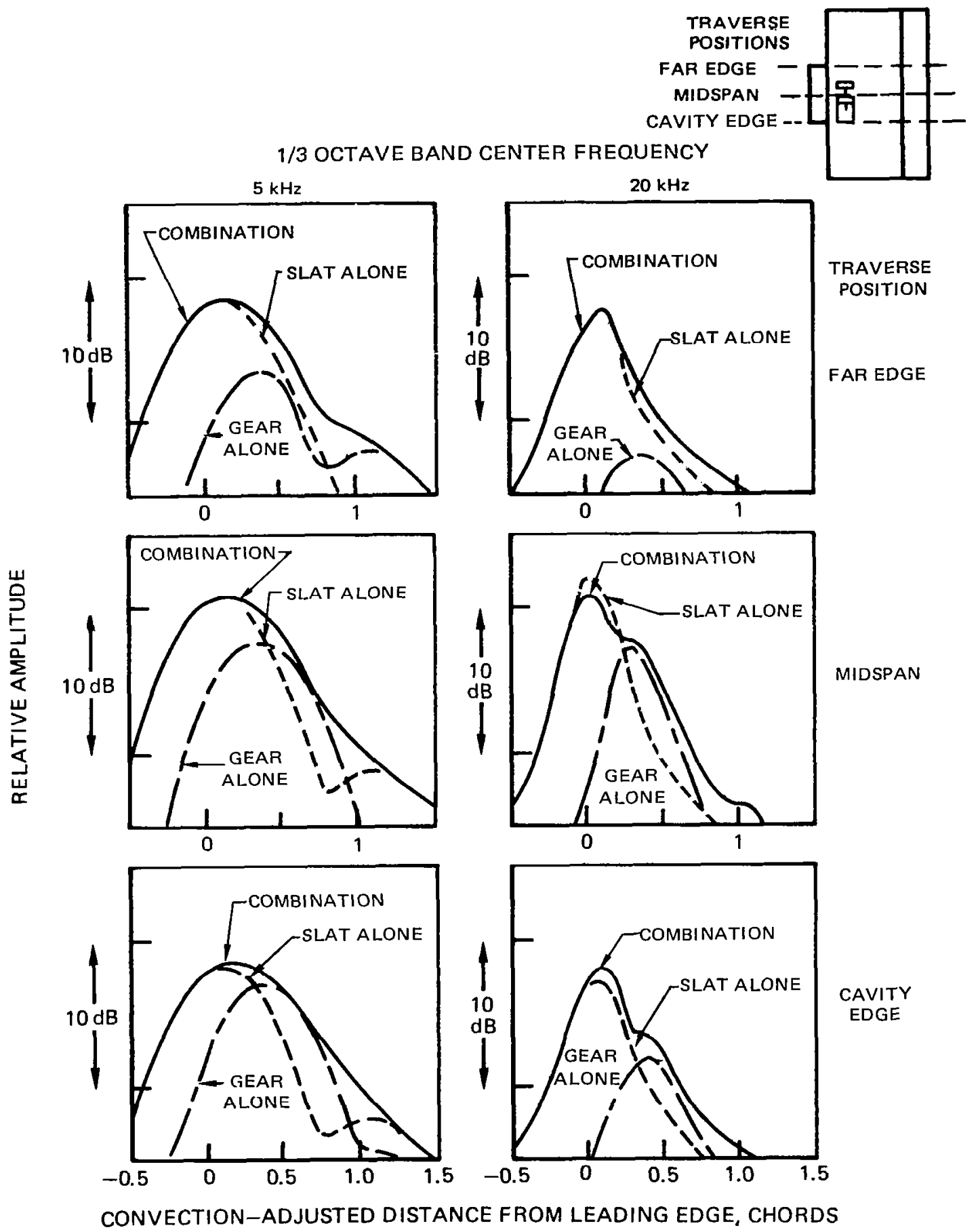

Figure 44 - Comparison of Noise Source Strength Distributions for Leading Edge Slat, Landing Gear Midspan Combination with those of Components Alone. 


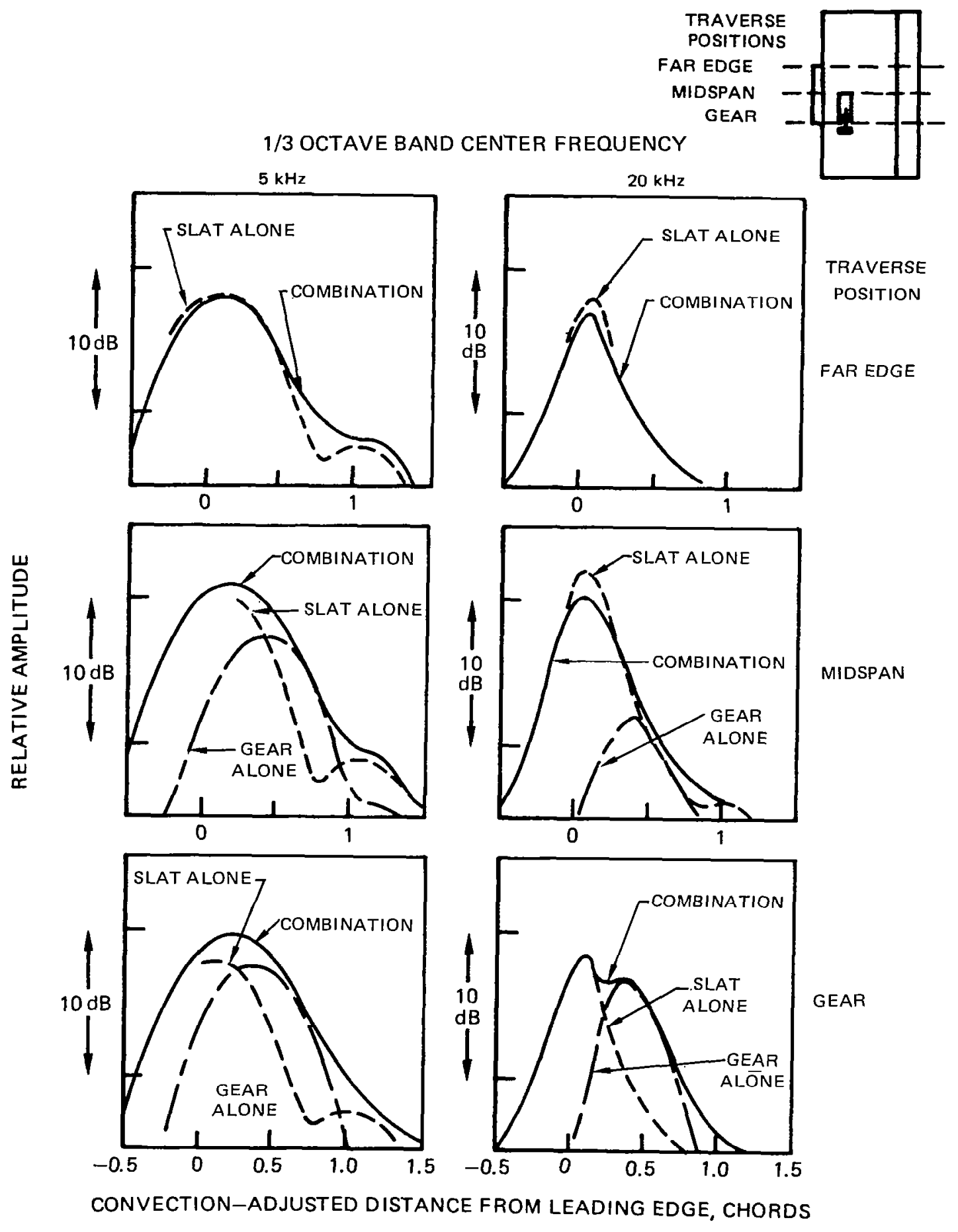

Figure 45 - Comparison of Noise Source Strength Distributions for Leading Edge Slat, Landing Gear Part-Span Combination with those of Components Alone 

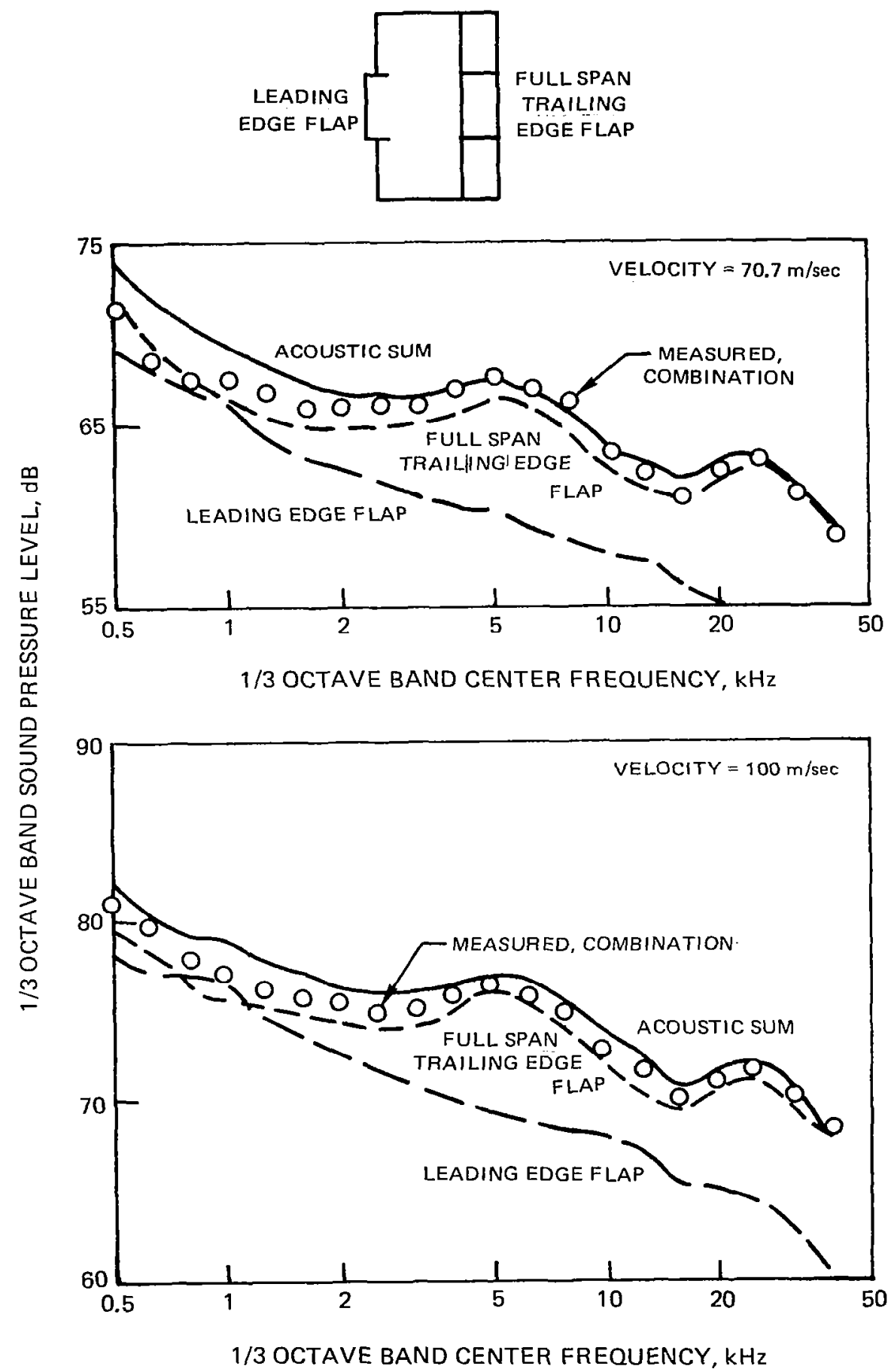

Figure 46 - Comparison of Spectra Measured with Leading Edge Flap, Full Span Trailing Edge Flap Combination and Sum of Spectra Measured with Individual Components. 900 Microphone Position, Shielded from Collector. 


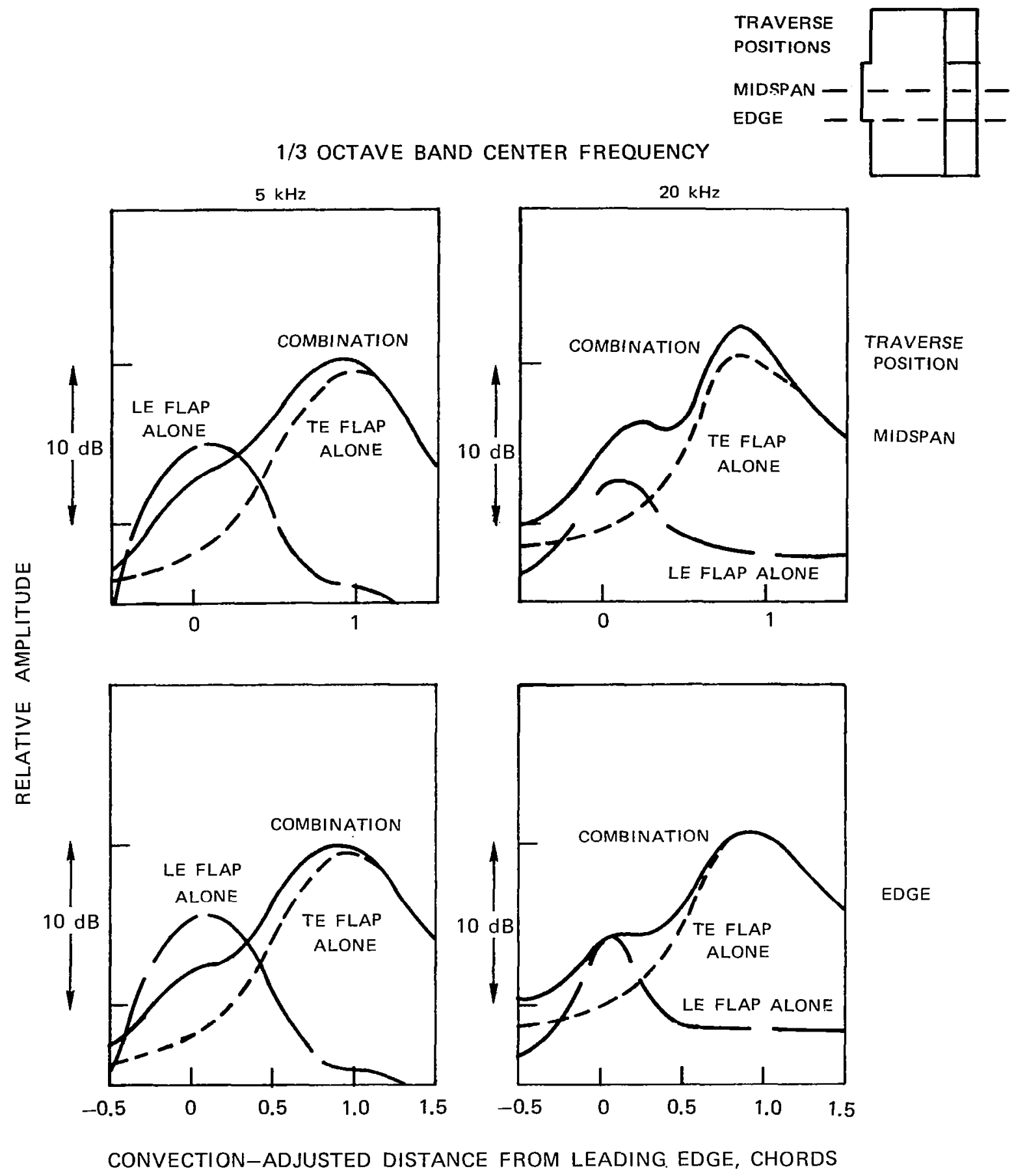

Figure 47-Comparison of Noise Source Strength Distribution for Leading Edge Flap, Full 104 Span Trailing Edge Flap Combination with those of Components Alone 


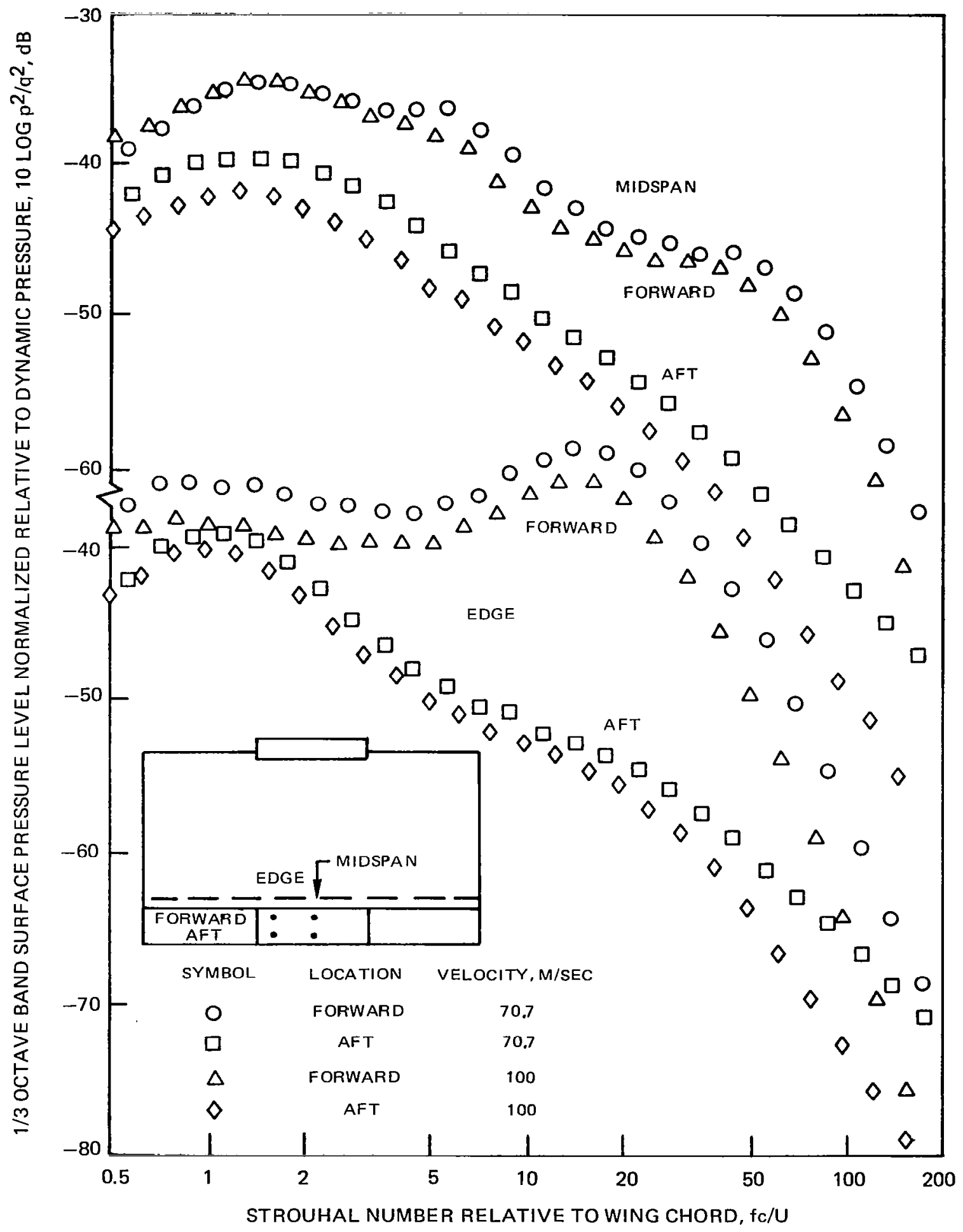

Figure 48-Normalized Surface Pressure Spectra on Upper Surface of Full Span $40^{\circ}$ Deflection Single Slotted Flap with Part Span Leading Edge Flap 


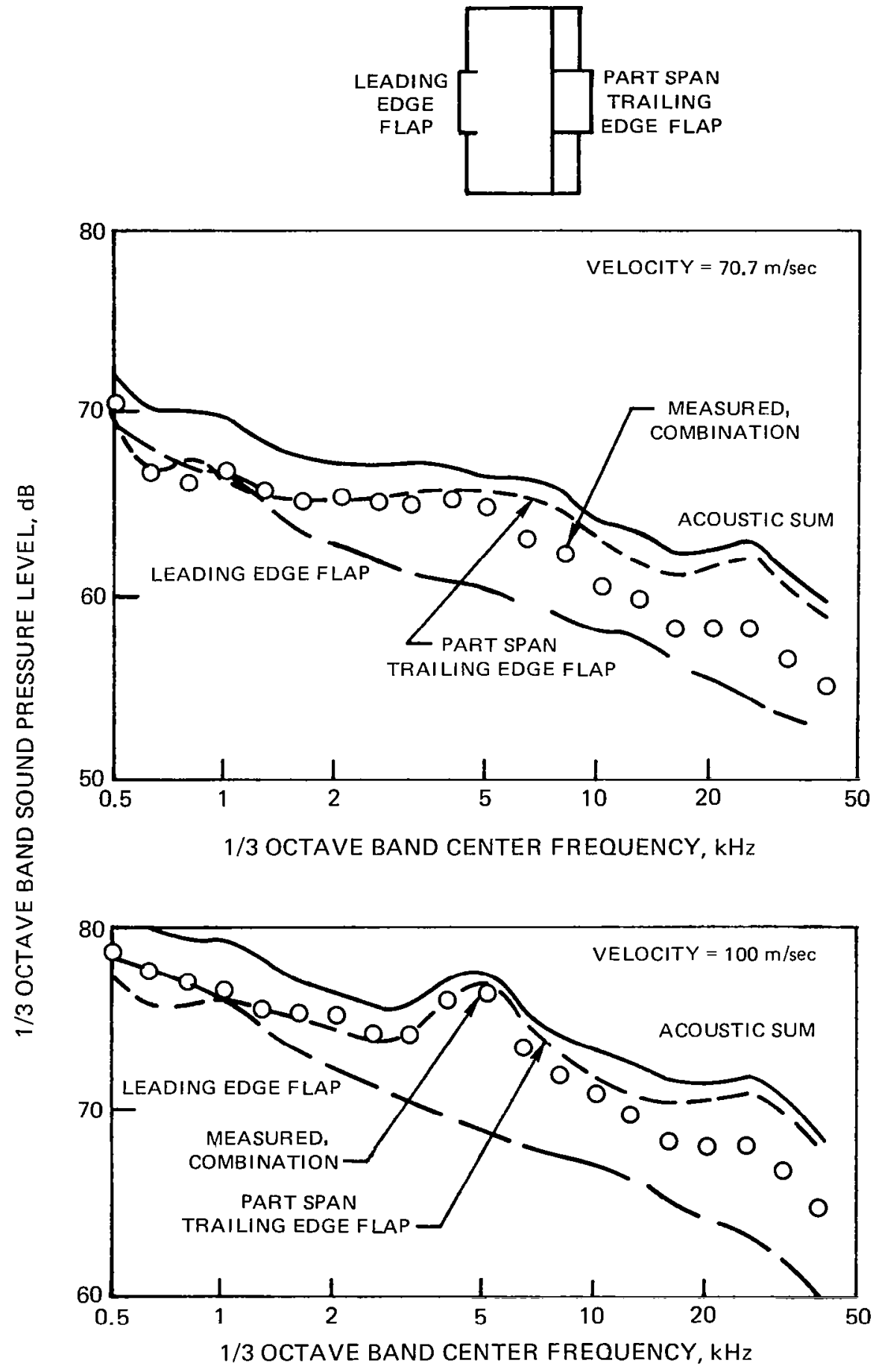

Figure 49 - Comparison of Spectra Measured with Leading Edge Flap, Part Span Trailing Edge Flap Combination and Sum of Spectra Measured with Individual Components. $90^{\circ}$ Microphone Position, Shielded from Collector 
1/3 OCTAVE BAND CENTER FREQUENCY
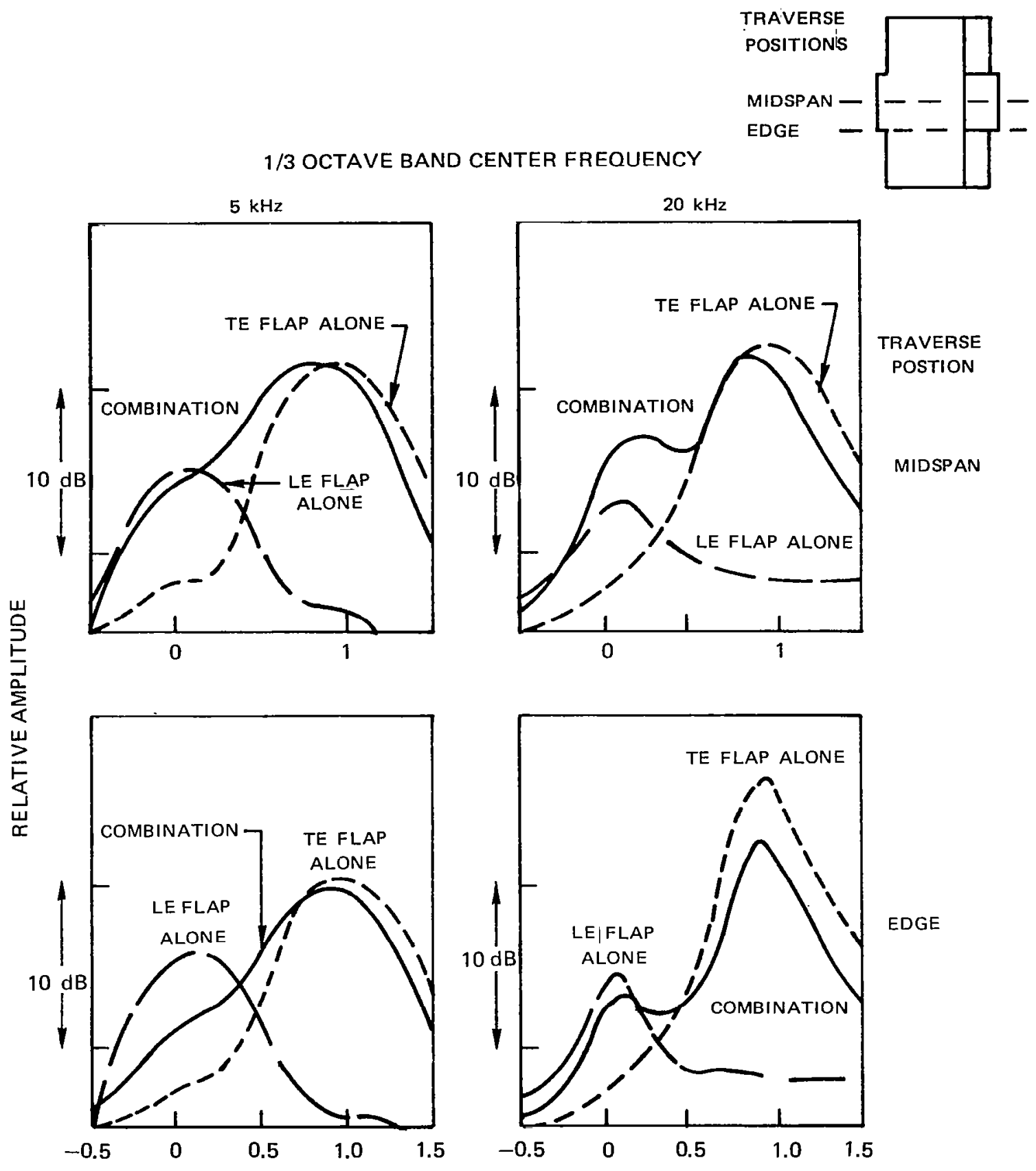

CONVECTION-ADJUSTED DISTANCE FROM LEADING EDGE, CHORDS

Figure 50-Comparison of Noise Source Strength Distribution for Leading Edge Flap, Part Span Trailing Edge Flap Combination with those of Components Alone 
TRAVERSE POSITION
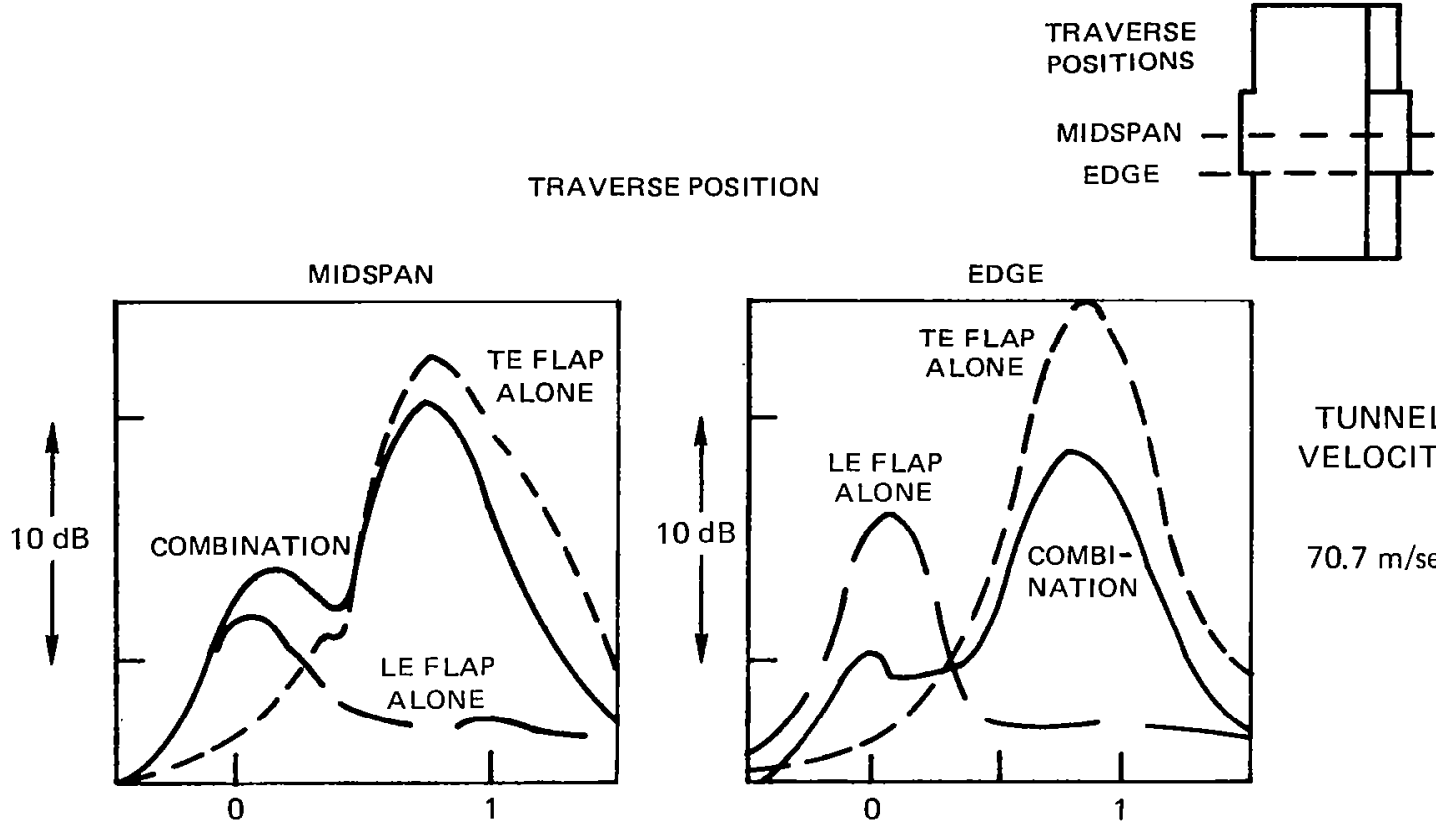

TUNNEL

VELOCITY

$70.7 \mathrm{~m} / \mathrm{sec}$
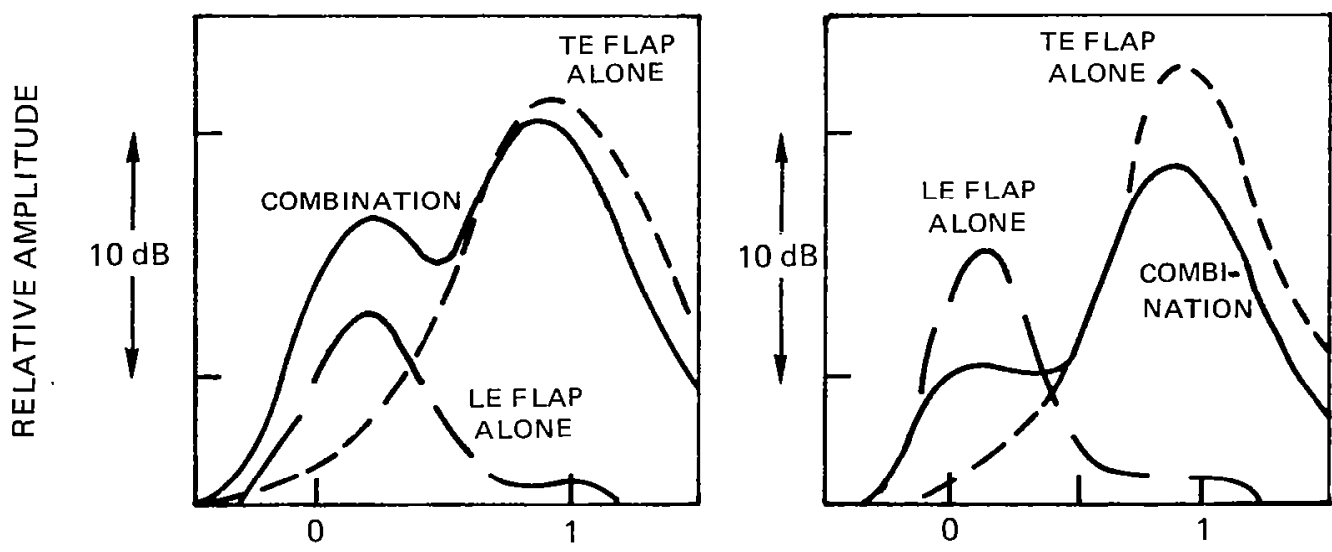

$100 \mathrm{~m} / \mathrm{sec}$
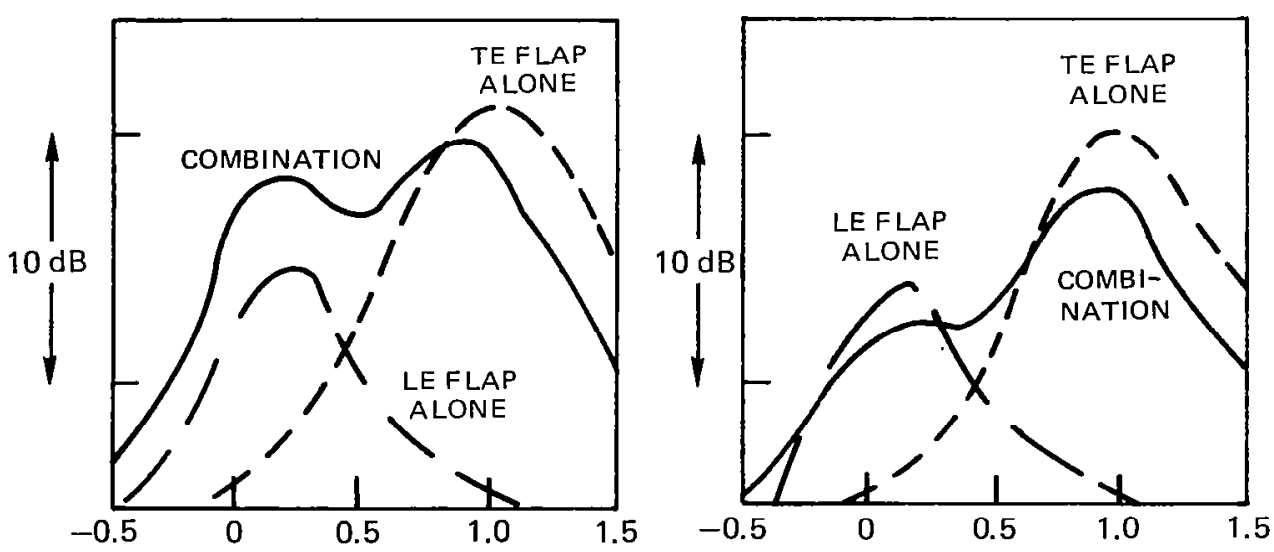

$141 \mathrm{~m} / \mathrm{sec}$

CONVECTION-ADJUSTED DISTANCE FROM LEADING EDGE, CHORDS

Figure 51 - Comparison of Noise Source Strength Distributions at $10 \mathrm{kHz}$ Center Frequency for Leading Edge Flap, Part Span Trailing Edge Flap Combination with those of 


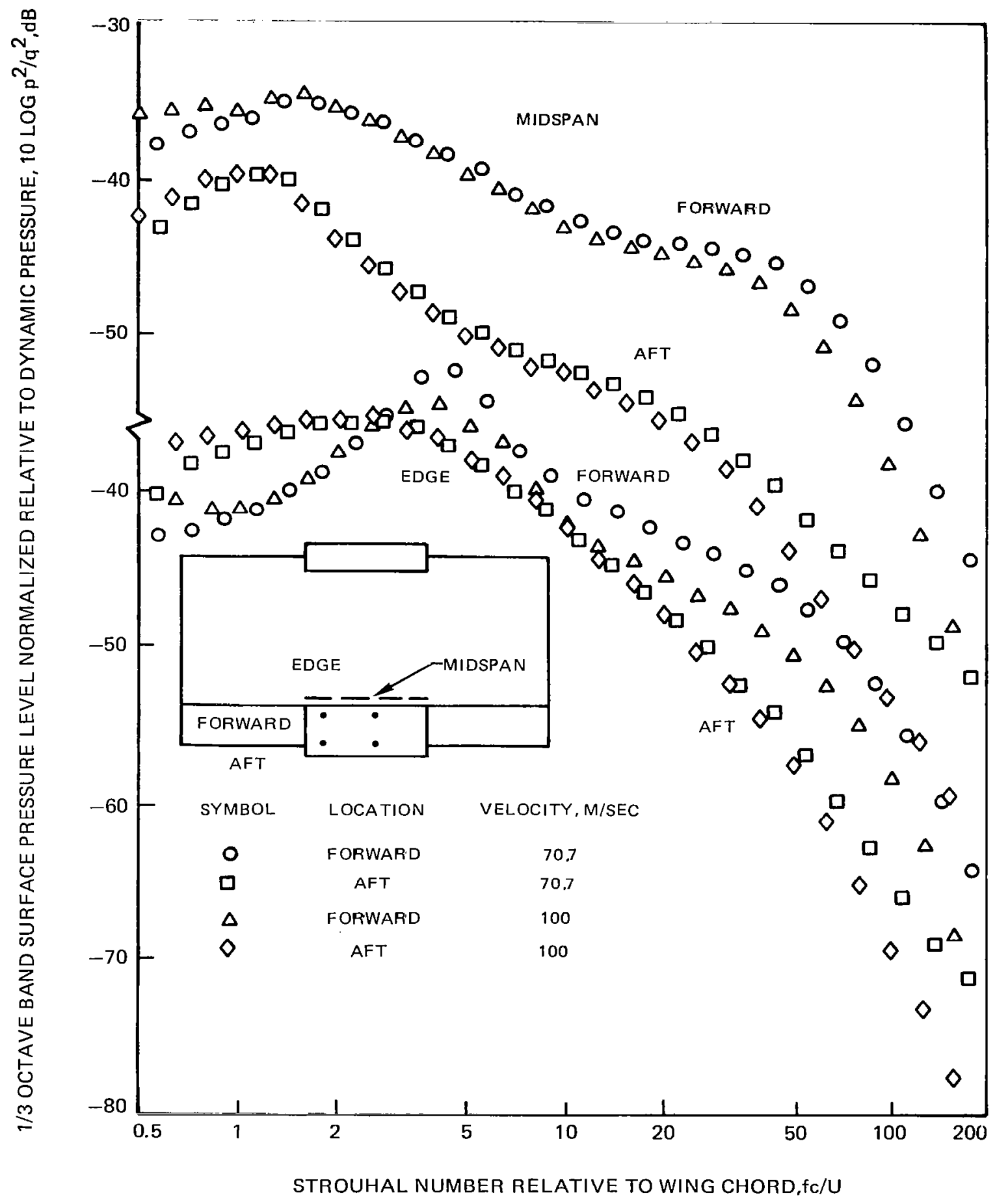

Figure 52 -Normalized Surface Pressure Spectra on Upper Surface of Part Span $40^{\circ}$ Deflection Single Slotted Flap with Leading Edge Flap 

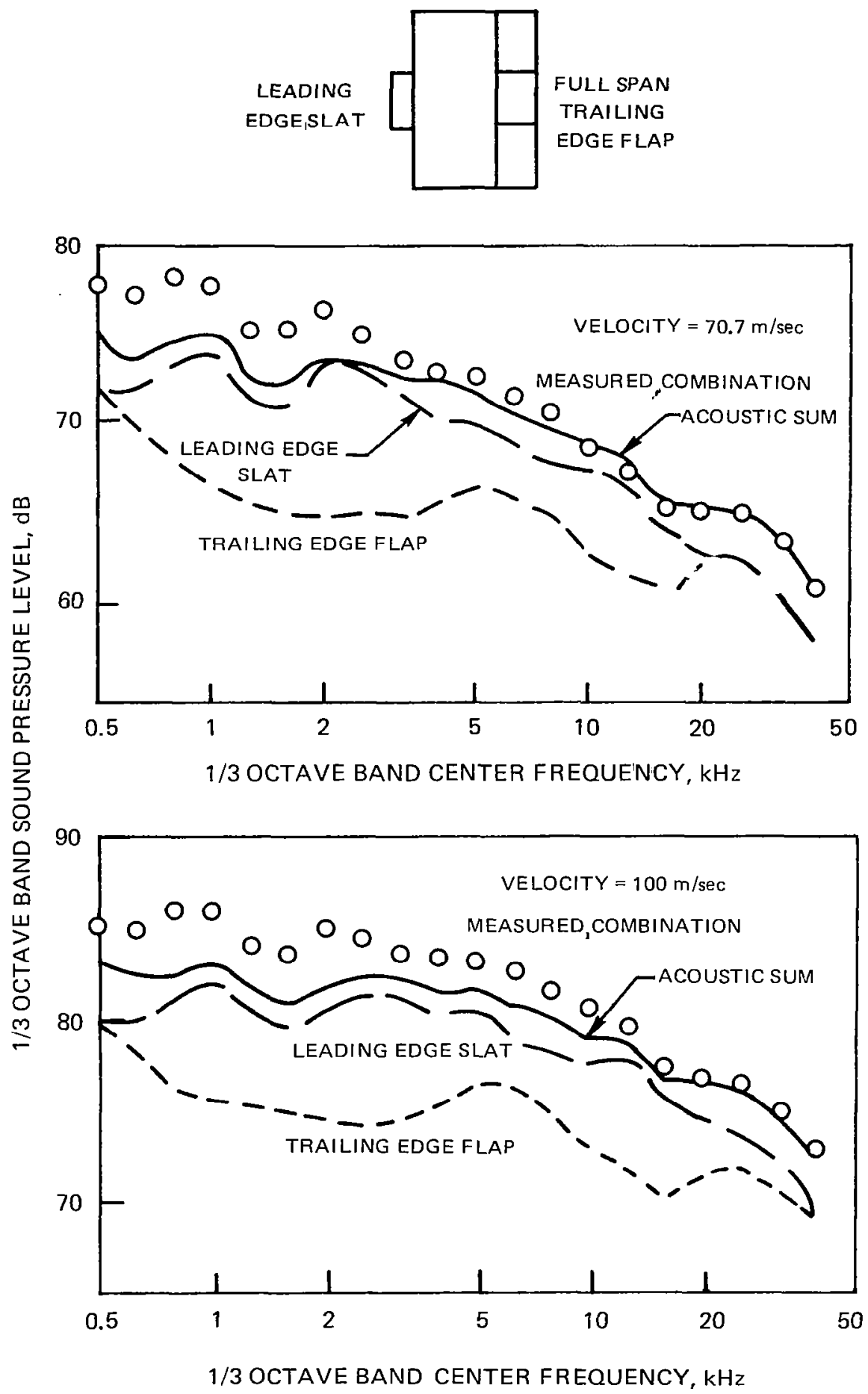

Figure 53 -Comparison of Spectra Measured with Leading Edge Slat, Full Span Trailing Edge Flap Combination and Sum of Spectra Measured with Individual Components, $90^{\circ}$ Microphune Position Shielded from Collector 


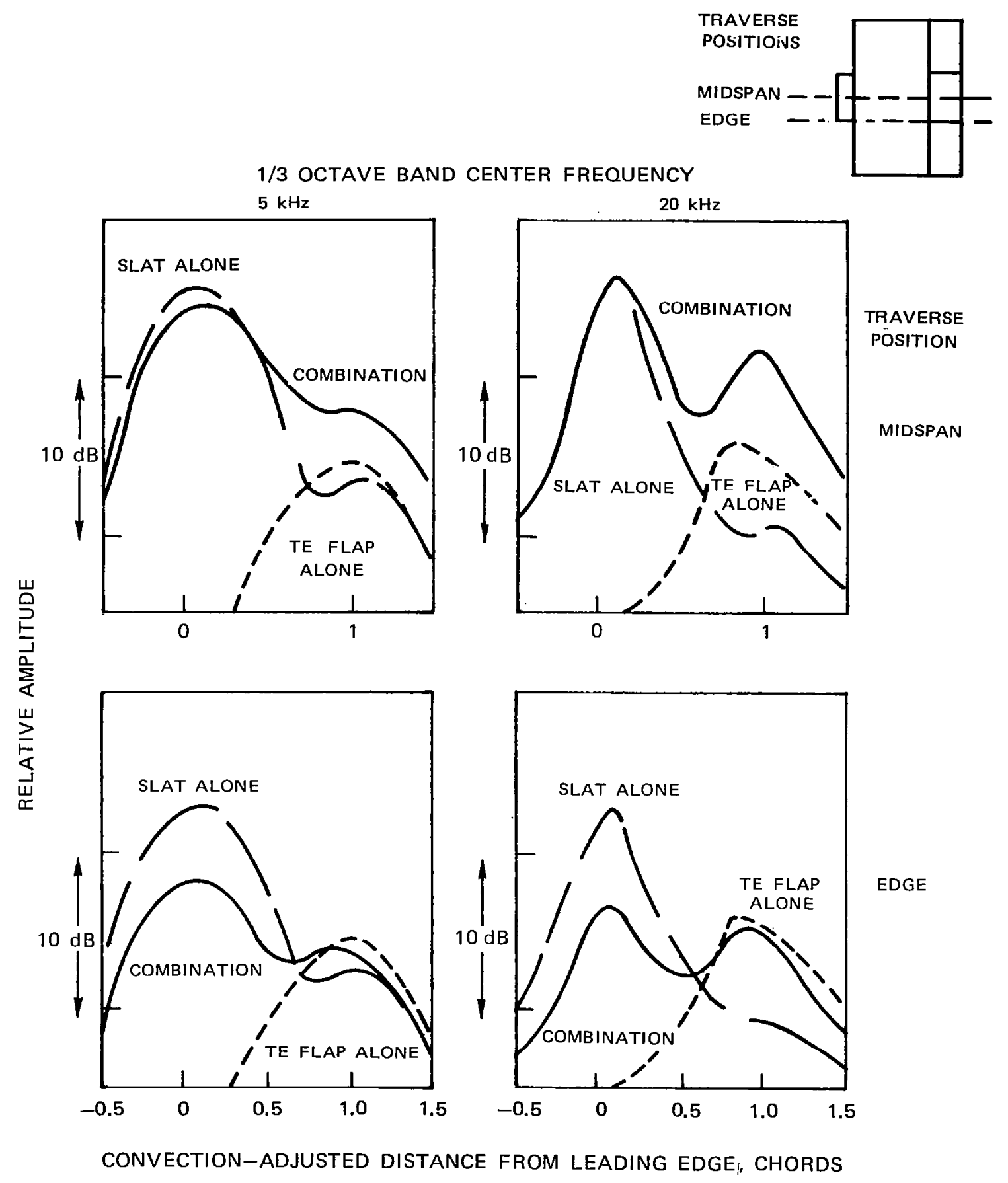

Figure 54 -Comparison of Noise Source Strength Distribution for Leading Edge Slat, Full Span Trailing Edge,Flap Combination with those of Components Alone 


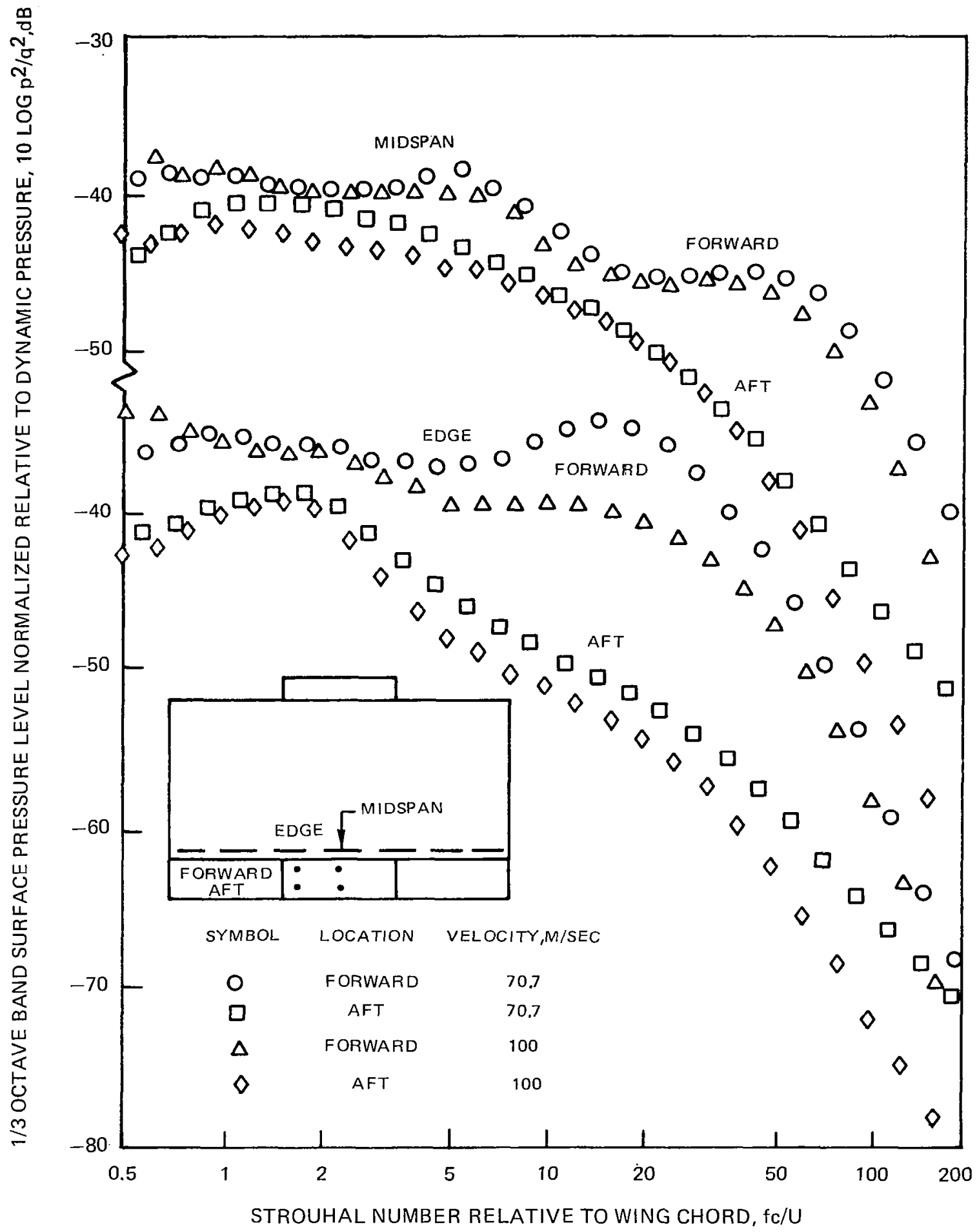

Figure 55-Normalized Surface Pressure Spectra on Upper Surface of Full Span $40^{\circ}$ Deflection Single Slotted Flap with Part Span Leading Edge Slat 

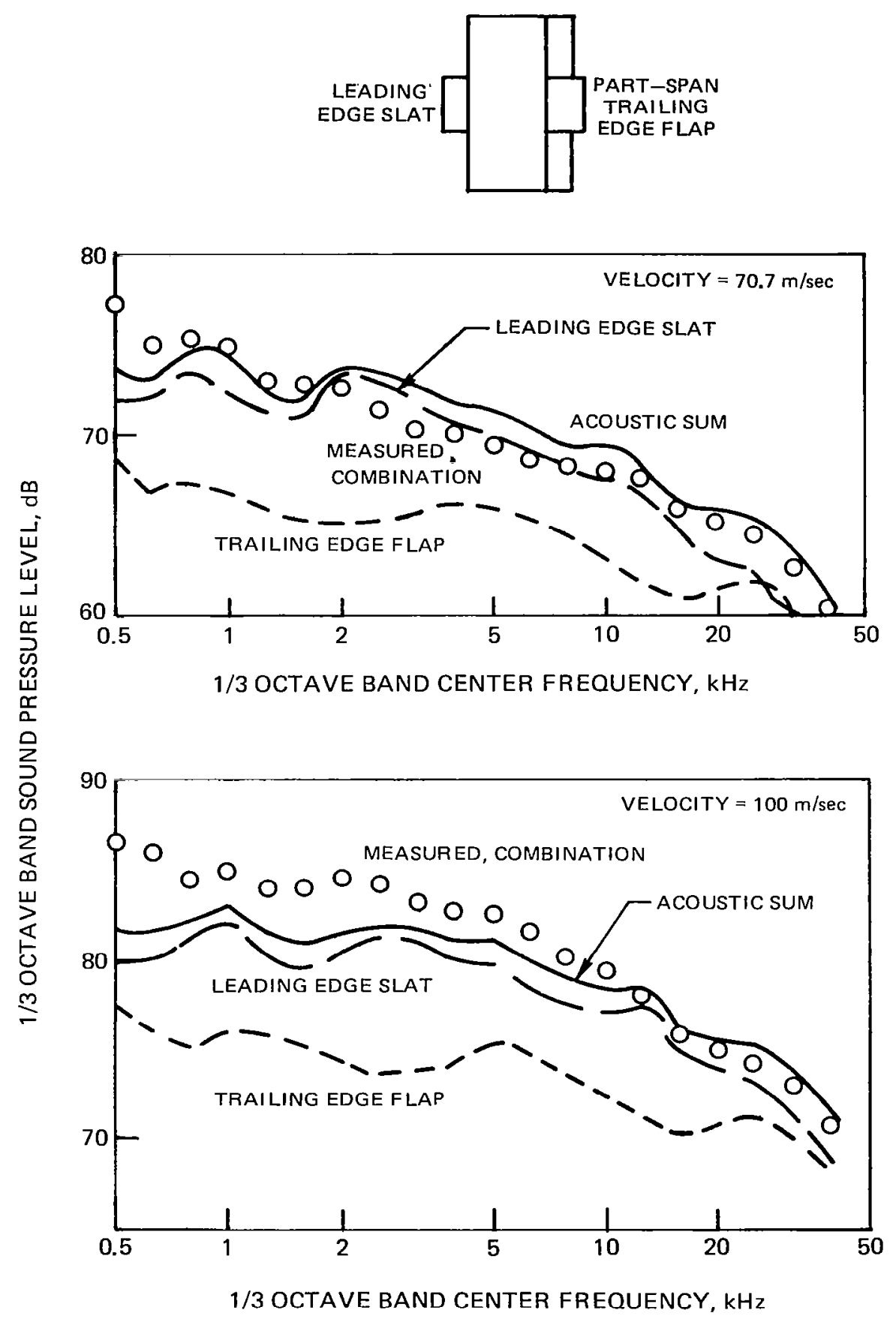

Figure 56 - Comparison of Spectra Measured with Leading Edge Slat, Part Span Trailing Edge Flap Combination and Sum of Spectra Measured with Individual Components. $90^{\circ}$ Microphone Position, Shielded from Collector 


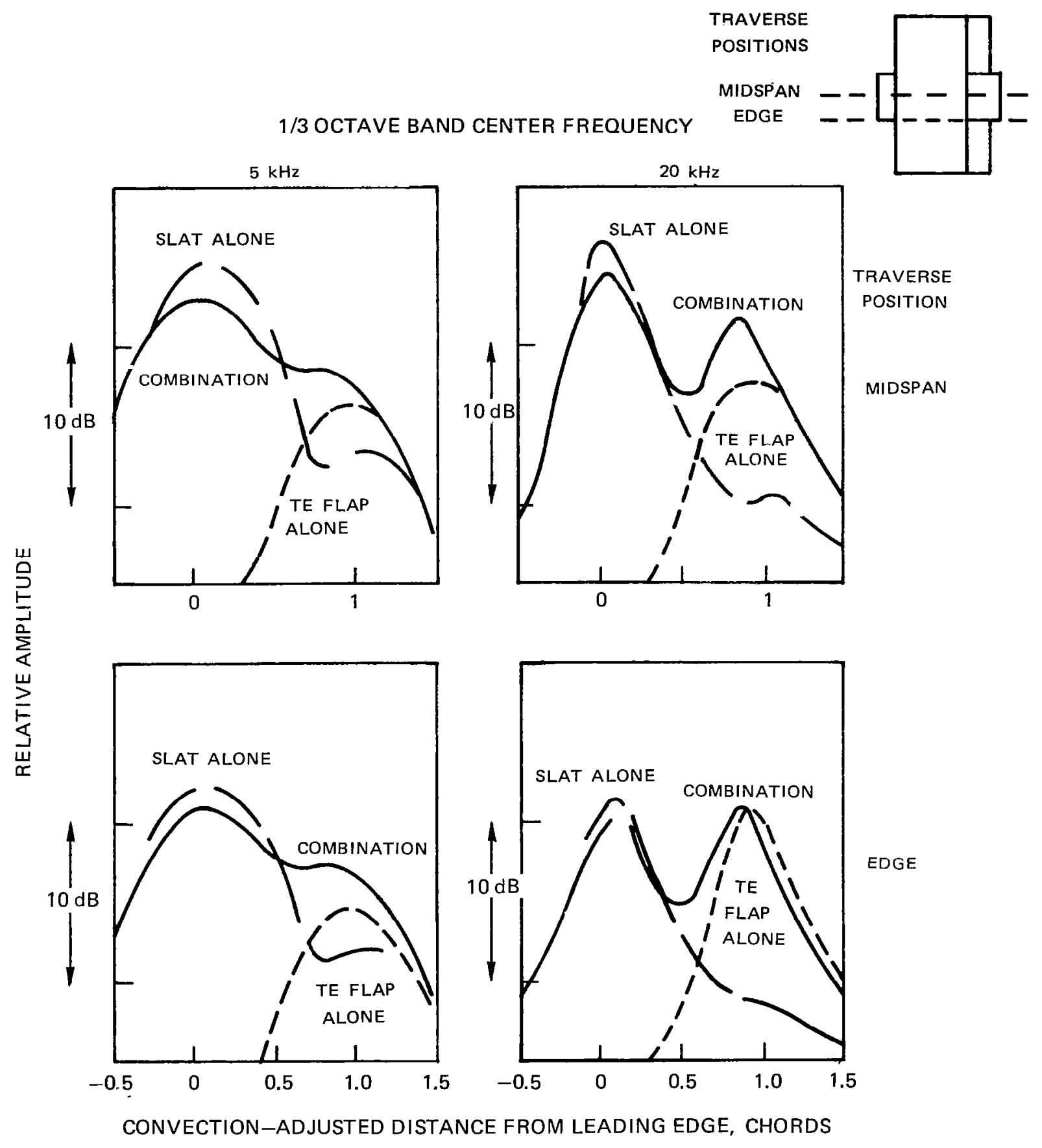

Figure 57-Comparison of Noise Source Strength Distribution for Leading Edge Slat, Part 114 Span Trailing Edge Flap Compination with those of Components Alone 


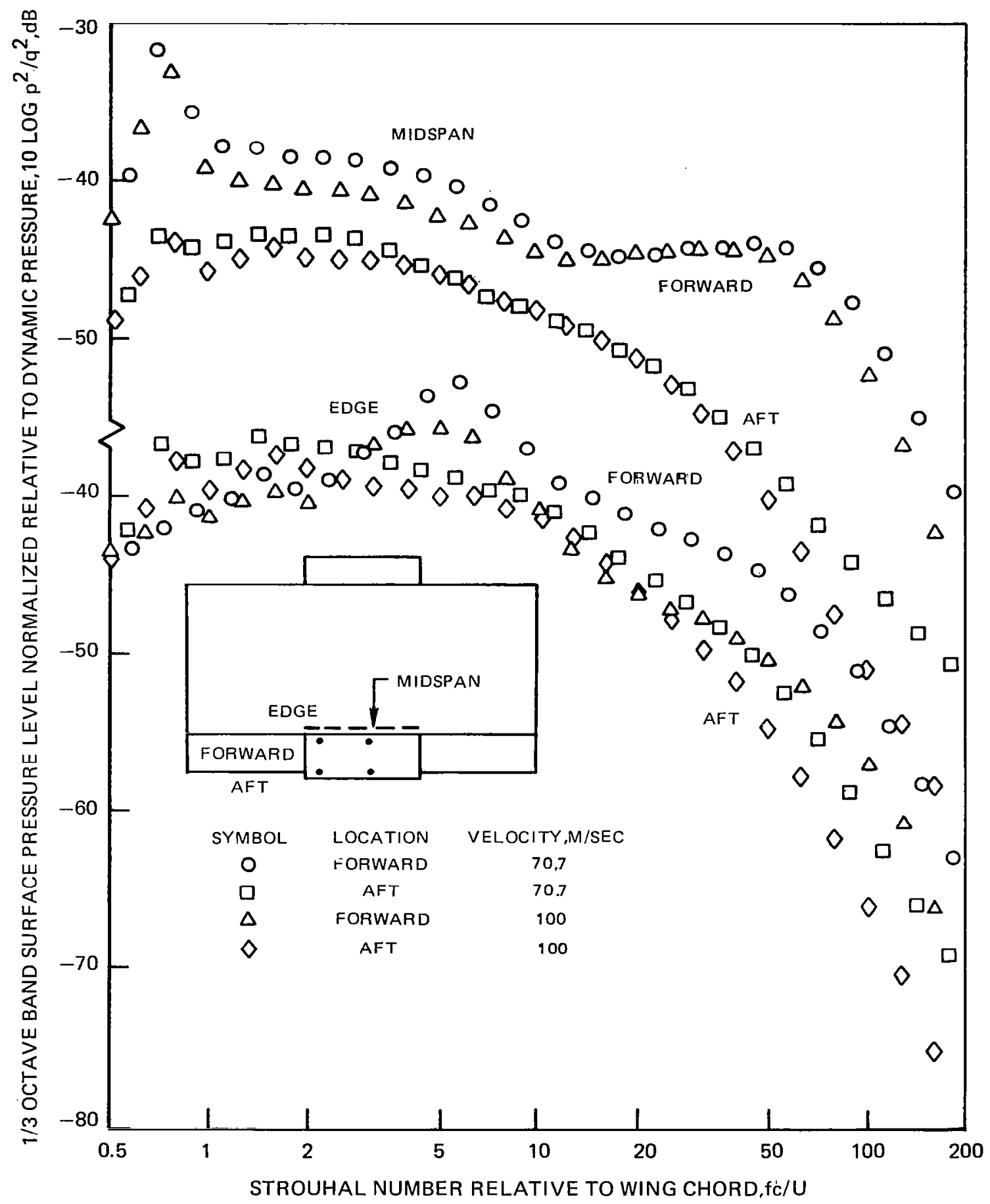

Figure 58 -Normalized Surface Pressure Spectra on Upper Surface of Part Span $40^{\circ}$ Deflection Single Slotted Flap with Part Span Leading Edge Slat 

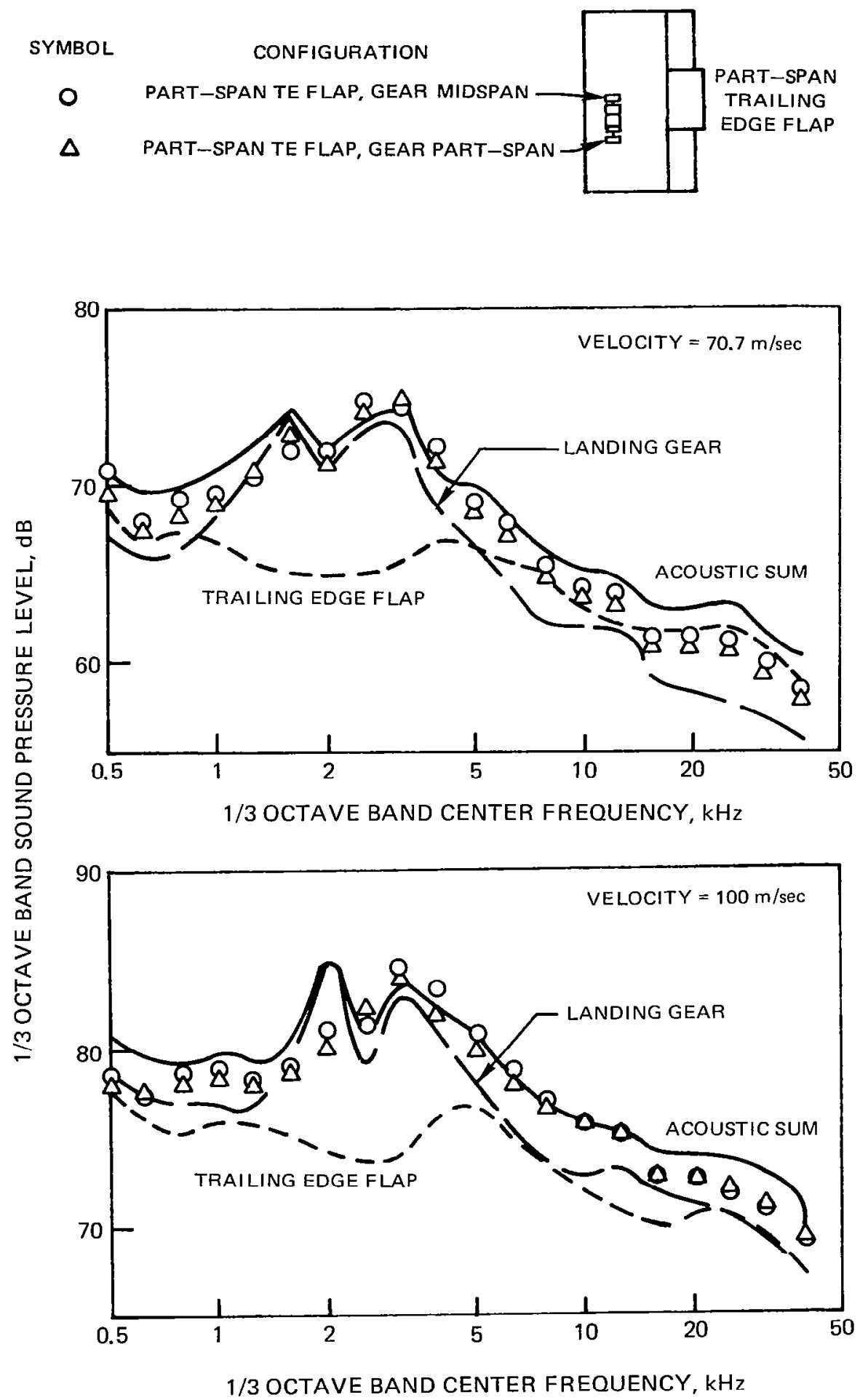

Figure 59 - Comparison of Spectra Measured with Landing Gear, Part Span Trailing Edge Flap Combinations and Sum of Spectra Measured with Individual Components. $90^{\circ}$ Microphone Position, Landing Gear Spectra Unshielded from Collector. All Other Spectra Shielded. 


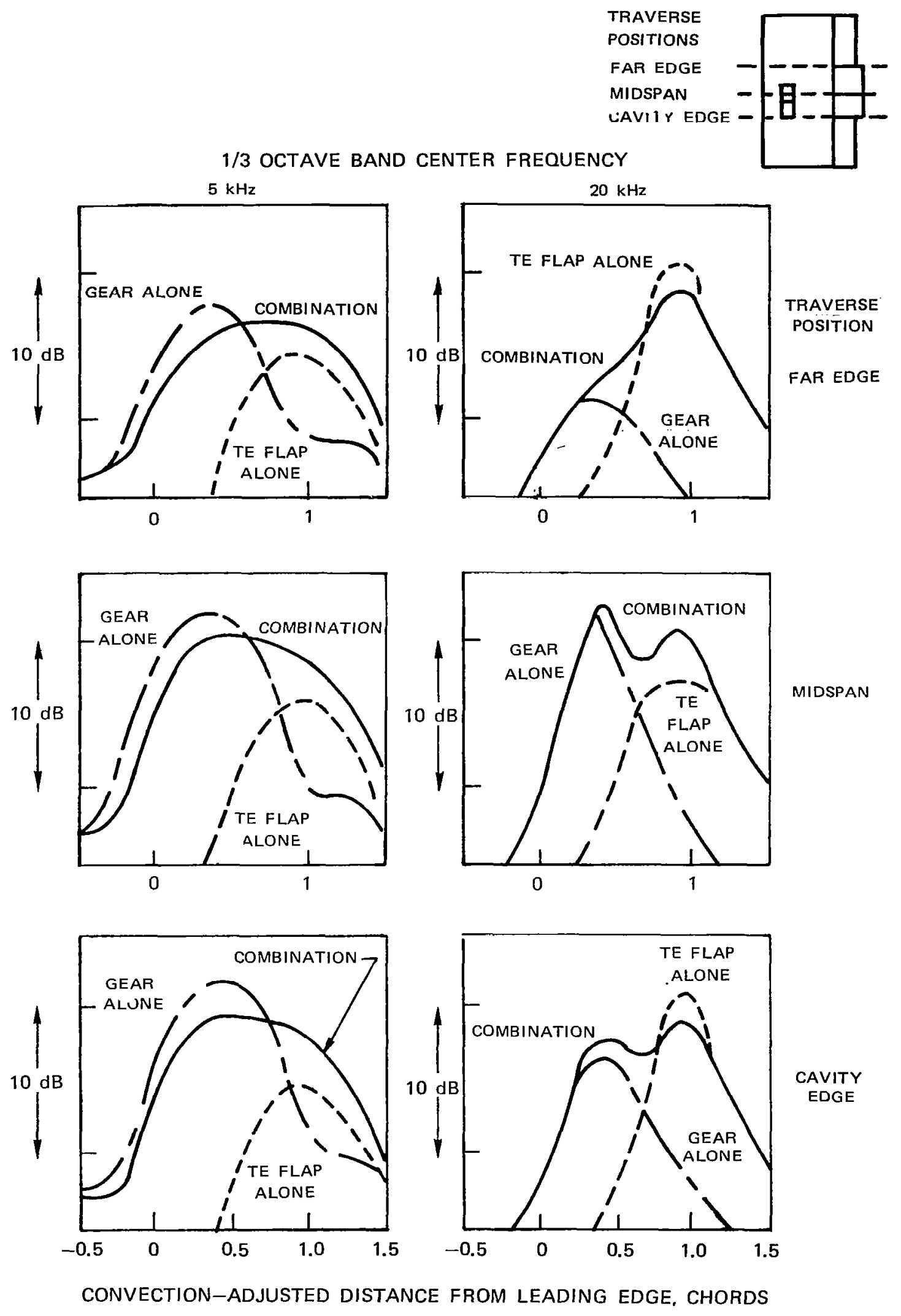

Figure 60-Comparison of Noise Source Strength Distributions for Landing Gear at Midspan, Part Span Trailing Edge Flap Combination with those of Components Alone 


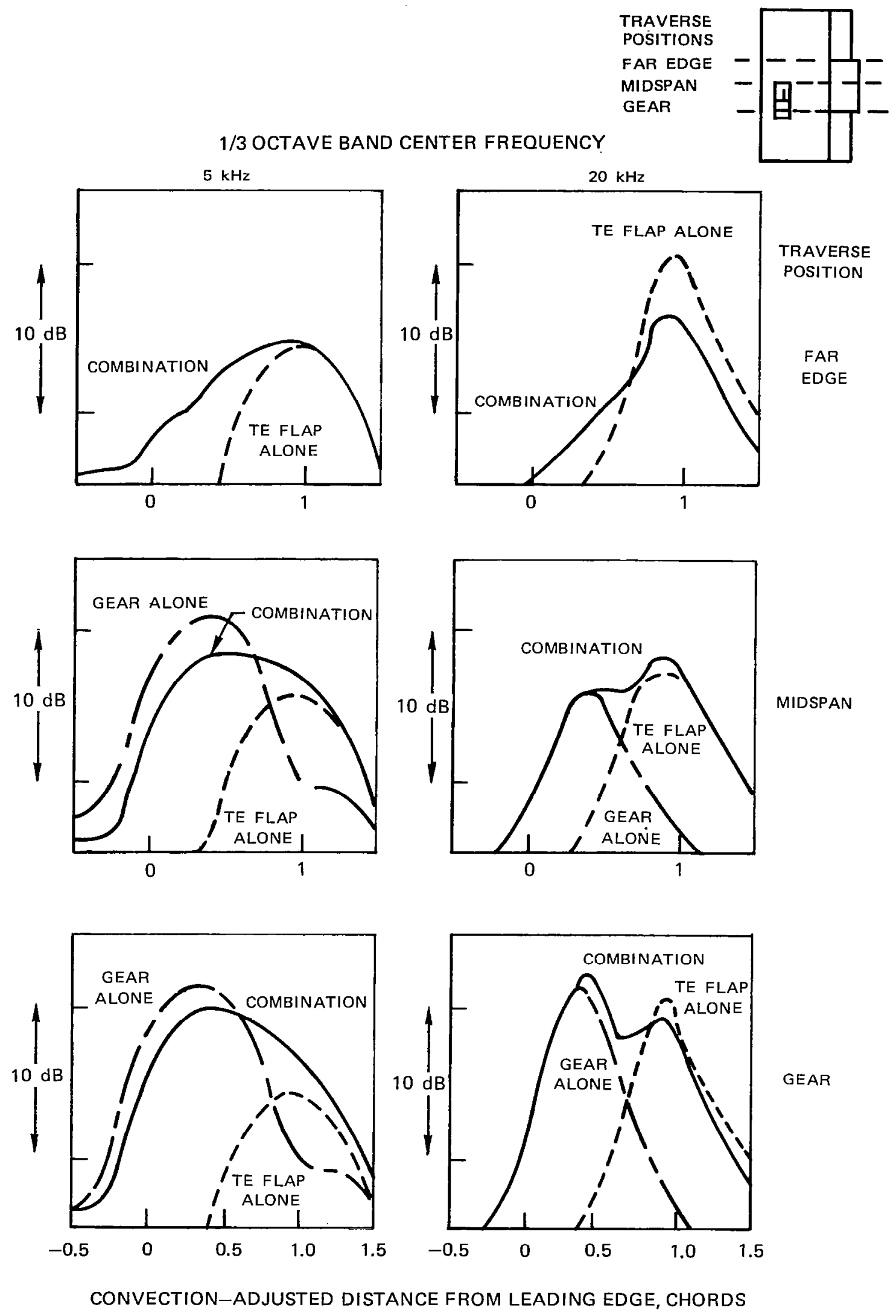

Figure 61-Comparison of Source Strength Distributions for Landing Gear at 1/3 Span, Part 118 Span Trailing Edge Flap Combination with those of Components Alone 


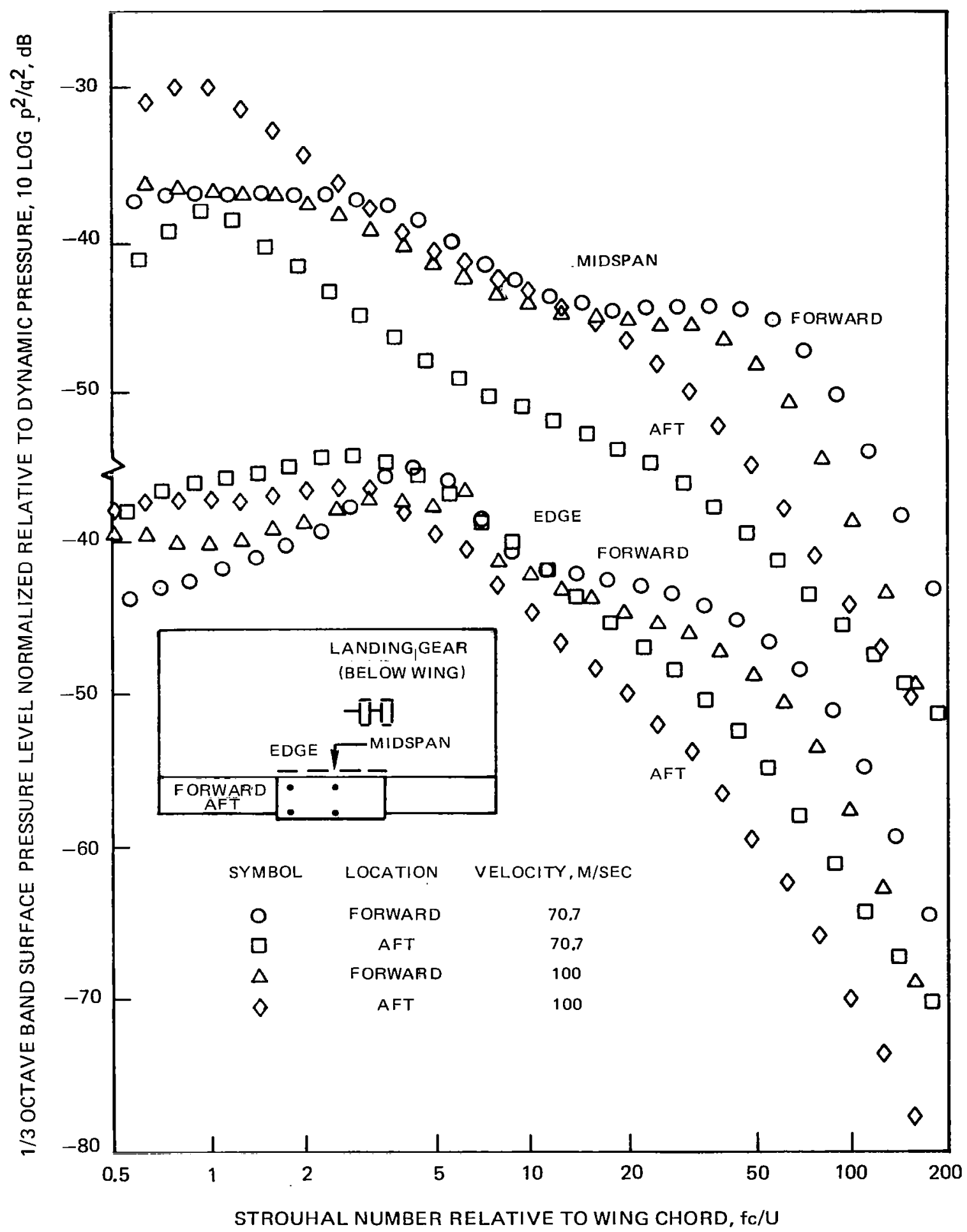

Figure 62-Normalized Surface Pressure Spectra on Upper Surface of Part Span $40^{\circ}$ Deflection Single Slotted Flap with Landing Gear at Flap Edge 


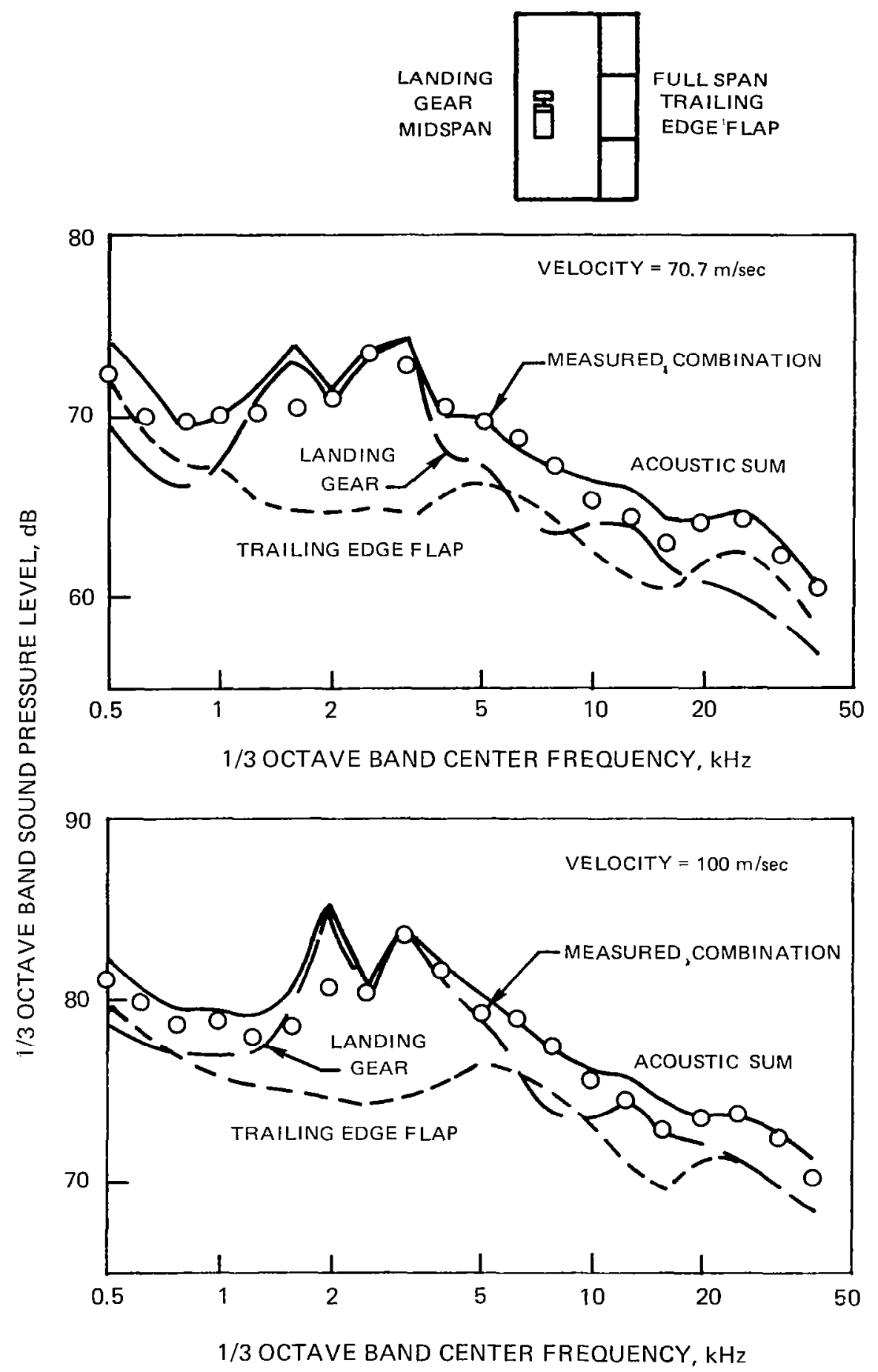

Figure 63 - Comparison of Spectra Measured with Landing Gear Midspan, Full Span Trailing Edge Flap Combination and Sum of Spectra Measured with Individual Components, $90^{\circ}$ Microphone Position, Landing Gear Spectrum Unshielded from Collector, Other Spectra Shielded. 


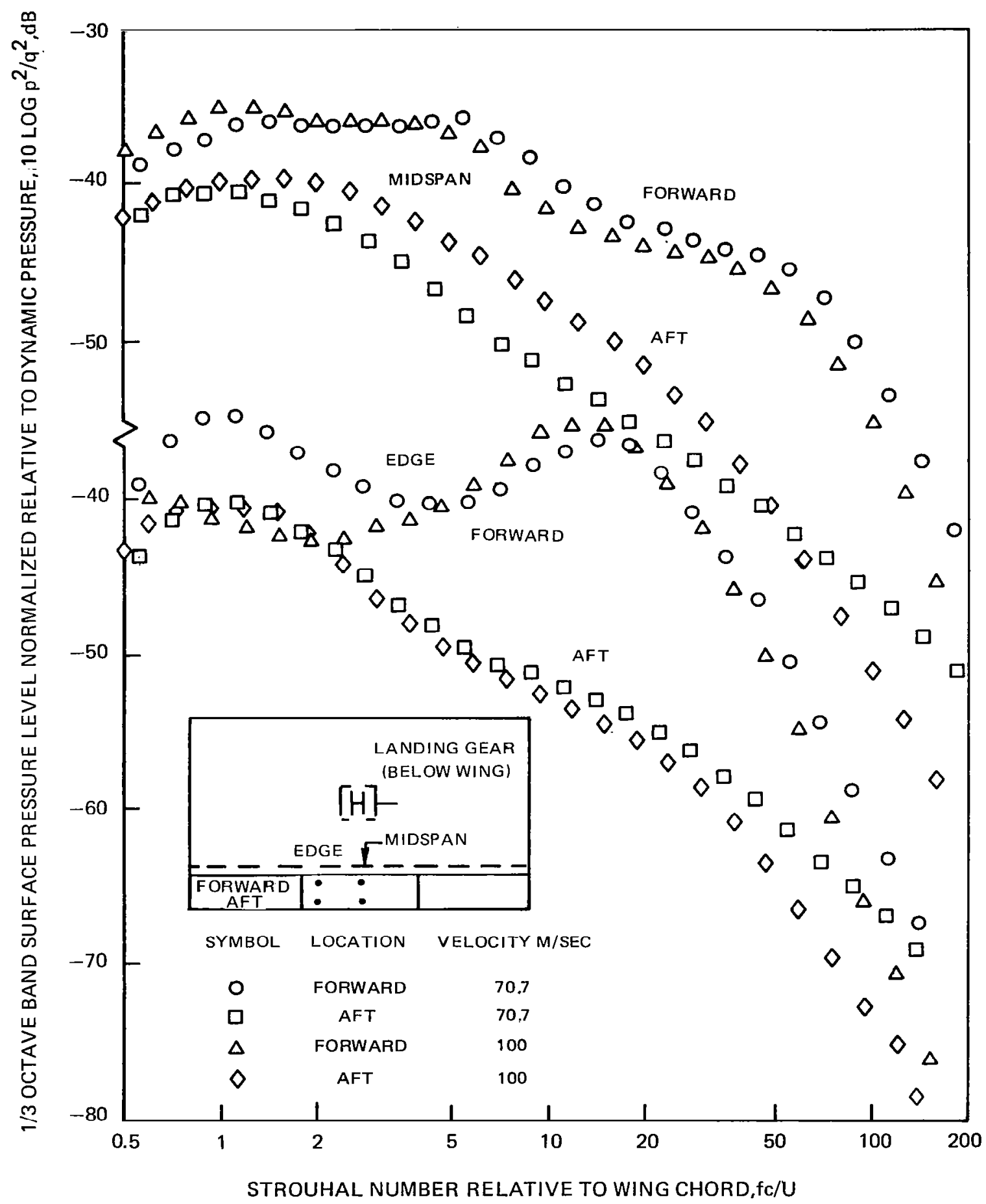

Figure 64 -Normalizer Surface Pressure Spectra on Upper Surface of Full Span $40^{\circ}$ Deflection Single Slotted Flap with Landing Gear at Midspan 


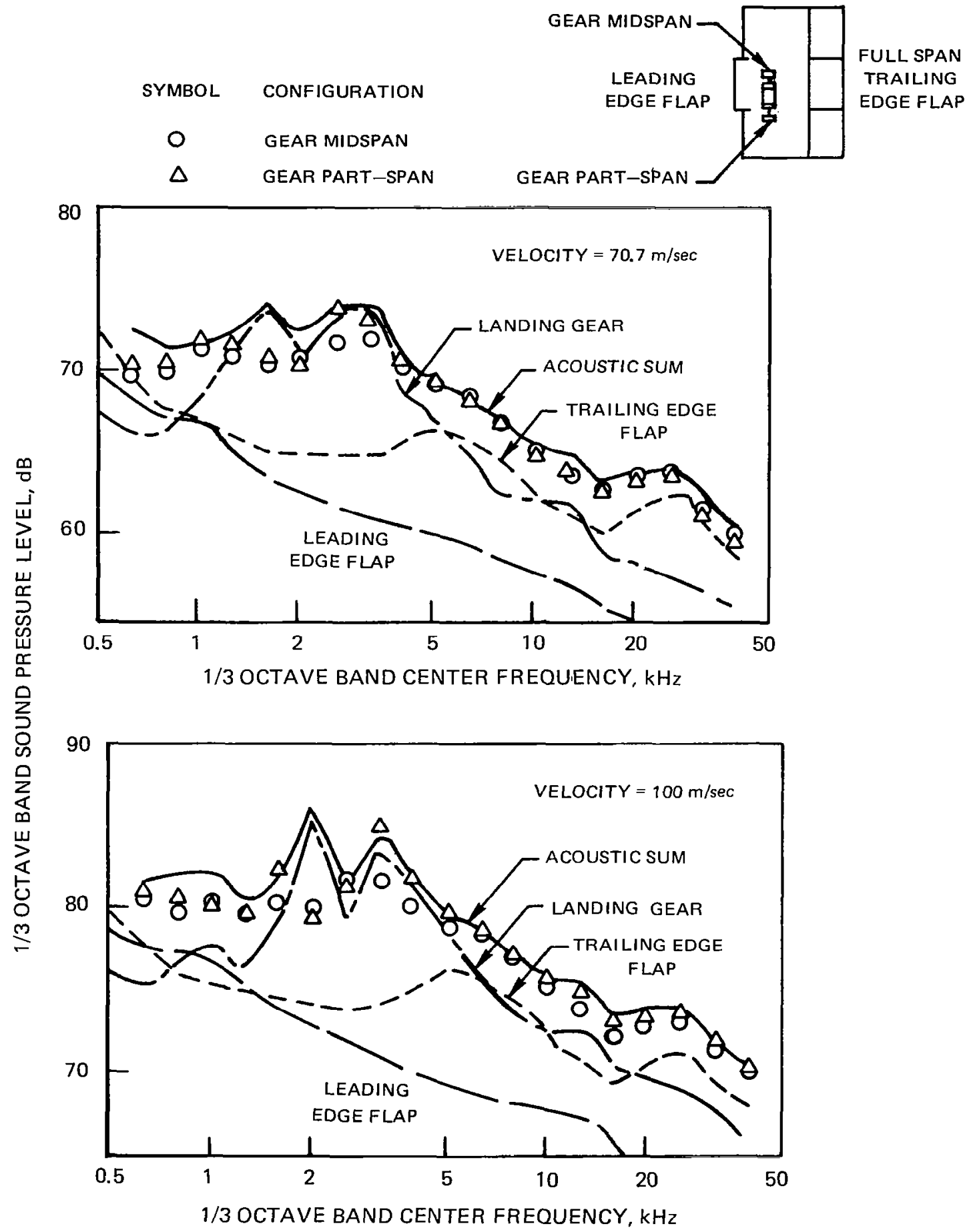

Figure 65 - Comparison of Spectra Measured with Leading Edge Flap, Full Span Trailing Edge Flap, Landing Gear Combinations and Sum of Spectra Measured with Individual Components. $90^{\circ}$ Microphone, Collector Unshielded for Landing Gear but Shielded for all Other Cases 


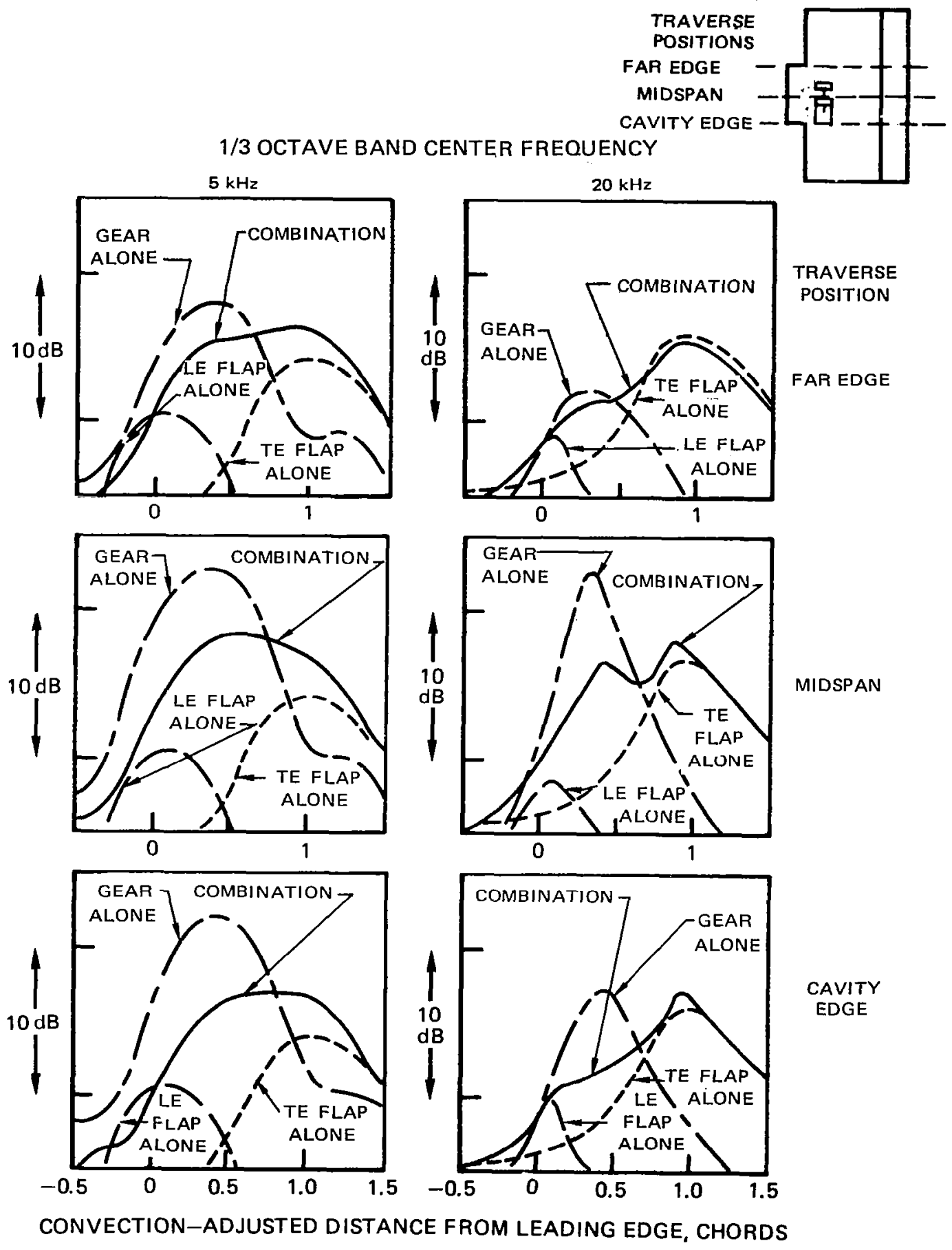

Figure 66 - Comparison of Noise Source Strength Distributions for Leading Edge Flap, Landing Gear Midspan, Full Span Trailing Edge Flap Combination with those of Components Alone 


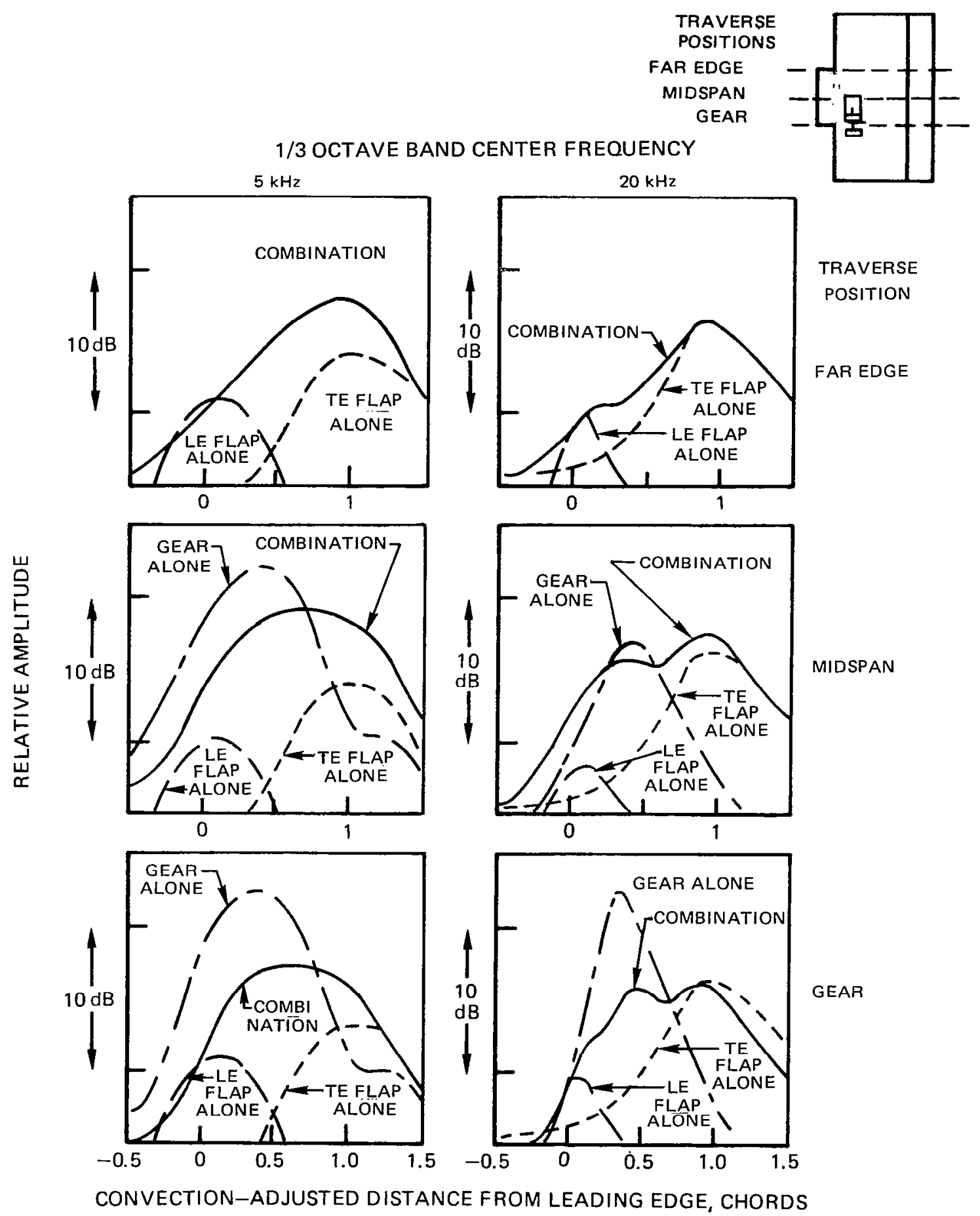

Figure 67 Comparison of Noise Source Strength Distributions for Leading Edge Flap, Landing Gear Part-Span, Full Span Trailing Edge Flap Combination with those of Components Alone 


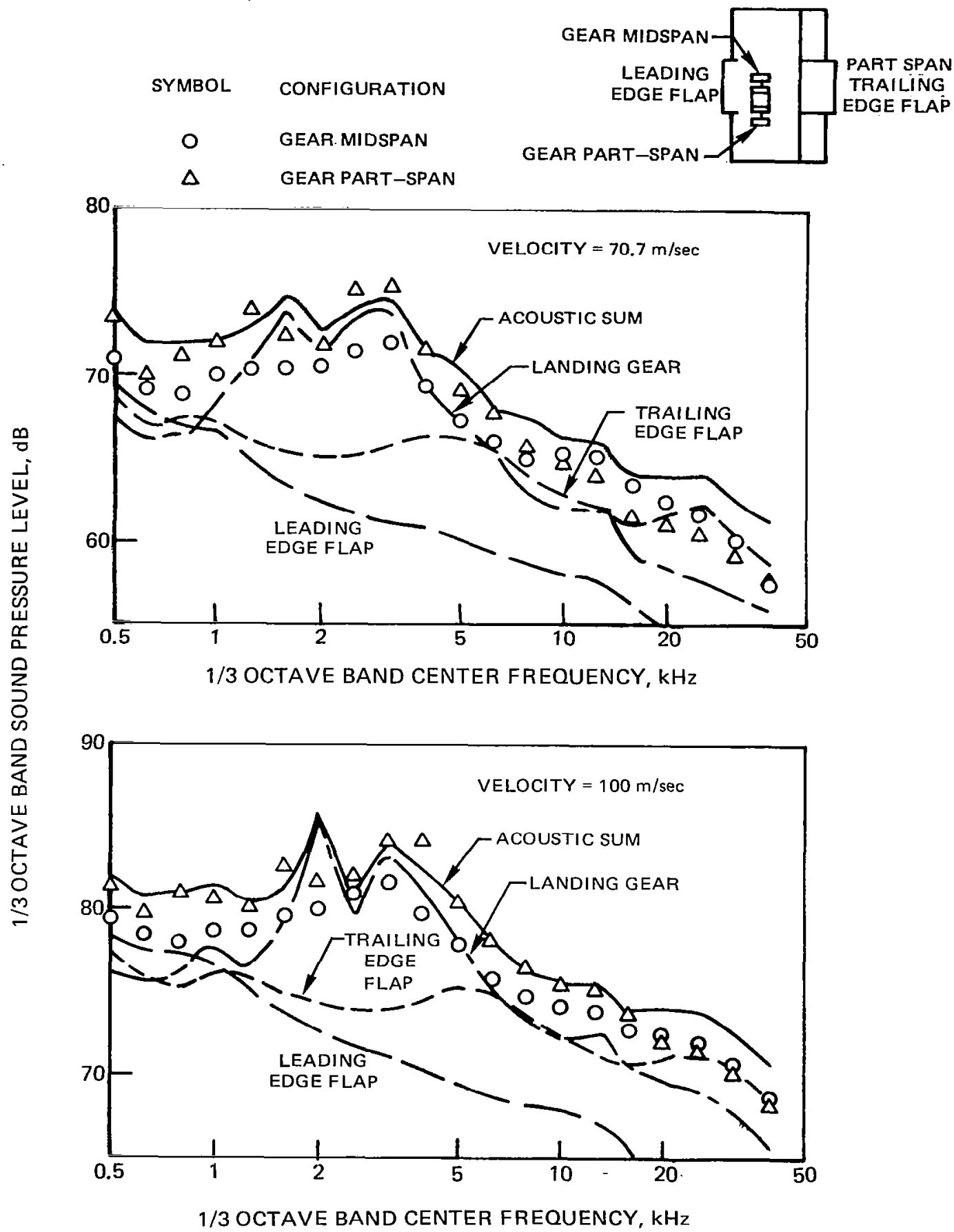

Figure 68 - Comparison of Spectra Measured with Leading Edge Flap, Part-Span Trailing Edge Flap, Landing Gear Combinations and Sum of Spectra Measured with Individual Components. 900 Microphone, Collector Unshielded for Landing Gear but Shielded for all Other Cases 


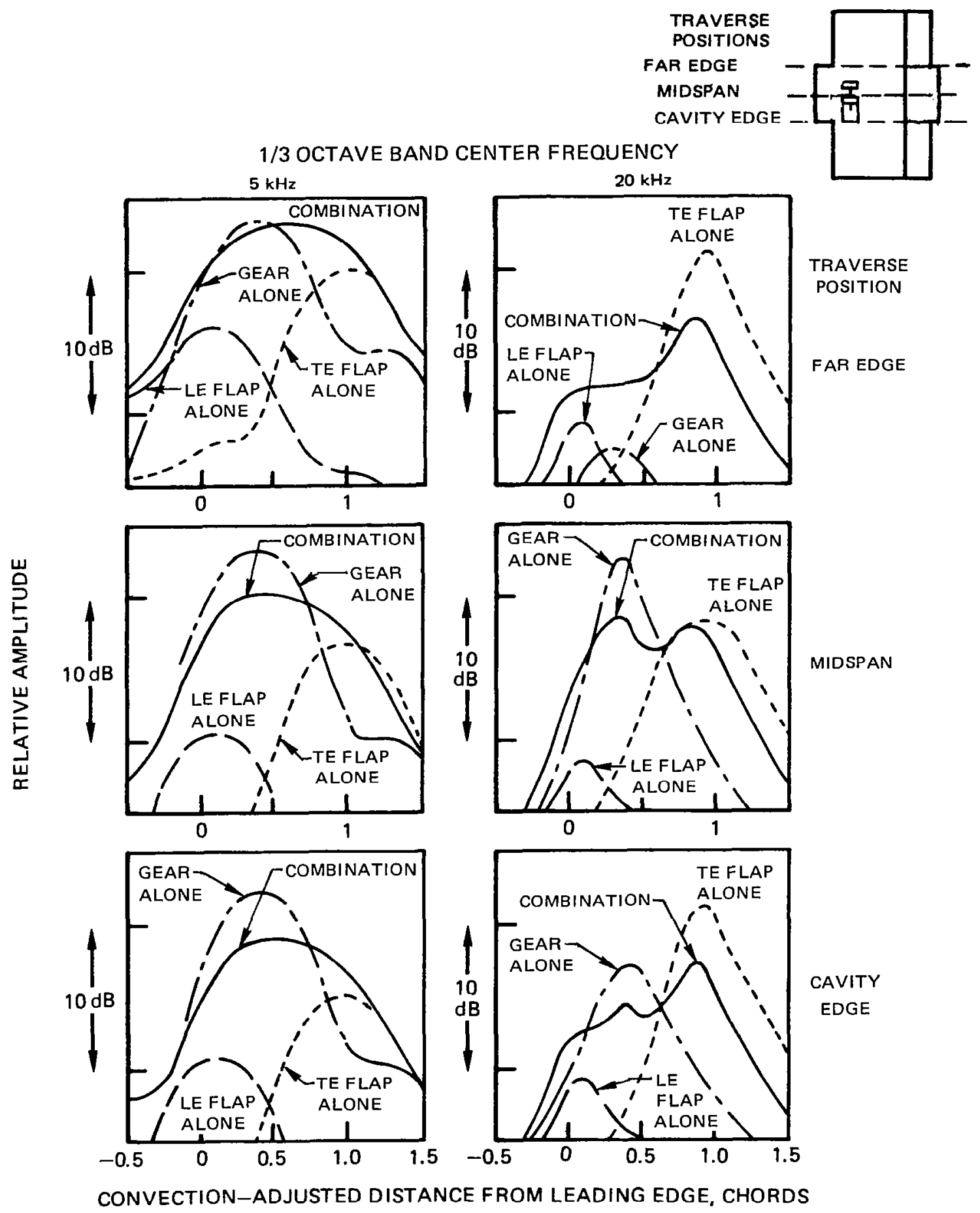

Figure 69 -Comparison of Noise Source Strength Distribution for Leading Edge Flap, Landing Gear Midspan, Part-Span Trailing Edge Flap Combination with those of Components Alone 



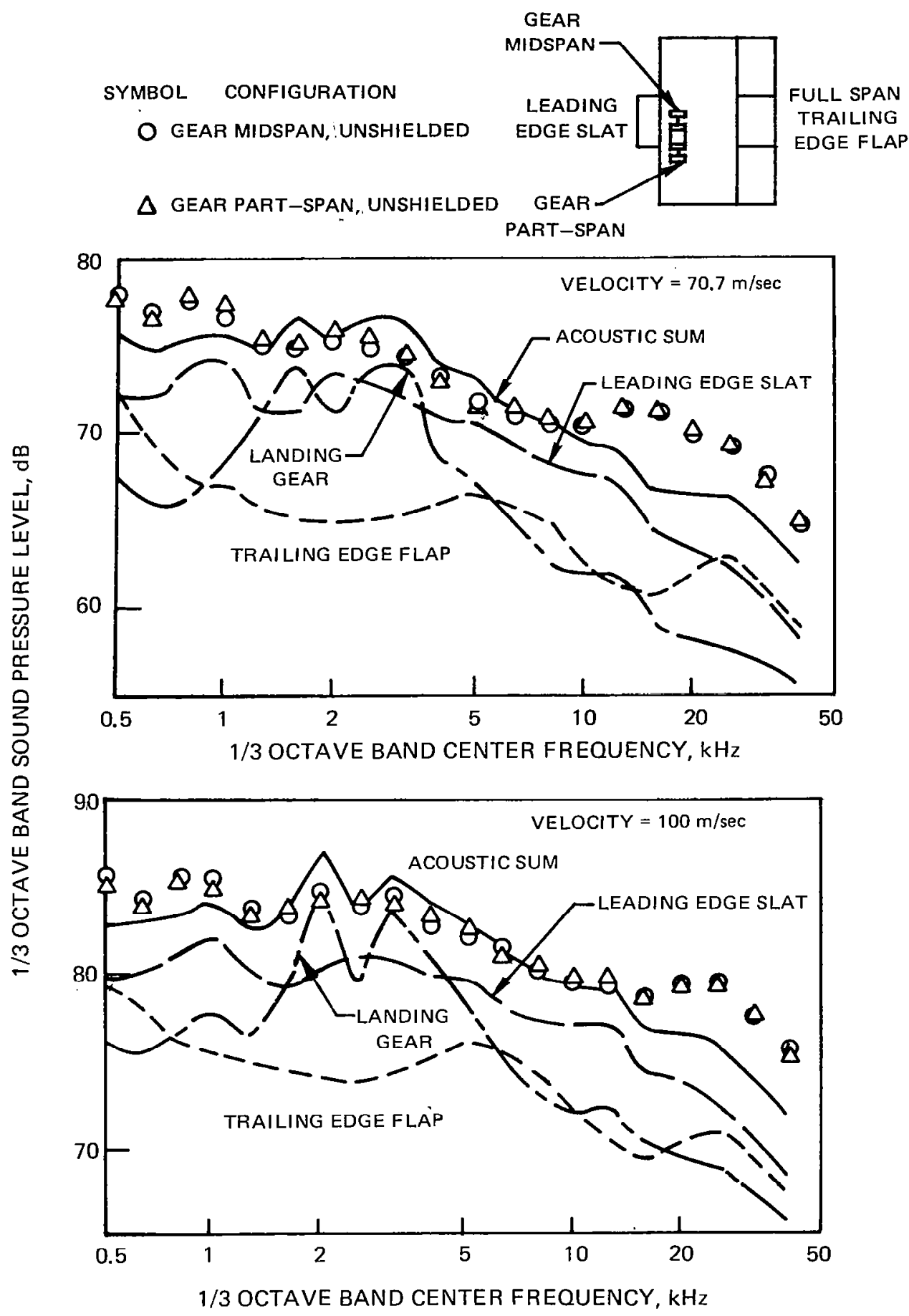

Figure 71- Comparison of Spectra Measured with Leading Edge Slat, Full Span Trailing Edge Flap, Landing Gear Combinations and Sum of Spectra Measured with Individual Components. $90^{\circ}$ Microphone, Collector Shielded for Slat and Flap but Unshielded for Combinations and for Landing Gear 


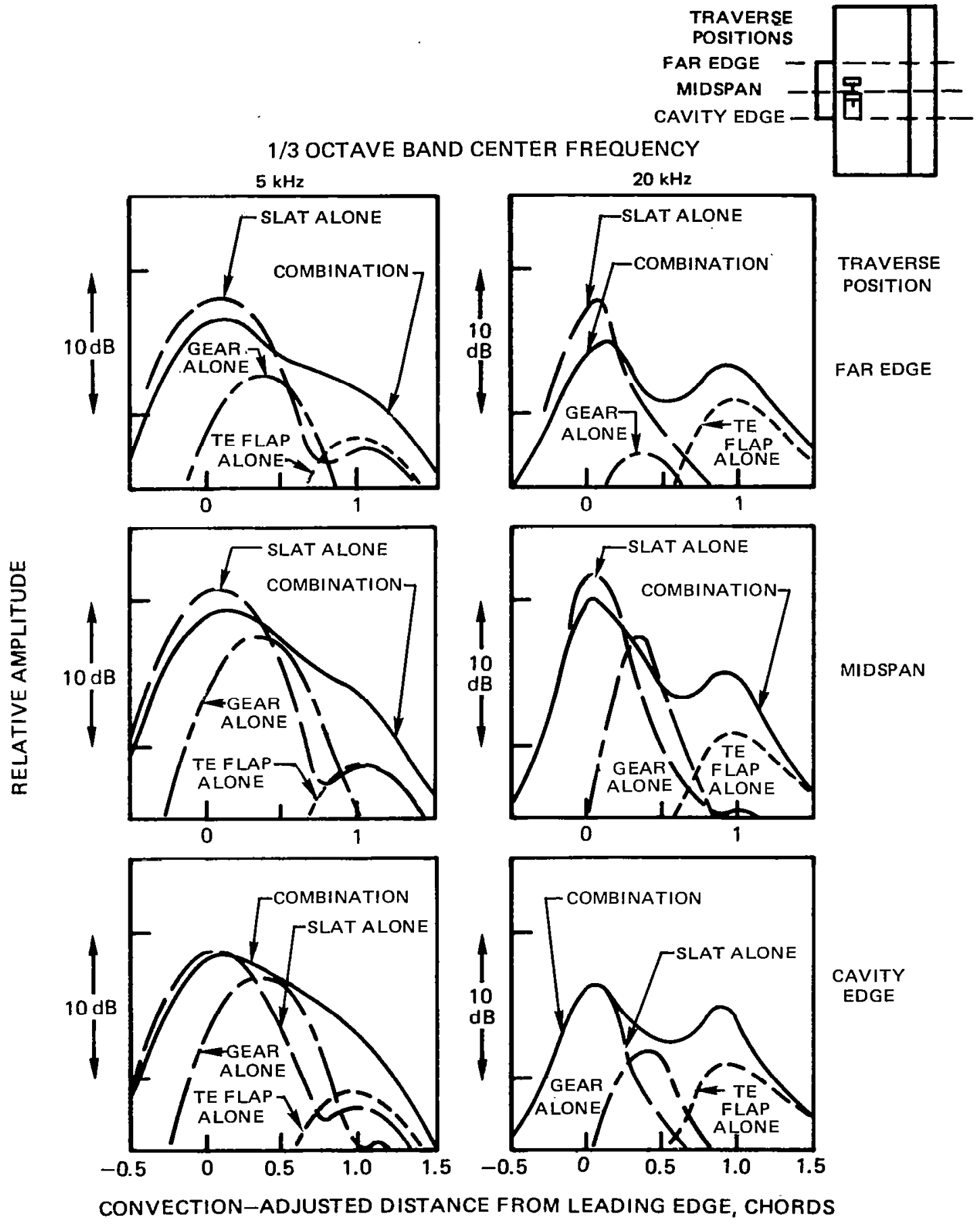

Figure 72 - Comparison of Noise Source Strength Distributions for Leading Edge Slat, Landing Gear Midspan, Full Span Trailing Edge Flap Combination with those of Components Alone 


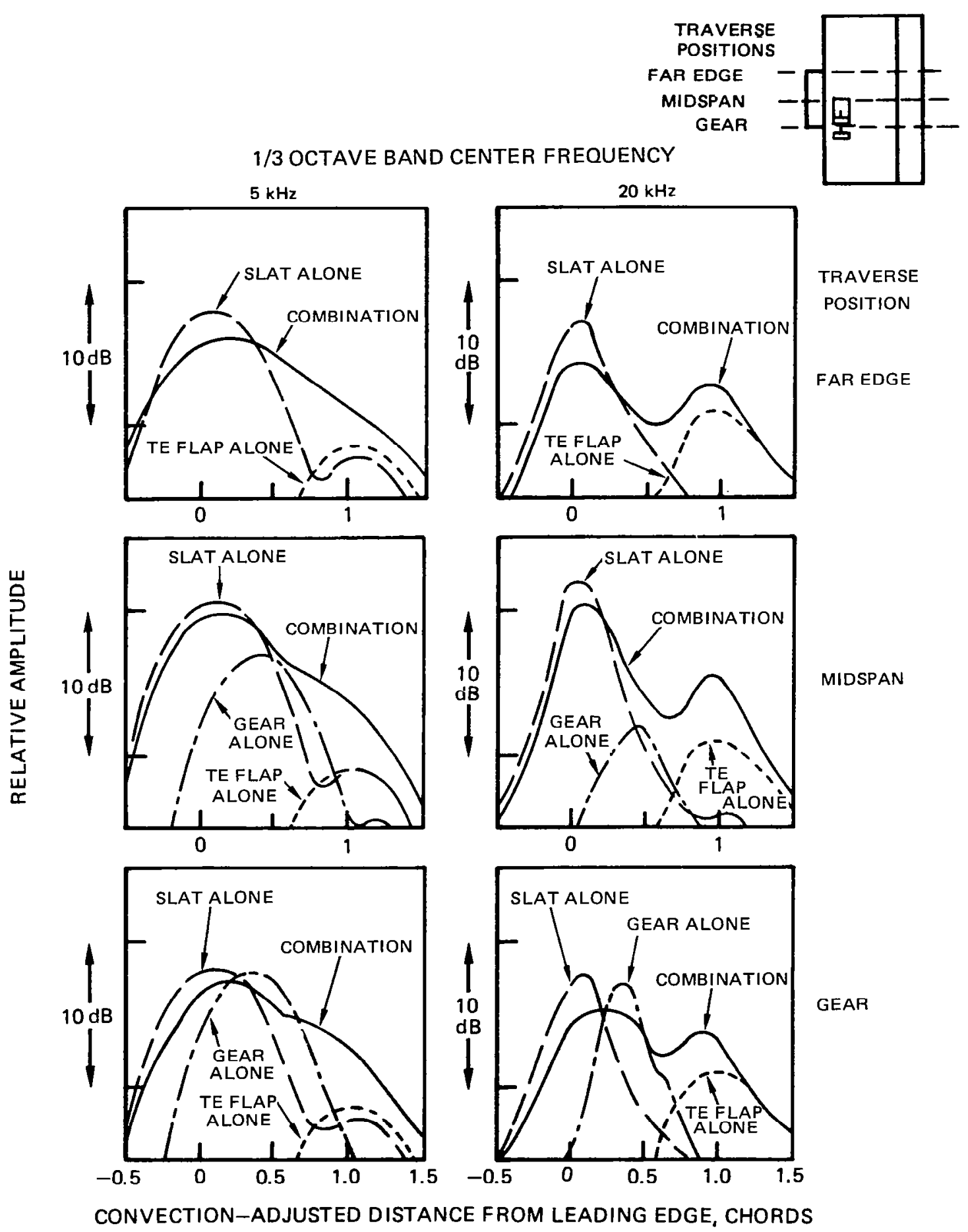

Figure 73 - Comparison of Noise Source Strength Distribution for Leading Edge Slat, Landing Gear Part-Span, Full Span Trailing Edge Flap Combination with those of Components Alone 

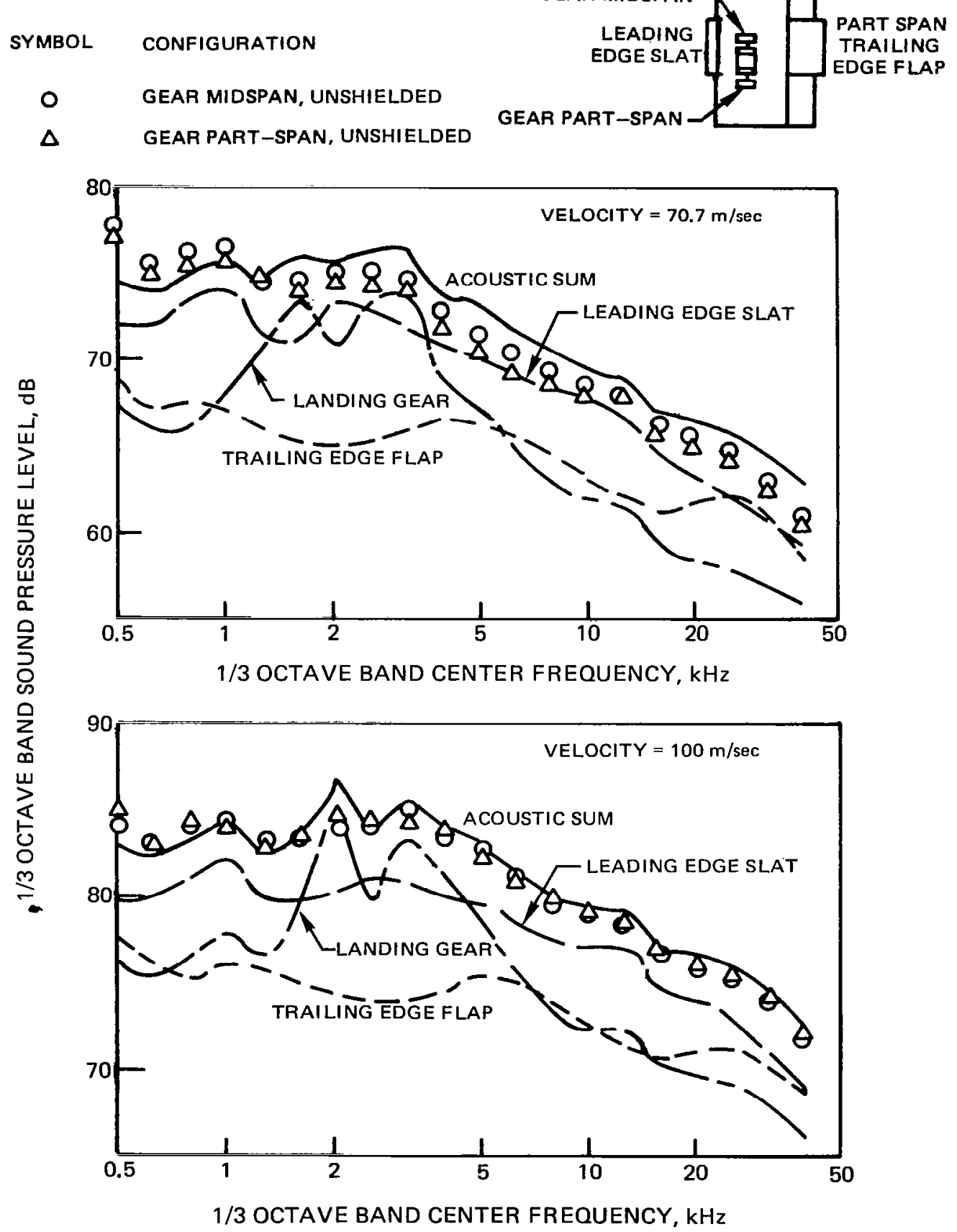

Figure 74 - Comparison of Spectra Measured with Leading Edge Slat, Part-Span Trailing Edge Flap, Landing Gear Combinations and Sum of Spectra Measured with Individual Components. 900 Microphone, Collector Shielded for Slat and Flap but Unshielded for Combinatıons and for Landing Gear 


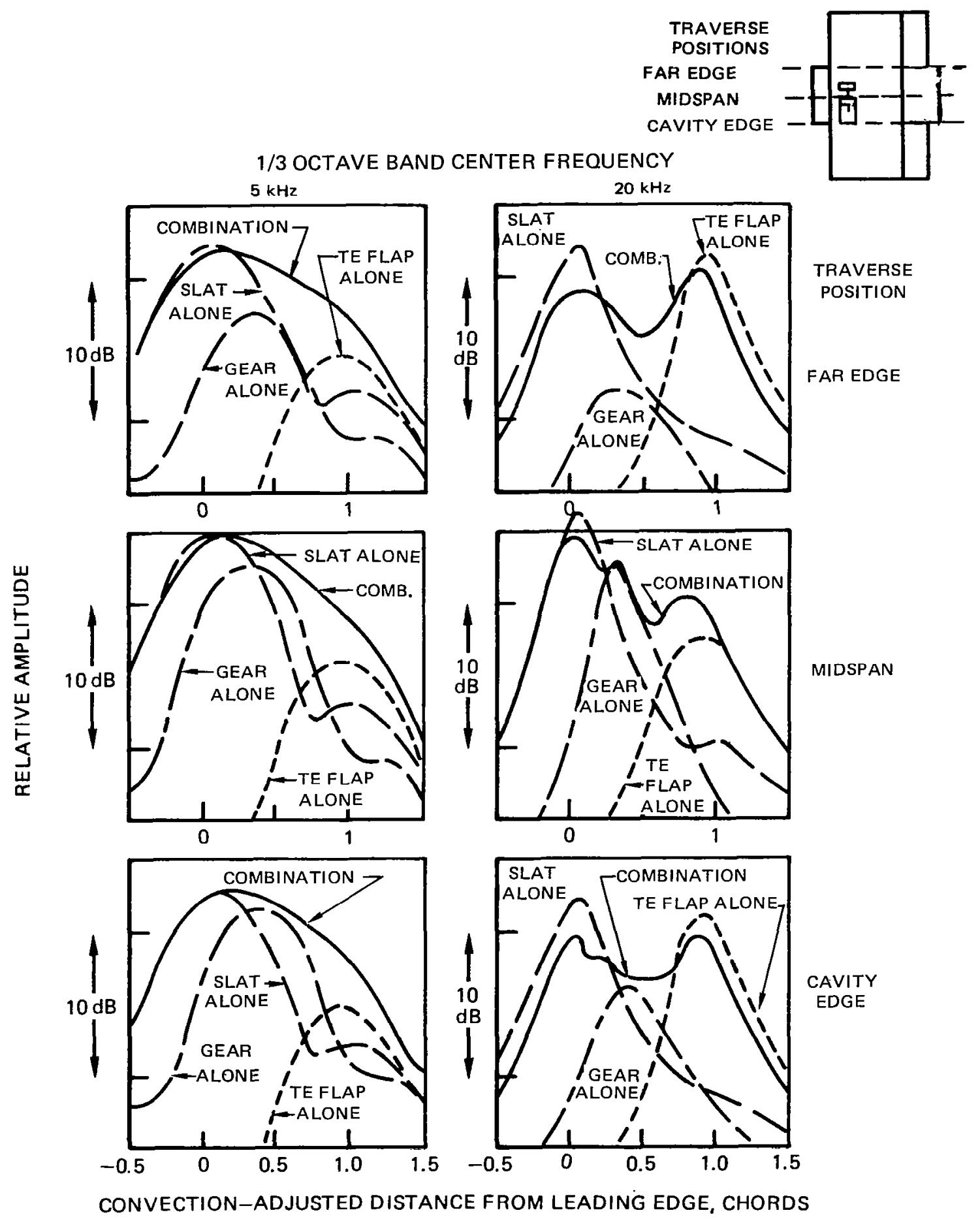

Figure 75 - Comparison of Noise Source Strength Distributions for Leading Edge Slat, Landing Gear Midspan, Part-Span Trailing Edge Flap Combination with those of Components Alone 


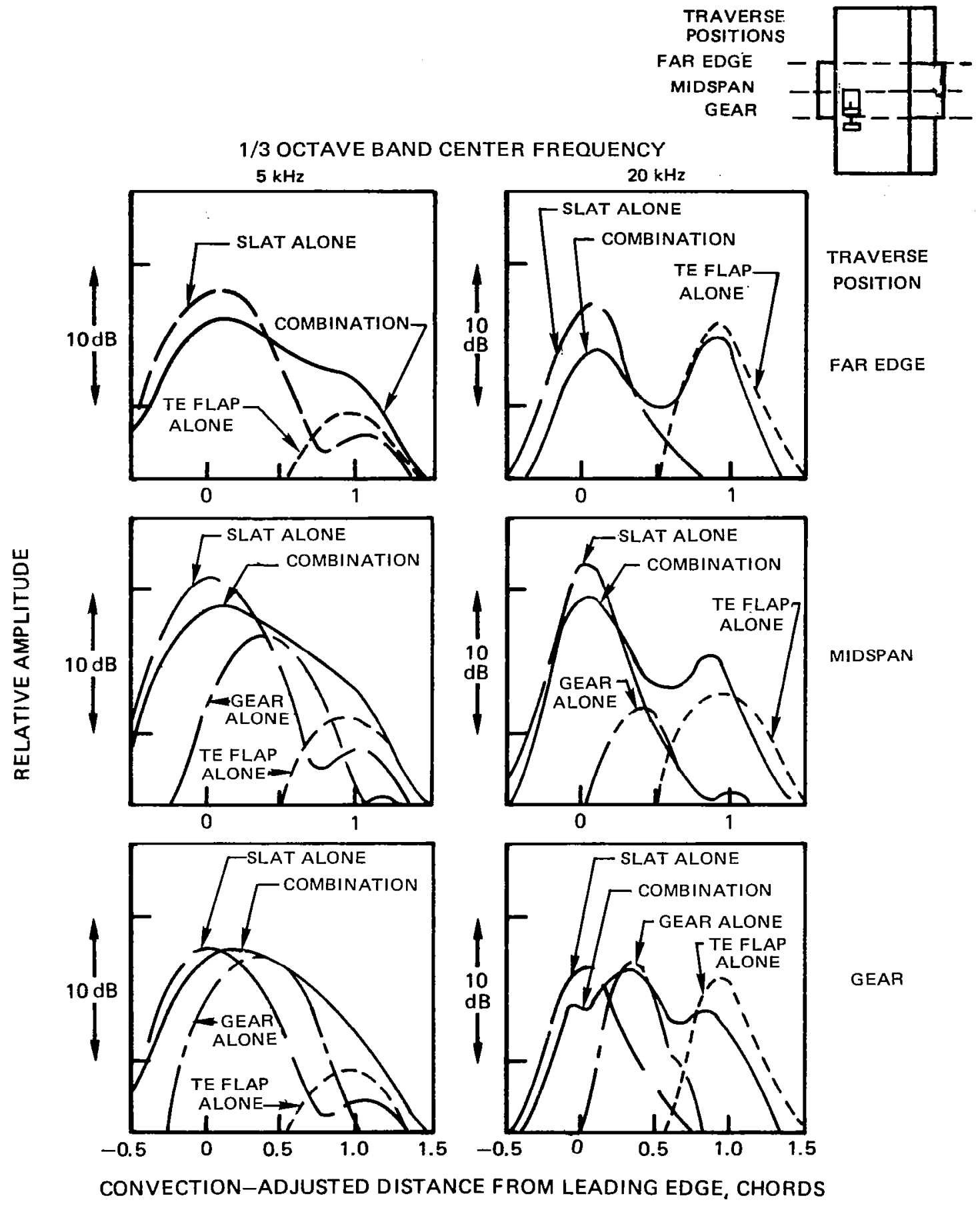

Figure 76 Comparison of Noise Source Strength Distributions for Leading Edge Slat, Landing Gear Part Span, Part-Span Trailing Edge Flap Combination with those of Components Alone 


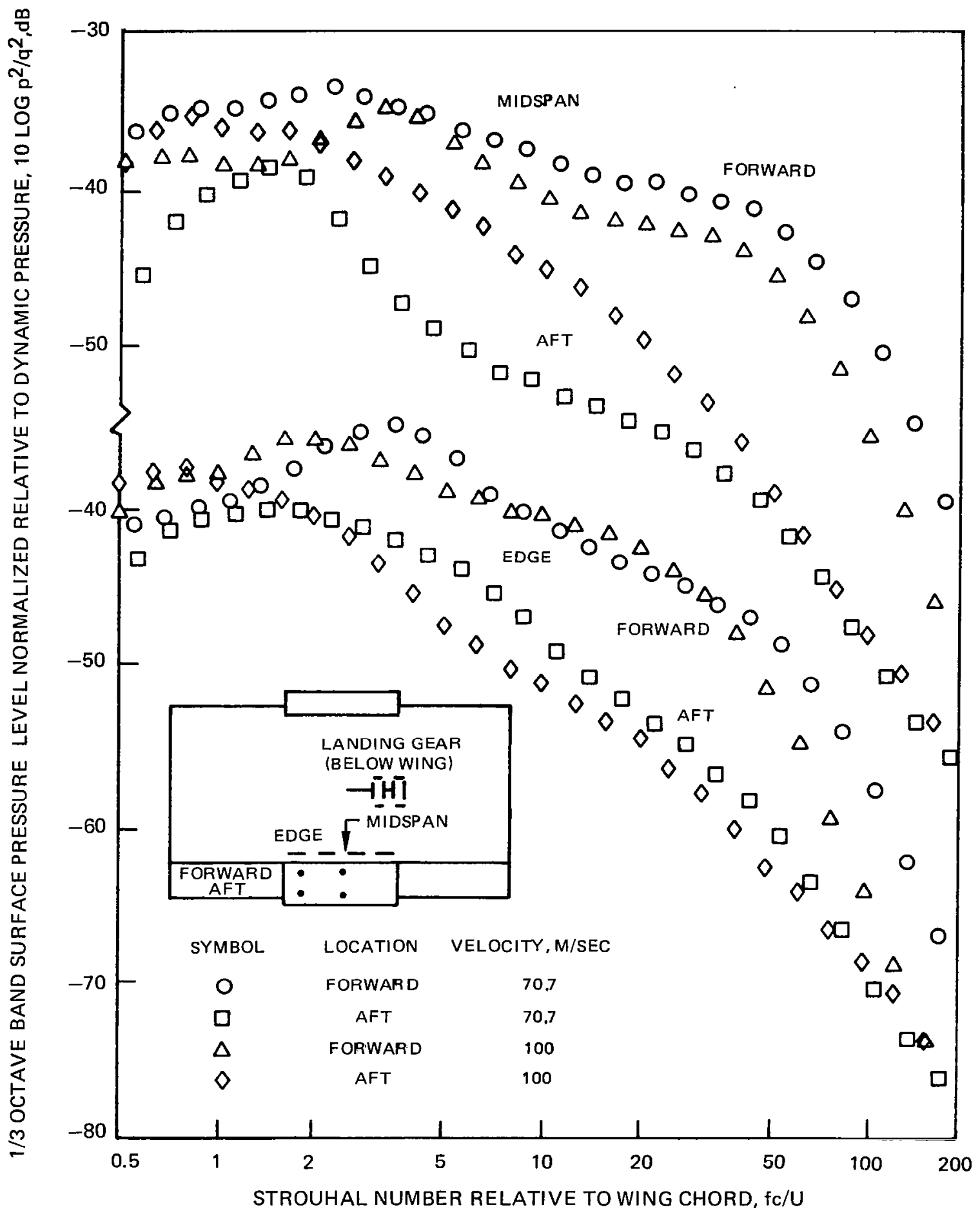

Figure 77 -Normalized Surface Pressure Spectra on Upper Surface of Part Span $40^{\circ}$ Deflection Single Slotted Flap with Leading Edge Slat and Landing Gear at Flap Edge 


\begin{tabular}{|c|c|c|c|c|}
\hline $\begin{array}{l}\text { 1. Report No. } \\
\text { NASA CR-3110 }\end{array}$ & \multicolumn{2}{|c|}{ 2. Government Accession No. } & \multicolumn{2}{|c|}{ 3. Recipient's Catalog No. } \\
\hline \multicolumn{3}{|c|}{ 4. Title and Subtitle } & \multicolumn{2}{|l|}{$\begin{array}{l}\text { 5. Report Date } \\
\text { March } 1979\end{array}$} \\
\hline \multicolumn{3}{|c|}{ Airframe Noise Component Interaction studies } & \multicolumn{2}{|c|}{ 6. Performing Organization Code } \\
\hline \multirow{2}{*}{\multicolumn{3}{|c|}{$\begin{array}{l}\text { 7. Author(s) } \\
\text { Martin R. Fink and Robert H. Schlinker }\end{array}$}} & \multicolumn{2}{|c|}{$\begin{array}{l}\text { 8. Performing Organization Report No. } \\
\text { R78-912996-12 }\end{array}$} \\
\hline & & & \multicolumn{2}{|l|}{ 10. Work Unit No. } \\
\hline \multicolumn{3}{|c|}{$\begin{array}{l}\text { 9. Performing Organization Name and Address } \\
\text { United Technologies Research Center } \\
\text { Silver Lane } \\
\text { East Hartford, CT. } 06108\end{array}$} & \multicolumn{2}{|c|}{$\begin{array}{l}\text { 11. Contract or Grant No. } \\
\text { NASI-15083 }\end{array}$} \\
\hline \multirow{2}{*}{\multicolumn{3}{|c|}{$\begin{array}{l}\text { 12. Sponsoring Agency Name and Address } \\
\text { National Aeronautics and Space Administration } \\
\text { Washington, D.C. } 20546\end{array}$}} & \multicolumn{2}{|c|}{$\begin{array}{l}\text { 13. Type of Report and Period Covered } \\
\text { Contractor Report }\end{array}$} \\
\hline & & & \multicolumn{2}{|c|}{ 14. Sponsoring Agency Code } \\
\hline \multicolumn{5}{|c|}{$\begin{array}{l}\text { 15. Supplementary Notes } \\
\text { Langley Technical Monitor: Donald L. Lansing } \\
\text { Final Report }\end{array}$} \\
\hline \multicolumn{5}{|c|}{$\begin{array}{l}\text { 16. Abstract Acoustic wind tunnel tests were conducted of a two-dimensional wing section } \\
\text { with removable high-lift leading and trailing edge devices and a removable two-wheel } \\
\text { landing gear with open cavity. An array of far field conventional microphones and an } \\
\text { acoustic mirror directional microphone were utilized to determine far field spectrum } \\
\text { levels and noise source distributions. Data were obtained for the wing with component } \\
\text { deployed separately and in various combinations. } \\
\text { The basic wing model had } 0.305 \mathrm{~m}(1.00 \mathrm{ft} \text { ) chord, which is roughly } 1 / 10 \mathrm{scale} \text { for } \\
\text { a one-hundred passenger transport airplane. Most of the data were obtained at } 70.7 \\
\text { and } 100 \mathrm{~m} / \mathrm{sec} \text { ( } 232 \text { and } 328 \mathrm{ft} / \mathrm{sec} \text { ) airspeeds, which bracket the range of practical } \\
\text { approach speeds for such aircraft. Data were obtained at frequencies to } 40 \mathrm{kHz} \text { so } \\
\text { that, when scaled to a typical full-sized airframe, the frequency region which strongl } \\
\text { influences perceived noise level would be included. }\end{array}$} \\
\hline \multicolumn{2}{|c|}{$\begin{array}{l}\text { 17. Key Words (Suggested by Author(s)) } \\
\text { Noise, Airframe noise, Wing noise, Leading } \\
\text { edge slat noise, Leading edge flap noise, } \\
\text { Landing gear noise, Trailing edge flap } \\
\text { noise, Airframe component interaction } \\
\text { noise. }\end{array}$} & \multicolumn{3}{|c|}{$\begin{array}{l}\text { 18. Distribution Statement } \\
\text { Unclassified-Unlimited } \\
\text { Subject Category } 71\end{array}$} \\
\hline $\begin{array}{l}\text { 19. Security Classif. (of this report) } \\
\text { Unclassified }\end{array}$ & \multicolumn{2}{|c|}{$\begin{array}{l}\text { 20. Security Classif. (of this page) } \\
\text { Unclassified }\end{array}$} & $\begin{array}{l}\text { 21. No. of Pages } \\
136\end{array}$ & $\begin{array}{l}\text { 22. Price" } \\
\$ 7.25\end{array}$ \\
\hline
\end{tabular}

* For sale by the National Technical Information Service, Springfield, Virginia 22151 